\title{
A CRITICAL REALIST STUDY OF POLITICAL IDENTITY IN AOTEAROA NEW ZEALAND \\ Materiality, Discourse and Context
}

JAY MICHAEL WOODHAMS

\begin{abstract}
A thesis
submitted to Victoria University of Wellington in fulfilment of the requirements for the degree of Doctor of Philosophy
\end{abstract}

Victoria University of Wellington

Te Whare Wānanga o te Ūpoko o te Ika a Māui

2015 
Jay Michael Woodhams: A Critical Realist Study of Political Identity in Aotearoa New Zealand, (c) 2015

Typeset by the author in $\mathrm{ET}_{\mathrm{E}} \mathrm{X}$.

The typeface is Linux Libertine and the transcript excerpts are Linux Biolinum. Both are licensed under the GNU General Public License and the sIL Open Font License.

SUPERVISORS:

Associate Professor Meredith Marra

Professor Janet Holmes 
Dedicated to the memory of Dr John William Macnab.

An inspiring teacher.

$1924-2000$ 

Political identity is a complex phenomenon that is generated within a rich sociocultural context. This thesis examines political identity in informal talk which is situated within a relatively under-explored context, New Zealand's capital city and political centre, Wellington. Grounding the study within the critical realist model of stratified reality provides the philosophical motivation to explore multi-layered discourses alongside the extra-discursive referents that underpin them. The analysis centres on a model of identity, contra postmodernism, which shows that identities, while socially recognised in discourse, are articulated in reference to physical and social structures. I adopt a comprehensive multi-layered approach to discourse by examining the macro sociocultural influences that appear to pattern interaction across the country, the meso-level subnational discourses that influence dialogue at a more situated level and the micro-level interactional stances taken up in everyday communication. Discourse at all levels is implicated in the identities I examine in this thesis and it is against this backdrop that I unpack political identity into its indexed discourses and constitutive stance acts.

Framed by my ethnographic immersion in the study context and drawing on in-depth semi-structured interviews with twenty-six individuals, I explore the way in which discourse and stancetaking are implicated in the genesis of the participants' political selves. I first consider the extra-discursive context, including the geographical, economic and cultural structures that underlie New Zealand discourses. This is followed by detailed analysis of sociocultural discourse as it appears in talk. I identify egalitarianism and tall poppy as two related discourses which are embedded within the historical context of the country. I also explore four subnational discourses relating to Wellington city, including the political town, left-wing and small town discourses, which occur alongside a discourse of contrast. These sociocultural and subnational discourses influence much of the talk that occurs in reference to politics in Wellington and are thus implicated in political identity as it is generated in moment-by-moment 
interaction. To explore this in further detail I examine the microlevel of interactional discourse, more specifically the processes of stancetaking, in two detailed case studies. The two focus participants demonstrate prominent stance processes which I argue are central to much identity work: intersubjectivity, in which the stances of all those involved in the discussion interact in complex ways; and multiplicity, when participants take numerous stance directions that appear to contribute to different aspects of their identities. The intensive focus on the case studies, alongside analysis of the full discursive and extra-discursive context, provides a multi-layered and philosophically anchored approach that seeks to contribute to current understandings of and approaches to the study of discourse and identity. 
For the unceasing support, guidance, perseverance and inspiration: I thank my supervisors, Meredith Marra and Janet Holmes. It seems I have come a long way since 2003 when I was a young undergraduate sitting quietly at the back of your sociolinguistics class. I did not imagine then that I would ever be where I am now. I am grateful for the many opportunities you have afforded me, the knowledge you have guided me towards and the challenges you have posed for me to overcome.

To all of the participants who volunteered to take part in this study, including those who agreed to be filmed during the pilot study: my sincere thanks. Without you all this project would have been a literal impossibility. I wish to express my gratitude to those who contributed in some way to the research process: David Pearson and Gary Hawke for their insights into egalitarianism; Alison Sealey for the food for thought regarding realism and constructionism; Elaine Vine for her feedback on the HEC application; Emily Greenbank for her work with tall poppy; and Chris Jennings for his attention to detail in the figures and advice on the archaeological literature.

Thanks to the Wellington Language in the Workplace Project team. My years with you as a research assistant have been incredibly fruitful and have provided me with invaluable research experience that has shaped my approach to this thesis. I am also thankful for the insightful feedback on my data which I gained from members of Victoria's Discourse Analysis Group and the Research Network for Workplace and Organisational Discourse.

Thank you to the staff at Student Learning, in particular Ann Pocock and Jan Stewart. I appreciate the casual employment (and complimentary baking) that provided welcome respite from my studies. I also wish to thank the academic and general staff of the School of Linguistics and Applied Languages Studies. I have been lucky to work alongside dedicated colleagues who all contribute to maintaining the collegial and productive atmosphere that we enjoy. 
An undertaking such as this is not without its financial implications. Thanks to Victoria University of Wellington for the threeyear Doctoral Scholarship and conference funding. Thanks to Victoria University Postgraduate Students' Association for awarding me the 2013 Postgraduate Research Excellence Award which allowed me to present some of the findings of this research at a conference in Hungary in 2014.

They say a doctorate, while enriching, is an exercise in isolation. This may be true, but I am fortunate enough to have many special people in my life who have supported me socially and emotionally over the last few years and, in doing so, have contributed in less visible ways to this thesis. Jeremy Koay-officemate, squash trainer, generous chef and friend-we made it. Keely Kidner, Rike Tegge and the rest of the postgraduate battlers. My parents, Oenone and Mike, who never doubt my choices and always leave the door open. Quiet afternoons looking out over your garden helped to sustain my drive to see this through to the end. My three brothers, Adrian, Angus and Carl. Claire Chittenden, for the limitless support from start to finish. And to the rest of my good friends in Wellington and abroad, thanks for giving me something else to talk about, providing good laughs and helping me over the obstacles that a doctorate inevitably places in the way.

Finally, I wish to thank my late grandparents, whose belief in the power of education set me on this path. My grandfather, my inspiration and to whom I dedicate this thesis, and my grandmother, Mrs Beryl Jean Macnab, who passed away as I embarked on this journey. Thank you both for believing in me until the very end. 


\section{CONTENTS}

1 INTRODUCTION AND AIMS 1

1.1 Study Rationale ................... 3

1.2 Research Aims . . . . . . . . . . . . . . . . 5

1.3 Thesis Structure . . . . . . . . . . . . . . . 7

1.4 Conclusion ................. 8

2 PHILOSOPHICAL BACKGROUND 9

2.1 Critical Realism . . . . . . . . . . . . . . 10

2.1.1 The Main Features of Critical Realism . . . . . . . 11

2.1.2 Critical Realism and Social Constructionism . . . . . 16

2.1.3 Deconstructing 'Construction' ........... 20

2.2 Sociocultural Discourse and Critical Realism . . . . . . 22

2.2.1 Defining Discourse ............. 22

2.2.2 Discourse and Realism ............ . 26

2.2.3 Sociocultural Discourse Applied . . . . . . . . 28

2.3 Ideology ................. . 31

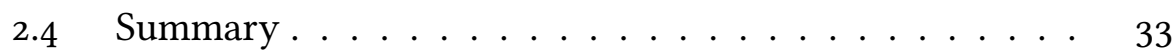

3 DISCOURSE IN IDENTITY 35

3.1 Discourse Approaches to Identity . . . . . . . . . . . 35

3.1.1 Sociocultural Linguistic Identity . . . . . . . . . . . 37

3.1.2 Emergent Identities . . . . . . . . . . . . 38

3.2 Critical Realist Identity . . . . . . . . . . . . . 40

3.2.1 The NIDA Model ................ . 42

3.2.2 Core Identity ................. . 48

3.2.3 Negotiation, Contestation and Recognition . . . . . . 49

3.2.4 Theoretical Model ............. 52

3.3 Summary................. 52

4 INTERACTIONAL DISCOURSE 55

4.1 Interaction .............. 55

4.1.1 Discourse Analysis and Critical Realism . . . . . . . 57

4.1.2 Critical Realist Discourse Analysis . . . . . . . . . 59

4.2 Interactional Sociolinguistics . . . . . . . . . . 62 
4.3 Indexicality . . . . . . . . . . . . . . 65

4.4 Stance ........................ 69

$4.4 .1 \quad$ Stance, Context and Identity . . . . . . . . . . 73

4.4.2 Political Identity and Stancetaking . . . . . . . . . 77

4.5 Summary. . . . . . . . . . . . . 79

5 DAta COLLECTION AND METHOD OF ANALysis 81

5.1 Implications of Critical Realism for Method . . . . . . 81

5.1.1 Approach to Study Design . . . . . . . . . . . 83

5.2 Human Ethics and Informed Consent . . . . . . . . . . 84

5.3 Pilot Study . . . . . . . . . . . . . . . . . . . 85

5.4 Participant Recruitment . . . . . . . . . . 86

5.5 Data Collection ................ 89

$5.5 .1 \quad$ Linguistic Ethnography .................. 90

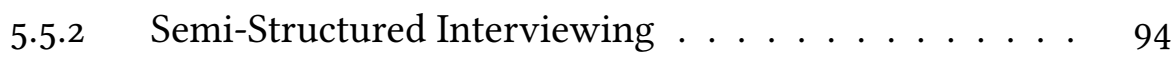

5.5 .3 Data Set . . . . . . . . . . . . . . 109

5.6 Data Analysis . . . . . . . . . . . . . . . 109

5.7 Follow-up Reporting . . . . . . . . . . . . . . . 114

5.8 Summary . . . . . . . . . . . . . . . . . 115

6 THE PHYSICAL AND SOCIAL LANDSCAPE 117

6.1 Setting and Context . . . . . . . . . . . . . 119

6.1.1 New Zealand's Political System . . . . . . . . . . . 123

6.2 Geographical Reality of the Small Country . . . . . . . . 124

6.3 The Reality of Inequality . . . . . . . . . . . . . . . . 130

6.4 Biculturalism and Multiculturalism . . . . . . . . . . 137

6.5 Summary. . . . . . . . . . . . . . . . . 144

7 SOCIOCULTURAL DISCOURSES 145

7.1 New Zealand Egalitarianism . . . . . . . . . . . . . . 146

7.1.1 Conceptualising Egalitarianism . . . . . . . . . . 151

7.1.2 Egalitarianism in Interaction . . . . . . . . . . 154

7.1.3 Mitigation of Power as Egalitarian Equity . . . . . . 164

7.2 Tall Poppies in New Zealand . . . . . . . . . . . . . . 167

7.3 Summary. . . . . . . . . . . . . . 175

8 SUBNATIONAL DisCOURSES 177

8.1 Political Identity in Wellington . . . . . . . . . . 178

8.2 The Political Town . . . . . . . . . . . . 180 
8.3 Left-wing Wellington . . . . . . . . . . . . . . . 189

8.4 Everyone Knows Everyone . . . . . . . . . . . . . . . . 195

8.5 Wellington in Contrast . . . . . . . . . . . 202

8.6 Summary. . . . . . . . . . . . . . . 209

9 INTERSUBJECTIVITY IN STANCETAKING 211

9.1 Introduction to the Case Studies . . . . . . . . . . 211

9.2 Ashley: From Balanced to Greenie . . . . . . . . . . . . 212

9.2.1 Stage One: First Contact . . . . . . . . . . . . 213

9.2.2 Stage Two: Talking Small . . . . . . . . . . . . 214

9.2.3 Stage Three: A Balanced Approach . . . . . . . . . . 218

9.2.4 Stage Four: Strengthening Inferences . . . . . . . . . 224

9.2.5 Stage Five: Establishing Credentials . . . . . . . . . . 228

9.2.6 Stage Six: Explicit Confirmation . . . . . . . . . . . . 236

9.2.7 Stage Seven: Identity Reinforcement . . . . . . . . . 239

9.2.8 Stage Eight: Ending the Conversation . . . . . . . . 244

9.3 Discussion .................... 246

10 StANCE MULTiPlicity 249

10.1 Steven: Politics and Religion . . . . . . . . . . . . 249

10.1.1 Political Affiliation . . . . . . . . . . . 250

10.1.2 Religious Intersections . . . . . . . . . . . . . 254

10.2 Discussion . . . . . . . . . . . . . 266

11 CONCLUSION 271

11.1 Philosophical Contribution . . . . . . . . . . . 271

11.2 Theoretical Contribution . . . . . . . . . . 272

11.3 Methodological Contribution ............ 273

11.4 Analytical Contribution . . . . . . . . . . . 273

11.5 Directions for Future Research . . . . . . . . . . . . . 275

11.6 Final Word . . . . . . . . . . . . . 276

A TRANSCRIPTION CONVENTIONS 279

B PARTICIPANT AND DATA SET DETAILS 281

B.1 Participants ................... 281

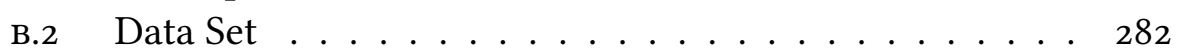

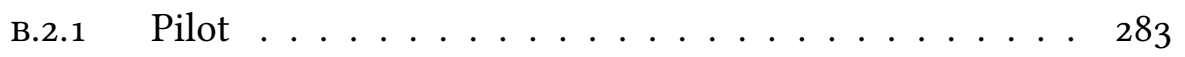


xii

CONTENTS

C INFORMATION SHEET AND CONSENT FORM

285

D HUMAN ETHICS MEMORANDA

289

E RECRUITMENT POSTERS

291

F FOLLOW-UP REPORT

293

GLOSSARY

299

REFERENCES

301 
Figure 1 A discourse-focused model of identity in structural context ............. 51

Figure 2 The stance triangle ............. 71

Figure 3 Map of New Zealand . . . . . . . . . 120

Figure $4 \quad$ Map of Wellington region electorates . . . . 122

Figure 5 Air New Zealand 747-400 aeroplanes displaying the koru . . . . . . . . . . . . . 139

Figure 6 'Modest, self-effacing NZ tall poppies always survive...'. Cartoon by James Hubbard, 22 January $2008 \ldots \ldots \ldots$

Figure 7 'The tall poppy syndrome'. Cartoon by Bob Brockie, 25 January $2013 \ldots \ldots$

Figure 8 A view of Wellington from Mount Victoria . 179

\section{LIST OF TABLES}

Table 1 The critical realist model of depth realism . . 13

Table 2 Four ways to view identity . . . . . . 43

Table 3 The contextualisation of identity genesis in interactional discourse . . . . . . . . 77

Table 4 The phases of a 'typical' semi-structured interview .................. 97

Table 5 Political parties in Parliament after the 2011 general election . . . . . . . . . . 125 


\section{LIST OF ABBREVIATIONS}

CA Conversation Analysis

CDA Critical Discourse Analysis

ECan Environment Canterbury

FPP First Past the Post

GT Grounded Theory

HEC Human Ethics Committee

IS Interactional Sociolinguistics

LE Linguistic Ethnography

LEC Labour Electorate Committee

LWP Language in the Workplace Project

MCA Membership Categorisation Analysis

MMP Mixed Member Proportional

MP Member of Parliament

PSA Public Service Association

TMSA Transformational Model of Social Activity 
- Figures 3 and 4 are courtesy of Chris Jennings, all rights reserved.

- Figure 5 by Charaka Ranasinghe/Wikimedia Commons is licensed under CC BY 2.o. https://creativecommons.org/licenses/ by/2.0/

- Figure 6 is reproduced with permission. 'Modest, self-effacing NZ tall poppies always survive...' Hillary. 22 January 2008. Hubbard, James, 1949- :[Digital caricatures and cartoons published from 1999-2005, and from 2008 onward]. Ref: DCDL0005081. Alexander Turnbull Library, Wellington, New Zealand. http://natlib.govt.nz/records/22800011

- Figure 7 is reproduced with permission. National Business Review (Newspaper). 'The tall poppy syndrome'. 25 January 2013. Brockie, Robert Ellison, 1932- :[Digital caricatures and cartoons published from 2007]. Ref: DCDL-0023884. Alexander Turnbull Library, Wellington, New Zealand. http://natlib.govt. $\mathrm{nz} /$ records/31984545

- Figure 8 by Gouldy99/Flickr is licensed under CC BY-NC-ND 2.o. https://creativecommons.org/licenses/by-nc-nd/2.o/ 

Man is by nature a political animal.

-Aristotle

As I sat in the kitchen of my student's house in southern Czech Republic, the conversation between us veered towards the inevitable topic of politics. After talking at length about spending her childhood and adolescence in a communist state, Lenka ${ }^{1}$ leaned over the table and looked me directly in the eyes. 'I hate communists. They should all be killed.' I expected a smile to cross her face but it never arrived. There was no trace of the wry humour that I looked forward to every week. She held my gaze for a few moments and looked down at the table, seemingly lost in thought, perhaps embarrassed at my reaction to the gravity of her statement. I was by then used to the sometimes stern demeanour of my Czech students, but this was different: after over a year of English conversation classes the topic had raised a passion within her that none other had before.

While living and working in the post-communist country, once veiled by the Iron Curtain and now rapidly embracing capitalism and private enterprise, I noticed a common theme arising from conversations with my English language students, though not always expressed with Lenka's vehemence: an overarching hatred of communism, a distrust of politicians and resignation to systemic political corruption. Colouring every interaction I had about politics in the Czech Republic was the country's communist past. Many of my students were vocal in their reactions against the shackles of socialism, recalling stories of the suffocating burden of statesanctioned surveillance, the widespread distrust of authority and a childhood spent in a climate of fear and totalitarian oppression. Without exception, those I talked to rejected communism as a flawed experiment in human suffering.

$1 \overline{\text { All names in this study have been }}$ replaced with pseudonyms. 
However, despite the anti-communist sentiment arising from those aged mainly in their fifties, many of whom had early memories of the 1968 Prague Spring and resulting Warsaw Pact occupation, the 2010 parliamentary elections told a different, and to many an infuriating, story: the KSČM, the Communist Party of Bohemia and Moravia, gained $11.3 \%$ of the parliamentary vote, winning 26 of the 200 lower house seats and retaining all seats gained in the 2006 election (ÁlvarezRivera, 2014). I wondered how this could be when such a clear picture had been painted for me by my students. Many of them laid blame at the feet of the older generations, folk who were nostalgic for past days of stability and employment and who felt threatened by the influx of foreigners, Western business and the corruption that results from sudden wealth and relative freedom. It was only later that I realised such a consensus was likely reached because my students had all sought me out to converse in the English language, a linguistic symbol of the Western world and a widely accepted passport to economic prosperity. My interaction with these students had been shaped by broader social influences, as English language proficiency had gained its own symbolic force in the Czech Republic which was tied inextricably to the social and political background of the country. English became a form of linguistic resistance to their communist past, particularly as the Russian language was once compulsory in schools across the country. What became apparent to me was that an understanding of the context in which I was operating was vital to eventually appreciating the nature of the conversations in which I had engaged.

Upon leaving the politically and historically complex state, armed with a host of experiences of political life in a country very much unlike my own, I returned home to New Zealand, a relatively stable democracy with arguably less political baggage. I began to reflect on my experiences in the Czech Republic and related them to my home country. I asked myself: How does politics affect us in New Zealand? Do we all define ourselves in relation to certain historical and social conditions? Are there seemingly universal political discourses that we all orient to? How does politics affect the way we talk? Then, digging deeper, conscious of the fact that the influence of politics is felt in almost every aspect of our lives, I asked myself: how does politics influence the kind of people that we are? 


\subsection{STUDY RATIONALE}

Political identity research within linguistic discourse analysis can be considered related to the field of political discourse analysis which is characterised by a wide range of analytical approaches (Chilton, 2004; Chilton \& Schäffner, 2002; Fairclough \& Fairclough, 2012; Fetzer, 2013b; van Dijk, 1997). A particularly influential strand of research exists within the Critical Discourse Analysis (CDA) tradition which is generally unified by a focus on power and ideology encoded within many forms of political language (Blackledge, 2005; Fairclough \& Fairclough, 2012; Wodak, 1989). These studies tend to focus on addressing social problems in the first instance (Fairclough, 2001, p. 236) and critically-oriented researchers cast eyes over the use and abuse of power by elites with a view to the emancipation of oppressed groups (Chouliaraki \& Fairclough, 1999, pp. 29-30; Phillips \& Jørgensen, 2002, p. 64; van Dijk, 1993; Wodak, de Cillia, Reisigl \& Liebhart, 2009, p. 7). Both CDA scholars and those with other theoretical leanings have examined political discourse from particular angles, analysing features as diverse as humour (Tsakona \& Popa, 2011), disagreement (Robles, 2011) and metaphor (Sharifian, 2009; Woodhams, 2012); topics such as immigration (Buonfino, 2004; Mehan, 1997; van der Valk, 2003; van Dijk, 2000), slogans (Lu, 1999) and terrorism (Wilson, 1991); and genres such as interviews (BlumKulka, 1983; Hutchby, 2011; Johansson, 2006; Lauerbach, 2006; Weizman, 2006), press conferences (Bhatia, 2006), blogs (Vesnic-Alujevic, 2011), governmental reports (Fairclough \& Fairclough, 2011), as well as speeches and parliamentary debates (Alvarez-Cáccamo \& PregoVázquez, 2003; Lyons, Stephens, Morgan, Praat \& Tuffin, 1996; Rapley, 1998; Reyes, 2011; Wilson \& Stapleton, 2012). Political discourse analysis is a wide-ranging and active field with valuable analyses of what presidents, parliamentarians and their parties have to say and how they say it. However, such studies generally focus on only one side of the political coin, that is, the language of political elites, the politics-from-above that also includes the media (Fetzer, 2013a). If we accept Aristotle's claim, noted at the outset of the chapter, that people are, by nature, political animals, then citizens themselves are certainly worthy of a similar intensity of focus. Politics-from-below 
(Fetzer, 2013a) is an important counterweight to the voices of those in power.

Researchers across disciplines, including linguistics, sociology, political science and communication studies, have followed this line of thought and investigated political discussions in groups such as families (Gordon, 2004) and informal gatherings (Walsh, 2004), and examined the political talk of adolescents (Bhavnani, 1991; Yates \& Youniss, 1998) and the urban poor (Baiocchi, 2003). Others have studied political discussion groups (Price, Nir \& Cappella, 2006), political talk in various online fora (Al Nashmi, Cleary, Molleda \& McAdams, 2010; González-Bailón, Banchs \& Kaltenbrunner, 2012; Sotillo \& Wang-Gempp, 2004; van Zoonen et al., 2007) and the role of peer discussion and social networks (Huckfeldt \& Sprague, 1987; Klofstad, 2007). Particularly relevant is work on national identity (de Cillia, Reisigl \& Wodak, 1999; Wodak \& Meyer, 2009), where CDA analyses have shown that identity formation in interaction occurs within a multi-dimensional and increasingly globalised social context. This body of research tends to focus on the 'ordinary' person as a political agent operating within a complex structured social world.

In consideration of these two research strands, this study attempts to strike a balance between a focus on the individual and the wider sociocultural context, an issue which broadly maps to the question of structure and agency, both of which are conceptualised to operate in a dialectical relationship (Bhaskar, 1979; Collier, 1994, p. 141; Fairclough, 1992). Critical realism, a philosophy of science and social science, supports this conceptualisation (Bhaskar, 1975, 1979). Critical realism consists of a social ontology in which reality is stratified and where a multitude of mechanisms tend to result in events which may or may not make their way to human experience (Collier, 1994).

Further rationale for this research is provided by its setting. Much of the above cited work on political discourse has been carried out in Europe and the United States and little has focused on the nature of identity within New Zealand. This study takes place within its capital city, Wellington, which is a politically engaged city and hence a productive site for research of this kind. This is borne out in Wellingtonians' level of political participation: at the 2011 and 2014 general elections the highest proportion of voters in the country turned out to vote in the Wellington Central electorate 
(Electoral Commission, 2015; see also Chapter 6). Wellingtonians are substantially more politically involved, at least as measured by voter turnout, than anywhere else in the country. Furthermore, Wellington is the centre of political activity in New Zealand and is the location of Parliament and all government ministry headquarters. Its prominence is underscored by not only the physical presence of political institutions but also politicians who are often visible throughout the city. This unique context is particularly well suited to a study of political identity that takes into account both talk and its structural influences.

\subsection{RESEARCH AIMS}

Rather than adopting a CDA-style focus on power and emancipation, which is a fruitful direction within the critical realist paradigm (see, for example, Chouliaraki \& Fairclough, 1999; Fairclough, Jessop \& Sayer, 2002), the primary motivation for this study is to contribute a systematic approach to identity which is grounded in critical realist philosophy. In more specific terms, a critical realist approach expands upon and grounds social constructionism (Berger \& Luckmann, 1966; Burr, 2003) and hence enhances constructionist approaches to identity (e. g., Angouri \& Marra, 2011; Bamberg, de Fina \& Schiffrin, 2011; Bucholtz \& Hall, 2005; de Fina, Schiffrin \& Bamberg, 2006; Holmes, 2006a; Holmes, Stubbe \& Vine, 1999; Ochs, 1993; Omoniyi \& White, 2006). It does so by providing an ontology for identity genesis in interaction, specifically in the philosophically supported recognition of the extra-discursive and the causal effects of social structures (Bhaskar, 1979), including discourse (Foucault, 1969/2002a; Gee, 2014). The overt presence of critical realism may not be as apparent in turn-by-turn analysis of interaction given its status as a guiding philosophy. It nevertheless affects the way in which this study moves through method and eventually to linguistic analysis (Sayer, 2010). Discourse analysis provides the tools necessary to investigate both deeper levels of context and moment-by-moment interaction, with the aim of gaining a fuller picture of the processes of identity genesis.

The ultimate destination for this study is an exploration of identity as it is generated through stancetaking (Du Bois, 2007; Englebretson, 2007; Jaffe, 2009b). A critical realist approach, however, necessitates an understanding of the material and structural context, to which 
three chapters of this thesis are devoted (see Section 1.3), surveying the structural landscape before moving in to closer linguistic analysis.

Drawing on the original inspiration for this study and in consideration of the research context, the broad aims of the study can be articulated in a single question: How are the political identities of Wellingtonians generated through interaction in context? This question can be broken down into its constituent parts which each contain a set of assumptions. These are listed below.

1. How may refer to linguistic and discursive features or any other salient mechanics of identity, including the processes involved in stancetaking (Du Bois, 2007; Englebretson, 2007; Jaffe, 2009b) and the influence of wider material or sociocultural structures (Bhaskar, 1979; Collier, 1994, Foucault, 1969/2002a; Gee, 2014).

2. Identity functions as shorthand for accumulated stancetaking and their indexical relationships to more durable social identities (Ochs, 1992, 1993). Political identity in this context refers to stancetaking in relation to political topics (Du Bois, 2007).

3. Wellingtonians is a general label operating as a convenient descriptor of the pool of participants who volunteered to take part in this study, specifically eligible New Zealand voters, resident in the Wellington region.

4. Throughout the thesis I use the verb generate and noun genesis to replace the more commonly used 'construct' and 'construction' (Hacking, 1999; Sayer, 1997b). The rationale behind this choice, in light of the philosophical foundation of critical realism, is discussed in detail in Chapter 2.

5. Interaction in this sense refers to speech, writing and other forms of intersubjective meaning-making (Fairclough et al., 2002), particularly casual conversation.

6. Context involves both the material and structural environment, including discourse, in which interaction is located. Critical realism inspires an unconventional approach to the analysis of talk: to understand identity genesis at a micro level, salient macro layers should first be uncovered in order to hypothesise 
as to their nature and potential influence on interactional processes.

\subsection{THESIS STRUCTURE}

This introductory chapter is followed by two chapters which lay out the philosophical and theoretical frameworks through which the data is analysed. Chapter 2 introduces the aforementioned philosophy of critical realism alongside the particular approach to sociocultural discourse used in this thesis, which is drawn largely from the work of Foucault (1969/2002a; see also Fairclough, 1992; Gee, 2014). It is followed by Chapter 3 which situates theories of identity and interaction within this philosophical background, leading to a critical realist model of identity that expands upon current social constructionist approaches (Bucholtz \& Hall, 2005; Gee, 2000). In Chapter 4 the approach to interactional discourse adopted in this study is discussed, drawing on interactional sociolinguistics (Gumperz, 1982a), indexicality (Silverstein, 2003) and stance (Du Bois, 2007), which form the bulk of the analytical frame in later chapters. Chapter 5 outlines the data collection procedure and method of analysis, charting the implications of critical realism for method (Sayer, 2010) and the subsequent steps through which the study design progressed. It outlines a method guided by critical realism that adopts an intensive, exploratory design, which is argued to promote the necessary access to rich contextual information required to better understand the nature of the mechanisms that sustain certain discourses (Sayer, 2000, 2010). It provides a discussion of the two main data sources, the ethnographic approach supported by semi-structured interviews, and explains the way in which transcription and analysis of this data was carried out. Rather than restricting the study to answering one research question, the iterative and cyclical nature of the analysis utilised in this study, as discussed in Chapter 5, results in specific research questions being addressed at each stage of analysis. The three subsequent chapters serve as combined results and discussion sections, each focusing on a different structural influence on political identity. Chapter 6 explores the extra-discursive underpinnings of identity genesis, such as the geographical constraints of 'small country' New Zealand and its enduring sociopolitical structures. Chapter 7 
moves focus to the discursive system, investigating the sociocultural discourses that shape individuals' negotiation of stance and identity, and identifying two particularly salient examples, egalitarianism and tall poppy. A proposed model of these discourses is then tested against the talk of participants. Chapter 8 narrows the focus to more situated subnational discourses, particularly those related to the site of study, Wellington, with participants' talk indicating the presence of discourses of the political, left-wing, and small town, existing in a discursive frame of contrast to elsewhere in the country. The subsequent two chapters present case studies that examine a salient process of stancetaking in action. Chapter 9 contains analysis of the specific interactional features of political identity genesis, presented in the form of a detailed case study. The development of political allegiance throughout the course of an entire discussion is the focus of this chapter, identifying intersubjectivity as a core process in stancetaking and hence identity work (Du Bois, 2007; Kärkkäinen, 2006). In Chapter 10, the second case study focuses on stance multiplicity, examining the way in which multiple identities and constituent stance acts are managed as a complex discursive achievement (Jaffe, 2009a). The thesis ends with Chapter 11 which summarises the content of each chapter and considers the contributions this study makes and potential areas for future research.

\subsection{CONCLUSION}

This study is positioned to contribute insight into the workings of politics and discourse within Wellington and attempts to open the way for future research into this unique political context. It articulates an alternative approach to that which is commonly adopted in constructionist discourse analysis in New Zealand by anchoring its feet in a realist model of reality. In its most general sense, this thesis aims to contribute to the body of work that seeks to disturb the intellectual pendulum from swinging towards the apex of postmodernism and attempts to position it in a more central and balanced location through which both structure and agency are given adequate consideration. In this way, this study attempts to explore who we are as political animals that exist in a rich world of discursive influence and material constraint. 
Reality is that which, when you stop

believing in it, doesn't go away.

-Philip K. Dick

The aim of this chapter is to explain the philosophical background of this thesis by attempting to climb on the shoulders of those who came before (Archer, 1998, p. 198) with the goal of pushing the boundaries towards a reconfiguration of the philosophies that underlie much discourse analytic practice. The late Roy Bhaskar, a key figure in the development of the foundational philosophy of this study, critical realism, states that its purpose is to perform a kind of philosophical 'underlabouring', by 'getting rid of the rubbish that lies in the way to knowledge' (Volckmann, 2013). This chapter attempts to carry out this ground-clearing. It only clears the way, however; a philosophy does not in itself provide the answers. What it does provide are the tools and the clean slate required to do so.

As a study in linguistics the focus of this thesis is discourse in its many senses, the ultimate destination being the micro-level analysis of interaction. The current chapter is thus organised to build from broader philosophy into a theory of discourse. The main features of critical realism as relevant to this study are discussed first, showing how it addresses the pitfalls of other philosophical paradigms such as positivism and then discussing how it adds to the popular social constructionist approach. Next, a theory of sociocultural discourse, also known as (neo-) Foucauldian or 'big-D' discourse (Gee, 2014, p. 25), is situated alongside critical realism. The final section of this chapter attempts to fit the famously elusive concept of ideology into the philosophical and theoretical tapestry. 


\subsection{CRITICAL REALISM}

Critical realism comprises both philosophies of natural and social science, and the philosophy pertaining to the latter is just that: a philosophy, not a social theory (Sayer, 2004, p. 15). Why, then, is it important to dial back to the broad recommendations of philosophy in a study concerned with the examination of political identity? Collier (1994, p. 16) explains succinctly that

the alternative to philosophy is not no philosophy, but bad philosophy. The 'unphilosophical' person has an unconscious philosophy, which they apply in their practicewhether of science or politics or daily life.

Philosophy, then, is implied in all scientific work which philosophical work makes explicit (Collier, 1994, p. 17). This is central to any critical ${ }^{1}$ research enterprise and its elaboration forms the purpose of this section.

A major benefit of critical realism as a guiding philosophy is that it addresses the apparent failures of other philosophical approaches to provide an adequate ontology, or theory of being (Collier, 1994; Sayer, 2000). As Sayer (2004, p. 15) notes, critical realism provides 'guidelines for researchers grounded in ontological and epistemological arguments that avoid the pitfalls of positivism on one side and idealism and relativism on the other.' These particular claims are examined in more detail in the following sections. Critical realism, amongst other important contributions, offers a strong foundation for discourse analysis. In particular, it provides the opportunity to ground discourse analysis in a rigorous realist ontology where material and social structures are given adequate philosophical support whilst accepting epistemic relativism, or the view that the world can only be known or experienced through discourse (Sayer, 2000, p. 47), a theory that holds significant currency within some social constructionist

1 The 'critical' within critical realism derives generally from its acknowledgement that theories about the world are fallible and thus open to critique and change (Scott, 2010, p. 12). This study is considered critical in the sense that it resides within a 'new critical' paradigm within linguistics which problematises and examines the connection between language and society, an approach that CDA shares but to which a critical orientation is not restricted (Blommaert \& Bulcaen, 2000, p. 456; see also Gee, 2014, pp. 9-10). 
circles (see the discussion in Section 2.1.2). As Coupland and Jaworski (2009, p. 17) note, critical realism challenges the view that we "talk society into existence" each time we use language.'

Critical realism has attracted attention in both the natural and social sciences since its main proponent in Britain, Bhaskar, published A Realist Theory of Science in 1975. In his work, Bhaskar presents a philosophy of science he calls 'transcendental realism', a form of realism which in its most general sense holds that there is a material world independent of our knowledge of it (Collier, 1994). Bhaskar's philosophy addresses perceived weaknesses inherent in the long tradition of empiricism and positivism in science (Sayer, 2000). Bhaskar's subsequent work The Possibility of Naturalism: A Philosophical Critique of the Contemporary Human Sciences, introduces the philosophy of 'critical naturalism' which applies transcendental realist insights to the social sciences. In this work, Bhaskar addresses issues that relate to the influence of positivist science on social scientific inquiry (Sayer, 2000, pp. 2-3). These two philosophical strands are unified under the banner of critical realism. As a philosophy of both natural and social science, critical realism addresses longstanding dualisms, such as individualism and collectivism, mind and body, nature and society, structure and agency, objectivity and subjectivity, realism and idealism, and qualitative and quantitative methodology (Archer, 1995; Archer, Bhaskar, Collier, Lawson \& Norrie, 1998, pp. xiii-xiv; Scott, 2010, p. 3; Danermark, Ekström, Jakobsen \& Karlsson, 2002, Chapter 6; Sayer, 2010). How this is achieved is examined in the next section, where the main features of critical realism as considered applicable to this study are introduced.

\subsubsection{The Main Features of Critical Realism}

Central to critical realism is the notion that ontology, the theory of being, is distinct from epistemology, the theory of knowledge. Conflating the two constitutes what Bhaskar calls the 'epistemic fallacy' which is the view that 'statements about being can be reduced to or analysed in terms of statements about knowledge' (Bhaskar, 1975, p. 36). Critical realists believe that this fallacy permeates the Western scientific tradition and has led to the anthropocentric privileging of human knowledge which results in questions of ontology being given 
scant academic treatment (Archer et al., 1998, p. xii). An example of this would be the broad claim that 'reality is socially constructed', which, from a critical realist viewpoint, must be reformulated as 'our knowledge/perception/experience of reality is socially constructed'; reality itself is not. In order to address this, Bhaskar (1975, p. 21) distinguishes between the 'transitive' and 'intransitive' dimensions of science. Theories are the transitive objects of science which scientific work attempts to transform. These theories attempt to gain knowledge of the world that exists independently of the theories about it; this 'real' world is the intransitive object of science (Collier, 1994 , p. 51). Sayer (2000, p. 11) provides the example that the shift from a flat Earth theory to a spherical Earth theory did not mean that the shape of the Earth changed; rather, the transitive objects (i. e., the competing theories) transformed but the intransitive object (i. e., the Earth) remained the same. Bhaskar's distinction between the transitive and intransitive dimensions redefines questions about knowledge and questions about being as distinctly separate, and in doing so, addresses the epistemic fallacy.

A second feature of critical realism is its view of the 'depth' of reality: it is stratified into the 'Real', 'Actual' and 'Empirical' (Bhaskar, 1975, p. 13). These domains are outlined in Table 1. At the Empirical level are our experiences or perceptions. The Actual contains the series of events that occur, whether these are experienced or not. The Real comprises all of these things in addition to the mechanisms that underpin these events and experiences (Collier, 1994, p. 44). The model distinguishes critical realism from ontologies that collapse these levels into one another and counters any approach that privileges surface sense data, such as positivist science (Archer, 1998, p. 196). For example, treating sense perception as the only indicator of what exists conflates the three levels of reality and is an example of the epistemic fallacy (Collier, 1994, p. 45).

In order to distinguish the Empirical from the Actual, it is important to note that things happen whether we perceive them or not. Collier (1994, p. 44) notes that 'when we find the garden muddy in the morning, we assume a real rainstorm, though we slept through it.' These events, perceived or unperceived, lie at the level of the Actual. In turn, these events are caused by mechanisms, the 'causal powers of things' (Bhaskar, 1975, p. 50), the existence of which presupposes 


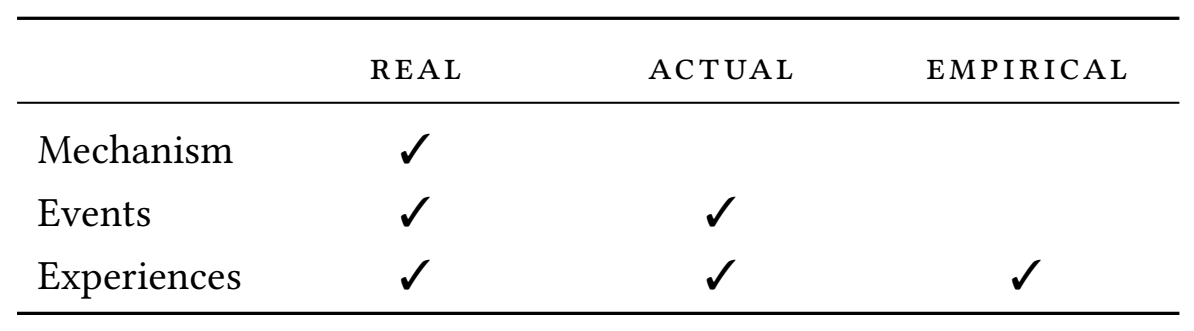

Table 1: The critical realist model of depth realism (Bhaskar, 1975, p. 13).

a deeper level of reality. In order to differentiate the Real from the other two levels, it is necessary to distinguish between events and mechanisms. Collier (1994, p. 42) gives the example of riding a motorcycle: we know that it has the power to go 200 kilometres per hour even though its rider may never make it do so. We can predict this power despite the fact that this particular bike may have never travelled that fast; we know enough about the bike's structure to understand that this power exists. Therefore, things gain their powers from their structures, and rendered in critical realist terms, mechanisms (i. e., structures) which reside at the Real level are said to generate events (i. e., powers) in the Actual (Collier, 1994, p. 43).

The stratified model of reality is related to a third feature of critical realism: emergence. In a philosophical sense the term differs from but is related to its common usage within discourse and identity research, further discussed in Chapter 3. Emergence theories hold that 'the more complex aspects of reality (e. g., life, mind) presuppose the less complex (e.g., matter)' but are 'irreducible, i.e., cannot be thought in concepts appropriate to the less complex levels... because of the inherent nature of the emergent strata' (Collier, 1994, pp. 110-111). In other words, life and mind presuppose matter but cannot be explained completely in terms of it (Bhaskar, 1979, p. 125), even though matter is required for life and mind to exist (Sayer, 2000, p. 12). Higher-order complex phenomena are emergent from and rooted in the stratum below (Collier, 1994, p. 110) and these higher levels have emergent properties or laws (i. e., mechanisms) which make complete reduction impossible (Collier, 1994, pp. 110-111).

Higher-order strata are also affected by mechanisms of the lower orders. Collier (1994, p. 47) explains that the animal kingdom is governed by the laws (i.e., emergent mechanisms) of biology and 
zoology but they are nevertheless affected by lower strata, such as the physical and chemical, which contain laws that also have an effect upon animals. Collier (1994, p. 47) notes that it is mechanisms rather than things that are stratified in nature; the biological, chemical and economic do not refer to concrete things; they refer to different mechanisms which may operate simultaneously (Bhaskar, 1975, p. 119). In the case of explaining the animal kingdom, zoological, biological, chemical and physical mechanisms all have influence. However, the way in which these mechanisms are realised in terms of the events they produce is not always regular.

A single mechanism is never solely responsible for a series of events outside of an experimental scenario where variables have been controlled, producing an artificial 'closed system' (Collier, 1994, p. 33). Both nature and the social world are to different extents 'open systems' where 'a multiplicity of mechanisms jointly [produce] the course of events' (Collier, 1994, p. 46). In an open system it is impossible to determine cause and effect to the same degree as that in a closed laboratory experiment. This leads to the fourth feature of critical realism, its distinctive model of causality. Critical realist causation stands in opposition to the model of causal regularity, that is, the Humean 'successionist' view in which a cause is followed by an effect in a regular manner (Sayer, 2000, pp. 13-14). According to the critical realist view, this succession can only occur in closed systems. Sayer (2000, p. 15) notes that 'the same causal power can produce different outcomes, according to how the conditions for closure are broken.' In other words, any number of mechanisms can interact in various ways to create a different event. Sayer (2000, p. 15) provides the example that 'economic competition can prompt firms to restructure and innovate or to close.' The event that is realised depends on the influence of other mechanisms within the open system. The critical realist model of causality has significant implications for social scientific practice in that the theories produced are explanatory, not predictive (Collier, 1994, pp. 57-58). Due to the complex interaction of any number of mechanisms, predictions cannot be made in the same way as they can within closed scenarios. In fact, as Collier (1994, p. 58) explains, certain sciences

can achieve high explanatory power without being able to make a single prediction (evolutionary biology, gen- 
erative grammar). This inability is not a failure; it is a theoretically demonstrable feature of the real object of these sciences that explanations of it will not generate predictions.

With this in mind, the nature of explanation in open systems must be in terms of tendencies (Bhaskar, 1975, p. 50). In much the same way that a power can exist but remain unexercised, as in the case of a motorcycle's high speed, a tendency can exist and be exercised but may be incompletely realised due to the interaction of other mechanisms (Collier, 1994, p. 63). Collier (1994, p. 63) observes that oak trees

tend to grow tall, but not in Beddgelert Forest because of the wet soil; yet their tendency to grow tall is not without effects in Beddgelert Forest-they do get taller than the gorse bushes, and many of them do fall over.

A statement that a certain thing 'tends to happen' is therefore not an ambiguous diversion; it is, as Bhaskar (1975, p. 97) argues, 'the logical form of all the laws of nature known to science.'

The critical realist model of causality stands in opposition to approaches which search for regularities and 'treat the world as if it were no more than patterns of events, to be registered by recording punctiform data regarding "variables" and looking for regularities among them' (Sayer, 2000, p. 15). Hence, the implications of critical realism for social scientific method are numerous (see the discussion in Chapter 5). In brief, critical realist philosophy leads to a preference of 'intensive' research design over 'extensive' methods, though the two approaches are not mutually exclusive (Sayer, 2010).

The question at this point is how critical realism relates to more common paradigms within linguistic discourse analysis, most prominently, that of social constructionism. The following section demonstrates how critical realism is indeed compatible with most forms of constructionism, particularly in the context of identity research, and can provide it with the support it requires to adequately deal with questions of ontology and to avoid the epistemic fallacy. 


\subsubsection{Critical Realism and Social Constructionism}

The weaknesses of positivism and the critical realist answer to this have been briefly explained in the previous section. Less clear, however, is the relationship between critical realism and social constructionism. Social constructionism is, according to Alvesson and Sköldberg (2009, p. 15), the predominant orientation within many areas of social science. It has been very influential on sociolinguistics (Coupland \& Jaworski, 2009, p. 17) and discourse analysis in New Zealand and elsewhere, as evidenced by the many important constructionist volumes in the field (see, for example, Angouri \& Marra, 2011; Gunnarsson, Linell \& Nordberg, 1997; Holmes, Marra \& Vine, 2011; Holmes \& Stubbe, 2003; Phillips \& Jørgensen, 2002). Critical realism stands alongside social constructionism as an alternative to positivism (Alvesson \& Sköldberg, 2009) and it is therefore important to evaluate how they intersect. Doing so will help to position this study in relation to the vast constructionist identity literature and demonstrate that certain forms of constructionism are indeed compatible with critical realist principles. Their point of crossover, epistemic relativism, is outlined in this section (Al-Amoudi \& Willmott, 2011; Bhaskar, 1979).

Social constructionism is an epistemology, or philosophical theory of knowledge, that in its very broadest sense holds that our beliefs and knowledge of reality emerge through our interactions in the social world (Burr, 2003). Social constructionism is however multifaceted and contains within it many different theoretical orientations (Alvesson \& Sköldberg, 2009) and has been applied to topics as varied as gender and quarks (Hacking, 1999). The general approach can be divided roughly into two main schools of thought, the 'weak' and the 'strong' (Sayer, 1997b, p. 466). Weak social constructionism, as characterised by Searle (1995), allows for the existence of 'brute facts' independent of human thought, yet holds that knowledge and institutions are socially 'constructed' (Sayer, 1997b, p. 466). Strong constructionism holds that reality itself is not independent of human thought and is, in addition to knowledge, socially constructed (Berger \& Luckmann, 1966). Critical realism is compatible with the former, while the latter violates critical realist principles in multiple ways, 
most prominently in being an example of the aforementioned epistemic fallacy (Sayer, 1997b, p. 482).

Despite the internal variation, social constructionism, particularly its weaker form, is a useful lens through which interaction and thus identity can be approached. According to Holmes et al. (2011, p. 21),

The social constructionist approach frames communication as a process which is instrumental in the creation of our social worlds, rather than simply an activity that we do within them. It emphasises the dynamic aspects of interaction, and the constantly changing and developing nature of social identities, social categories and group boundaries, a process in which talk clearly plays an essential part.

This interpretation of social constructionism contains many elements of use to the discourse analyst: the primacy of talk, the interface of identity and the influence of social norms. It also makes no explicit ontological claims which indicates prima facie compatibility with critical realist principles.

Strong constructionism contrasts most starkly with critical realism as the former is considered a 'flat' ontology (Sayer, 2000) that conflates the three domains of reality, as it treats the Real and Actual as residing at the Empirical level. In doing so it analyses questions of being (i. e., Real) in terms of questions of knowledge (i. e., Empirical) and thus commits the epistemic fallacy (Sayer, 1997b, p. 482). As stated above, weak constructionism allows for the existence of a mind-independent reality, but its stronger form leaves it a legacy of ontological 'muteness' (Nightingale \& Cromby, 2002). This has led to criticism from those working 'on-the-ground' who see little by the way of practical application; for example, Houston (2001, p. 848), a social worker, comments that 'constructionists have found it difficult to offer normative theories which can be applied to a world ravaged by poverty, disease and social conflict.' Others argue that if social structures are viewed as merely the products of thought then it is difficult to offer theories that can effect change, a goal which critical realism is arguably better placed to address (Sayer, 1997a).

Bhaskar's Transformational Model of Social Activity (TMSA) conceptualises social structure as 'both the ever-present condition (mater- 
ial cause) and the continually reproduced outcome of human agency' (Bhaskar, 1979, p. 43). ${ }^{2}$ This is explained by Manicas (1998) through the example of language. He notes that language is both enabling and constraining; having language means an individual can speak but it also means that they are bound to a certain extent by the rules of that language. Interaction through speaking and writing reproduces language, so for it to continue to exist it requires continued interaction. Language may not be real in the same sense as a natural structure, but in critical realist terms a social structure, such as language, is real in that it has its own causal mechanisms and can thus be the object of theory (Manicas, 1998, p. 318). As Bhaskar (1979, pp. 4849) notes, social structures are unlike natural structures because they a) do not exist independently of the activities they govern; $b$ ) do not exist independently of the agent's conceptions of what they are doing in their activity; and $c$ ) may be only relatively enduring.

Social structures are also transformed as they are reproduced (Manicas, 1998, p. 319). The potential for changing or replacing possibly oppressive social structures is underplayed by social constructionism because, as Archer (1998, p. 193) states, 'ultimately any representation of "structures" as constructs, subject only to discursive negotiation, sells out on human emancipation.' This is central to critical approaches to discourse grounded in realism that model their approach on Bhaskar's (1979) notion of explanatory critique (e. g., Chouliaraki \& Fairclough, 1999; Fairclough, 2001). In order to address this issue, ontology must be restored to its rightful place in social scientific work. Critical realism provides this philosophical grounding (Willig, 1999).

The key to critical realism and social constructionism being compatible is the critical realist distinction between the two dimensions of science: the transitive and intransitive. Collier (1994, p. 90) notes that

Bhaskar accepts what he calls 'epistemic relativism', i. e., the recognition that our beliefs are socially produced, transient and fallible. But he claims that this does not

2 Archer (1995, p. 137) notes that Bhaskar's (1979) TMSA has parallels with Giddens's (1979) structuration theory but she argues that both Giddens's view of structure and agency as conflated and the foundation of the TMSA in emergentism differentiates the two models. 
commit us to judgemental relativism, i. e., the idea that 'all beliefs are equally valid in the sense that there are no rational grounds for preferring one to another.'

Epistemic relativism as defined above is similar to weak social constructionism. This is acceptable to Bhaskar because, in critical realist terms, beliefs exist within the transitive dimension alone. No claim as to the 'construction' of the intransitive dimension, i. e., the Real, can be made. This is not to say that intentional human agency has no effect upon structure; according to the TMSA, they exist in a dialectical relationship. It follows that rather than every belief being treated as equally valid, as in some constructionist and postmodernist positions (see Purvis \& Hunt, 1993), a certain belief or interpretation can be considered more accurate than another due to its higher 'explanatory power', i. e., it can explain the nature of certain mechanisms more accurately (Lawson, 1998, p. 157). ${ }^{3}$

Social constructionism, at least in its weaker form, can live sideby-side with critical realism largely due to the separation of the transitive and intransitive, the central distinction of the critical realist thesis. Critical realism provides the ontological 'legs' on which social constructionism can stand (Willig, 1999). The question at this point is whether research can still be productively located within the social constructionist paradigm despite its ontological vacuum. Due to its fragmented and diffuse nature and the myriad theoretical orientations its proponents adopt (Alvesson \& Sköldberg, 2009), a 'cleaner' way forward is provided by critical realism; rigorous critical realist underlabouring clears the way for social constructionist thinking to be imported and ontologically grounded. For that reason, this study works alongside social constructionist studies yet proposes a philosophical successor. Therefore, I dispense with the metaphor of 'construction', a characteristic of social constructionist literature. A brief discussion of the construction metaphor and the reason for selecting an alternative is provided in the following section.

3 Critical realism distinguishes horizontal explanation, 'the explanation of events by mechanisms and antecedent causes', from vertical explanation, 'the explanation of one mechanism by another, more basic one' (Collier, 1994, p. 48). 


\subsubsection{Deconstructing 'Construction'}

Hacking (1999) lists at the start of his book The Social Construction of What? examples of the metaphor of construction in the titles of studies across literal $\mathrm{A}-\mathrm{Z}$ of topics. In a tongue-in-cheek manner, Hacking argues that the metaphor 'once had excellent shock value, but now it has become tired' and has led to constructionist analyses that are 'boring and blunted' (p. 35). He continues on to trace the origin of the metaphor back to Kant (p. 41) and tracks its spread across mathematics, philosophy and sociology. Hacking states that due to its overuse it has become a 'dead metaphor' (p. 49), meaning that its users may not realise that it is figurative. Besides arguing for dropping the 'social' from 'social construction' except in cases of emphasis (pp. 39-40), Hacking does not seem to offer an alternative other than suggesting a revitalisation by linking it to its literal meaning of building. A brief survey of discussion on this topic is presented in this section in order to help make a case for change.

The construction metaphor has attracted the attention of scholars for various reasons, most of whom have reservations along similar lines to Hacking (1999). Alvesson and Sköldberg (2009, p. 36) point out that the construction of a building is a planned activity which does not cleanly map to the analogous meaning of social construction, which is spontaneous or unplanned. They argue that use of the metaphor suggests that social constructions, such as institutions, are 'intentionally planned, thus almost manipulatively created.' Alvesson and Sköldberg (2009) do not, however, mention a simple issue apparent to a realist: it does not acknowledge the ontological difference between a building, a concrete thing, as opposed to social constructions which do not 'exist independently of the activities they govern' (Bhaskar, 1979, pp. 4849). The distinction is subtle, however, because in critical realist terms social structures have associated mechanisms and exist in the domain of the Real. Nevertheless, talking about physical buildings and institutions in the same terms could be considered slightly misleading. If we reinvigorate 'construction' by linking it to the process of physical building as Hacking (1999) suggests, then a term is needed to talk about social structure.

Sayer $(2000,2004)$ partially addresses this in proposing a more nuanced understanding of the metaphor. He breaks it down into 
the processes of 'construal' and 'construction'; the former refers to 'making a mental construction of the world' and the latter to 'materially constructing something' (Sayer, 2004, p. 7). He goes on to argue that construals, or interpretations, can influence constructions, and constructions can become independent of their construals. Giving the example of a university, he notes that it is a 'social construction based upon a set of ideas, but it is always something more than the latter' (p. 7). Still, the issue with ontology remains. This is addressed more directly in Sayer's (1997b) earlier work. He argues that social constructionists, particularly those of the 'weak' school of thought, often have no problem acknowledging the existence of a mind-independent reality (notwithstanding the lack of a supporting ontology). He goes on to argue that the use of the hopelessly misleading metaphor of construction invites idealist slippage, for it evades the question of the relationship of our social constructions to the nature of their referents' (Sayer, 1997b, p. 468). This evasiveness is encoded within the metaphor itself and its synonyms. The statement 'identity is a socially constructed phenomenon', for example, ignores how identity is connected to its objects.

This begs the question of what can replace the popular metaphor of construction. In light of the philosophical background of this study, I must select a term that is compatible with realist principles particularly in acknowledging the reality of referents. In taking partial inspiration from Margaret Archer, the author of Realist Social Theory: The Morphogenetic Approach (1995), I adopt the second part of her formulation: 'genesis.' Archer (1995, p. 5) notes in her rationale for choosing 'morphogenetic' as the name of her model, drawing inspiration from Bhaskar $(1979$, p. 44), that " genetic"... is a recognition that [society] takes its shape from, and is formed by, agents, originating from the intended and unintended consequences of their activities.' Therefore, in this thesis, I write of:

- The genesis of identity. ${ }^{4}$

- Identity being generated.

4 I have avoided the term 'generation' for much the same reason Hacking (1999, p. 36) notes of 'construction'-it is ambiguous as to whether this refers to product or process. 
Identity genesis is influenced by a multi-layered system of discourse. The following section examines its broadest form, the sociocultural, that influences talk across situated contexts and, as argued in Chapter 7, is particularly salient in political identity genesis in talk in Wellington.

\subsection{SOCIOCULTURAL DISCOURSE AND CRITICAL REALISM}

The focus of this section is 'sociocultural' discourse, otherwise known as (neo-) Foucauldian or 'big-D' discourse (Gee, 2014, p. 25). ${ }^{5}$ Sociocultural discourse is tied most intimately to the writings of Michel Foucault, expounded most explicitly in his theoretical works The Archaeology of Knowledge (1969/2002a) and The Order of Things (1966/2002b). Contemporary approaches to discourse analysis are fragmented across disciplines with numerous theoretical interpretations often entailing particular research methods of their own. Within linguistics, discourse analysis has been split into theoretical schools that originate from very different ontological and epistemological assumptions (Egan Sjölander \& Gunnarsson Payne, 2011). This section seeks to define discourse for the purposes of this study and situate it alongside critical realism.

\subsubsection{Defining Discourse}

In Foucault's (1969/2002a) terms, discourse as a unifying concept is a continual movement from the level of the 'statement' to that of the 'discursive formation.' The term 'discourse', while seemingly referring to discrete, cleanly bounded objects, does not have fixed boundaries; discourses can split, meld, transform, appear and disappear (Gee, 2014, pp. 55-57). This fluidity makes its precise definition difficult. Foucault (1969/2002a) himself was no stranger to the messiness of the discurs-

5 It is helpful to acknowledge that the division of discourse into sociocultural and interactional categories as used in this study is an abstraction for the purposes of analytical convenience. The broader discursive formations of social knowledge (McHoul \& Grace, 1998, p. 31), in other words the sociocultural level, and momentby-moment language use, the interactional, can both be referred to by 'discourse.' Where there is ambiguity, the terms sociocultural and interactional are used for clarification. 
ive; he highlighted at length both the contradictions within discourses (pp. 166-173) and their propensity to change and transform (pp. 183195). This section traces the Foucauldian origins of discourse as a basis for the approach adopted in this study.

It is apparent that this study, and all others utilising discourse analysis for that matter, owe much to the work of Michel Foucault. His works are split into two broad phases, his archaeology, concerned with historical knowledge and discourse, and genealogy, extended to deal with the nature of power (Smart, 1985, p. 41). As Foucault's object of focus shifted over time, so did his theories. Some have characterised his body of work as having 'conceptual and empirical incoherence' which is subject to numerous interpretations (Marsden, 1999, p. 166). Others argue that Foucault's meta-theory remains largely intact throughout (Al-Amoudi, 2007, p. 557). His work The Archaeology of Knowledge (1969/2002a) nevertheless forms the starting point for understanding discourse, its constituents and the rules of its formation.

Foucault's central thesis in the Archaeology is that history is not a linear progression of events; rather, it is a series of ruptures, discontinuities and transformations of discourse. He provides a definition of discourse, referring to it as 'a group of statements in so far as they belong to the same discursive formation' (1969/2002a, p. 131). He describes the statement as the most basic unit, 'the atom of discourse', which he goes to lengths to demonstrate is not equal to or reducible to a sentence, proposition or speech act and is neither equal to a material object nor Saussurean sign (pp. 90-97). Foucault's negative definition makes precise application of the concept difficult (Blair, 1987, p. 367). However, Blair (1987, p. 368) makes the important observation that after the publication of the Archaeology, Foucault wrote a letter to John Searle conceding that he was wrong in saying that statements are not speech acts. Blair (1987, p. 369) notes that 'speech acts and statements share significant traits even though they are not identical constructions', the main distinction being that the former is based on spoken discourse and the latter written (p. 368). The statement is however more inclusive than the speech act because it includes a wider range of modes such as graphical representations (Blair, 1987, p. 368), like those present in genealogical trees (Foucault, 1969/2002a). The statement can thus productively be understood to 
have a function similar to the speech act, clarifying McHoul and Grace's (1998, p. 37) observation that '[statements] do things, bring about effects rather than merely "represent" states of affairs.' The rules that statements are bound by are not the same as those of language; they 'are not like grammatical rules; they have to do with historically variable bodies of knowledge; they are the rules for what it is possible to know' (McHoul \& Grace, 1998, p. 38). The critical realist notion of emergence becomes relevant again in noting that statements are not reducible to language (Blair, 1987, p. 372), thus discourse is not equated with language (Fairclough, 1992, p. 40). In fact, Foucault's theory of discourse is non-linguistic, focusing instead on the social conditions of the formation of discourses (Purvis \& Hunt, 1993, p. 490). Despite this, statements 'can still be located in talk and texts' (McHoul \& Grace, 1998, p. 40). Analysing text, in all its forms, is a way of uncovering regularities between statements which point to the existence of discursive formations and hence discourses. This provides the imperative for discourse analysis.

A discursive formation is most simply a grouping of statements. Foucault $(1969 / 2002 a$, p. 41$)$ states that a discursive formation is present

Whenever one can describe, between a number of statements, such a system of dispersion, whenever, between objects, types of statement, concepts, or thematic choices, one can define a regularity (an order, correlations, positions and functionings, transformations).

In other words, when regularities between statements can be identified, there is evidence for a grouping, or a discursive formation. A discursive formation is regarded as the group, the statement the unit and discourse the totality of statements within a formation itself. In Foucault's (1969/2002a, p. 121) words,

The term discourse can be defined as the group of statements that belong to a single system of formation; thus I shall be able to speak of clinical discourse, economic discourse, the discourse of natural history, psychiatric discourse.

Thus the New Zealand version of egalitarianism, as discussed in Chapter 7 , comprises an egalitarian discourse indicated by a regu- 
larity that arises through the systematic analysis of the talk of New Zealanders. Gee (2014, p. 56) notes that discourses need not be large in scale; they can in fact exist in a much more limited manner. These more limited discourses can be, for example, subnational discourses such as left-wing Wellington that this study identifies in Chapter 8.

In its most general sense, discourse constrains what it is possible to know and thus speak about (McHoul \& Grace, 1998, p. 31). Discourses occur within certain social contexts and historical periods and are subject to transformation (Fairclough, 1992). Discourses also transcend the immediate, can be drawn upon diachronically, are reinforced and changed, contested and promoted; Gee (2014, p. 55) states that 'Discourses have no discrete boundaries because people are always, in history, creating new Discourses, changing old ones, and contesting and pushing the boundaries of Discourses.' The fluidity and shift of discourse is central to Foucault's understanding of history, but also applicable in the more immediate sense as certain discourses, while able to be referred to with seemingly fixed labels, are always open to change. By way of simple example, the manner in which racial differences were characterised in the 19th century differs radically from today because of a shift in discourse. Back then it was beyond the realm of knowledge to conceive of and articulate ethnicity in the way we do now; dominant discourses of the time constrained the way it could be thought of and articulated in various statements.

It is important to note however that the subject is not at the mercy of discourses, as the relationship between discourse and the social subject is considered dialectical, as highlighted by Bhaskar's TMSA. As Fairclough (1992, p. 45) notes, 'social subjects [are] shaped by discursive practices, yet also [are] capable of reshaping and restructuring those practices.' Fairclough's (1992) 'discursive practices' refers to language and other forms of semiosis, which I refer to for the purposes of this thesis as 'interactional discourse.' Sociocultural discourses as conceptualised for this study are subsumed within Fairclough's (1992) notion of 'social practice.' Chouliaraki and Fairclough (1999, p. 21) define social practices as 'habitualised ways, tied to particular times and places, in which people apply resources (material or symbolic) to act together in the world.' Within this are discourses which focus on broader aspects of social life: 
A discourse is a particular way of representing certain parts or aspects of the (physical, social, psychological) world; for instance, there are different political discourses (liberal, conservative, social-democratic, etc.) which represent social groups and relations between social groups in a society in different ways. (Fairclough, 2005, p. 925)

Discourse, by this view, is much more than solely language, though Fairclough's (1992, 2010) discourse analytic approach centres on the linguistic analysis of texts, both spoken and written. The particular approach to discourse analysis for this study is discussed further in Chapter 4 .

The alignment of this study with Foucault's approach to discourse is carried out with awareness that his work tends to exclude human agency, the so-called 'death of the subject' (Allen, 200o), though, like Fairclough (1992), this study views discourse as constraining yet open to transformation. The next section examines this relationship further, approaching the Foucauldian theory of discourse from a critical realist perspective and demonstrating how Foucault's work is broadly compatible with realist tenets.

\subsubsection{Discourse and Realism}

Foucault remained open to the existence of the 'non-discursive', defining the statement, his 'atom of discourse' (1969/2002a, p. 90), as intersecting material reality (p. 98) and providing examples of nondiscursive domains such as 'institutions, political events, economic practices and processes' (pp. 179-180). As Fairclough (1992, p. 49) explains, Foucault's 'materiality' of statements 'means not its property of being uttered at a particular time or place, but the fact of it having a particular status within particular institutional practices.' In later years, some theorists expanded the discursive to incorporate all of social life, including that which they argue only seems to be non-discursive (Laclau \& Mouffe, 2001). According to critical realism, structures, and their generative mechanisms, exist outside discourse, a point that theorists such as Laclau and Mouffe (2001) and the associated field of Discourse Theory may contest. ${ }^{6}$ Critical realism

6 See the debate between Laclau and Bhaskar (1998) for more on this topic. 
demonstrates that the domain of the Real is, by its very definition, nondiscursive, even though our interaction with it may be mediated by discourse; the critical realist distinction between mind-independent world (the intransitive dimension) and our theories about it (the transitive dimension) again becomes relevant. Foucauldian discourse theory appears compatible with critical realism precisely because it seems open to the existence of the extra-discursive. ${ }^{7}$

Some work has previously been carried out aligning Foucault more closely with a realist philosophical perspective (Al-Amoudi, 2007; Marsden, 1999; Pearce \& Woodiwiss, 2001). Al-Amoudi (2007, p. 561) notes that while Foucault may be broadly characterised as a relativist, '[his] relativism is an epistemic relativism about the transitive dimension [and] that... does not imply an ontological relativism about the intransitive dimension.' In other words, Foucault's work can be situated within critical realism in much the same way weak social constructionism is considered compatible: both remain unconcerned with the intransitive dimension. Al-Amoudi (2007, p. 553) argues that Foucault's implicit ontology is largely along critical realist lines, particularly as expounded in his later genealogical works. Purvis and Hunt (1993, p. 490) make the observation that

it is not that [Foucault] thinks that there is somewhere a realm outside discourse, because all practices and institutions function through the medium of discourse. Rather social practices and institutions are not reducible to discourses; they have their conditions of possibility that are not provided for by discourse alone.

The critical realist view of emergence accounts for the irreducibility of social structures to discourse as mentioned by Purvis and Hunt (1993). However, it does not follow that they have no reality beyond discourse. What is clear is that situating Foucault's concern within

7 Phillips and Jørgensen (2002, p. 90) note that drawing a line between the discursive and non-discursive is difficult and cites this as a leading argument against realism. This discussion is easily addressed by the concept of emergence, in that the discursive emerges from but is not reducible to the non-discursive (Collier, 1994, pp. 110-111). In an emergentist framework, drawing a distinct line between an emergent phenomenon and its base is misplaced. In this thesis I will refer to the 'extra-discursive' in acknowledgement that discourse mediates our understandings of the Real, which reference to the 'non-discursive' tends to hide. 
the transitive dimension alone, as noted by Al-Amoudi (2007), allows compatibility with critical realism.

As discussed in the next section, a main consideration is that discourse is emergent from but not reducible to language. Discourses have their own internal generative mechanisms, from the level of the statement to that of discursive formation. Sayer (2004, p. 13) notes that

reasons and other discursive phenomena may be causally efficacious... [but] (a) it is contingent whether these causal powers are activated; and (b) if they are, the effects depend on conditions, such as the properties of other discourses, motivations and interests.

In the open system of the social world the effects of certain discourses are never regular; competing discourses, the actions of certain agents and other complicating factors can fundamentally alter how certain events are realised. Fine-grained discourse analysis at the level of interactional discourse, the level aligned most closely with that of Foucault's statement, therefore seems a productive starting point for uncovering the nature of broader sociocultural discourses, their conflicts and struggles, and the effects they tend to have within a thoroughly grounded critical realist ontology. Further discussion on critical realism as it relates to discourse analysis is provided in Chapter 4 .

The following section provides examples of how Foucault's theories have been interpreted and applied by certain scholars, and works towards a practical critical realist approach to discourse.

\subsubsection{Sociocultural Discourse Applied}

Gee (2014, p. 51), drawing on Foucault, defines sociocultural (or in Gee's terms, 'big-D') discourse as 'socially accepted associations among ways of using language, of thinking, valuing, acting, and interacting, in the "right" places and at the "right" times with the "right" objects.' Simply put, sociocultural discourse is 'language plus "other stuff" (Gee, 2014, p. 52). Gee adds the notion of social acceptance to his definition of discourse, which is also central to his model of identity (see Chapter 3). His interpretation of Foucault is useful in 
that it brings fairly abstract theoretical notions closer to analytical availability.

Sociocultural discourses influence individuals' talk and are simultaneously emergent from their cumulative practice in interaction. Language is intimately tied to discourse at every level, making its analysis a window onto the structuring of discourse in both its senses and their close interrelation. From a critical realist perspective, any discourse is emergent from language and therefore has its own internal mechanisms. Indeed, discourses (and their statements) can encompass more than language; Purvis and Hunt (1993, p. 485) give the example of a man opening a door for a women being a practice that is part of a particular discourse organised by 'a strict sexual division of labour.' It is tempting to view discourses as entirely linguistic given the analysis of talk and text is the main entryway within linguistic discourse analysis. Critical realism, however, conceptualises language as a structure with its own causal powers, and while it is a very important and influential factor in the creation and sustenance of discourses, it is not the only factor, in much the same way that reality is not entirely discursive.

Sociocultural discourse can be illustrated through the example of a tree, as provided by Howarth, Norval and Stavrakakis (2000, pp. 23). Contrary to their theoretical orientation as discourse theorists, a tree from a critical realist perspective is considered a non-discursive material object subject to the interplay of a multitude of mechanisms that affect its realisation, including the chemical, biological and social. Within the sociocultural discourse of environmentalism (notwithstanding the fuzzy boundaries of such labels) the tree may be given meaning (amongst many other competing interpretations) as, for instance, 'a beautiful example of a living organism that represents our natural environment.' The internal logic of environmental discourse renders the following entirely plausible: without trees our environment would turn to ruin, as they convert carbon dioxide to oxygen, a necessity of life; thus, the tree should be protected. However, as contestation occurs not only within discourses but also between them (Foucault, 1969/2002a), other discourses may offer competing meanings: the discourse of economic development may fail to assign the same importance to the tree; it may be generated as 'an inconvenient barrier to the creation of an arterial road that 
will bring economic prosperity to an area.' The internal logic of this discourse foregrounds the importance of development; without it fewer people would gain employment and higher wages which directly affects the standard of living of the populace. Cutting down the tree, or perhaps even a forest, is a minor concession to make for a more comfortable and prosperous existence. This example highlights the influence sociocultural discourses can have on shaping the way we talk about the things around us. Environmental discourse may cross over with discourses of biological science or ecological conservation, and economic development discourse may be co-drawn with discourses of wellbeing, prosperity or capitalism. Sociocultural discourses constantly clash with others and are reinforced by and merged with similar discourses and those smaller sub-discourses within them (Gee, 2014; Macdonell, 1986). In addition to influencing the way we think about certain objects, discourses can also provide various positions for agents to adopt; Howarth et al. (2000, pp. 23) note in reference to their tree example that the subject positions available could be 'developers', 'naturalists', 'environmentalists' or 'eco-warriors.' Managing these identity positions is an inherently political process in that it involves power and struggle (Foucault, 1969/2002a; Howarth et al., 2000).

Control over discourses, whether conscious or unconscious at the individual level, or as part of a broader social movement, is a constant struggle for dominance. This occurs most obviously in the arena of politics where political actors vie for discursive control, whether it is politicians 'framing' debates (Lakoff, 2004) or citizens forming grassroots organisations determined to rewrite the discursive terrain (see Kidner, 2015). The importance of politics and power to discourse is acknowledged by Foucault (1969/2002a, p. 136): '[discourse] is, by nature, the object of a struggle, a political struggle.' Howarth et al. (2000, pp. 2-3) also note that

a political project will attempt to weave together different strands of discourse in an effort to dominate or organise a field of meaning so as to fix the identities of objects and practices in a particular way.

An example of this arose during the 2011 New Zealand election campaign where the partial sale of shares in state-owned assets, 
including the national airline and a number of power stations, was characterised as either an example of 'asset sales' and 'privatisation', terms used by the Opposition, or the 'mixed-ownership model', a term coined by the Government. This is a simple example of linguistic items indexing two competing discourses that are engaged in a struggle for dominance.

The next section shifts to a brief examination of ideology, a related yet distinct phenomenon that is relevant to the investigation of political identity and its associated discourses.

\subsection{IDEOLOGY}

Ideology has a long and contested history in the social sciences and I will not outline its development in detail. This is due to its less immediate applicability in light of the analytical aims of this study. Nevertheless, a brief treatment of the concept and an examination of how it sits alongside the theories in use in this study is important in order to provide a fuller picture of the theoretical context.

Hamilton (1987, p. 38), after a review of many competing definitions of the term, arrives at the following synthesis:

An ideology is a system of collectively held normative and reputedly factual ideas and beliefs and attitudes advocating a particular pattern of social relationships and arrangements, and/or aimed at justifying a particular pattern of conduct, which its proponents seeks to promote, realise, pursue or maintain.

Hamilton's definition is relevant to discourse analytic practice as these 'ideas and beliefs' may arise in interaction and become analytically salient. The social aspect is important to Hamilton's definition, which van Dijk (2006b, p. 116) adds to with his definition, stating that ideologies consist of social representations that define the social identity of a group, that is, its shared beliefs about its fundamental conditions and ways of existence and reproduction.' A notable feature of van Dijk's (2006b) definition is the place of social identity, which, as shown in Chapter 3, is particularly relevant to this study. Ideology, in van Dijk's (2006b) sense, is relevant to discourse analysis concerned with political identity, as ideologies can play a significant role. The 
way an individual aligns with a political ideology, for example, can be regarded as indexing a particular social identity, but one that has its own 'ways of existence and reproduction' (van Dijk, 2006b, p. 116) which includes, in Hamilton's $(1987$, p. 38) words, 'a particular pattern of conduct.' In this sense, all social identities have ideological components. As Liu, McCreanor, McIntosh and Teaiwa (2005, p. 15) note, identities 'carry ideological prescriptions with them that enable society to maintain and reproduce itself.'

Ideology is conceptualised for the purposes of this study as an organising framework of discourse and hence is of less analytical priority in later chapters. To return to Purvis and Hunt's (1993, p. 485) example of a man opening a door for a woman, it is both a practice that comprises part of a discourse and an ideological act in the sense that it "pertains to relations of domination/subordination, facilitates their reproduction and...masks the structural inequalities that underlie and are the condition of such practices' (p. 497). They note that discourses are ideological when they are connected to 'systems of domination' which can present 'sectional or specific interests... as universal interests' (p. 497). Politics, then, is clearly an ideological arena. If an individual were to index the identity of 'libertarian', they would bring to bear ideological understandings of what it means to be a libertarian. Certain discourses would also influence the way that this identity is realised and reproduced. In much the same way as the language-discourse and discourse-identity relationships, ideology is not reducible to discourse. In fact, Purvis and Hunt (1993, p. 476) make a connection to realism in their own work; they note that distinguishing between the 'internal' focus of discourse on linguistic and semiotic aspects and the 'external' focus of ideology on connections to lived experience requires an 'intellectual commitment to some version of philosophical realism.' The parallel with critical realism is evident, indicating that alongside discourse, ideology is also well served by a critical realist account of reality. As ideology is not a major focus of this study, a critical realist approach to its analysis appears to be a worthwhile avenue for further research within the New Zealand context (see Chapter 11). 


\subsection{SUMMARY}

Critical realism provides the philosophical grounding for this study. In addition to its avoidance of the epistemic fallacy, its division of the two dimensions of science, its models of depth reality and causation and its approach to explanation in the form of tendencies, critical realism provides ontological substance to weak social constructionism and is also compatible with Foucauldian discourse as used in this study and the related notion of ideology. Furthermore, critical realism inspires the abandonment of the 'dead metaphor' (Hacking, 1999) of 'construction', replaced instead by the 'genesis' of social structures and identities which encodes in its definition the place of agency acting within structural constraint but with the power to influence its reproduction. Critical realism is considered a successor to other philosophical paradigms, most notably positivism, and is a powerful, elegant and liberating philosophy that breaks down longestablished dualisms that have long plagued the natural and social sciences. Critical realism stands to contribute much to the practice of discourse analysis. This thesis provides an example of how this philosophy can be the productive underlabourer for a discourse analysis distinguished by its ability to treat reality as something that doesn't go away. 

Identity is a complex phenomenon with many associated research strands (de Fina, 2012). This chapter seeks to unpack the nature of identity and explore the way in which it can be analytically accessed for the purposes of this thesis. This study centres on widely used approaches within discourse analysis in which language and interaction are considered the central drivers of identity genesis. A brief survey of the discourse and identity literature is first provided to situate this study within the burgeoning field, with a particular focus on constructionism. The influence of constructionism on discourse and identity research has been fruitful but has also led to issues considered problematic from a critical realist standpoint. Unfortunately, critical realists have not engaged thoroughly with identity research (Groff, 2010), at least when evaluated against the constructionist literature. This chapter addresses this by examining an influential framework within the constructionist paradigm, Bucholtz and Hall's (2005) 'sociocultural linguistic approach', positioning their insights within a critical realist frame. Gee's (2000) identity model is then investigated as a complement to Bucholtz and Hall's (2005) approach, particularly due to its inclusion of extra-discursive components of identity. These are unified under the critical realist banner and illustrated in a graphical model at the end of the chapter.

\subsection{DISCOURSE APPROACHES TO IDENTITY}

Identity is the focus of a rich research history within linguistics and other disciplines, spanning social and political psychology, anthropology and sociology (Huddy, 2001). De Fina (2012) notes of the vast literature that

Identities can be regarded as collective or individual, as social or personal, as mental constructs or as the product of actions. At the same time, language can be 
seen as reflecting, conveying, constructing identities or as carrying out all those functions at the same time.

This section provides an overview of identity as it is approached discursively, that is, focusing on approaches to identity that treat language and interaction as central to its genesis, as noted in Chapter 2. Constructionism is considered the most influential and pervasive approach to discourse and identity research (de Fina, 2012). It is therefore necessary to investigate its main tenets in more detail.

De Fina (2012) states that 'modern discursive conceptions about identity have, in one way or another, all been influenced by social constructionism', particularly through the work of Berger and Luckmann (1966). Constructionist identity research exists in strong opposition to a more essentialist view of the self 'as an isolated, selfcontained entity' (de Fina, 2011, p. 264) that exists entirely in the mind of the individual (de Fina, 2012, p. 1), aligning it with postmodern approaches that oppose essentialist identity, such as 'performativity' (Butler, 1999; Litosseliti \& Sunderland, 2002). Constructionism entails a focus on the social processes through which identity is generated in discourse (Bamberg et al., 2011, p. 178). It asserts that identity genesis in interaction results in multifaceted and multiple identities which are socially negotiated (de Fina et al., 2006, p. 2). This study has a similar focus on interactional discourse as the key driver of identity genesis. However, while constructionist tenets are highly influential in the subsequent analysis, they require explicit realist extension.

Narrative approaches to identity analysis are particularly influential (Bamberg, de Fina \& Schiffrin, 2007b; de Fina, 2012). Narrative and identity research is generally unified by a focus on how 'selves are made coherent and meaningful through the narrative or "biographical" work that they do' (Benwell \& Stokoe, 2006, p. 42). Narrative has been the focus of many identity research strands with most taking a constructionist standpoint (Benwell \& Stokoe, 2006, p. 42). Narrative as a linguistic structure has also been a feature of widespread interest, including in sociolinguistics (Labov \& Waletzky, 1967), and within Conversation Analysis (CA), Membership Categorisation Analysis (MCA) and CDA (Bamberg, de Fina \& Schiffrin, 2007a). Narrative analysis appears in Chapter 10, as Steven's recollection of his job interview has a significant role to play in his identity genesis as he balances his political and professional selves. 
In the next section, the constructionist framework of Bucholtz and Hall (2005) is examined from a critical realist standpoint, with a particular focus on the theorisation of emergence.

\subsubsection{Sociocultural Linguistic Identity}

An important identity framework that has had considerable influence on the constructionist discourse analytic tradition is the sociocultural linguistic approach of Mary Bucholtz and Kira Hall (2005). They undertook the impressive task of teasing out a coherent framework of the processes of discursive identity genesis from research across fields such as social psychology, linguistic anthropology and sociolinguistics (p. 586). Their framework proposes five main principles of sociocultural linguistic identity: emergence, positionality, indexicality, relationality and partialness. The utility of this identity framework lies in its articulation of the core processes of identity genesis in interactional discourse which are situated alongside practical examples that illustrate the manner in which each principle can manifest in talk.

The five principles are all relevant to this study in different ways. The first, emergence, is of interest in mainly philosophical terms, given the different interpretation of the term from a critical realist viewpoint in relation to the rootedness and irreducibility of emergent strata (Collier, 1994, pp. 110-111). Emergence will therefore form the bulk of discussion in this chapter. The principle of relationality refers to the intersubjectivity of identity, central to the model of stance (Du Bois, 2007), and this forms the focus of the case study which is discussed in Chapter 9. Indexicality, which provides a link between language and context (de Fina et al., 2006, p. 4; Silverstein, 2003), is discussed in Chapter 4, and both positionality (the multilevelled nature of identity) and partialness (its fragmentary and dynamic composition) are implicit in Gee's (2000) NIDA model which is introduced in Section 3.2.1. In the next section, I explore the nature of emergence and the way in which Bucholtz and Hall's (2005) framework can be grounded ontologically in order to carry it through to analysis in this thesis. 


\subsubsection{Emergent Identities}

The first principle is that of emergence. In their words, 'identity is best viewed as the emergent product rather than the pre-existing source of linguistic and other semiotic practices and therefore as fundamentally a social and cultural phenomenon' (p. 588). An implication of this principle is that identity is not to be viewed as a category of the individual, which positions Bucholtz and Hall's (2005) framework, like much other constructionist work, against traditional essentialist views that treat identity as a self-contained notion of oneself (de Fina, 2011, p. 264). According to Bucholtz and Hall (2005, p. 591), identities are 'not... ontologically prior to the discourse that calls them forth' and are therefore inseparable from language. They do, however, state an important qualification: while identities may be emergent from interaction, this does not discount the fact that "they may draw on "structure"-such as ideology, the linguistic system, or the relation between the two' (p. 588).

A critical realist reading takes no issue with the claim that identity is primarily social and cultural nor with the claim that identity is not the source of linguistic practice. There are however three issues that are raised that require further elaboration:

1. The definition of emergence;

2. the statement that identities are not 'ontologically prior' to discourse; and

3. the nature of 'structure.'

The first issue relates to Bucholtz and Hall's (2005) definition of emergence and the philosophical tradition behind the word on which critical realism rests. They tend to use the term in the general sense of 'becoming visible' or 'being produced.' In contrast, the philosophical notion of emergence, as discussed in Chapter 2, holds that an emergent stratum is rooted in but irreducible to that below it (Collier, 1994, pp. 110-111). Identity can therefore be viewed as emergent from but irreducible to discourse because it possesses its own set of mechanisms that can have causal effect upon the world. If the philosophical interpretation of emergence is accepted then Bucholtz and Hall's second claim becomes particularly problematic. 
The second issue lies in the claim that identity is not 'ontologically prior' to discourse (p. 591). This is articulated in direct contrast to essentialist approaches that implicitly treat identity categories, such as age and ethnicity, as prior to the linguistic behaviour which correlates with that category (Benwell \& Stokoe, 2006, pp. 26-27). This aim is unproblematic for the approach adopted in this study. From a critical realist viewpoint, however, the authors make an ontological statement, implying that identities do not exist outside of discourse and hence lie entirely in the realm of epistemic relativism. Their constructionist view seems to lead to a reductionism that is incompatible with the philosophical notion of emergence; if identity has its own causal powers then it must be something above and beyond discourse. In this sense Bucholtz and Hall's claim appears to be an example of the epistemic fallacy, discussed in Chapter 2. More evidence of this is found in their statement that 'reality itself is intersubjective in nature, constructed through the particulars of self and other in any localized encounter' (Bucholtz \& Hall, 2005, p. 605). Adjusting the statement to 'our experience of reality' instead poses no problem from a critical realist standpoint.

Critical realism requires a more nuanced approach to ontology that addresses these shortcomings. Its proponents would argue that identity can indeed exist independently of discourse, even though it is through discourse that it is generated and recognised. Identities are not reducible to discourse by the very nature of their emergence. This is captured in the model of identity presented at the end of this chapter.

The third issue relates to structure and agency. Bucholtz and Hall tackle this by promoting a compromise position. Firstly, they sidestep the issue by arguing that traditional debates about agency are not within their remit, as 'sociocultural linguists are generally not concerned with calibrating the degree of autonomy or intentionality in any given act; rather, agency is more productively viewed as the accomplishment of social action' (p. 606). Secondly, they deal with structure and its relationship to agency by arguing that

On the one hand, it is only through discursive interaction that large-scale social structures come into being; on the other hand, even the most mundane of everyday conversations are impinged upon by ideological and material 
constructs that produce relations of power. Thus both structure and agency are intertwined as components of micro as well as macro articulations of identity. (Bucholtz \& Hall, 2005, p. 607)

The dialectical nature of structure and agency as proposed in Bhaskar's TMSA is potentially compatible with Bucholtz and Hall's approach. However, the quotation above remains problematic to a critical realist because they do not deal with the ontological nature of 'large-scale social structures' nor do they elaborate on what they mean by 'intertwined.' Archer (1998, p. 203) states that

Any theory which treats structure and agency as a mutually constitutive amalgam also implies that causation is always the joint and equal responsibility of the two and therefore that no state of affairs is ever more attributable to one than the other.

An 'intertwined' structure and agency is therefore inadequate for a critical realist. Bhaskar's TMSA provides a model that separates the two and allows for constraint and transformation to coexist unproblematically (see also Fairclough, 1992). The TMSA provides a more sophisticated approach that can replace that taken by Bucholtz and Hall (2005).

Bucholtz and Hall (2005) provide a thorough framework of identity in interaction that is of immense use to discourse analytic approaches. With a little ontological ground-clearing, their framework remains useful for analysis of identity genesis. The following section examines how critical realism can further add more to the study of discourse in identity.

\subsection{CRITICAL REALIST IDENTITY}

A largely fragmentary approach to identity across fields has meant that the word 'identity' itself tends to lack conceptual uniformity (Brubaker \& Cooper, 200o). Brubaker and Cooper (2000, p. 3) state that this 'identity crisis' in the social sciences has arisen from the overuse and devaluation of the word. They note that constructionist approaches that treat identity as fluid, constructed and multiple deny 
it 'analytical purchase', particularly as it is seemingly unable to deal with more rigid identities that exist over longer stretches of time (such as 'core' identity, discussed in Section 3.2.2), that it does not rigorously theorise the place of external influences on identity, and cannot, for example, deal with the 'terrible singularity that is often striven forand sometimes realized-by politicians seeking to transform mere categories into unitary and exclusive groups' (Brubaker \& Cooper, 2000, p. 3). A realist approach to identity is required that allows analysts to look for influences that reside outside discourse and which addresses these caveats.

As argued in Chapter 2, constructionism is compatible with critical realism provided that the former avoids ontological claims that may be at odds with realist tenets; certain such claims by Bucholtz and Hall (2005), for example, have been examined in the previous section. Critical realism brings more than ontological grounding of constructionist approaches; it takes its own perspective on the ontology of identity. Identities are considered to have components that may exist outside discourse (yet still rely on discourse for their social recognition), as they can

relate to determinate characteristics and acts, to what actors, groups, societies have done. These acts, of course, are open to differing interpretations, but the latter in turn have some things in common-the interpretandum-over which they differ. (Sayer, 2000, p. 46)

In contrast to an essentialist approach, Sayer (1997b) argues in an earlier paper that any object does not have one deterministic 'essence', a 'dangerously misleading' view that is often taken to mean sameness across categories; rather, when rendered in critical realist terms, if an object has causal effect upon the world it could have any number of underlying generative mechanisms, the experience of which can be interpreted in many ways. This reflects the richer ontology of critical realism that transcends, among other things, the essentialist versus anti-essentialist debate (Sayer, 1997b, p. 455). In the above example, the various interpretations of certain acts are negotiated in discourse but still refer to extra-discursive objects, i. e., the act itself. Sayer (2000, p. 46) gives the example of an identity parade (or police lineup) which exists 'to establish the identity of an (alleged) criminal.' The identity 
of 'criminal' or 'murderer' has entirely discursive aspects, including institutional components (Gee, 2000), but the object to which these components of identity refer is the act of murdering someone-as Sayer notes, 'they relate to what the person so identified has done' (2000, p. 46). Indeed, interpretations can be shown to be true or false and can be contested or ratified, in this example in a court of law. The use of 'identity' in this case is however only one aspect of the model adopted for this study; Sayer's (2000, p. 46) main point from a critical realist standpoint is that identity 'is not merely a matter of discourse.'

The next section presents a model of identity that is compatible with critical realism and which is relevant to addressing the aims of this study. It is necessary to provide a model that allows for the analysis of social structures as they influence individuals while simultaneously giving individuals the power to transform social structures themselves, a compromise position between the twin poles of humanism, concerned with agency, and structuralism, concerned with structure (Collier, 1994, p. 141). A realist theory of identity must also understand it as a complex phenomenon that includes components constrained and influenced by material strata while accepting that identities can simultaneously be considered 'a social fact, a meaning-laden, normative practice that precedes [their] enactment by any given individual' (Groff, 2010). This is in addition to viewing identity as having a localised, contextually informed component that is negotiated and contested in interaction, but also acknowledging that discourse is only one, albeit an important, part of identity.

\subsubsection{The NIDA Model}

Identity, according to Gee (2000, p. 99), is simply 'being recognized as a certain "kind of person", in a given context.' Gee's identity theory accepts that one can have multiple identities that are context dependent yet also allows for the continuity of identity across contexts. Being a certain kind of person is a complex achievement that is influenced from four directions and hinges on the process of social recognition through discourse. The four identity strands are introduced in Table 2. Gee (2000, p. 101) explains that these components 
are not separate from each other. Both in theory and in practice, they interrelate in complex and important ways. Rather than discrete categories, they are ways to focus our attention on different aspects of how identities are formed and sustained.

\begin{tabular}{lccc}
\hline & PROCES & POWER & SOURCE \\
\hline $\begin{array}{l}\text { Nature- } \\
\text { identity: a } \\
\text { state }\end{array}$ & $\begin{array}{c}\text { developed } \\
\text { from }\end{array}$ & forces & in nature \\
\hline $\begin{array}{l}\text { Institution- } \\
\text { identity: a } \\
\text { position }\end{array}$ & authorised by & authorities & $\begin{array}{c}\text { within } \\
\text { institutions }\end{array}$ \\
$\begin{array}{l}\text { Discourse- } \\
\text { identity: an } \\
\text { individual } \\
\text { trait }\end{array}$ & recognised in & the discourse/ & $\begin{array}{c}\text { of/with } \\
\text { 'rational }\end{array}$ \\
\hline $\begin{array}{l}\text { Affinity- } \\
\text { identity: } \\
\text { experiences }\end{array}$ & dialogue & individuals' \\
\hline
\end{tabular}

Table 2: Four ways to view identity (Gee, 2000, p. 100).

Each identity strand does not function in an isolated manner, though studies of identity can differ as to the focus assigned to a certain component, as this study does in its focus on D-identity. Nevertheless, while each strand may be interrelated and inseparable from the others, Gee argues that 'we can still ask, for a given time and place, which strand or strands predominate and why' (p. 101). This allows scope for identity analysis to focus predominantly on one strand over another, depending on research goals, while remaining sensitive to the influence of other aspects of identity. In addition to these four components of identity, a core self provides a sense of continuity to the individual across time and space (Gee, 2014, p. 58), rounding out the model into a comprehensive realist theory of identity. 
Gee's (2000) identity theory demonstrates how discourse, while considered the main driver of identity recognition, does not comprise the entirety of the theoretical concept. Critical realism adds to this the influence of extra-discursive phenomena, such as physical acts mentioned by Sayer (2000), leading to a comprehensive approach to identity as it is generated in context. This study seeks to demonstrate that critical realism is a useful foundation to this model and as such is a practical philosophical paradigm under which discourse and identity research can productively take place.

\subsubsection{N-Identity}

Gee's model begins with nature-identity, or N-identity. N-identity arises from the 'force of nature', as in Gee's personal example, being an identical twin (p. 101). Being an identical twin is not something that has been accomplished by an individual; rather, the $\mathrm{N}$-identity of being an identical twin 'develops from' a certain 'force'; in this case, it has developed from genetic material of which Gee had no control. This process, at its lowest level, operates outside society, outside discourse and outside institutions. Nevertheless, in order for $\mathrm{N}$-identities to be considered identities at all, they must be recognised 'as meaningful in the sense that they constitute (at least, in part) the "kind of person" I am' (p. 102). Social recognition, tied more closely to the other strands of identity, is therefore required for $\mathrm{N}$-identity to become an aspect of one's identity at all. Gee explains that in his case, having a spleen is not an N-identity as it is not (currently) socially meaningful but there is at least the potential that having a spleen will develop into a meaningful and socially recognised identity (p. 102). In critical realist terms, $\mathrm{N}$-identity comprises a host of unexercised powers (Collier, 1994, p. 37) located in the physical body and its material conditions. The inseparability of $\mathrm{N}$-identity from the other identity strands is again emphasised by Gee (2000, p. 102), as ' $\mathrm{N}$ Identities must always gain their force as identities through the work of institutions, discourse and dialogue, or affinity groups.' A charge of biological reductionism is avoided, as he states that

N-Identities always collapse into other sorts of identities.

Of course, when people (and institutions) focus on them as 'natural' or 'biological,' they often do this as a way 
to 'forget' or 'hide' (often for ideological reasons) the institutional, social-interactional, or group work that is required to sustain them as identities. (Gee, 2000, p. 102)

$\mathrm{N}$-identity is therefore considered the base level of identity which mediates between the physical and the social, allowing for aspects of identity to have their ontological origins outside of the social. Nidentity pertains primarily to the individual but at a deeper level it can be considered underlain by extra-discursive factors, such as material space and physical acts that constrain the body in myriad ways. Indeed, extra-discursive factors influence each of the four strands and can thus be thought of as an influence over the entire model. This is illustrated in the model discussed in Section 3.2.4.

\subsubsection{I-Identity}

The second strand of Gee's identity theory is institution-identity, or Iidentity. I-identities are 'authorised' by 'authorities' in institutions. Institutions in capitalist societies can be understood, along Althusser's (1972, pp. 136-137) lines, as including education, family, law, politics, trade-union, communications and culture. In the educational institution, namely the university, Gee (2000, p. 102) gives the example of the 'Professor' identity being institutionally sanctioned; the university authorities have authorised the use of the Professor title along with the institutional responsibilities assigned to the position. I-identities vary on a spectrum in terms of whether they are a 'calling' or an 'imposition', in other words, whether they are actively or passively inhabited as identities (p. 103). In Gee's case, being a Professor is a 'calling' which is actively inhabited; he gives the example of an imposed I-identity being that of a prisoner who is subject to an Iidentity imposed by the legal, judicial and correctional institutions of the state (p. 103). The earlier example of a murderer can also have an I-identity component imposed by a court of law.

Ideology is fundamental to the formation of I-identities, as ideologies offer sets of beliefs to which institutions and individuals orient, as discussed in Chapter 2. This in turn shapes interactional discourse resources and hence the formation of $\mathrm{D}$-identities. 


\subsubsection{D-Identity}

The third strand of identity is discourse-identity, or D-identity. Didentity involves an individual trait being recognised by others in interaction, making it a meaningful aspect of one's identity. Gee (2000, p. 103) gives the example of being charismatic; one is not born with charisma (i.e., it is not a heritable trait) and one is not charismatic by oneself; it is only through recognition in interaction that being charismatic becomes socially meaningful for D-identity.

It is immediately apparent that D-identity is tied closely to Iidentity, because

institutions have to rely on discursive practices to construct and sustain I-Identities, but people can construct and sustain identities through discourse and dialogue (D-Identities) without the overt sanction and support 'official' institutions. (Gee, 2000, p. 103)

I-identities therefore need discourse but not necessarily vice versa. Didentities can also relate back to $\mathrm{N}$-identities; in the case of having a charismatic personality, while generated and reinforced at the level of interactional discourse, it may also have $\mathrm{N}$-identity components such as a psychological tendency towards extraversion, for example, which in turn requires interaction with others in order to be regarded as meaningful and recognised as an extroverted person. D-identities can be influenced by sociocultural discourses, that is, social ways of knowing (Foucault, 1969/2002a) that can constrain interactional discourse resources which inevitably shape how D-identities may be realised in interaction. Investigating how D-identities are formed in interactional discourse can provide a window into the macro influences and material constraints that make up the conditions of their recognition. This is the basis of the material, sociocultural and subnational chapters (6 to 8 ) of this thesis.

Gee (2000, p. 104) notes that D-identities can also be ranked in terms of their passive and active 'recruitment', stretching across a spectrum from 'ascription' to 'achievement.' D-identities can be achieved, such as someone who actively builds a charismatic D-identity, or they can be ascribed by others, such as a child being labelled as learning disabled by his or her teacher in a parent-teacher interview (which 
can simultaneously be thought of as an I-identity being imposed by the educational institution; p. 104).

Bucholtz and Hall's (2005) focus on interactional discourse can be located within the D-identity strand as it is concerned with social interaction and recognition. Discourse is considered a central and important driver of identity, and the main focus of this thesis, but it is crucial to appreciate that D-identity is only one aspect of a larger model.

\subsubsection{A-Identity}

The fourth and final identity strand is affinity-identity. An A-identity is comprised of shared experiences of what Gee calls 'affinity groups', which can also be viewed as a distributed imagined community (Anderson, 2006) that is not necessarily present in the same physical location. Gee (2000, p. 105) gives the example of Star Trek fans, or 'Trekkies', a group which 'is made up of people who may be dispersed across a large space... [and] may share little besides their interest in...Star Trek.' Shared experience is meaningful to the creation of an A-identity, requiring discourse to be created and sustained, but as Gee (2000, p. 105) notes, the focus at the A-identity level is 'on distinctive social practices that create and sustain group affiliations, rather than on institutions or discourse/dialogue directly.' There is significant crossover here with social psychology, as Gee's concept of A-identity echoes Tajfel's (1974, p. 69) definition of social identity, 'that part of an individual's self-concept which derives from his knowledge of his membership of a social group (or groups) together with the emotional significance attached to that membership.' The emotional significance of membership is an important aspect that sustains A-identities, giving members of the group reason to maintain its existence and continue their affiliation. Gee (2000, p. 105) notes that affinity group members primarily orient to the practices of the group and secondarily to its other members. This has parallels to other more localised group theories such as 'community of practice' (Lave \& Wenger, 1991).

The next section discusses how the NIDA model works with the sense that we have a continuing thread of self across time, or a core identity, a view that is often neglected in more constructionist 
approaches that tend to focus on the situated negotiation of identity (Bucholtz \& Hall, 2005).

\subsubsection{Core Identity}

In this study, core identity is considered that which provides an individual a sense of continuity over time. It is not an explicit analytical focus of later chapters but it is an important part of the wider theoretical background. A core self can indeed change, but more slowly than the other components of identity (see also Bell, 2001, p. 164). Gee (2000, p. 111) defines it in the following way:

Each person has had a unique trajectory through 'Discourse space.' That is, he or she has, through time, in a certain order, had specific experiences within specific Discourses (i.e., been recognized, at a time and place, one way and not another), some recurring and others not. This trajectory and the person's own narrativization (Mishler, 2000) of it are what constitute his or her (never fully formed or always potentially changing) 'core identity.' The Discourses are social and historical, but the person's trajectory and narrativization are individual (though an individuality that is fully socially formed and informed).

Core identity is therefore different to the four strands of identity as introduced above; instead of being related to one of the four strands directly it is rather the accumulation of identity practice over an individual's life, the particular path an individual has carved through space and time, the sum of combinations one has inhabited across contexts. As sociocultural discourses change and identity bids shift in meaning and interpretation, our core selves remain more fixed, yet are also open to social influence and change. Implicated in Gee's above definition is the place of narrative, acknowledging the aforementioned rich literature in narrative and identity which view the narratives we tell about ourselves as an important linguistic form of identity genesis. Narratives are discussed further as they arise in the data throughout the analytical chapters of this thesis. 
The next section further examines the nature of social recognition, as it is the central driver of D-identity, and situates this process within the constraints of sociocultural discourse.

\subsubsection{Negotiation, Contestation and Recognition}

Human agency is given breathing room in the NIDA model. Gee (2000, p. 109) states that 'people can accept, contest, and negotiate identities in terms of whether they will be seen primarily (or in some foregrounded way) as N-, I-, D-, or A-Identities.' Identity is not a static attribute that stays unchanged with individuals throughout their lives (though some parts of identity, such as a core self, may be more durable than others). People have the ability to 'negotiate and contest how their traits are to be seen' (p. 108) and actively or passively influence how they are recognised. This all occurs in the ever-present context of structural constraint. Coupland (2007, p. 111) points out, however, that not all identity work is strategically controlled; sometimes identities " "leak" from our behaviour and our verbal and non-verbal displays.' Bell (1999) notes that stances and identities, indicated through style shifting, can also run a spectrum from 'evocation' of another's voice to 'whole-hearted identification with the group.' Whatever the degree of identification or conscious projection, all rely on the process of recognition to be made socially meaningful (Gee, 2014, p. 54).

Social recognition is not a straightforward process. An individual may argue that they were 'born with' charisma, making a bid for it to be assigned at the level of $\mathrm{N}$-identity, rather than seeing charisma as arising from a certain family environment (which could be viewed as an I-identity). Another may contest that their wealth was the result of inheriting their parents' 'entrepreneurial' genes (contesting an $\mathrm{N}$-identity), arguing that it was instead due to a series of lucky investments (refocusing instead on D-identity, as being wealthy relies on social recognition in interaction; a wealthy identity also relies on institutional authorisation in the form of higher tax brackets and also affinity group affiliations such as rich lists). The way our traits are socially recognised is not left up to chance; we have an active role in forming our identities whether these attempts are accepted or not. Certain structures can have a strong influence on this process. Also 
evident is the level of crossover between the four strands which makes isolated analysis difficult, if not impossible.

Achieving or contesting certain identities can be done in many ways, including interactional, behavioural and material practices. Gee (2000, p. 109) terms this a 'combination', an attempt to be recognised as having a particular identity or being a particular kind of person (see also Gee, 2014, p. 23). A combination collectively refers to speech and writing, gesture and body language, emotional states and material practices. Utilising certain combinations constitutes 'an active "bid" to be recognized in a certain way' (Gee, 2000, p. 109); if one was to dress in studded black leather, have long straight hair, gesture with the 'horns' hand signal, listen to heavy metal music, dislike mainstream popular music and perhaps play the electric guitar, then in contemporary Western society this particular combination would be an active bid to be recognised as a 'metalhead.' However, if the same combination was to be carried out in medieval Europe, one could imagine that recognition would not be the same.

Identities are formed in a manner that is contextually bound, including time, space and setting. Combinations that allow for recognition as a certain kind of person are what Gee (2000, p. 110) calls a 'Discourse'. His definition differs slightly from that of sociocultural discourse, as Gee expands it beyond Foucault's definition to include wider social practices and groupings. However, his conclusion is equally applicable to Foucauldian discourse, as certain combinations, operating within sociocultural discursive constraints, are socially and historically situated with different meanings at different times and in different places.

Without recognition, a trait would not constitute being a certain kind of person and therefore would not constitute an aspect of one's identity (p. 109), as in the spleen example above. Recognition is the central process of identity formation; however, while D-identities are most directly associated with recognition, this does not exclude the other strands of identity from utilising recognition to become socially meaningful. As Gee (2000, p. 109) argues,

While D-Identities appeal to recognition (in discourse and dialogue) directly, the other sorts of identities rely on recognition as well, although this recognition is filtered through a particular perspective on 'nature,' the workings 
of an institution, or the distinctive practices of a specific affinity group.

The absence of some sort of combination, however partial, results in a trait not being made socially meaningful through the process of recognition. The social, in the form of human recognition, and reflected in interactional discourse, is considered of prime importance in the NIDA model. The analysis of interaction is a productive place to begin the investigation of identity in all its complexity, despite the fact that it is irreducible to discourse. This study takes a sensitive analytical approach that appreciates this fact, understanding that other processes perhaps not observed in interaction may be simultaneously responsible for influencing identity at other levels. The use of Gee's NIDA coupled with critical realism means that the physical and material are no longer forgotten, and discourse, both sociocultural and interactional, while being considered central to identity genesis, is no longer the sole focus.

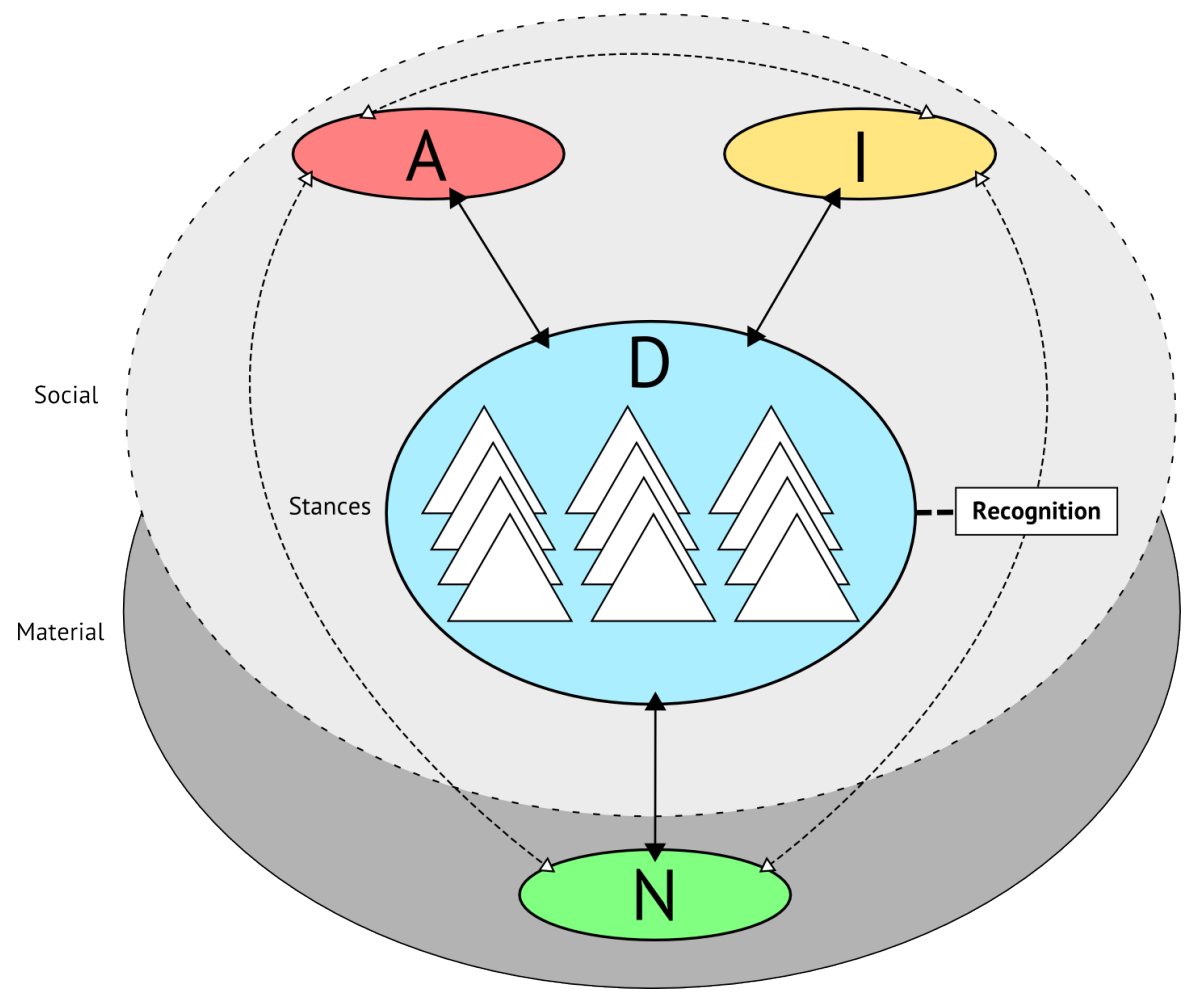

Figure 1: A discourse-focused model of identity in structural context. 


\subsubsection{Theoretical Model}

The model presented in Figure 1 is a synthesis of Gee's (2000) NIDA which I have located in a broader critical realist frame. Discourse is the site of identity genesis and recognition and thus a productive place to investigate this process as it occurs within both social and material context. The diagram attempts to convey the centrality of discourse but also illustrates the connections to other aspects, including the $\mathrm{N}-$, I- and A-identity structures as they influence identity genesis in talk. These aspects are also linked, showing that each N-, I- and A-identities can influence each other; for example, being a professor in a particular field could be linked to the affinity membership of a more global group of scholars. The model suggests that D-identity is comprised of a multiplicity of stances which then leads to social recognition. This is the heart of identity genesis and also the focus of the case studies presented in Chapters 9 and 10. The social and material circles provide the context in which identity is generated. These are critical to its full realist exploration and are thus the focus of Chapters 6 to 8 .

\section{$3 \cdot 3$ SUMMARY}

Identity is a complex phenomenon with aspects residing at numerous levels which is readily accessible through the analysis of interactional discourse. The wide literature in this vein is largely dominated by constructionist approaches, and as a result discourse and identity research has tended to background the influence of the extra-discursive. The most comprehensive constructionist framework of identity is that of Bucholtz and Hall (2005), who draw together five central principles that run through this study in many ways, including the indexical function of stances, the multi-levelled nature of identity and the intersubjective negotiation of localised stancetaking. Critical realism provides ontological depth to this framework, with the most prominent reformulation made to the notion of emergence. The NIDA model of identity (Gee, 2000) provides a theoretical scaffold into which Bucholtz and Hall's principles can slot, expanding the constructionist approach by theorising structural and sociocultural aspects that reside beyond discourse. The process of recognition in interaction is considered the primary mechanism through which 
identities are formed. This is compatible with the critical realist enterprise and is illustrated in a theoretical model that synthesises these insights from the literature. 

INTERACTIONAL DISCOURSE

The moment-by-moment use of language is constrained by and transformative of sociocultural discourses. It is the site of identity recognition and thus forms the main focus of analysis presented in the latter part of this thesis. The first section of this chapter introduces interactional discourse, followed by an examination of critical realist attempts to engage with discourse analytic approaches to talk. Interactional Sociolinguistics (IS), the supporting framework of analysis, is then introduced, which is followed by a discussion of indexicality, the means by which context is connected to talk. Stance, the tripartite act of evaluation, positioning and alignment that participants take up throughout interaction, is the focus of the second half of the chapter, including a discussion of its links to the identity model presented in Chapter 3. To conclude, the chapter narrows towards the concept of political identity, conceptualised in terms of stances that participants take up in the evaluation of political topics; stances that are socially recognised as forming part of their political selves.

\subsection{INTERACTION}

At the opposite end of the spectrum to sociocultural discourse is interactional discourse. ${ }^{1}$ In Gee's (2014, p. 52) terms, interactional discourse is 'little-d' discourse, that is, 'language-in-use.' This study draws on spoken interaction in the first instance and relates to Fairclough's (1992) notion of 'discursive practice', discussed below. ${ }^{2}$

1 'Interactional discourse' is used in this thesis rather than 'interaction' alone, as using 'discourse' at both levels helps to make apparent the constitutive and dialectical relationship between interactional discourse and sociocultural discourses (Fairclough, 1992; Ochs, 1992).

2 It is acknowledged that there are differences in meaning between the terms conversation, talk, interaction, dialogue and semiosis. 'Conversation' is generally restricted to verbal communication; Goffman (1974, p. 36) notes that it can refer to either casual everyday talk or can be extended to cover 'talk' more broadly. 
Granted, there are forms of interaction outside spoken and written language which are of interest to discourse analysis (Chouliaraki \& Fairclough, 1999, p. 38; Fairclough et al., 2002). The rationale for a focus on spoken interaction has been briefly discussed in the previous chapter, and further discussion of the rationale and a description of how this is supported by ethnographic data is provided in Chapter 5 .

The relationship between sociocultural discourse and interactional discourse is, as Fairclough (1992) notes, dialectical, in much the same way that the relationship between structure and agency is theorised in Bhaskar's TMSA. It is through discursive practice, or interaction, that subjects can reproduce and transform sociocultural discourses whilst simultaneously operating within their constraints (Fairclough, 1992). The close analysis of interactional discourse, then, can identify both the existence of sociocultural discourses (Foucault, 1969/2002a) and the nature of identity genesis as it plays out in interaction (Bucholtz \& Hall, 2005). Discourse analysis is therefore well positioned to contribute insight into how we are generated as political agents.

Fairclough (1992, p. 4) brings together both senses of discourse by treating any discursive event as 'simultaneously a piece of text, an instance of discursive practice, and an instance of social practice.' The term 'text' in Fairclough's sense refers to a spoken or written product, such as the recorded interactions that form the main data source for this study. Discursive practice refers to the processes that generate certain texts and include the way in which sociocultural discourses are drawn upon to do so. Fairclough's notion of social practice refers to broader institutional and organisational aspects, in which discursive practices are subsumed. Discourse analysis, then,

The latter sense is often replaced with 'talk-in-interaction' within the field of CA (Psathas, 1995). 'Interaction' generally extends beyond the verbal to include nonverbal communication (Psathas, 1995, p. 2). To complicate the picture further, 'dialogue' is defined by Linell (1998, p. 10) as 'interaction through symbolic means by mutually co-present individuals' and is used in this sense by $\mathrm{Du}$ Bois and Kärkkäinen (2012). The word is however also complicated by a long history of literary and philosophical usage (Linell, 1998). 'Semiosis' is preferred by Fairclough et al. (2002) and refers to the 'intersubjective production of meaning' which again is not restricted to language. For the purposes of this thesis, the more inclusive term 'interaction' is adopted. The data in this study are spoken interactions in casual settings and therefore the terms used throughout make implicit reference to this data set. 
focuses upon 'processes of text production, distribution and consumption... [which] are social and require reference to the particular economic, political and institutional settings within which discourse is generated' (Fairclough, 1992, p. 71). His reference to the importance of context, particularly the political, is highly relevant to the goals of this study. Likewise, his approach to discourse analysis, specifically his alignment with critical realism (Chouliaraki \& Fairclough, 1999; Fairclough, 2005; Fairclough et al., 2002), has many points of crossover with the multi-layered sociocultural-interactional discourse analysis carried out in this thesis. This study, exploratory in nature, does not however explicitly promote emancipatory change as do those studies aligned more closely with CDA, as discussed in the following section. The next section also examines the mixed success of critical realist attempts to engage with interactional discourse analysis and positions this study to contribute a multi-layered approach that addresses existing weaknesses.

\subsubsection{Discourse Analysis and Critical Realism}

Despite attempts to ground discourse analysis within critical realism, explicit critical realist approaches to discourse analysis do not seem to have the same level of popularity as constructionist approaches (at least as indicated by a quick and non-scientific Google Scholar search which returned 2,300,000 results for 'social construction' + 'discourse' and 273,00o for 'critical realism' + 'discourse'). ${ }^{3}$ With current interest in the material manifestations of discourses (e.g., Wodak, 2014), it is necessary to draw on discourse analytic theory that rests on a philosophical basis that is able to adequately deal with the extradiscursive. Demonstrating how critical realism may be relevant to discourse analysis in this sense is the aim of this section.

Fairclough (1992, p. 60) argues along realist lines that discursive practices are 'constrained by the fact that they inevitably take place within a constituted, material reality, with preconstituted "objects"

3 Critical realism, however, being a philosophy, may not be mentioned as foundational even if its tenets influence analysis. Social constructionism could also be overrepresented due to the popularity of the metaphor of construction (as discussed in Chapter 2). Nevertheless, it provides a noteworthy indication of the theoretical proclivities of many discourse analysts. 
and preconstituted social subjects.' Acknowledging extra-discursive reality entails looking outside constructionist methods of discourse analysis. Explicit approaches to this include that by Chouliaraki and Fairclough (1999), who draw heavily on critical realism in their theoretical grounding of CDA within critical social science. Fairclough et al. (2002) also note that the study of semiosis, or 'the intersubjective production of meaning' of which interactional discourse is included, can benefit from critical realism, and vice versa. They argue that there needs to be continued critical realist engagement with a 'critical semiotic analysis' that is 'concerned with the relationship between semiosis and the material and social world' (p. 13). This thesis addresses this gap by bridging the macro (Chapters 6 to 8 ) and the micro (Chapters 9 and 10).

Fairclough's approach to CDA, grounded within critical realism, is summarised as follows:

The objective of discourse analysis... is not simply analysis of discourse per se, but analysis of the relations between discourse and non-discoursal elements of the social, in order to reach a better understanding of these complex relations (including how changes in discourse can cause changes in other elements). (Fairclough, 2005, p. 924)

Change, as indicated at the end of the quotation, is the predominant focus of CDA scholars. The field is generally united by an interest in the semiotic aspects of power relations, ideology and a commitment to emancipatory change (Fairclough, 2010; Wodak, 2011; Wodak et al., 2009). This aligns with critical realism's roots in Marxism and Bhaskar's notion of explanatory critique (Collier, 1994). However, this study applies critical realist tenets to a discourse analytic approach that does not have the same focus. In the first instance, this study is positioned to expand constructionist approaches to discourse and identity, including consideration of material and social structures alongside detailed linguistic analysis. Questions of power and the transformation of hegemonic social structures that may constrain identity genesis are considered complementary and a worthwhile direction for future research. As an exercise in underlabouring for the field of identity and discourse analysis within linguistics, such goals 
are respectfully acknowledged but remain largely outside the scope of this thesis.

\subsubsection{Critical Realist Discourse Analysis}

There has been a less consistent focus on critical realism in relation to discourse analytic approaches which, as in the case of this thesis, may not share the same agenda as CDA. One example of an explicit critical realist discourse analysis is provided by discursive psychologists SimsSchouten, Riley and Willig (2007). They argue that the prioritisation of discourse in the relativist paradigm has resulted in three main issues: an inability to theorise why people use one construction over another, the marginalisation of extra-discursive experiences and theoretical neglect of material practices (p. 102). The authors propose a critical realist approach that addresses these issues, arguing, as I have in Chapter 2, that materiality has ontological status and is therefore not reducible to discourse. They note that critical realism combines constructionist and realist positions and argue that this standpoint means that

the ways in which people can understand themselves are structured both by the available discourses in their social milieu and the material conditions in which they find themselves and which offer a range of possible waysof-being. Discursive and material conditions thus form and constrain the social constructions that structure the way we understand ourselves. (Sims-Schouten et al., 2007, p. 107)

Within their argument, Sims-Schouten et al. (2007, p. 103) draw on Parker (1992, p. 38) who argues that 'discourses... never fully escape the material conditions in which they are reproduced and transformed' naming four possible candidates for such conditions: direct physical coercion, the material organisation of space, the physical orientation of the individual to discourses and the positioning of selves (Parker, 1992, pp. 38-40). The first three of these are clearly extra-discursive which, according to Sims-Schouten et al. (2007), a critical realist discourse analysis is well placed to address. 
Before presenting their method, Sims-Schouten et al. (2007, p. 104) discuss two possible critiques of critical realism. The first, broad in nature, is that the extra-discursive can be viewed as discursively constituted, as claimed by theorists such as Laclau and Mouffe (2001). This issue lies at the heart of the relativism/realism debate which I have addressed in Chapter 2. Less clear, however, is the answer to the second critique, that critical realism has no way of distinguishing the discursive from the extra-discursive. In answer to this, SimsSchouten et al. (2007, p. 106) recommend restricting focus to embodiment, institutions and materiality; with their example of women and childcare, they suggest focusing on the number of children a woman has, the nature of governmental policies on childcare and whether there are adequate childcare facilities available. These three aspects, while having discursive components, have easily identifiable material referents. Critical realism thus inspires a reconfiguration of analytical priorities to include influences that may be considered, to different extents, extra-discursive. However, a more definitive answer to the second critique, I suggest, is that the notion of emergence deals neatly with any request to define a clear boundary between the discursive and extra-discursive: discourse is considered emergent from yet irreducible to its social and material conditions. Any attempt to define a dichotomising line in the sand is considered a blind alley that obscures the ontological nature of the strata in question.

For their method, Sims-Schouten et al. (2007, p. 107) recommend a multi-level discourse analysis that includes an examination of discourse practice, Foucauldian discourse and the extra-discursive. Their recommendation aligns with the method adopted for this study: the extra-discursive is analysed alongside both the interactional and sociocultural levels of discourse (see Section 5.1). Sims-Schouten et al. (2007) propose a three-step analysis within this frame. Firstly, a literature review is carried out to identify the possible influences of embodiment, institutions and materiality on the item of focus, in their case, women's experiences of motherhood, childcare and employment (pp. 108-109). Secondly, the identified extra-discursive influences are assessed within the participant's context. Finally, the participant's talk is gathered and analysed in reference to these factors.

Sims-Schouten et al. (2007) provide a worthwhile sketch of a critical realist discourse analysis that relies on unified multi-level analysis 
that takes the extra-discursive into account. However, their imposition of categories on the data at the first stage, by way of literature review, is unhelpful in that it has the potential to influence what is seen to arise at later stages. Speer (2007) provides a further critique in noting that the discourse analytic techniques adopted by SimsSchouten et al. seem to come from perspectives which they criticise. This hinges on the observation that 'two essentially incompatible epistemologies [i.e., realism and constructionism] means that the analyses have a tendency to veer inconsistently between the two' (Speer, 2007, p. 129).

These critiques need not undermine the critical realist discourse analytic project in its entirety. In relation to the problematic analytical procedure of Sims-Schouten et al. (2007), an initial examination of talk should occur in the first instance which may then indicate any salient sociocultural or extra-discursive influences, as in the case of this thesis. This avoids the problem of imposing categories on the data in a top-down fashion. After this step the remaining analytical stages can be carried out, returning repeatedly to the analysis of interactional discourse. This study addresses these weaknesses through an iterative, cyclical analysis that begins and ends with the data (see Chapter 5). Furthermore, the critique that Speer (2007) makes seems to arise from a misunderstanding of critical realism as a philosophy that is compatible with epistemic relativism. Recruiting discourse analytic techniques from fields within the relativist paradigm is unproblematic to a critical realist, with the caveat that these must be ontologically grounded. Rather than being 'essentially incompatible', critical realism's ontological realism and epistemological relativism (Groff, 2004, p. 10) mean that (weak) constructionist interpretations are entirely compatible. Speer (2007, p. 130) does however raise an important issue regarding the influence of the interviewer on the direction of the interviews, an issue that is addressed in Chapter 5. In addition, Speer's critiques raise a wider concern with critical realist discourse analysis. As it is often viewed in opposition to relativism, it is important to communicate clearly both the nature of critical realism as a philosophy and its compatibility with (weak) constructionism. Critiques such as these highlight the difficulty with which a critical realist discourse analysis can make clear what is offered above and 
beyond constructionist analyses (A. Sealey, personal communication, 1 September 2014).

Any attempt to move from an abstract philosophy to a concrete method is fraught with difficulty. This thesis makes such an attempt in contributing to the articulation of a more systematic approach to critical realist discourse analysis particularly as it relates to discourse and identity. Chapter 6 moves beyond constructionist accounts by 'taking seriously' the existence of the extra-discursive and examining the material influences on identity. Even within the discursive realm, as explored in later chapters, critical realism remains relevant in its theorisation of the real nature of social structures. In a sense, rather than being a replacement for constructionist discourse analysis, I contend that critical realist discourse analysis offers a richer account and a deeper understanding of the nature of structures that provide the context for articulations of who we are.

The following sections of this chapter serve as an introduction to the supporting frameworks of interactional discourse analysis adopted for this study: IS, indexicality and stance. These provide theoretical support of and analytical access to identity genesis as it occurs in talk and are drawn on in detail in Chapters 9 and 10.

\subsection{INTERACTIONAL SOCIOLINGUISTICS}

Discourse analysis in this thesis is carried out from an IS perspective (Gumperz, 1982a). Interactional sociolinguistics arose from ethnography of communication (Hymes, 1964) in which language is investigated in context at the level of community and society, drawing heavily on ethnographic methods. This section introduces Is from a theoretical perspective as its assumptions underlie both method and interactional analysis in this study.

Generally, IS studies are concerned with how context is linked to interaction (Gumperz, 1999, 2001, 2009). As such it forms in a basic sense a framework for the study of indexicality in language use and provides a useful toolkit with which to undertake a context-sensitive investigation of communication. Interactional sociolinguistics has to a certain extent been taken for granted in the field of linguistic discourse analysis given its status as a foundational framework (and is reflected in the influential series Studies in Interactional Sociolin- 
guistics, Cambridge University Press, which includes important works that are drawn upon in this study, including Brown and Levinson, 1987; de Fina et al., 2006; Gumperz, 1982a, 1982b; Schiffrin, 1987). It is likely inconceivable to any analyst that context would be restricted in interpretation, with the notable exception of CA (see Billig, 1999). A grasp of the importance of ethnographic methods is similarly widespread (see Rampton, $2007 \mathrm{~b}$ ). The fundamental nature of IS means it is important to explicitly examine its tenets in order to provide a background to the methodological and analytical assumptions of this study.

According to IS, context is partly signalled in talk through what are termed 'contextualisation cues', defined by Gumperz (2001, p. 221) as

any verbal sign which, when processed in co-occurrence with symbolic grammatical and lexical signs, serves to construct the contextual ground for situated interpretation and thereby affects how constituent messages are understood.

Code-switching is provided as an example of a contextualisation cue as its many social functions, for instance the indication of role-taking and the shift of social distance (Myers-Scotton \& Ury, 1977), can signal contextual information which then influences the interpretation of utterances (Gumperz, 1982a, p. 98). Coupland (2007, p. 17) notes that the use of the discourse marker oh, coupled with falling intonation and a raised eyebrow, is a cue that can signal disagreement. Other cues include pronunciation, prosody, rhythm and tempo (Gumperz, 2001, p. 221) which include Goffman's (1981) 'footing', small prosodic shifts that indicate a change in alignment (see Section 4.4.1). Contextualisation cues are indexical and the key to their definition is the interpretation of their meaning by participants. This occurs in terms of 'frames' (Goffman, 1974), or ways of organising experience, which help individuals determine what is happening during a conversation (Gumperz, 2009, p. 598). In interaction, participants arrive at an understanding of the 'speech activity' currently occurring which in itself constitutes a kind of frame (Tannen, 1993); a participant may question the frame by asking themselves 'are we fighting or are we playing?' For example, a contextualisation cue such as lilting intonation may indicate that two people are engaged in a mock or play 
argument (also related to 'keying', which indicates communicative motivation; Coupland, 2007, p. 114). Their mutual understanding of this speech activity constitutes the frame through which the interaction is understood. If contextualisation cues indicate that a participant is taking the previously light-hearted debate seriously, such as through a quickened tempo, the mutual interpretation of the speech activity and hence frame can shift, for example to one of serious debate. Identity genesis is also affected, as framing is 'crucially involved in determining how particular identities are made relevant or salient in discourse' (Coupland, 2007, p. 112). Contextualisation cues are thus central to both how we interpret what is going on and how we engage in identity work in interaction. This is relevant to this study particularly in my avoidance of the 'interview' frame, discussed in Chapter 5 .

There is a culturally relative aspect to contextualisation cues and therefore research within IS tends to focus on communication in intercultural settings (e.g., Bremer \& Roberts, 1996; Gumperz \& Roberts, 1991; Kotthoff \& Spencer-Oatey, 2007; Roberts, 1998; Scollon, Scollon \& Jones, 2012), though it is also influential within discourse analysis more widely (e.g., Rampton, 2006; Schiffrin, 1987; Tannen, 2005, 2007). Much successful research within the IS paradigm has also been carried out in workplace settings and covers a range of topics, such as leadership, ethnicity and identity (Holmes et al., 2011; Holmes \& Stubbe, 2003; Sarangi \& Roberts, 1999). To demonstrate the importance of contextualisation and the high stakes that can be involved in intercultural settings, Gumperz (2001, pp. 220-221) provides the example of a South Asian electrician who undergoes a job interview in Britain and compares it to a similar interview with a local English bricklayer. The electrician supplies only short answers to the questions he is asked when more involved and collaborative responses are the norm in that particular context. The interview with the electrician results in eventual communication breakdown. By contrast, the bricklayer provides more complex utterances. For example, the interviewer asks, 'Did you look in at the brick shop?' and the bricklayer responds with, 'Ah yeah. We had a look around the brickshop.' The electrician, when asked a similar question about the workshop, responds only with 'yes.' The bricklayer collaborates with the interviewer and thus displays a level of familiarity with local 
interactional norms, whereas the electrician fails to do so. Gumperz (2001, p. 221) argues that while prejudice could have been a factor, it is clear that due to communicative and cultural factors both men interpreted the interactions differently by making different contextual inferences. The bricklayer, by virtue of his correct interpretation of cues, is more communicatively successful. Analysis from an IS perspective therefore makes apparent the connection between language and wider context. This is useful in the analysis of contextual influences on political identity in discourse as carried out for this study, and is explained in more detail in Chapter 9.

Interactional sociolinguistics provides the analytical perspective through which analysis in this thesis is carried out. Indeed, Is has implications for method, the most prominent of which is the adoption of ethnographic methods, as discussed further in Chapter 5. Ethnographic methods help to give the analyst an understanding of the nature of cultural and interactional norms in certain contexts and in doing so aid interpretation, as in the case of the job interview above. The next section introduces and examines indexicality, the process through which contextualisation cues in talk reference wider context.

\section{$4 \cdot 3$ INDEXICALITY}

The notion of 'index' comes from the work of American philosopher Charles Sanders Peirce (1895/1998) who introduced it as being one of three kinds of sign, alongside 'icons' and 'symbols.' Peirce (p. 14) argues that, 'An index stands for its object by virtue of a real connection with it, or because it forces the mind to attend to that object.' He provides the following example:

a low barometer with a moist air is an indication of rain; that is, we suppose that the forces of nature establish a probable connection between the low barometer with moist air and coming rain. (Peirce, 1895/1998, p. 14)

The weather theme is continued by Johnstone (2010, p. 31), who gives the example of the indexical nature of thunder; when we hear it, "we often experience lightning, rain and a darkening sky, so the sound of thunder may lead us to expect a storm'; thunder is thus said to index storminess. The term, when applied to language, refers to the ability 
of a linguistic form, whether a word or other construct, to invoke components of the social context (de Fina et al., 2006, p. 4). Indexicality is therefore a process through which language is connected to context.

Indexicality is a key element of identity genesis and forms one of the five principles of Bucholtz and Hall's (2005) identity framework. It is also a critical consideration due to its ability to make sociocultural reality available for analysis by linking it to interactional discourse (Silverstein, 2003, p. 227) and is thus the process through which contextualisation is achieved. As Bucholtz and Hall (2005, p. 594) state, identity work in interaction is indexical in a number of ways, for example, through explicit labelling, implicatures, footings or ideologically associated linguistic structures. When Ashley, a participant of this study, labels herself a 'greenie' (see Chapter 9), this forms an indexical link between her utterance and a wider sociopolitical identity (via stance).

Indexicality operates directly and indirectly (Ochs, 1993). Ochs (1992, pp. 341-343) gives the example of the third-person pronoun he being a direct index of gender. Indirect indexical links are a further step removed, in that certain linguistic forms can become associated with particular social identities which are thought to be associated with certain stances (Bucholtz, 2009). For example, in Japanese, intensifiers can directly index affective stances, e. g., coarse or gentle (Du Bois, 2007; Ochs, 1992, p. 341). However, as coarse or gentle affective stances become gendered through ideological processes (discussed further below), the use of these intensifiers can become indirectly linked to gender categories: in Japanese, the use of coarse intensifiers is stereotypically associated with men and gentle intensifiers with women (Ochs, 1992, p. 341). Ochs (1992) calls this a 'constitutive' relationship, as stances help to shape social categories and vice versa. This process is consistent with with Bhaskar's TMSA where individuals are considered to be socialised by societies yet also unconsciously reproduce and transform them (Collier, 1994, p. 145).

Silverstein (2003) argues that indexicality is ordered and layered rather than simply being direct and indirect. He describes this as the 'indexical order', divided into first-, second-, third- and higher-orders. Johnstone and Kiesling (2008) explain that a correlation between a certain linguistic variable and an identity is an example of first-order indexicality and parallels this with Labov's (1972b) notion of 'indic- 
ator'. For example, particular phonetic features can be considered indicators of New Zealand identity, such as the centralisation of the KIT vowel (e.g., in the word 'fish'; Bell, 1997). Second-order indexicals are a subset of the first-order which have gained social meaningfulness by being included within an ideologically-driven metapragmatics' (Silverstein, 2003, p. 219). At the second-order level, features such as the New Zealand English tag particle eh (Meyerhoff, 1994) can index style, social class, ethnicity or even gender, depending on the context of use. Certain linguistic variables of the secondorder can be attributed social meaning and show stylistic variation, though speakers may not be conscious of their usage, the connection made here to Labov's (1972b) 'marker' (Johnstone \& Kiesling, 2008, pp. 9-10). Higher-order indexicals, such as the third-order, are a subset of the second-order which have become meaningful through yet another ideological frame, similar to Labov's (1972b) 'stereotype'. This can include explicit metadiscourse about the token itself and also performances of certain identities (Bell, 2014; Johnstone \& Kiesling, 2008, p. 9). For example, an Australian comedian may demonstrate awareness of a token's social meaning when using a centralised KIT vowel to poke fun at New Zealanders during a stand-up routine (e. g., 'fush and chups'). In this context the comedian creates humour in her performance by using the form and drawing on its ideological connotations through the vowel's indexical link with the New Zealander identity at a higher, indirect level (see also Bell, 2014). Silverstein (2003) gives the example of wine talk as another form of third-order indexical. By adopting wine terms, such as those present in tasting notes, a speaker 'becomes' the person corresponding to that manner of speaking (Silverstein, 2003, p. 226). The prestige attached to a wine connoisseur identity in Western culture means that wine talk is a speech style sought out by elites or those who desire to perform such an elite identity (Silverstein, 2003, p. 226). Silverstein's (2003) notion of indexical order is useful in tracing the link between an utterance and higher-order ideological frames that provide new aspects of meaning. Indexical order is therefore important in analysing how what we say is linked to the wider sociocultural field, lends depth to the notions of direct and indirect indexicality (Ochs, 1992), and charts the process through which stances are taken and identities indirectly 
accessed. This makes it relevant to the model of identity presented in Chapter 3 and thus to the analysis carried out in this thesis.

Indexicality is a complex, ordered and ideologically informed process which provides the means for social identity formation. Ideological structures shape the associations that are made between linguistic forms and particular identities and are therefore a key influence on how indexicals are patterned (Bucholtz \& Hall, 2005, p. 594). Relevant here is Eckert's (2008) notion of 'indexical field' which acknowledges that in addition to existing within an ideological frame, certain meanings have ideological relationships with others. For example, when a linguistic variable is used in talk, rather than having a fixed meaning it has the ability to call down a 'constellation of ideologically related meanings, any one of which can be activated in the situated use of the variable' (Eckert, 2008, p. 454). The indexical field is subject to change as ideological links in meaning shift; the aforementioned example of $e h$ in New Zealand English (Meyerhoff, 1994) exemplifies this process. Initially associated with Māori, eh spread over time to middle class usage and appeared in more formal settings, demonstrating an ideological shift influencing its appropriacy in certain contexts. Indexicality, in addition to making sociocultural discourses visible in interaction, also opens up the possibility of exploring the ideological connections that exist between certain meanings.

From a critical realist viewpoint it is important to note that indexical signs can refer to the extra-discursive, as they have the ability to 'point towards associations that do not have to be in the same existential realm' (Joseph, 2010, pp. 16-17). Indexical ties can therefore link to social structures or material referents, a process central to the analysis in later chapters. Furthermore, focusing on direct firstorder indexicality alone tends to reduce the analytical importance of the interactive context in the interpretation of utterances and associated stances. It also backgrounds the ability of tokens to index multiple identities simultaneously which is a central component of constructionist approaches to identity (Bucholtz \& Hall, 2005; de Fina et al., 2006). Indexical tokens of the second-order and above that are relevant to identity are considered linked in the first instance to stance (discussed in the following section) which can then go on to index various elements of identity. In other words, stance provides a 
mediating layer between utterances and identities; while first-order indexicals correlate with certain sociodemographic categories to the degree that is visible to an outsider (Johnstone \& Kiesling, 2008, p. 8), this is not considered in itself fully constitutive of an identity (see Benwell \& Stokoe, 2006, pp. 26-27). It is the interpretation of discourse identity (Gee, 200o) through the medium of stance which is considered relevant to identity genesis. Hence it is the second-order and above which is of particular analytical interest in this thesis.

\subsection{STANCE}

John W. Du Bois, author of the model of stance drawn upon in this study, regards stance as 'the smallest unit of social action' (2007, p. 173). It is a core component of interaction whether overtly present or not, considering that 'every utterance in interaction contributes to the enactment of stance, even if this stance is only evoked and not explicitly spelled out' (Du Bois \& Kärkkäinen, 2012, p. 438). Most importantly for this study, stance is considered the mediating layer between interaction and identity.

Du Bois (2007, p. 163) defines stance as the following:

Stance is a public act by a social actor, achieved dialogically through overt communicative means, of simultaneously evaluating objects, positioning subjects (self and others), and aligning with other subjects, with respect to any salient dimension of the sociocultural field.

The stances that we adopt in interaction therefore achieve three things: $a$ ) evaluation of an object of stance; $b$ ) positioning of ourselves as a particular kind of person who would make such an evaluation; and c) alignment (on scale of convergence or divergence) with our conversational partner or partners (Du Bois, 2007; Du Bois \& Kärkkäinen, 2012, pp. 439-441). An example is again provided by participant Ashley (Chapter 9). Evaluation is present in her statement that the Greens 'have a really admirable internal democratic process', which simultaneously positions her as a possible Green Party supporter. It also aligns Ashley with her conversational partner; if he were a Green supporter then it would be considered convergence in solidarity; if he were a National Party supporter, then it would likely be considered 
stance divergence or an act of distancing. Indeed, context is important in deciphering any stance act, as Du Bois (2007, p. 142) notes that it 'cannot be fully interpreted without reference to its larger dialogic and sequential context.'

$\mathrm{Du}$ Bois (2007, p. 145) notes that evaluation, positioning and alignment are not three separate types of stance. Instead, they are 'different facets of a single unified stance act.' He warns that we have to be careful in describing the contents of a stance and claiming that it is the full stance itself, as is evident in analytical claims such as 'He's taking a conservative stance.' Du Bois (2007, p. 171) explains that

Stance is best understood in terms of the general structure of the evaluative, positioning, and aligning processes that organize the enactment of stance, rather than as a catalog of the contents of stance, or even... of the sociocultural value categories that are referenced by stance.

Using the term stance in its lay sense (i.e., attitude or standpoint) is thus monodimensional. When broken down into its constituent processes, the statement 'He's taking a conservative stance' may bundle together the following: 'He's evaluating the National Party in a positive way'; 'He's positioning himself as a conservative'; and 'He's diverging from my progressive stance.' If this is repeated throughout the course of a discussion, or if the stance is taken up in a salient context (see next section), the conversational participant may infer that he is indeed a conservative. Hence, 'He's taking a conservative stance' can be considered a convenient shorthand for arriving at this conclusion, though it obscures the precise structure of the stance act.

Du Bois (2007) offers a particularly useful model of stance that unifies its three processes. This is represented in his model of the stance triangle, presented in Figure 2. Du Bois (2007) places particular emphasis on dialogicality; in other words, stance is an intersubjective achievement. He states that 'taking a stance cannot be reduced to a matter of private opinion or attitude. ... There are no private stances' (Du Bois, 2007, p. 171). Hence the presence of a minimum of two subjects on two corners of the stance triangle.

The three core functions represented in the stance triangle are as follows: 


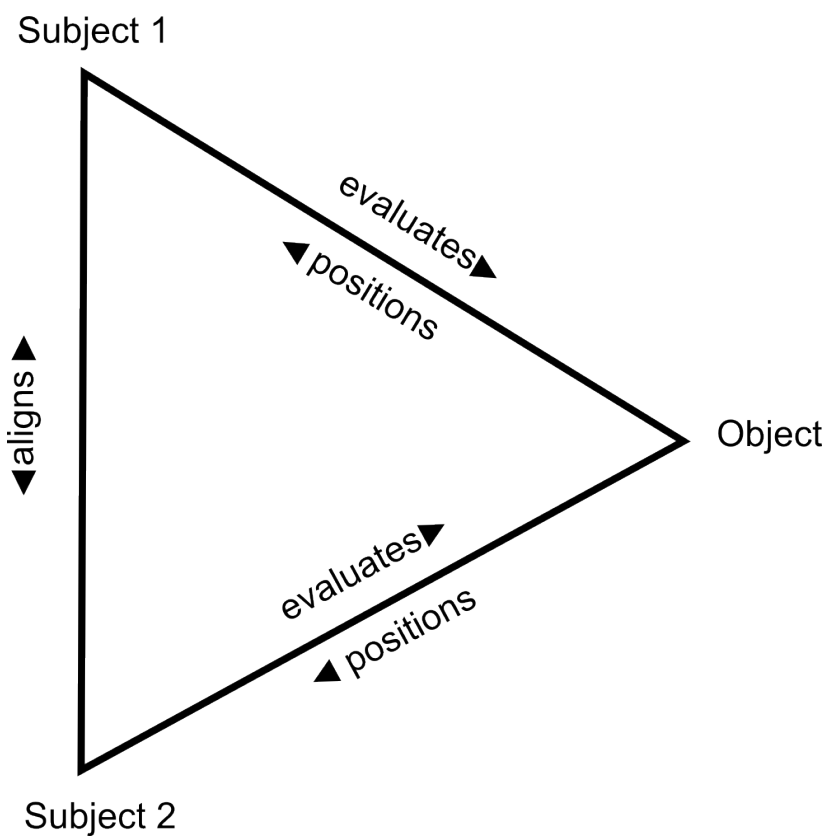

Figure 2: The stance triangle (Du Bois, 2007, p. 163).

- Evaluation. This refers to 'the process whereby a stancetaker orients to an object of stance and characterizes it as having some specific quality or value' (Du Bois, 2007, p. 143). ${ }^{4}$ In saying 'It's a real shame that so many young people didn't vote at the last election', the clause 'many young people [that] didn't vote at the last election' is the object of stance and the subject of evaluation. The stance object need not be an object in the material sense; it can be 'a thing, a person, a situation, an utterance, even another participant's stance' (Du Bois \& Kärkkäinen, 2012, p. 439).

- Positioning. Defined as 'the act of situating a social actor with respect to responsibility for stance and for invoking sociocul-

4 There is a rich literature on evaluative language in linguistics (see, for example, Hunston, 2011; Hunston \& Thompson, 2000; Martin \& White, 2005; Thompson \& Alba-Juez, 2014). For the purposes of this thesis I adopt Du Bois and Kärkkäinen's (2012) focus on quality or value which is supported by Hunston's (2011, p. 1) definition of evaluative language as '[expressing] an attitude towards a person, situation or other entity and is both subjective and located within a societal valuesystem.' 
tural value' (p. 143). ${ }^{5}$ In other words, when evaluating an object, 'the subject in effect shows herself to be the kind of person who would make that kind of evaluation about that kind of thing' (Du Bois \& Kärkkäinen, 2012, p. 440). To continue with the above example, evaluating the clause 'many young people [that] didn't vote at the last election' could potentially position the speaker as someone who is concerned with youth voting and likely with politics at large. However, the precise nature of the stance in question is ambiguous without a grasp of the wider context; it is particularly important in the first instance to know who the stancetaker is and the stance to which the speaker is responding (Du Bois, 2007, p. 146).

- Alignment. This is 'the act of calibrating the relationship between two stances, and by implication between two stancetakers' (p. 144). The stances one takes up are inevitably bound up with the stances of others, but alignment is more than just polar agreement and disagreement; it is rather

a subtly nuanced domain of social action, in which speakers negotiate along a continuous scale the precise nature of the relation between their presently realized stance and a prior stance, whether overtly expressed or left implicit by another. (Du Bois \& Kärkkäinen, 2012, p. 440)

Again, it is important to examine the interaction at large to get a sense of the degree of stance alignment between subjects ( $\mathrm{Du}$ Bois, 2007, p. 142).

Stance is considered the formative 'stuff' of identity as it has the ability to indirectly index discourse identities, group memberships, institutional affiliations or extra-discursive influences (Gee, 2000).

5 There are parallels here with positioning theory, which involves 'the assignment of fluid "parts" or "roles" to speakers in the discursive construction of personal stories that make a person's actions intelligible and relatively determinate as social acts' (van Langenhove \& Harré, 1999, p. 17). The term 'positioning' is used in a more restricted sense in the context of Du Bois's stance triangle model. In particular, it reinterprets positioning theory's focus on role and narrative (Harré, Moghaddam, Cairnie, Rothbart \& Sabat, 2009, p. 12) as that of responsibility for certain stances (Du Bois, 2007, p. 173). 
Stance and identity are mutually constitutive, meaning that various elements of our identities have the power to shape how stances are taken up and these stances have the ability to shape aspects of our identities. It is through interactional discourse that our stances and eventually identities are recognised (Gee, 2000). Analysis using the stance triangle combined with the Gee's NIDA identity model presented in Chapter 3 allows for fine-grained analysis of the ingredients of identity as they appear in discourse.

The next section connects stance with contextualisation in the IS sense and discusses how it is particularly relevant to the analysis of identity.

\subsubsection{Stance, Context and Identity}

The relationship between stance and contextualisation in interactional discourse is explored by Jaffe (2009a). As argued in the previous section, indexicality is the process through which the interactional and sociocultural is linked. Contextualisation cues, drawing on their indexical value, provide the contextual information for participants to interpret what is going on in interaction. In terms of stance, contextualisation cues are considered 'basic, culturally specific tools or resources for stancetaking' (Jaffe, 2009a, p. 10). Stancetaking is also a form of contextualisation in itself because it indicates how the speaker's position with respect to a particular utterance or bit of text is to be interpreted' (Jaffe, 2009a, p. 10). In other words, both stances and stance constituents provide information through which interaction can be interpreted.

Goffman's (1981) aforementioned notion of footing provides further detail as to the structure of stance. Footings are small shifts that occur in interaction at the prosodic level, such as pitch, volume, rhythm, stress and tonal quality (Goffman, 1981, p. 128). These are included within Gumperz's definition of contextualisation cue, meaning that shifts in footing are the most specific means through which a stance can be achieved. Goffman (1981, p. 128) argues that

A change in footing implies a change in the alignment we take up to ourselves and the others present as expressed 
in the way we manage the production or reception of an utterance.

Immediately apparent here is the relationship between footing and the stance triangle presented in the previous section, through Goffman's reference to the process of alignment. The connection is further elaborated by Jaffe (2009a, p. 10), who notes that stance can be understood as 'the inventory of footings taken in the course of communication: it is the "how" of the process of alignment.'

Stancetaking is indexically linked to identity. An indexical link from a particular utterance to a certain identity is not always direct; rather, it can be mediated through various stances (Bucholtz \& Hall, 2005, p. 595). More specifically, as Ochs (1993, p. 289) argues, it is participants' understandings of the function of certain stances that mediate language and identity as well as how individuals associate certain stances with certain identities. These understandings are inevitably bound up in the ideological context. For example, if someone evaluates deforestation negatively with the utterance 'It's disgusting how the Government allows the forests to be cut down', this constitutes a stance act which, depending on context, may be considered by their conversational partner to be indexically linked to the social identity of environmentalist. Thus, through discourse, the utterance indirectly indexes the environmentalist identity via the mediating layer of a certain stance. The environmentalist identity has both discursive and wider social aspects as it is recognised in interaction and includes the speaker within a larger and possibly global group of environmentalists (Gee, 200o).

Identity is inferred through others' stance acts and these can be achieved through a vast range of linguistic structures (Ochs, 1993). Ochs (1993, p. 289) notes, however, that a singular stance can be used as a resource for a wide range of identities, with some stances being more straightforwardly linked to certain identities than others. The inferences we make about others' stances can sometimes be mistaken and it follows that analysis of stance acts can be more or less accurate. We can however achieve more accurate analyses by making 'reference to [stance's] larger dialogic and sequential context', a critical component in deciphering any given stance act (Du Bois, 2007, p. 142). How participants perceive stance as being linked to identity and the inferences that follow are central to identity 
formation through stancetaking. Therefore, 'the objective question of how many times a stance was actually taken by a certain speaker is subsidiary to interactants' perception that the stance is attached to the stancetaker's identity' (Damari, 2010, p. 625). Clues as to the way stances are perceived, as well as interpreted, challenged, negotiated, taken up, reinforced or retracted are scattered throughout interactional discourse in many forms. This is examined in talk about politics in the two case studies presented in Chapters 9 and 10.

Individual stances taken up in interaction can become associated with more durable identities through the process of stance 'accretion' (Damari, 2010, p. 625; Eckert, 2008, p. 469; Rauniomaa, as cited in Bucholtz \& Hall, 2005). This refers to habitual stancetaking that has the potential to accumulate into a socially recognised identity and which may have implications for other aspects of identity. Eckert (2008, p. 469) provides an example of stance accretion:

While anger or cynicism may be momentary and situated stances, people who are viewed as habitually taking such stances may become 'angry' or 'cynical' people... By 'becoming an angry or cynical person,' I mean that one may come to be socially positioned as angry or cynicalthat anger and cynicism become part of one's identity (in the sense of Bucholtz and Hall, 2005) or one's habitual persona.

Eckert's reference to social positioning is, in other words, the recognition process of discourse identity (Gee, 2000). Her reference to 'habitual' stancetaking implies that frequency is central to this process, seemingly at odds with Damari's (2010) observation that the perceived connection to identity is more significant. It is important to note that based on the claims of social dialectologists such as Wolfram (1970), one salient occurrence of a token in a significant context can be interpreted as definitive, meaning that frequency is not always the most relevant factor ( $\mathrm{J}$. Holmes, personal communication, $31 \mathrm{July}$ 2014). Stances can thus be associated with identities through either accretion or salient connection. What is clear in either case is that context is a critical factor in how stance acts are deciphered. The analyses in Chapters 9 and 10 are carried out with this important fact in mind. 
Stancetaking is not ideologically neutral, in much the same way as its central process, indexicality. Jaffe (2009a) notes in reference to gender, curiously without citing Lakoff (1975), that

using 'mitigating' language to make requests or demands is not a direct index of femininity, but rather represents a kind of stance that is taken up (or imposed on) a variety of less powerful people in society, including, but not limited to, women. (Jaffe, 2009a, p. 13)

The connotations of 'imposition' and reference to the 'less powerful' highlights the ideological nature of stance, also recognised by Bucholtz and Hall (2005, p. 596), who note that forging indexical links 'is inherently ideological, creating in bottom-up fashion a set of interactional norms for particular social groups.' They also note, as does Jaffe (2009a), that stances can be imposed top-down by those in positions of power (Bucholtz \& Hall, 2005, p. 596). Thus, to extend the above example, mitigating language can become directly associated with femininity through an ideological process that hides the indirect nature of the link. In other words, 'political and ideological processes may "naturalize" some of these indexical relationships such that they are treated as having a direct, even iconic connection to social identities' (Jaffe, 2009a, p. 13; see also Ochs, 1992). In fact, anyone, regardless of gender, can utilise mitigating language, but ideological processes nevertheless influence how such language is interpreted in terms of stance and identity.

Stance provides an effective means to bridge sociocultural and interactional discourse in the context of identity research, as it is through indexical processes that wider sociocultural values can be brought into specific stance acts (Du Bois, 2007). The final clause of Du Bois's definition of stance, 'with respect to any salient dimension of the sociocultural field' (p. 163), places micro articulations of stance within a background of broader discourses. This becomes particularly useful in the analytical chapters of this study, as sociocultural discourses such as egalitarianism are indexed by participants in numerous ways through their stancetaking and identity work (see Chapter 7). There is a multitude of ways in which context and interpretive schema can be signalled in talk which has a significant influence on the negotiation of meaning between participants. Ana- 


\begin{tabular}{lcccc}
\hline FOOTING & $\rightarrow$ & STANCE & $\rightarrow$ & IDENTITY \\
& a component of & & indexes an & \\
\hline
\end{tabular}

All contribute to the participants' understanding of FRAME

Table 3: The contextualisation of identity genesis in interactional discourse.

lysis in this thesis, as in IS research in general, attempts to understand how utterances are interpreted through the investigation of various contextualisation cues; stance is the most relevant to this study. Table 3 presents a synthesis of the model thus far.

As footings and stances change in conversation, so do frames of understanding, or our 'interpretive frameworks' which affect how utterances are understood (Goffman, 1974; Goffman, 1981, p. 230). Shifts in frame, for example from mock debate to heated argument, result in the introduction of another set of available footings (Ribeiro, 2006, p. 52) which has an effect on the stances that are subsequently taken up. Table 3 outlines the components of the process of interpretation within any given contextual frame. Since the interpretation of stance affects how identities are eventually generated and recognised, the process through which context is signalled in talk becomes central to the analysis of identity in discourse.

The analysis of interactional discourse with a focus on stance is carried out throughout this thesis, utilised throughout all analytical chapters. Stance analysis is the specific focus of Chapters 9 and 10, where detailed case studies are presented in order to highlight different aspects of stancetaking in interaction. Given that stancetaking at the interactional level is held to be the driving force of identity genesis, the stances we adopt in interaction can be considered to contribute to the reproduction and transformation of sociocultural discourses. The question remains about how this relates to the notion of political identity, which is the subject of the next section.

\subsubsection{Political Identity and Stancetaking}

The next challenge is to define what is meant by 'political' identity, a term that I have used in this thesis unproblematically up to this point. 
The first issue is one of definition. Bhaskar (1986/2009, pp. 118-119) defines politics in the following way:

Politics may itself be conceived most abstractly as any practice oriented to the transformation of the conditions of human action; more concretely, as practices oriented to or conducted in the context of struggles and conflicts over the development, nature and distribution of the facilities (and circumstances) of human action; more starkly, as practices oriented to the transformation of the structured sets of social relations within which particular social structures operate and particular social activities occur.

Bhaskar's definition purposefully covers a lot of ground. Gee (2014, p. 8) provides a more restricted definition of politics within this frame, arguing that it is 'about how to distribute social goods in a society: who gets what in terms of money, status, power, and acceptance on a variety of different terms.' Based on these definitions, aspects of constraint, authority or power seem important in determining whether something is considered to be related to politics. Gee (2014, p. 8) notes however that all language use is political in a 'deep' sense as any interaction we engage in occurs within a political and ideological sphere. In order to narrow these definitions towards the aims of this thesis, it is useful to take as a point of reference the understanding of politics that is most relevant to the participants of this study. Most understand politics as referring to state governance and its related issues, indicated by their voiced assumptions about the purpose of the project at the beginning of the interviews and their comments thereafter. This understanding of politics is indeed subsumed in Bhaskar's and Gee's definitions and forms a touchstone for the definition of politics and hence political identity throughout this thesis. Nevertheless, this is not the only form of politics identified by the participants; while most refer to state governance and its related issues almost exclusively, which is perhaps a product of the method of data collection (as discussed in Chapter 5), a small number identify a more abstract type of politics that relates to power and authority and the effect they have on everyday decisions and actions, for example, when shopping for clothes or crossing the street. This is reflected in the observation of de Cillia et al. (1999, p. 152), who 
note that 'a wide notion of the "political"... not only focuses on the discourses of the elites in power, but also on (discursive) actions.'

For discourse analysis, political identity as an interactional achievement can be conceptualised as comprising stancetaking that is made in relation to political stance objects. These can be defined as those which the participants (and their partners in conversation) recognise as political within the context of a discussion about politics. This is bounded by the broad criteria set down by Bhaskar and Gee. The political stances that are taken up in interaction can index wider and more durable political identities (or subject positions, see Chapter 2), such as 'conservative' or 'liberal', which entail their own sociocultural discourses. Being a political conservative, for example, can be considered an identity which is enacted by adopting stances that index its sociocultural discourse. A person could then be socially recognised as conservative through the accretion or salient usage of such stances. It is a political identity in that it relates to practices as defined by Bhaskar and Gee, it is identified by the participant as political and it is socially recognised as such. In sum, an interaction, utterance or linguistic feature is considered relevant to a political aspect of your identity if it is socially recognised as making you a certain kind of political person.

\subsection{SUMMARY}

Interactional discourse is the means through which this study accesses both macro and micro influences on political identity. It is the specific object of focus through the lens of stancetaking in Chapters 9 and 10. It is also drawn upon to highlight broader discursive and extradiscursive influences in Chapters 6 to 8 . Interactional discourse is the site of the genesis of wider sociocultural discourses and identities and thus its analysis provides a window into these processes in action. Critical realism has had uneven representation in discourse analysis outside of realist-inspired approaches to CDA. This study attempts to contribute a philosophically grounded form of discourse analysis that can be applied productively to the study of identities in discourse. A multi-levelled discourse analysis stretching from sociocultural and interactional into the extra-discursive provides the opportunity to investigate the many potential influences on 
identity genesis. The analytical framework of this thesis, comprising IS, indexicality and stance, supports the investigation of identity in interactional discourse by theorising how wider context is drawn into interaction. Analysis of stance is, then, a productive means by which political identity can be examined as it is generated in interaction. 
With the acknowledgement that political identities are generated in an open social system comes the need for a research method that is designed to deal with a complex and messy reality. This study attempts to gain a deeper understanding of political identity genesis as it operates within the constraints of various social and material structures. This is achieved through a combined study of both the sociocultural and interactional levels of discourse and an investigation of the reciprocal relationship between them. The rich data set, which includes multiple data sources, allows ongoing contextualisation of data and provides an effective basis for the exploration of the research questions. This chapter first presents a discussion of the critical realist implications for method and the assumptions that lie behind the study design. Then, an outline of the research procedures is provided, leading into a discussion of the data sources including the ethnographic and interview data. The chapter ends with an outline of the analytical techniques adopted and a description of the follow-up report provided to the participants of this project.

\subsection{IMPLICATIONS OF CRITICAL REALISM FOR METHOD}

A central methodological implication of critical realism is the disestablishment of the 'limiting and misleading' qualitative/quantitative dichotomy (Danermark et al., 2002, p. 163). Danermark et al. (2002, p. 162) argue that the 'metatheoretical' foundations of these two approaches have a restraining influence, particularly due to the logical positivism often associated with quantitative approaches. Within critical realism, this dichotomy is reconceptualised as comprising complementary approaches under the wider guidance of one coherent philosophical approach (p. 163). The favoured terminology within this schema is that of 'intensive' and 'extensive' research design (Sayer, 2010, p. 243). This represents more than a simple switch in terminology as it unifies largely disparate methodological traditions, 
places them within a critical realist ontology and demonstrates the complementary role of each. It takes a 'mixed-methods' approach and makes the ontological-methodological link explicit by acknowledging that research questions always have an 'implicit or explicit conception of the nature of reality' (Danermark et al., 2002, p. 153).

Sayer (2010, p. 242) explains that the aim of intensive designs, such as the one developed for this study, is to investigate causal processes in a limited number of cases as compared to extensive designs which aim to discover common properties and patterns amongst a population. Intensive research can also be exploratory. This means that participants 'need not be typical and they may be selected one by one as the research proceeds and as an understanding of the membership of a causal ${ }^{1}$ group is built up' (Sayer, 2010, p. 244). This implies a fluidity of research design that is modified and developed as the study progresses and is reflected in the refinement of method that occurred throughout.

Sayer (2010), in his seminal text that grounds social scientific method within critical realism, argues in response to common criticisms of intensive designs, that 'we must avoid the absurd dogma that no study of individuals, in the broad sense, is of interest except as a representative of some larger entity' (p. 249). For the purposes of causal explanation, the core of the critical realist enterprise, extensive designs are considered weaker in that they focus on aggregate patterns and aim for generalisation which means that causality is difficult to investigate (Sayer, 2010, p. 245). Intensive and extensive designs however can be combined in what Danermark et al. (2002, pp. 150176) call 'critical methodological pluralism', though this study adopts primarily an intensive design as it focuses on a smaller number of cases in greater detail.

The preference for intensive research design is due to the critical realist model of explanatory (rather than predictive) research in social science. In sum, the empiricist model is replaced with one that

1 Sayer (2010, p. 244) discusses the difference between taxonomic groups, where individuals are related through the sharing of common attributes, and causal groups, where members relate to one another structurally; in the case of this study, the group is considered causal due to the connection of aspects of participants' identities to political discourses and ideologies rather than through any specific taxonomic similarities such as age, gender, or so on. 
relies on the reasoning processes of abduction, where individual phenomena are recontextualized with the help of general concepts and categories' and retroduction, where 'accidental circumstances are abstracted in order to arrive at the general and universal' (Danermark et al., 2002, p. 113). A retroductive analysis involves creating 'a theoretical model of what might exist and what, if true, could explain the existence of that which is observed' (Frauley \& Pearce, 2007, p. 19). This contrasts with induction and deduction which 'are concerned with confirmation and verification, or, more generally, justification' (Frauley \& Pearce, 2007, p. 19). The model of critical realist explanatory research that Danermark et al. (2002, pp. 109-111) present is implicitly followed throughout this thesis (see also Bhaskar, 1979; Collier, 1994).

Sayer (2000, p. 20) notes that researchers, when examining discourses, have to rely on interpretation in place of abstraction, and in order to interpret the social practices of individuals, we 'have to relate their discourse to its referents and contexts.' Guided by the critical realist model of stratified reality, Sayer (2000, p. 20) cautions that 'social reality is only partly text-like.' This means that a deeper understanding of discourse outside interaction is needed and a research design required that takes into account that which resides beyond talk. This study seeks to provide this through the combination of methods outlined in this chapter.

\subsubsection{Approach to Study Design}

As mentioned above, an intensive and exploratory study is open to a fluidity of method that may change as the study progresses. The design of this study went through many iterations as the techniques employed were continually refined. Data collection and analysis occurred concurrently, the results of which further guided the subsequent participant recruitment and research direction, in addition to the guidance afforded by the ethnographic data set (introduced in Section 5.5.1.1). In many ways, these methods appear to resemble Grounded Theory (GT) in practice (Charmaz, 2006; Glaser and Strauss, 1967/1999; Strauss and Corbin, 1994), a sophisticated and widely used qualitative research method (Oliver, 2012, p. 376). This includes the collection of rich data through ethnography and interviewing; 
a multi-phased transcription and coding procedure; and a form of memo writing (Charmaz, 2006). I have also referred to notions such as 'theoretical saturation' (Bowen, 2008; Charmaz, 2006, pp. 113-114; Guest, Bunce \& Johnson, 2006) and have used a form of theoretical sampling that became more prominent at later stages (Charmaz, 2006, pp. 99-108; Coyne, 1997).

Critical realist method and GT however arise from very different philosophical foundations. Some critical realist scholars criticise GT for its reliance on positivist inductive reasoning (Danermark et al., 2002; Frauley \& Pearce, 2007, p. 19), though others argue that modern reformulations of GT make it an ideal critical realist method (Oliver, 2012). This study acknowledges the many points of compatibility between critical realism and GT, yet recognises that more needs to be done to replace the underlying inductive approach of GT with critical realist abduction and retroduction (see Collier, 1994; Danermark et al., 2002; Oliver, 2012; cf. Charmaz, 2006, pp. 103-104). ${ }^{2}$ Critical realism provokes a broader approach that focuses on structures outside particular discourse data sets which necessitates retroductive explanatory logic (Sayer, 2010). This study, in addition to work carried out by others such as Oliver (2012), serves as a starting point for an exploration of critical realist method in action.

\subsection{HUMAN ETHICS AND INFORMED CONSENT}

All research at Victoria University of Wellington that involves human participants must gain Human Ethics Committee (HEC) approval and be in line with the Human Ethics Policy of the University, which ensures that research follows ethical practice including respect and care for persons, social and cultural contexts and the natural environment (Victoria University of Wellington, 2007). A key criterion is that informed consent must be gained. In the case of this study this was satisfied by the use of an information sheet and consent form that was signed by all participants, including those involved in the pilot

2 As Frauley and Pearce (2007, p. 19) point out, 'the critical realist question, "What must the object be like in order for it to be known in the way proposed?"' is discovery-oriented and hence retroductive in nature, as opposed to the narrower inductive focus of GT which 'aims to generate a specific substantive theory to explain the particular cases utilized as data.' 
and those that observed discussions in small group situations. The information sheet, consent form and demographic information survey are included in Appendix C. Ethics approval was gained on 16 October 2012 and the memorandum is attached in Appendix D, alongside subsequent memoranda relating to minor adjustments made to the information sheet and recruitment posters after initial approval.

\section{$5 \cdot 3 \quad$ PILOT STUdY}

The research design was piloted with five volunteers who were all close friends or family. I was the interviewer in all instances. The pilot consisted of:

- A sixty minute individual pre-interview with three participants, audio recorded, and carried out in an office, a library and in a participant's home.

- A 1.5 hour focus group with five participants, video and audio recorded and observed by a colleague, which took place in a private conference room at the public library.

- A thirty minute individual post-interview with four participants, audio recorded, and carried out in an office, a café and over the phone.

A colleague sat in and observed the focus group held at the local library on 1 November 2012 and provided detailed feedback after its conclusion. The primary outcomes of the pilot studies were the abandonment of clipboards, and eventually questionnaires, as they seemed to make participants feel uncomfortable due to their perceived 'formality.' It also led to a significant revision of the question schedule that formed the framework for the subsequent study, and gave an indication as to the logistical demands of organising a focus group. The study design was later changed significantly, due in large part to the insights gained during the pilot study, and proving the worth of the pilot as an indispensable stage in research design (van Teijlingen \& Hundley, 2002). 


\subsection{PARTICIPANT RECRUITMENT}

I sought to recruit participants, details of whom are included in Appendix B, through the use of posters that I placed on noticeboards throughout the city, including at the university, public library and town hall. ${ }^{3}$ I also handed out copies to acquaintances and asked them to distribute them throughout their networks. The first version of the poster, attached in Appendix E, used the phrase 'Politics in New Zealand' as the headline. This poster was distributed for the first month. Upon first making contact, participants that had seen this poster remarked that they lacked overt knowledge of 'politics' and were therefore somewhat hesitant to take part. When I reassured and eventually interviewed them, all of these participants seemed comfortable discussing highly political topics. This was a pattern repeated throughout the study and relates to the dual understanding of politics as either state governance or abstract power and authority in everyday life, as discussed in Chapter 4. In response to these factors, I amended the poster, also attached in Appendix E, to refer to 'social and political issues in NZ' rather than purely 'politics.' The response I received indicated that the revised version was less intimidating as participants did not comment as often on their ability to 'talk about politics.'

The two iterations of the poster drop throughout the city attracted half a dozen participants. The remainder were recruited through the referral chain method, otherwise know as the 'snowball' or network sampling technique (Biernacki \& Waldorf, 1981; Buchstaller \& Khattab, 2013, pp. 80-81; Milroy \& Gordon, 2003, p. 32). These chains were initiated from those who responded to the posters and also contacts through friends, family and colleagues. Snowball sampling is often used in sociolinguistic studies, particularly those interested in social networks (Milroy, 1987a; Milroy \& Gordon, 2003). Part of its success in these contexts, and reason for its suitability in this study, is the enhanced initial trust the researcher receives when viewed as a 'friend of a friend' (Milroy, 1987a).

3 Participants were not rewarded monetarily, but I did offer koha [a gift] of coffee or tea for those I interviewed in café settings. In the pilot study, participants were given light refreshments as a token of my appreciation. 
The posters provided the initial links in the chain and following them often led to three, four, or, in one case, five new participants. Wellington is classed as a city but retains the characteristics of a small town (discussed further Chapter 6) and a common refrain of the people that live in the city is that 'everyone knows everyone' (explored further in Chapter 8). As a result I was able to gain a spectrum of participants from different backgrounds with relatively little effort as the chains were self-perpetuating once they had been established. I had a pre-existing connection with a few of the participants, particularly those that were referred to me through friends and family, though their views on politics were largely unknown to me. Due again to the small city, I often had an acquaintance in common with those volunteers whom I did not know. This worked in my favour as it meant that trust was gained quickly (Milroy, 1987a), in addition to the initial solidarity that occurred simply because we were from the same city. During the initial small talk stage, I noticed that when I discussed with participants the secondary school they attended, especially with the younger participants (those under 30), it acted as a quick way of placing each other in national context. As outlined by Coupland (2000), small talk such as this can have many interpersonal functions that enhance solidarity, trust and rapport (see also Holmes, 1999, 2000a, 2003).

Issues of verifying eligibility in snowball sampling, as discussed by Biernacki and Waldorf (1981, pp. 150-152), were largely sidestepped given the broad criteria of eligibility for this study (driven by causal rather than taxonomic criteria, see Sayer, 2010, p. 244): the ability to vote in New Zealand and being located in Wellington during the study period. The criteria for voting in New Zealand are:

- 18 years or older;

- a New Zealand citizen or permanent resident; and

- have lived in New Zealand for one year or more without leaving the country (Electoral Commission, 2014).

These criteria were followed primarily for logistical reasons, limiting the possible scope of the study to Wellington. The rationale behind limiting it to those who can vote in New Zealand meant a higher chance of recruiting participants who were politically engaged and 
willing to talk about political issues in detail. In New Zealand it is a legal requirement to enrol but casting a vote in either a general or local election is not compulsory. Granted, those who refuse to enrol would have made for interesting case studies in their own right. No such participants volunteered, likely because the method of recruitment meant that the purpose of my study was often passed on as 'talk about politics' (Biernacki \& Waldorf, 1981, p. 153). All of the participants who took part were enrolled to vote and all except two voted in the 2011 election. A few participants remarked on their lack of interest in politics, which indicates that enrolling and voting is not an accurate gauge of political interest or involvement (see Blais, 2000, p. 13). Nevertheless, the above criteria were treated as a guideline to provide some structure and limit to participant recruitment in light of the intensive design adopted (Sandelowski, 1995).

I had no control of how the initial volunteer described the project to their acquaintances with a view to recruiting them, often leading to a distorted view of the aims of the study, a demonstrated weakness of the chain referral method (Biernacki \& Waldorf, 1981, p. 153). Many participants remarked that they were expecting me to 'test' them about their political knowledge due to the way in which their friend had summarised the project. As a result, those that were recruited by a previous participant had to be informed of the aims of the project when I met them for the first time. This likely affected the kind of people who were willing to participate. For example, one particular referral chain gathered three political science students. It also likely had an effect on the nature of the discussions, particularly in the first few minutes. After occasional awkwardness at the beginning of the conversation the vast majority appeared to have forgotten about being recorded after a few minutes had elapsed, a finding common to sociolinguistic research that relies on audio or video recording (see also Holmes, 2007b; Holmes et al., 2011; Holmes \& Stubbe, 2003; Holmes \& Woodhams, 2013).

The number of chains initiated through various channels meant that the spectrum of participants was relatively broad, though they all shared an interest in politics. I performed a basic analysis when listening to the early recordings and as a result I became more selective in later recruitment in order to broaden the spectrum further, a technique that resembles a form of GT theoretical sampling (Charmaz, 
2006; Coyne, 1997). The nature of intensive research methods and a focus on causal groups meant that recruitment in relation to demographic features was largely unnecessary (Sayer, 2010). What each participant shared was an interest in what they thought of as politics. This meant that aspects of their identities generated in interaction all shared a connection to wider political discourses. As generalisation to a population is not the goal, this approach satisfies the requirements of an intensive project which seeks to gain an understanding of the nature of underlying mechanisms in as much detail as possible (Sayer, 2000, 2010).

\section{$5 \cdot 5$ DATA COLLECTION}

When focus groups were carried out during the pilot test, and when compared to the early results of the one-on-one interviews, it quickly became clear that semi-structured interviews led to higher quality data. This was primarily through their potential for developing certain lines of questioning in more detail (Corbin \& Morse, 2003) and the apparent increased comfort of participants in more convenient and self-selected settings (Herzog, 2005). Herzog (2005) notes that the participant's choice of location for the interview can also be viewed as a sociopolitical assertion that is bound to context, which in itself has implications for identity genesis (Elwood \& Martin, 2000; Sin, 2003). For example, in choosing a café, a participant may be demonstrating familiarity with local social norms. Allowing the participants to choose the location also helps to make the relationship between the interviewer and interviewee more equitable (Seidman, 2013, p. 53). A notable observation is that changes in method occurred alongside the development of the philosophical background. As I became more familiar with critical realism and intensive research, I moved from a more structured focus group design to that of semi-structured interviews. The subsequent reflection and resulting refinement of interviewing technique is due to the reflexive and cyclical nature of the study design.

Despite the interviews taking centre stage in terms of their prominent contribution of linguistic data, the study was underpinned by another data source that is of equal, or perhaps more, importance: that of ethnography. The next section explores how exactly ethnography 
relates to the study design and how the interviews were located within an ethnographic frame.

\subsubsection{Linguistic Ethnography}

The use of ethnography in this study is inspired by IS in which it is recommended in order to acquaint the researcher with local presuppositions and to aid in the interpretation of contextualisation cues (Gumperz, 2001). This section outlines the approach to ethnography that I adopted throughout this study.

Atkinson and Hammersley (2007, p. 3) note that ethnography does not have a well-defined meaning due in part to its complex history of use and development across disciplines. They do however offer a core definition based on ethnography in practice:

ethnography usually involves the researcher participating, overtly or covertly, in people's daily lives for an extended period of time, watching what happens, listening to what is said, and/or asking questions through informal and formal interviews ... in fact, gathering whatever data are available to throw light on the issues that are the emerging focus of inquiry. (Atkinson \& Hammersley, 2007, p. 3)

The design of this study falls loosely within the above definition, with the exception of spending extended periods of time with participants; however, my insider status in the community appears to address this, as discussed below. Following their detailed description of the features of ethnography more closely, it is evident that this study satisfies many of the criteria: I talk to people in their everyday contexts, avoiding artificial or experimental scenarios; I include a range of data sources; I focus on a few case studies in my later analysis; and the audio data I collect is situated within its wider context (Atkinson \& Hammersley, 2007, p. 3). What differentiates this study is that I was already part of the community of people I sought to research. This does not automatically mean a privileged insight; as Molgaard and Byerly (1981, p. 159) warn, it is a mistake bordering on insensitivity to assume...that in doing research in one's own society one is a native.' Thus, a critical requirement is 
a commitment to 'reflexivity', or 'turning back on oneself' (Davies, 2008, p. 4), and an acknowledgement that my participants (i.e., not subjects) intersubjectively influence the creation of meaning (JacobsHuey, 2002). Reflexivity highlights my 'different positionalities in the field' which arise from my 'ethnic, linguistic, gendered, educational and class/caste backgrounds' (Jacobs-Huey, 2002, p. 799). With these important factors borne in mind, and subsequently factored into analysis, the ethnographic information I hold due to my being a politically interested Wellingtonian is recognised as a fruitful data source from which I contextualise my approach to both method and analysis.

Ethnography is committed to locating data within its local and wider contexts (Atkinson \& Hammersley, 2007, p. 3). It is largely based on a critique of quantitative methods, particularly in terms of their generalisation of findings to populations, lack of observation, insensitivity to change and neglect of cognitive and social influences (Hammersley, 1990, pp. 597-598). Ethnography thus seeks to provide a 'thick description' (Geertz, 1973) of certain events and gains understanding of them in context. This aim is clearly in line with critical realist tenets.

Ethnographic methods have been used within linguistics for some time, most notably under the label Linguistic Ethnography (LE), which combines the two in order to utilise the strengths of both. Wetherell (2007, p. 661) states simply that LE 'investigates acts of communication in their contexts' which in many ways echoes the aims of IS (Gumperz, 1999). Rampton (2007a), a central figure in LE, outlines its assumptions in more detail:

i) the contexts for communication should be investigated rather than assumed. Meaning takes shape within specific social relations, interactional histories and institutional regimes, produced and construed by agents with expectations and repertoires that have to be grasped ethnographically; and ii) analysis of the internal organisation of verbal (and other kinds of semiotic) data is essential to understanding its significance and position in the world. Meaning is far more than just the 'expression of ideas', and biography, identifications, stance and nuance are 
extensively signalled in the linguistic and textual finegrain.

Rampton's call for fine-grained analysis that includes a focus on stance and identification aligns closely with the analysis as carried out in Chapters 9 and 10. Rampton (2007b, p. 596) notes further that ethnography '[invites] reflexive sensitivity' which again underlines the importance of self-awareness in an ethnographically informed research process.

Despite its strengths, ethnography is not without criticism, particularly for the epistemological assumptions made in the use of theoretical (or thick) description (Hammersley, 1990; Porter, 1993, p. 592). Sealey (2007, p. 644) observes however that LE is 'not incompatible with realist precepts' but there remains a need to examine the assumptions of ethnography with a view to seeing how critical realism can act as its underlabourer, or philosophical backbone (Porter, 1993, 2002). In particular, Porter (1993, p. 592) states that it is necessary to 'make explicit the ontological status ascribed to social structures' which his 'critical realist ethnography' aims to achieve (Porter, 2002). The two roles of ethnography from this perspective are to 'infer the structural conditioning of interactions' and then 'test the veracity of theories concerning the natures and effects of structures pertaining' (Porter, 2002, p. 18). Therefore, the ethnographic data collected for this study, and described in the following section, is used to gain insight into the structural influences on interaction, i. e., sociocultural discourses, and to test whether the theories generated about these influences have sufficient explanatory power.

\subsubsection{The Ethnographic Data Set}

The conversations occurred within the frame of my personal engagement in the political life of Wellington. This engagement took both general and more situated forms. The general forms in particular are responsible for the contextualisation of all data analysed in this thesis, and, of course, influenced the choice of adopted methods and indeed the original inspiration for research. These ethnographic data were gained in the following ways:

- I maintain an ongoing immersion in the political culture of the capital and wider New Zealand through print, television 
and online media. This involves daily reading of newspapers, blogs and political opinion pieces; listening to radio interviews, commentary and debate; watching television news and current affairs; and participating in frequent conversations with acquaintances about New Zealand politics.

- I was born and raised in the Wellington region and have an intimate knowledge of the city and surrounds, the issues that have shaped its history and sociocultural understandings, both in terms of local, Wellington norms, and national, New Zealand influences.

In addition to the general ethnographic data, participation in the political life of Wellington took a few specific situated forms during the period of research, where I engaged with three important and high profile political issues that helped me gain an understanding of the political climate of the time around data collection. Participation in these political events also provided me guidance when these topics were inevitably raised by participants, allowing me to engage on a more personal level having had firsthand experience. These issues were the closure of public television channel TVNZ Seven, the Government's state-owned asset sales agenda and the passing of the Marriage (Definition of Marriage) Amendment Bill. These are described further below:

- In May 2012 I was present at a town hall meeting regarding the fate of the television channel TVNZ Seven, a publicly funded channel free of commercial content, similar to PBS in the United States. Political figures from the opposition Labour Party gave speeches and passionate audience members made clear their views against its closure.

- In May 2012 I attended a large protest through Wellington's central streets that marched on Parliament. The protest was in opposition to the Government's asset sales agenda. The leaders of all Opposition parties gave speeches on the steps of Parliament House.

- In April 2013 I attended the final reading of the Marriage (Definition of Marriage) Amendment Bill which legalised marriage 
between same-sex partners. Due to the public gallery in the debating chamber being full, a projector was set up in the Legislative Council Chamber which played the debate to a large crowd. Many people had to be turned away for lack of room. This was undoubtedly a landmark event in New Zealand's political history, demonstrated by its heavy media coverage, substantial public attendance at Parliament and its frequency as a topic of conversation by my participants and around the city in general.

These experiences, both general and situated, are what will be referred to as the 'ethnographic data set.' Gathering detailed information through these channels ensured that a picture of the political culture of Wellington and New Zealand could be painted from both the bottom-up, in terms of what participants said about politics and political issues, and the top-down, from the broader sociocultural discourses that influence everyday interaction. From a more practical standpoint, it allowed me to stay abreast of current affairs, as participants often brought up political issues that required a certain level of knowledge for me to contribute appropriately.

My aforementioned in-depth knowledge of Wellington and the wider region adds a deeper analytical dimension to this research as it is invaluable in interpreting the discourses that circulate throughout the city. Drawing on this knowledge recognises, from a critical realist perspective, the inseparability of the researcher from the research context. ${ }^{4}$ The semi-structured interviews were carried out within this rich ethnographic frame. The following section outlines the theoretical considerations underpinning the use of these interviews, delving further into their structure and exploring their ethical considerations.

\subsubsection{Semi-Structured Interviewing}

Interviewing has a long and illustrious history in the sociolinguistic tradition, most famously through the pioneering social dialect work of William Labov (1966). Sociolinguistic interviewing as a research method has led to significant advances in the field and it has demon-

4 Where analysis draws on prior knowledge of the social context that is not immediately obvious, I make a note of it for the benefit of the reader. 
strated its utility in language research, particularly in the case of language variation (Labov, 1972a, 1984; Milroy \& Gordon, 2003; Tagliamonte, 2006). The interviewing method used in this study is not strictly that of the Labovian sociolinguistic interview when compared to its broad research goals (Labov, 1984, pp. 32-33). Nevertheless, there are important similarities with the interviews adopted in this study, such as a desire to record high quality audio, to elicit narratives of personal experience and to explore the topics of most interest to the speaker. Labov's (1984) other, more quantitative goals, such as the study of phonological features of speech through the use of minimal pair tests and word lists are not relevant given their different research emphasis and basis in quantitative, empiricist methodology. This study does, however, follow in the spirit of sociolinguistic interviewing and draws on the interview as an effective method of gathering naturalistic speech data, demonstrated through not only its success in linguistics, but its long tradition of use in the wider social sciences (Arksey \& Knight, 1999; Briggs, 1986). The purpose of this section is to introduce the theoretical issues surrounding interviews, particularly in regards to their structure and ethical application. The specific application of the interviews and their refinement across time is discussed in the following section.

Talmy (2011) notes that there are two ways to conceptualise research interviews, the conventional 'interview as research instrument' and the alternative 'research interview as social practice.' The former considers interviews 'a tool for investigating truths, facts, experience, beliefs, attitudes, and/or feelings of respondents' (p. 26) and within this paradigm 'interview data are ontologically ascribed the status of reports of respondents' biographical, experiential, and psychological worlds, with the interview thus conceptualized as the epistemological conduit into these worlds' (p. 27). The critical realist can immediately identify issues with this theorisation, in that interview data is never a clear window onto ontological reality as it is always embedded in epistemic relativity. In response to this, I conceptualise interviews as the latter: a form of social practice, where rather than being neutral conduits, interviews are 'representations or accounts of truths, facts, attitudes, beliefs, mental states, etc., coconstructed between interviewer and interviewee' (p. 27). Despite Talmy's use of the metaphor of construction his point is a salient 
one: it is impossible to completely efface the researcher's influence from the interview process. This is because the answers participants provide in an interview situation

are oriented to, shaped by, and designed for the questions that occasion them; as well, answers are built on previous questions and answers the respondent has been asked and has (not) answered over the course of an interview or series of interviews. (Talmy, 2011, p. 31)

The interviewer and the way in which they ask questions are therefore inextricable parts of the interaction. Analysis of the resulting data in this study is carried out with this in mind.

Talmy (2011, p. 31) notes that power is another important consideration in interviewing. Choosing to begin and end a line of discussion is an exercise in power; in the conversations that form the bulk of the data set in this study, I held control through my position as the interviewer and by setting the overall research agenda. I made attempts to mitigate this effect by giving participants opportunity (or providing access, see van Dijk, 1996) to pursue their own conversational topics and even flip roles in asking questions of me, most frequently in the form of questions about my past research and motivations. Reframing the interview as an informal conversation seemed to relax the constraints of the interview as a speech act (Milroy \& Gordon, 2003, p. 62), making it easier for participants to take control of the direction of the interview and going some way to address questions of equity (Seidman, 2013, p. 53).

The method adopted in this study aligns most closely with what Corbin and Morse (2003) characterise as semi-structured interviews, moving into unstructured interviewing at certain times. In terms of power relations, semi-structured interviews are designed around the notion that the 'researcher determines the structure of the interview and agenda... [and] the participant controls the amount of information provided in responses' (p. 340). As the interview continues and the participant becomes more comfortable, they often take more control of the direction and assume an equal footing with the interviewer (p. 340). These observations were borne out in my interviews, with conversation often becoming less rigid as time progressed and as we became more comfortable with each other as conversational 


\begin{tabular}{ll}
\hline \multicolumn{1}{c}{ PHASE OF INTERVIEW } & \multicolumn{1}{c}{ CHARACTERISTICS } \\
\hline Preinterview & $\begin{array}{l}\text { Consists of small talk through } \\
\text { which the participant and re- } \\
\text { searcher begin to feel more re- } \\
\text { laxed. }\end{array}$ \\
\hline Tentative & $\begin{array}{l}\text { The participant 'tests' the re- } \\
\text { searcher to see whether he or } \\
\text { she is trustworthy. }\end{array}$ \\
\hline Immersion & $\begin{array}{l}\text { If the researcher 'passes' the } \\
\text { previous phase, the participant } \\
\text { and researcher gradually be- } \\
\text { come engrossed in the story of } \\
\text { the interview. }\end{array}$ \\
\hline Emergence & $\begin{array}{l}\text { The participant and researcher } \\
\text { exit the story, reducing in emo- } \\
\text { tional intensity and discussing } \\
\text { less sensitive topics. }\end{array}$ \\
\hline
\end{tabular}

Table 4: The phases of a 'typical' semi-structured interview (Corbin \& Morse, 2003, pp. 341-344).

partners. In contrast, unstructured qualitative interviews are much more free-form, as the 'agenda is set by the participant' and the 'participant has the control over the pacing of the interview, what will be disclosed... and the emotional intensity' (Corbin \& Morse, 2003, p. 340). As mentioned above, the conversations I held occasionally satisfied these conditions, particularly after some time had elapsed.

Most interviews follow a common structure, including the "preinterview phase, the tentative phase, the phase of immersion, and the phase of emergence' (Corbin \& Morse, 2003, pp. 341-344). The characteristics of these phases are presented in Table 4. In this study, not all of these stages were progressed through in the linear fashion that Table 4 suggests. It does however provide a general representation of the way many discussions tended to progress. From experience I found that the emergence phase was as important as the 
others, if not more so, as some participants took the opportunity to reveal additional information after they felt that the more 'formal' stages of the interview speech act had been completed (Milroy \& Gordon, 2003, p. 62). The kind of information given in this phase was oftentimes crucial, such as in Excerpt 5.1, which occurs at the very end of a conversation:

Excerpt $5.1^{5}$

Steven Wheeler, 43-47 year old NZ European/Pākehā male

Setting: Wellington café

Context: I have asked Steven if he knows anyone else who would be keen to talk to me, particularly those with right-wing views.

Time: 46:54.5-47:58.3

1 SW it's a it's a left wing town to a large //extent

2 JW /it is $\backslash / /$ yeah

3 SW /it's $\backslash \backslash$ the bloody p s a [Public Service Association] for you

4 JW yeah

5 SW er [laughs] [...]

6 SW yeah obviously i tend to attract

7 JW [laughs]

8 SW loony lefties like myself

9 JW [laughs]

10 SW um bleeding heart liberals

11 JW [laughs]: yeah:

Had I switched the recorder off when I first offered my thanks I would have missed Steven's characterisation of Wellington as a left wing town (line 1) and his light-hearted apportionment of blame to New Zealand's public sector union, the Public Service Association (PSA) (line 3). I would have also missed his self-characterisation as a loony lefty (line 8) and a bleeding heart liberal (line 10), important indexical labels that warrant closer analysis (see Chapter 10). My ability to capture data such as this resulted from a lesson I learnt the hard way: I missed recording a substantial narrative by Desmond Morain about his firsthand experience during the 1967 Prague Spring where he witnessed protesters clashing with Warsaw Pact troops. I regrettably did not turn the recorder on as soon as I arrived at his house. After this experience, I made sure to switch the recorder on as soon as I met

5 The transcription conventions are provided in Appendix A. 
with the participant and turned it off only after we parted ways (this is discussed in more detail in the following section).

In addition to its benefits in terms of data quality, allowing the participants enough time to exit from their stories is crucial for a sensitive and responsible researcher as ending abruptly whilst engaged in an in-depth narrative could leave participants feeling as though there has been no conclusion reached and consequently with unresolved feelings (Corbin \& Morse, 2003). Talking about politics in the New Zealand context, while raising the passions of certain individuals, is unlikely to get to the level where harm could occur, at least in comparison to the sensitive topics of trauma, abuse and illness that concern health researchers (e. g., Booth \& Booth, 1994; Corbin \& Morse, 2003; Dickson-Swift, James, Kippen \& Liamputtong, 2007; Johnson \& Clarke, 2003; Kavanaugh \& Ayres, 1998; Orb, Eisenhauer $\&$ Wynaden, 2001). Their insights into the ethical uses of interviewing nevertheless remain applicable to all intensive interviewing whether or not the topic is of a highly sensitive nature.

The political conversations I held provided some evidence of benefit to the participants, as demonstrated in Excerpt 5.2.

\section{Excerpt 5.2}

Linda Foley, 78-82 year old NZ European/Irish female

Setting: Linda's kitchen

Context: We are wrapping up the conversation. There are three people present: JW, LF, and her granddaughter, MP.

Time: 1:58:25.1-1:58:38.3

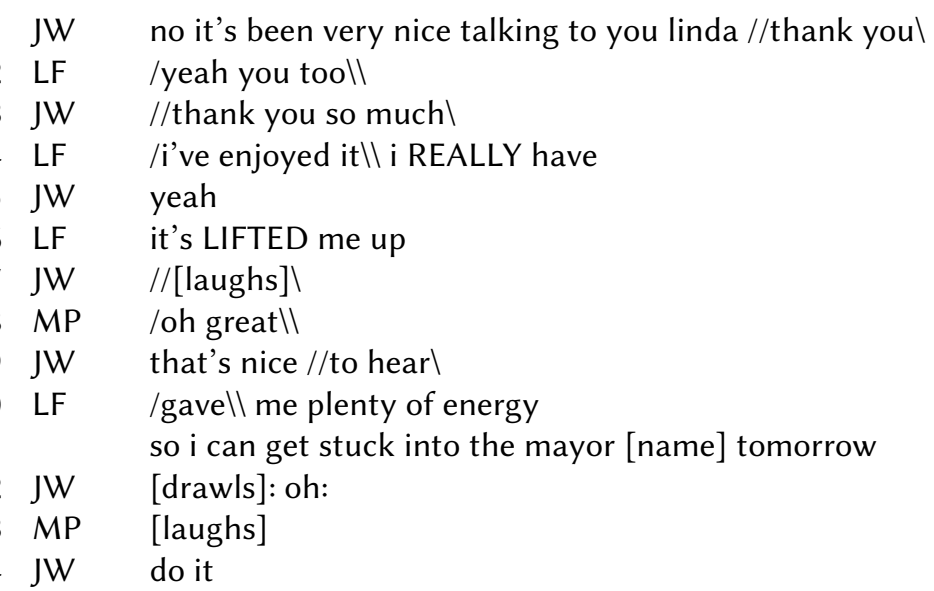


This excerpt demonstrates that there is a benefit to Linda, specifically in that our almost two-hour conversation at her kitchen table had left her with an energised feeling that LIFTED me up (line 6). Linda remarked afterwards that she enjoyed taking part in the project as few people had taken the time to listen to her political views at length. The sense of catharsis experienced by Linda is supported by research which indicates that interviews can help contribute to a sense of purpose, self-awareness and empowerment (Hutchinson, Wilson \& Wilson, 1994). This was repeated in comments from other participants who noted that their attempts to talk about politics with their family and friends often fall on deaf ears and result in glazed eyes. In fact, several enthusiastic participants said that they would like to meet with me to discuss politics again, and I have done so with May Porter and Isaac Quinn, whom I have met spontaneously at various places around the city, and Steven Wheeler, whom I met again for another informal chat about politics in a different Wellington café.

\subsubsection{Audio and Video Recording}

The logistics of audio recording were relatively straightforward. A small black digital notetaker was placed on the table, often on top of its neoprene case in order to reduce vibration, with the builtin microphone positioned adjacently to capture speech from both myself and the participant. Modern digital audio recorders are such that the built-in microphones are powerful enough to capture detailed linguistic information and simultaneously filter unnecessary noise (Negrón, 2012). Even so, there were times when the recorder struggled, particularly in my first café conversation with Michael Teoh. In this case I placed the recorder too far away from both of us, as we had both opted to sit in opposite sofas that invited reclining, increasing the distance from mouth to microphone. In addition it was a noisy café setting at lunchtime with the clinking of cutlery and crockery emanating from the nearby counter and background music playing from a small overhead speaker. Unsurprisingly the resultant recording was of poor quality and Michael's utterances were occasionally difficult to interpret, as reflected in my notes at the time (discussed further in the following section). In subsequent conversations I adjusted the positioning of the recorder and was 
more conscious of timing, background noise, seating arrangement and location. As a result, the quality of the recordings in public spaces improved substantially. Conversations that took place in people's homes and offices often produced much higher quality recordings due to the lack of background noise. In total, eleven took place inside cafés, one of these being in an outside area. The large majority of café interviews was likely due in no small part to Wellington's 'café culture' (Ministry for Culture and Heritage, 2014). Seven recordings took place in the participants' homes, one in a workplace and another in the lobby of a university building. In general, the café conversations were held in quiet corners where possible, and the presence of cups of coffee often served to break the ice and make the participant more comfortable after the relatively formal consent form signing was completed.

Video recording was utilised in the pilot focus group and not for the main phases of data collection for three main reasons. The first were issues of logistics, as setting up a tripod and video camera in a café, by far the most preferred setting for the majority of participants, is not a subtle task, as it can draw the attention of other patrons (cf. Kidner, 2015). Placing a video camera on a tripod next to a café table is obtrusive to both participant and others nearby, who also may not consent to being inadvertently captured on video. In the interests of remaining sensitive to my participants, and drawing on my own knowledge of the social norms of Wellington cafés, video recording was considered an imposition on both participant and bystanders that I was unwilling to make. The second reason was that a video camera can be intimidating to both researcher and participant. In contexts such as workplace meetings, video recording has been used with great success as participants often forget about video cameras when they are left in a static position for a number of days (Holmes et al., 2011; Holmes \& Stubbe, 2003). The nature of the design of this study meant that setting up a video camera and tripod prior was not feasible, as discussions were often scheduled at short notice and at places most convenient to the participant. Nevertheless, the participants were sometimes noticeably conscious of the notetaker on the table, indicated by their glances at it, and occasional explicit mention or interaction with it. This is demonstrated by Steven in Excerpt 5.3. 


\section{Excerpt 5.3}

Steven Wheeler, 43-47 year old NZ European/Pākehā male

Setting: Wellington café

Context: Steven has just explained why he is not currently active within the Labour Party.

Time: 7:10.6-7:18.7

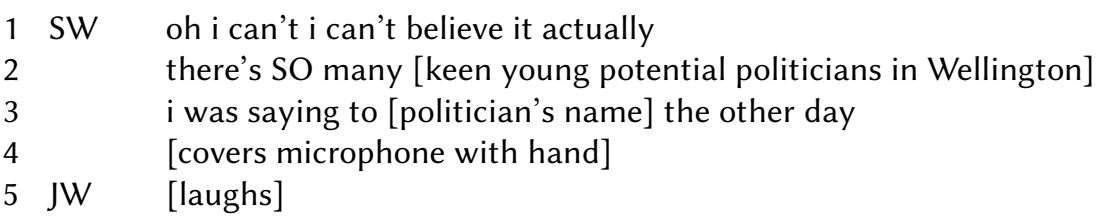

Some participants used the recorder as a prompt or topic of conversation, as in Briar's case in Excerpt 5.4, where she describes her efforts to record her stories for the purpose of writing a book.

\section{Excerpt 5.4}

Briar Murphy, 48-52 year old European/Pākehā female Setting: Briar's workplace

Context: I have asked permission to turn the recorder on.

Time: 0:07.9-0:15.6

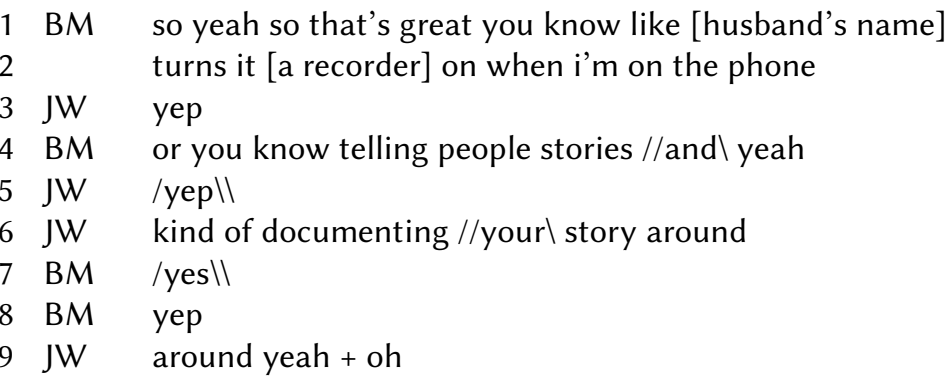

In all cases the participants ceased to look at the recorder after a period of time, sometimes in as little as a few minutes into the conversation. Often their forgetting about the recorder was related to the intensity with which they were invested in the topic of conversation. This recalls Labov's (1972b, p. 113) finding that his well-known 'Danger of Death' questioning often led to participants forgetting about the constraints of the interview situation due to their investment in their answer. The degree of participant investment, related to the phase of immersion in Table 4, thus has an important influence on the nature of talk gathered. 
The third reason for using audio recording alone was in consideration of the research goals of this study. Visual aspects of stance are undoubtedly important and multimodality is a burgeoning area of research in discourse analysis that has contributed significant insights into the semiotic aspects of gesture, facial expression and bodily movement (Norris, 2004, 2011). In order to go some way to acknowledge this, I recorded any gestures the participants made in the notes I took immediately after every interview (for example, when Briar gestured to her ears while saying 'in one ear and out the other'). This approach was limited because I chose not to take notes during the interview to avoid disrupting the interaction and it also relied on a gesture being noticeable enough to warrant noting it down afterwards. Often, when I had not made a note of a gesture, I recalled it as I listened again to the recording during transcription. Judged on the balance of logistics and naturalistic interaction versus capturing a fuller range of semiosis, I opted for the former in light of the research aims of this thesis.

The next section explores how the interviews were applied in practice, charting my experience of refining questioning technique, revising the interview design and eventually arriving at the informal one-on-one conversation as the method of audio data collection.

\subsubsection{Interview Design and Application}

I initially designed a questionnaire in order to ensure some consistency between the pilot focus groups and later used this to guide the semi-structured discussions. The questionnaire was formulated in reference to the guidelines of Litosseliti (2003), who recommends moving from broad to specific questions, talking about the present before the past and future and grouping the questions into thematic categories. Arksey and Knight (1999, pp. 93-96) also provide advice on question formulation, recommending the avoidance of jargon, ambiguity and leading questions, and warning about assuming that the interviewee has specialist knowledge. These specific recommendations, particularly in relation to wording, were more difficult to import into a less structured discussion. I did, however, attempt to remain consciously aware of my questioning technique throughout. 
The questionnaire was originally designed to elicit talk about a variety of political topics from the participants, covering a wide range of political issues such as trust in politicians, views on certain high profile current affairs, voting behaviour and thoughts about the future heading into the 2014 general election. However, I did not have a questionnaire in hand throughout the majority of the discussions (after finding that it intimidated participants, see below) and many of them veered away from the points listed and explored political topics that held interest for them. I reduced the questionnaire to a series of prompts which provided a mental guideline to which I could refer in order to stimulate previously unexplored topics of conversation. It was also a useful backup in cases of silence. The prompts I memorised took the following form:

1. To begin:
a) Introduction
b) Q \& A about the project
c) Information sheet and consent form

2. Discussion points:
a) Their reasons for becoming interested in politics
b) Opinions on political issues in NZ
c) Notable political figures
d) Voting behaviour
e) Parliamentary structure
f) Engagement and trust
g) Activism and change
h) View to the future
i) Where we should go
j) Upcoming election

The shift from more rigid interviews, guided by a questionnaire, to informal conversations and memorised prompts was initially encouraged by insights from the pilot test, the first two interviews with participants in late 2012 and through substantial subsequent 
reflection. My first interview, with Joe Branstad in November 2012, was relatively structured in terms of adherence to the question schedule and as such demonstrated the limitations of restricting the questioning to prepared topics. Nevertheless, I felt as if it was successful. From my research notes after the interview:

foe seemed generally comfortable, but the interview itself raised new topics such as local government which were not included on the schedule. He seemed to respond well to the question schedule and was unfazed by the presence of the recorder and paper. I did find myself torn between wanting to provide my own opinion and giving foe the chance to speak by himself. However, without my input, the questioning seemed stilted, so I participated enough so that it seemed more like a conversation. This is a balance I will need to strike as I continue with my research.

As my notes indicate, I was struggling to deal with topics that were not on the question schedule. Also, the desire to provide one's own opinion in an interview is an experience common to interviewers. Corbin and Morse (2003, p. 347) attribute this to a discomfort with silence and a lack of experience on the interviewer's behalf. My desire to make the interview 'more like a conversation' in order to gain higher quality data was reinforced through my second interview. This interview, conducted with Michael Teoh, took place in December 2012. The notes taken afterwards indicate my feeling that it was unsuccessful in terms of the quantity and quality of data recorded:

Michael was a bit reticent and the noise levels in the café made it difficult to hear his responses, and the recorder struggled at points. After a rough start he seemed to become more comfortable, but it was obvious that the presence of the question schedule was making him wait for my prompt before talking, leading to a stilted, more formal and unnatural interaction. I tried my best to be informal and relaxed, but at times Michael didn't have an answer for my questions which showed me that perhaps having a question schedule with detailed points of conversation laid out in order is probably a bad idea. 
The observation I made after the interview about the struggle to encourage speech is acknowledged by Milroy and Gordon (2003, p. 62) as a constraint of the interview as a speech act:

Individuals who are being questioned will seldom produce large volumes of speech in their replies... Interviewers may work to 'fudge' the nature of the event in an attempt to encourage the interviewee to relax and produce larger volumes of speech, but the well-defined nature of the interview as a speech event, along with the associated social and discourse roles of the participants can make such efforts very difficult.

This led to reflection about 'the interview as a speech event' and how I could possibly reduce its influence on the participants. As a result I made changes to the study design: I opted to revise my material, such as the information sheet and consent form, to refer to the interviews as informal discussions or conversations, in addition to referring to them as such in all communication with participants. I eventually abandoned the questionnaire and transitioned fully to semi-structured informal conversations guided by the above question prompts. My notes on question design from January 2013 list the changes made:

After consideration, the question schedules have been entirely revised...Discussion points will be used as prompts; a full question schedule makes for much too formal interactions, with participants waiting until they are prompted by a new question. Initial discussions will be the focus, with the collection of as much data as possible... The prompt will be used as a safety net if the conversation falters, and will be on a square of paper that can fit in my hand. A paper and pen will be handy if I need to write something, but not in my hand and not an object of focus.

The conversation points I settled on were memorised and provided a general framework in the case that conversation was lacking; however, as I went on, these were relied on less and less.

The third conversation, with Isaac Quinn in February 2013, was the first in which I trialled the new semi-structured discussion without a 
physical questionnaire guiding the process. It was in my view a great success. This was reflected in my notes after the fact:

This was the first time I trialled an unstructured [more accurately a semi-structured] interview. It went much better than the previous two. Isaac was relaxed, happy to talk at length on certain topics, and I contributed a bit but tried to steer it towards topics that I had in mind.

Refining this formula led to the informal one-on-one conversation becoming the central focus of the study design given the high quality of data it generated. Not all of the interviews were one-on-one however; a small group discussion took place with two participants and two colleagues who were acquaintances of the participants, and another took place with a grandmother and her granddaughter. These group discussions were run in much the same way as the one-on-one discussions. They allowed opportunity for participants to talk amongst themselves which provided some insightful data, as presented in Chapter 8. This indicates that informal group discussion may be a fruitful direction of future research, as it remains to be seen how being in an informal group affects political identity and stancetaking in the New Zealand context (cf. de Cillia et al., 1999; Gordon, 2004; Walsh, 2004; Wodak \& Meyer, 2009).

As I continued my data collection, I became much more comfortable and experienced in leading the interviews. I found the next difficulty to arise in answering the question of when to cease data collection. This is addressed in the next section.

\subsubsection{Theoretical Saturation}

After interviewing multiple participants I began to notice that similar themes tended to recur. This was partly due to the fact that participants referred their acquaintances who were often quite similar to the referrer both demographically and in terms of political orientation. Biernacki and Waldorf (1981, p. 157) state that

The number of cases provided through any type of referral chain should also be limited when the data becomes repetitious. At this point the researcher should be confident that the possible variations extant in that particular subgroup have been exhausted. 
Somewhat clinical, due to its basis in being judged by the positivist yardstick, this nevertheless became apparent mid-way through my data collection even though analysis had been largely limited to the acknowledgement of general themes that were raised and corroborated by my post-interview field notes. Repetition of themes is an indication that a certain referral chain is 'exhausted' and following it further would yield little more analytical insight. This is captured by the concept of 'theoretical saturation' (Bowen, 2008; Charmaz, 2006, pp. 113-115; Guest et al., 2006). From my notes on 19 April 2013:

The notion of theoretical saturation is a good one that seems to describe the feeling I was getting after covering centreleft political views in Wellington in detail. I was starting to see the same themes arise to the point where I could almost predict what a Green or Labour voter would say.

Thematic repetition was an intuitive point at which I arrived, indicating that $\mathrm{I}$ was reacting to a form of saturation and that $\mathrm{I}$ should push my recruitment in different directions. However, centreright participants proved much more difficult to recruit than I had anticipated, though eventually a spectrum of views was attained.

The concept of theoretical saturation provides sophistication to the relatively simplistic notion of 'repetition.' Guest et al. (2006) discuss theoretical saturation and aim to operationalise its use, defining it as 'the point in data collection and analysis when new information produces little or no change to the codebook' (p. 65). This does however anticipate the use of a codebook (which they define as a list of 'content-based coding schemes') during data collection and refining it accordingly, as required of GT studies (Charmaz, 2006, pp. 42-71). That was not exactly the case in this study: the data were collected over a series of months, and while preliminary analysis and description took place during the data collection period, focused linguistic analysis and coding began only after all data had been collected due to its intensive time requirement. Furthermore, saturation is not a foolproof method for determining the end of semi-structured interviewing because, as Guest et al. (2006, p. 75) note, in less structured settings it is a 'moving target' due to new and unanticipated themes that are introduced by participants. The definition of 'theme' is also recognised as abstract and thoroughly reliant on analyst intuition, and which also should 
be linked to concrete evidence in the data (p. 77). Despite these shortcomings, theoretical saturation provided general support to the feeling that I had exhausted various lines of inquiry and helped to push my data collection in new directions.

\subsubsection{Data Set}

After the six-month data collection period, which began in November 2012 and ended in May 2013, I had collected a data set comprising 20 separate interviews with 21 individuals, totalling roughly 22 hours of audio recording. When the data collected during the pilot study is included, the data set includes 26 individuals, almost 25 hours of audio recorded interviews and over 1.5 hours of video data. Further details about the composition of the data set are provided in Appendix B.

\subsection{DATA ANALYSIS}

The bulk of the detailed analytical work was carried out within QSR International's NVivo 10 software (2012). NVivo 10 aids the researcher in describing and transcribing audio and video data, and provides the ability to 'code' the transcripts, referring to assigning portions of the transcript to certain categories known as 'nodes.' NVivo also allows the researcher to run detailed queries and generate reports based on the data. At points where more detailed analysis of the audio files was needed, the software package Audacity ${ }^{\circledR}$ (2013) was used.

The analytical process generally followed this sequence:

1. Import interview recording into NVivo

2. Divide the interview into thematic arcs

3. Describe each portion of the interview

4. Tag each segment with keywords

5. Transcribe relevant sections

6. Code sections of the transcript into nodes

7. Run queries 
These steps were followed and revisited often in a different order, depending on the patterns that had arisen from the data and the questions I was seeking to answer at the time. A detailed description of each step is provided below:

1. IMPORT INTERVIEW RECORDING INTO NVIVO: NVivo allows the researcher to link external audio files to a transcript that resides within the software.

2. Divide the IntervieW into thematic ARCs: The transcripts were segmented following the general characteristics of a 'stanza', which Gee (2014, p. 158) defines as 'a group of lines about one important event, happening, or state of affairs at one time and place, or it focuses on a specific character, theme, image, topic, or perspective.' Discourse markers such as so, well and oh also helped to mark the introduction of a new topic or question (Schiffrin, 1987) as did the intonational contour (Gee, 2014, pp. 151-154). This is also relates to the notion of 'intonation unit' (Chafe, 1987; Gee, 2014, p. 152). Identifying thematic boundaries is not precise, as some stanzas are tightly bound with smooth transitions and others are anaphoric or cataphoric (Gee, 2014, p. 162). In these cases intuition provided an adequate compass to guide thematic division. Portioning the data in this way located relevant information together in one section of the transcript which aided analysis and navigation of the data. Certain sections were much longer than others, with some lasting only a minute or two and others for fifteen-minute stretches. However, this never became unwieldy when working with the data within NVivo as the software provides a new row for each segment which is linked directly to a time range in the audio file. Certain transcript sections can then be isolated and played directly. This made returning to specific parts of the audio recording at later stages much easier.

3. DESCRIBE EACH PORTION OF THE INTERVIEW: This technique is the same as used by the Wellington Language in the Workplace Project (LWP) team (Holmes et al., 2011; Holmes \& Stubbe, 2003; Vine, Johnson, O’Brien \& Robertson, 2002), for which I had gained some previous transcription experience. The benefits of 
describing (or roughly transcribing) first, rather than moving directly to full transcription, is that it allows a more holistic approach to the data without frequent stops and starts. This helped me to get a sense of the prosody of the discussion and made it easier to comprehend topics that stretched over longer periods. Description took place by listening to the audio recording at normal speed and simply noting in a custom NVivo column a description of what was occurring. A sample of the recording description is provided below:

His views towards elections have changed since he was 18. It was a joke when he was younger, he voted for the Bill and Ben Party, just finished high school, did something stupid with the power he had. Quiet as forms are being filled. Talk about getting participants and how people think I am testing them on politics. Interesting methodological points mentioned here. Talk about LING. He mentions that people who have POLS degrees tend to take a one-sided view. This will be interesting to contrast with how he comes across. NARRATIVE of vicarious experience, about his old flatmate. After POLS his views got entrenched. First mention of SOCIALIST label 'I'm an incredible socialist' and everything is interpreted through that lens. Talks about debates with his flatmate. His flatmate has entrenched views you can't fight.

This provided enough detail to see patterns arise from the data while also working at a fast enough pace to get a sense of broader themes that develop across the stretch of an entire interview. The description stage also provided the opportunity for noteworthy analytical features to arise. In the case of the above discussion, I inserted these analytical notes into another NVivo column: NARRATIVE vicarious experience; INDEXICAL label; Stance: socialist. Everything subsequently through that lens. Criticises one-sided views but goes on to state his own throughout. This provided me with a quick reference and made it unnecessary to read through the entire description when later searching for analytical items of interest. 
4. TAG EACH SEGMENT WITH KEYWORDS: In another custom NVivo transcript column, alongside the analytical notes, I added tags. These were keywords that related to any identity work that was taking place. In the case above, the tag I used was 'socialist.' Like the analytical notes, the tags acted as prompts when quickly scanning the transcript which helped to find where identity work may be occurring. It also helped with seeing larger patterns arise within longer conversations and linking identity themes across participants.

5. Transcribe relevant sections: What counted as 'relevant' changed as my analytical focus shifted. At one point, metaphor became relevant, and at another, narrative. I attempted to strike a balance between capturing detail in the description and the speed of analysis, while remaining cognisant of the fact that transcription is a theoretical and political process that requires careful consideration (Bucholtz, 2000; Ochs, 1979). ${ }^{6}$ The description, analytical notes and tags allowed me to note where I had earlier seen narrative or metaphor or other important features to return to later. This raises an obvious issue: I could not foresee what my analytical focus would be later in the project and so I did not make a note of every important feature at the description stage. In order to address this I described the discussions in enough detail to see where these features may have occurred, and when needed, revisited each interview to determine if the feature of interest was present and if so, carried

6 Transcription was carried out in full awareness of the issues raised by Bucholtz (2000) and Ochs (1979). It involves relatively hidden issues of power embedded in both the interpretation of data and the choices made in its written representation. Transcripts reflect both the norms of the discipline and researcher and are shaped by research goals and guiding theories (Du Bois, 1991; Green, Franquiz \& Dixon, 1997; Ochs, 1979). For a critical realist, there is no theory-neutral vantage point from which research can take place (Sayer, 2004); likewise, there is no neutral approach to transcription (Bucholtz, 200o). In order to address these issues, the recommendation is similar to that adopted within the ethnographic frame: a commitment to responsible, reflexive practice 'in which the researcher strives not for an unattainable self-effacement but for vigilant self-awareness' (Bucholtz, 2000, p. 1461). 
out closer transcription. ${ }^{7}$ This method of analysis allowed for a holistic yet sensitive analysis, though it may have been at the expense of noticing every instance of a given feature. This is a trade-off that intensive studies can make for the benefit of greater analytical depth (Sayer, 2010).

6. Code SECTIONS OF THE TRANSCRIPT: Portions of the transcripts that were deemed relevant for analytical purposes were highlighted and linked to nodes within the NVivo programme, a process referred to as 'coding'. These nodes were created in reference to salient items that arose in the data; in other words, nodes were initially created for items that occurred frequently enough to be noticed, and these were subsequently refined as the analysis progressed. Critical realism guided the identification of nodes and thus influenced the direction of analysis, resulting in three categories: 'macro', 'micro' and 'extralinguistic'. Macro nodes included sociocultural discourses, such as egalitarianism, tall poppy, political ideology, characterisations of New Zealand and references to Kiwi identity. The micro node category included features such as metaphor, narrative, humour, pronouns (particularly the use of 'we') and topics such as characterisations of political parties and mentions of marriage equality. Extra-linguistic nodes included gesture and recorder awareness. Coding segments of the transcripts across the entire data set allowed for cross-referencing and comparison between certain features and made them available for use with NVivo's powerful query and reporting functions.

7 The transcription notation used throughout this thesis was adapted from that used by the LWP (Vine et al., 2002). The transcription key and a rationale for transcription decisions are provided in Appendix A. The LWP notation is designed to be an efficient transcription method that preserves linguistic detail but remains readable, taking a balanced approached to the issue of naturalised (promoting ease of reading) versus denaturalised (including accurate suprasegmental information) transcripts (Bucholtz, 200o, p. 1461). The LWP notation retains the ability to include additional information in square brackets if necessary. Part of being a responsible transcriber is to report that which is not included (Bucholtz \& Hall, 2007), thus omitted data not considered immediately relevant to analysis is replaced with ellipses in square brackets [...]. Suprasegmental information is generally not included, except in cases where it becomes necessary for interpretation. 
7. RuN QUERIES: Coding in NVivo allows the researcher to pull together excerpts from a large collection of transcripts to be viewed in one document. For example, coding for narratives allowed me to view all identified narratives in the data set with one command. Queries are another powerful function for extracting information from the data set. The text search was one commonly used query which helped to find certain words and their stems throughout the data set. This aided greatly in identifying wider patterns which indicated areas worthy of closer attention. This demonstrates the complementary nature of intensive and extensive techniques (Sayer, 2010).

As mentioned above, the study design changed dramatically as I continued. Since analysis took place even at the very early stages, the remaining question to answer is how developments in method affected my analysis. Perhaps the most salient example of this is the aforementioned interview with Michael Teoh in which I was unsuccessful in terms of putting him at ease and gaining high quality, naturalistic speech data. My analysis at that early stage was basic, but nevertheless it was apparent that a more rigid form of interview, using the structured question schedule, lent itself to an analysis of the themes and content of speech. Analysts have gone to lengths to demonstrate that discourse analysis is more than just thematic analysis (e.g., Antaki, Billig, Edwards \& Potter, 2003), though my early design tended to welcome such an analysis. As I became more familiar and comfortable with interviewing and embraced semi-structured interviews more fully, in addition to deepening my philosophical understanding and developing my skills as a researcher, my analysis opened up and took a more refined and reflexive approach to stance and intersubjectivity. The outcome of this development is evident in the analytical chapters, particularly in the close investigation of intersubjectivity in Chapter 9.

\subsection{FOLLOW-UP REPORTING}

The final step of contact with the participants who volunteered for this study, including those who attended the pilot, was to create and disseminate a report with my preliminary research findings, which is 
attached in Appendix F. In January 2014 I emailed the report to the participants, all of whom had requested a copy on their initial consent forms. It contained updates about the study and outlined the major patterns that had emerged at that stage. The report also included an overview of the final data set in terms of the number of participants and hours of recording, a summary of a conference presentation I had made about a small portion of the data and insight into the thematic and linguistic features that were evident. The report ended with a note of thanks. I received feedback from a number of participants who wished me well and thanked me for remaining in touch.

\subsection{SUMMARY}

The method this study follows is firmly located within the critical realist paradigm, which provides the rationale for an intensive focus on the interactional data and remains sensitive to extra-discursive influence. The study design passed through a series of iterations in which the pilot study and early-stage analysis fed into and further refined developments in data collection and analysis. The conversations gathered are framed by an ethnographic approach of which semistructured interviews are the keystone. The method resulted in a rich data set gathered from participants who seemed at ease, demonstrated by their willingness to engage and develop conversational topics in detail, in addition to explicit evidence of benefit provided to several interviewees. The resulting hours of recorded interviews from generous participants coupled with my ethnographic knowledge demonstrates how the guiding critical realist philosophy can influence the direction in which research moves. The results of this distinct approach are presented in the following analytical chapters, the first exploring the basis of our social world: the material. 

Whatu ngarongaro te tangata, toitu te whenua. People will perish, but the land is permanent.

-WHAKATAUKī (MĀORI PROVERB)

The analytical chapters of this thesis begin at an unusual point. The physical and social structural foundations are charted first in order to provide the basis for the subsequent chapters which work 'downwards' (if Blommaert's 2007 metaphorical direction is accepted) to 'lower-scale' or more momentary and local phenomena; from sociocultural and subnational discourses to the specific linguistic aspects of identity genesis in interaction. Thus the general move of the analytical chapters is from structure to agency. Bhaskar (1979, p. 25) argues for a similar deliberate ordering of his work A Realist Theory of Science, stating that

It reflects the condition that, for transcendental realism, it is the nature of objects that determines their cognitive possibilities for us; that, in nature, it is humanity that is contingent and knowledge, so to speak, accidental.

For a critical realist study it is imperative to first attempt to hypothesise the nature of structures which underpin discourse. All of the structures examined in this chapter have discursive components, as discourse is the means through which we can come to know them. However, as critical realism suggests, it does not follow that structures are entirely discursive (Sayer, 2000). This chapter thus examines three examples of structural constraint that appear to influence the discourses that are indexed by participants and hence their political identities. This occurs with the caveat that the 'real' nature of these structures cannot be accessed through a discursive lens; we can only hypothesise as to their composition based on the events that they produce and we experience (Collier, 1994). As discussed in Chapter 4, 
discourse analytic work from this perspective seeks to analyse 'the relations between discourse and non-discoursal elements of the social, in order to reach a better understanding of these complex relations' (Fairclough, 2005, p. 924). This chapter attempts to shed light on this interface with a particular emphasis on the extra-discursive side of the equation.

It is also necessary to stress that the separate nature of the analytical chapters does not suggest the separation or isolation of different components of discourse. For the purposes of this thesis it is helpful to imagine each analytical chapter as a spotlight directed at a certain part of the discursive system, shedding light on its nature and reproduction, while maintaining the connection to other levels of discourse and the extra-discursive (see also Gee, 2014, p. 52, who views 'big-D' discourses as inclusive of 'language, action, interaction, values, beliefs, symbols, objects, tools, and places'). Extra-discursive referents are couched in discourse at all levels and as such underpin all of the discourses identified in later chapters, even though they may not take analytical centre stage. This chapter, in its emphasis on these referents, seeks to illustrate how critical realism can contribute to widening the scope of constructionist discourse analysis of identity genesis by first exploring the context in which it is generated.

The first section introduces the setting and context of the study, leading into a discussion of the political system of New Zealand, which is necessary to contextualise the environment in which the discussions take place. The subsequent sections cover some of the most prominent extra-discursive aspects that affect the discourses of other levels. The first is the country's physical geography, particularly its relative isolation to other countries (Walrond, 2013), and seeks to examine how this may have observable effects in the discourse of participants. Inequality is then explored, investigating how wealth disparity and physical poverty exists in New Zealand and how this is raised as a topic of considerable interest for several participants. The final section examines the demographic context of the country, in particular the complex relationship between Māori, Pākehā and ethnic minorities, and attempts to show how reference to this context is present in participants' discourse. 


\subsection{SETTING AND CONTEXT}

Aotearoa New Zealand is a relatively small and geographically isolated democracy in the South Pacific and its isolation is bound up within a colonialist ideology, as discussed in Section 6.2. Its founding document, te Tiriti o Waitangi/the Treaty of Waitangi, signed by the British Crown and Māori chiefs on 6 February 1840, symbolised the beginning of the nation-state. Its strong ties to its imperial overseer, Britain, initially critical to its early prosperity and protection (Lipson, 1948/2011, p. 457), have gradually lessened in importance through a broadening of its export economy and an ongoing desire to assert its independent modern character. New Zealand's unique culture is influenced by both the majority Anglo-European settlers (known as Pākehā) $)^{1}$ and the indigenous Māori. It has developed into a modern multicultural state with a significant Asian and Pasifika population (Statistics New Zealand, 2015b). New Zealand was, in the post-war period, considered the leader of the world in terms of social equality, regarded as a 'social laboratory' where there was a lack of income disparity, a generous 'cradle-to-grave' social welfare system, high political participation and full male employment (Hawke, 1979, p. 379; Lipson, 1948/2011, p. 457). New Zealand has a history of priding itself in being world-leading despite its relatively small population, politically in respect to women's suffrage (instituted in 1893) and also through the global recognition of the efforts of certain individuals, including Hillary's pioneering ascent of Mount Everest, Rutherford's splitting of the atom, Mansfield's literary work and Batten's achievements in aviation (characterised as 'performance orientation' by Kennedy, 2008, pp. 406-407; see also Chapter 7). This mentality carries through to the modern day, most visibly in the focus on international sporting success, particularly in rugby union (Crawford, 1985; Phillips, 1996). New Zealand's colonial history has left an indelible impression on its national psyche, as has the culture and language of the Māori. While expressed within particular ideological frames, these attributes contribute in many ways to the nature of interaction gathered as part of this study and therefore to the way in which participants generate their own identities.

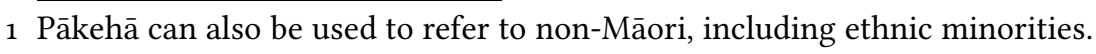


The data collection for this study was carried out in Te Whanganuia-Tara (Wellington), the capital city of New Zealand, over six months from November 2012 to May 2013. Wellington is the third most populous city in New Zealand, with around 191,00o usually resident inhabitants, following Ōtautahi (Christchurch), with 341,00o, and Tāmaki Makaurau (Auckland), with 1,416,00o (Statistics New Zealand, 2015b). By international standards, Wellington is a small city, and combines the conveniences of such with the status of a capital city. It is located at the southernmost point of Te Ika-a-Māui/the North Island, its centrality in the country being the justification for the presence of the House of Representatives (Martin, 2004, p. 40). The location of Wellington is shown in Figure 3.

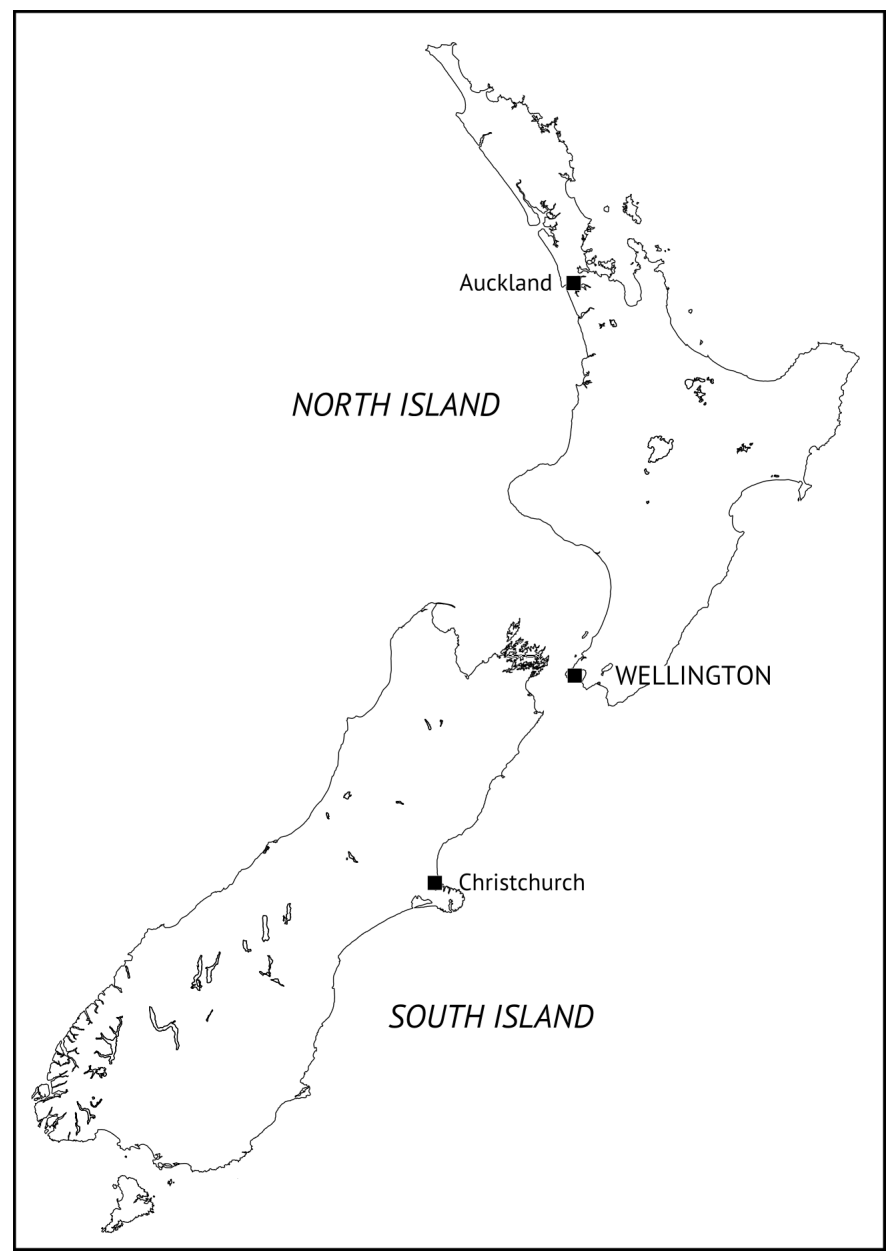

Figure 3: Map of New Zealand. 
Wellington was the obvious choice for carrying out a study of this kind: in addition to being the seat of government and location of Parliament, it is the centre of New Zealand's civil service and hosts the headquarters of all government ministries. It is not uncommon to see high profile politicians in the local supermarkets, retail stores and walking through the city's streets (occasionally in casual attire), making the perceived accessibility and relevance of the political life of the country more prominent in the capital (see, for example, the discussion with Cate and Michelle presented in Chapter 8). At the 2011 general election, which occurred just prior to data collection, $82.41 \%$ of those registered on the general roll in the Wellington Central electorate voted, the highest turnout in the country (the national turnout was $74.21 \%$; Electoral Commission, 2015). In 2014, Wellington Central again recorded the highest voter turnout in the country (84.6\% of those enrolled on the general roll voted). In 2011 , the following top four voter turnouts were in electorates located in the greater Wellington region (Ōhāriu, Rongotai, Ōtaki and Mana). Wellington region electorates also ranked in the top seven for turnout in 2014. These areas are shown in Figure 4.

Politics is also a prominent feature of Wellington city's physical landscape. Parliament occupies a significant downtown area and is readily visible from the main railway and bus stations, in view of those commuting from places across the region. Through sheer physical presence alone, coupled with the prominence of ministry buildings across the city, the machinery of central government is hard to ignore. Politics is both visible and accessible; members of the public can enter the grounds of Parliament and the House of Representatives at most times, and the public gallery of the debating chamber is a popular place for citizens to witness New Zealand's democracy in action. In general, New Zealand politicians tend to welcome interaction with their constituencies through their local offices and often increase their profiles by attending local events, providing interviews to community radio stations and communicating online through social media such as Facebook and Twitter. Members of Parliament (MPs) in New Zealand are, anecdotally, more visible and accessible than in many other large democracies around the globe. ${ }^{2}$

2 This is an observation from my own experiences working and living overseas. New Zealand does, however, consistently rank as one of the least corrupt countries in 


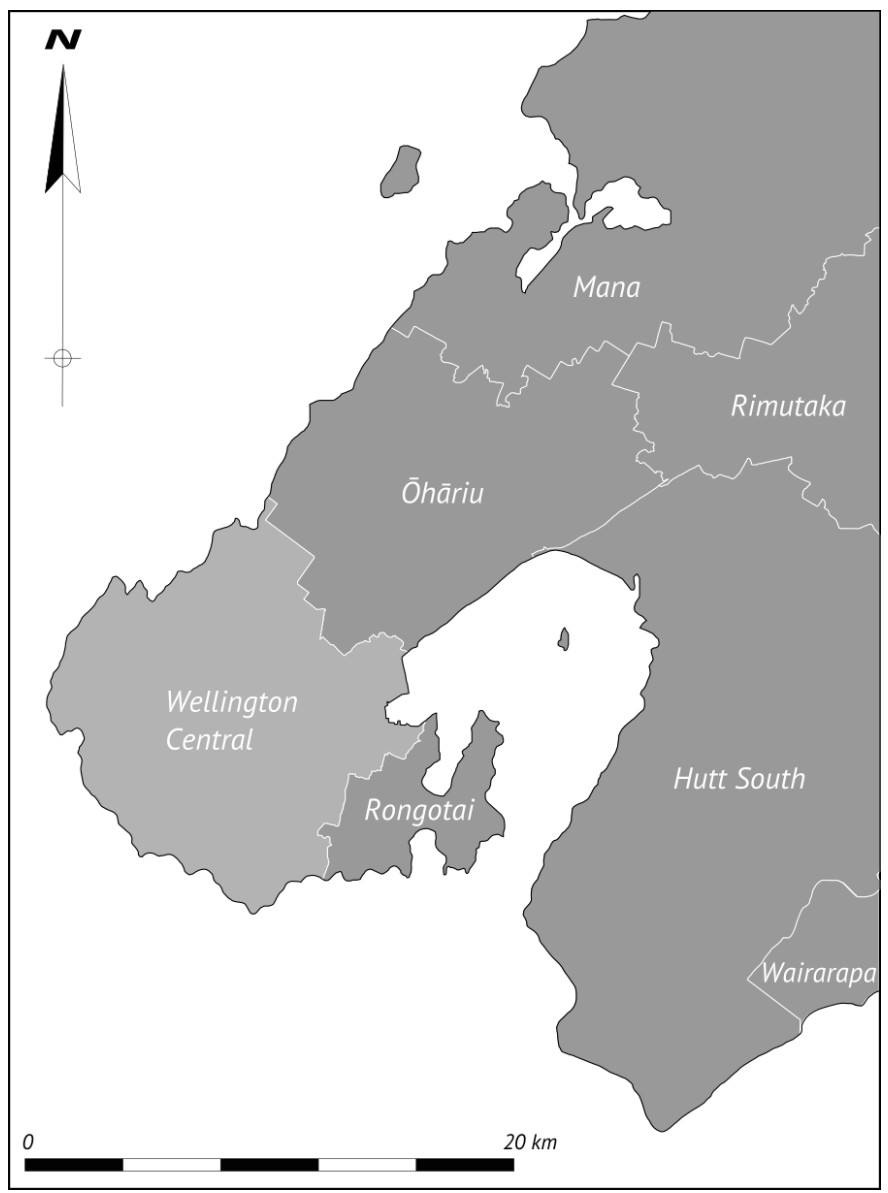

Figure 4: Map of electorates in the Wellington region.

New Zealand has 78 local authority bodies representing cities, districts and regions within the country. This includes 11 regional councils, 54 district councils, 12 city councils and one amalgamated Auckland council (Department of Internal Affairs, 2011). City councillors, and to a lesser extent regional councillors, appear at many important city events, such as formal openings, protests, parades and university graduation ceremonies. However, political engagement as measured by local election turnout bears a very different story than that of New Zealand's national politics: only $41.7 \%$ of registered voters in Wellington cast a vote in the 2013 local elections for mayor

the world in Transparency International's Corruption Perceptions Index, ranking second in 2014 (Transparency International, 2014). This goes some way to support these impressions. 
(Department of Internal Affairs, 2015). Regional council elections present a similar picture: Wellington had a $42.3 \%$ voter turnout in 2013. The reasons for such low levels of engagement with local politics are likely numerous and remain outside the scope of this thesis, though the dearth of interactions in the data set that broach the topic of local politics lends support to Wellingtonians' lack of enthusiasm for both regional and local governance.

\subsubsection{New Zealand's Political System}

A detailed introduction to New Zealand's political system is best left to specialist introductory texts such as those by Gold (1992), Miller (2006) and Mulgan (2004). This section presents only a brief description as considered necessary to contextualise the data gathered for this study.

New Zealand is governed by a unicameral Parliament, comprising the House of Representatives, the Sovereign as head of State and the Sovereign's representative in New Zealand, the Governor-General (Office of the Clerk, 2013). The House of Representatives usually has 120 members and is democratically elected in no more than every three years (Office of the Clerk, 2013). Since 1996, the Mixed Member Proportional (MMP) system has been used to elect MPs, superseding the First Past the Post (FPP) system. This has led to various 'minor' parties gaining representation in Parliament, provided they exceed the five per cent party vote threshold or win an electorate seat. The adoption of MMP also means that it is difficult for a single party to gain a majority (Mulgan, 2004, p. 102) and coalition negotiations with minor parties are usually necessary post-election. Voters register on either the general roll or the Māori roll (which is optional for those of Māori descent) and are given two votes: a party vote, through which a voter selects their political party of choice, and an electorate vote, which corresponds to the electorate where the voter resides and is the vote through which local representatives are elected. It is a legal requirement to be enrolled but voting is not compulsory (Electoral Commission, 2013).

The two 'major' parties are the New Zealand Labour Party (Labour) and the New Zealand National Party (National). Labour was formed in 1916 from the trade union movement, aligning with workers and 
their families, and has long been associated with humanitarian and socialist principles (Mulgan, 2004, p. 238). National, formed in 1936 in opposition to Labour's move into socialism, has been characterised as a functionalist, 'liberal-conservative' party (Miller, 2006; Mulgan, 2004, p. 239). After the 2011 general election of the 5oth New Zealand Parliament, the Government was formed by the National Party in agreement (known as 'confidence and supply') with the Māori Party, ACT and United Future. A list of the parties in Parliament after this election ${ }^{3}$ and their levels of support are outlined in Table 5 .

New Zealand has a unique political context which has a significant influence on the talk of the participants, as shown throughout the analytical chapters. The next section looks into how geographical reality, in particular the isolated nature of the country and small population base, arises in talk, which forms the material backdrop for discourses and identity.

\subsection{GEOGRAPHICAL REALITY OF THE SMALL COUNTRY}

New Zealanders are often told about the isolation and remoteness of their country relative to the old centres of Empire (Siegfried, 1914). This was once blamed for a lack of cultural and academic opportunities which some have labelled 'small country syndrome' (Walrond, 2012). The country's isolation is in part an explanation for why young Kiwi adults take part in what is known as the 'Big OE' [overseas experience], a rite of passage that involves departing our remote shores for an extended journey around the world, most often to Britain (Bell, 2002; Mason, 2002). The discourse of the isolated and small country occurs in relation to its physical geography, propelled by an Anglocentric view of the world which was central to the development of the colonies. Indeed, from England, New Zealand is a long way away.

André Siegfried, a French academic visiting New Zealand in 1914, wrote that

3 The results of the 2011 election are provided here as this was the most recent election at the time of data collection. The composition of Parliament changed after the 2014 election, with National slightly increasing their majority (Electoral Commission, 2015). 


\begin{tabular}{lclll}
\hline NAME & Formed & LEADER/s & \% OF VOTES & SEATs \\
\hline $\begin{array}{l}\text { New Zealand } \\
\text { National Party }\end{array}$ & 1936 & John Key & 47.31 & 59 \\
$\begin{array}{l}\text { New Zealand } \\
\text { Labour Party }\end{array}$ & 1916 & David Shearer & 27.48 & 34 \\
$\begin{array}{l}\text { The Green } \\
\text { Party of }\end{array}$ & 1990 & $\begin{array}{l}\text { Russel Norman } \\
\text { \&otearoa/New }\end{array}$ & 11.06 & 14 \\
$\begin{array}{l}\text { Zealand } \\
\text { New Zealand }\end{array}$ & 1993 & Winston Peters & 6.59 & 8 \\
$\begin{array}{l}\text { First Party } \\
\text { Māori Party }\end{array}$ & 2004 & $\begin{array}{l}\text { Tariana Turia } \\
\text { \& Pita Sharples }\end{array}$ & 1.43 & 3 \\
$\begin{array}{l}\text { MANA } \\
\text { Movement }\end{array}$ & 2011 & Hone Harawira & 1.08 & 1 \\
$\begin{array}{l}\text { ACT New } \\
\text { Zealand }\end{array}$ & 1994 & John Banks & 1.07 & 1 \\
$\begin{array}{l}\text { United Future } \\
\text { New Zealand }\end{array}$ & 2000 & Peter Dunne & 0.60 & 1 \\
\hline
\end{tabular}

Table 5: Political parties represented in Parliament after the 2011 general election (Electoral Commission, 2015). 
The thing that first strikes us when, glancing at a map of the Pacific, we discover in the blue immensity of that ocean these two small islands, which seem even more insignificant by contrast with the massive framework of the Australian Continent, is their more than insular character, their enormous distance from anywhere, their complete isolation. (Siegfried, 1914, p. 3)

Siegfried's observation is pertinent to the critical realist view that there is an extra-discursive component to the country which structures the discourses of focus in this study. In other words, there is a geographical reality which underpins the way we talk and thus the way in which our political identities are eventually generated. New Zealand is indeed physically remote in relation to other landmasses. Our closest neighbour, Australia, is 1600 kilometres to the west, Polynesia the same distance to the north and the Americas some 10,000 kilometres to the east (Walrond, 2013). The capital, Wellington, is 19,000 kilometres from London. In terms of physical size, New Zealand cannot be considered small given the land area is 270,000 square kilometres, larger than that of the United Kingdom (243,000; The World Bank, 2015). The population density of New Zealand is comparatively low, with 17 people per square kilometre, compared to the United Kingdom's 265. New Zealand's population, around 4.5 million at the time of writing (Statistics New Zealand, 2015a), is similar to that of Sydney, Australia. It is unsurprising that a popular image exists of relative remoteness and, at least outside of Auckland, population sparsity.

In light of the cyclical, iterative analysis as discussed in Chapter 5, it is useful to see how physical referents may appear in interactional discourse with a view to examining the relations between the two domains. A query of the data set for 'small' and its stems, including antonym 'big', returns, among other things, much reference to New Zealand as a 'small country.' Participants seem to draw on many connotations of the word 'small', including reference to limitations in geographical, economic and demographic size. To a certain degree, every instance of the small country discourse, as presented in the excerpts below, appears to include within in it reference to the physical configuration of the country's islands, albeit indirectly (Ochs, 1992, 1993). 
The discussion with Desmond, in Excerpts 6.1a and 6.1b, show orientation to the small country discourse which, as argued above, is constrained by physical structures.

Excerpt 6.1a

Desmond Morain, 73-77 year old NZ European/Pākehā male

Setting: Desmond's living room

Context: I have asked Desmond what he would like to see in terms of a political vision for $N Z$.

Time: 17:30.2-17:54.9

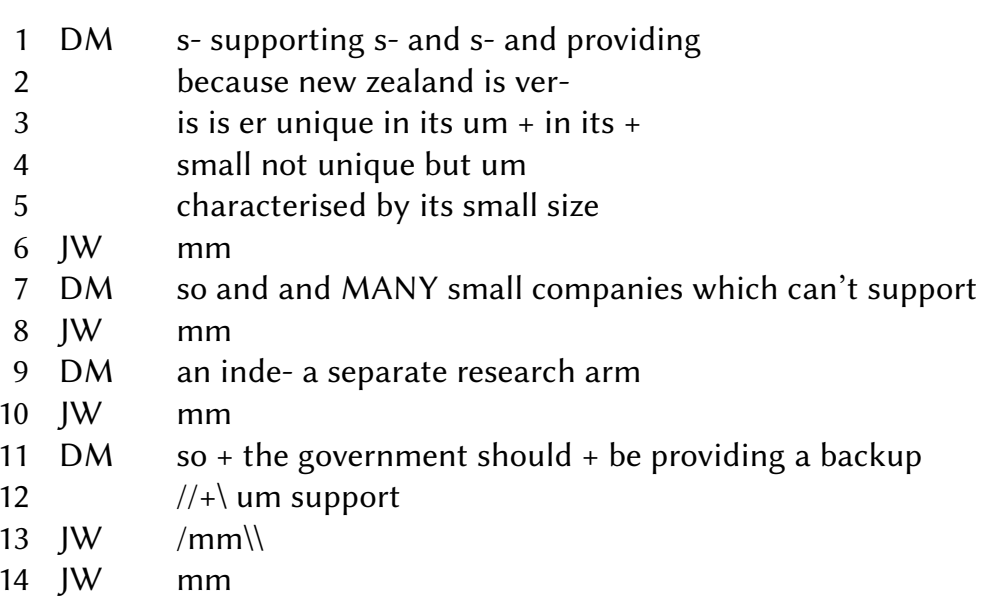

\section{Excerpt $6.1 \mathrm{~b}$}

Context: We have been talking about Desmond's concerns with climate change.

Time: 33:35.5-33:48.5

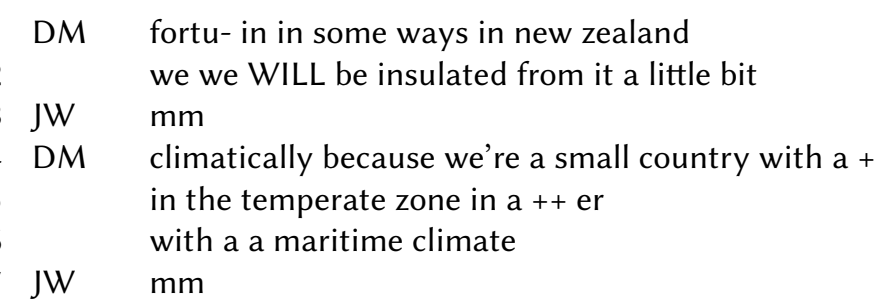

In Excerpt 6.1a Desmond refers to New Zealand's small size (line 5) though it is ambiguous as to whether he refers to geography or population. In light of his subsequent comment so and and MANY small companies (line 7), there is an indication that his earlier use of small size (line 5) indexes economic concerns as well. This demonstrates 
that extra-discursivity need not be physical, in terms of geography; it can also refer to social structures, such as economic systems, which are 'relatively enduring' (Bhaskar, 1979, p. 49) and have mechanisms of their own. Interestingly, he then links it to a political evaluation (line 11), demonstrating how the structural background can affect stancetaking. In Excerpt 6.1b, the referent of small country (line 4) is more clearly physical, as the utterance occurs in the context of a discussion of climate change followed by reference to geographical location and climate (lines $4^{-6}$ ).

Further ambiguity arises in Excerpt 6.2, where Cate indexes the discourse of small country which in turn points to an ambiguous referent (Ochs, 1992, 1993).

\section{Excerpt 6.2}

Cate Mclver, 18-22 year old NZ European/Pākehā female Setting: Wellington café

Context: Cate is characterising Labour voters in reference to more conservative businesspeople and investors.

Time: 28:51.3-29:09.9

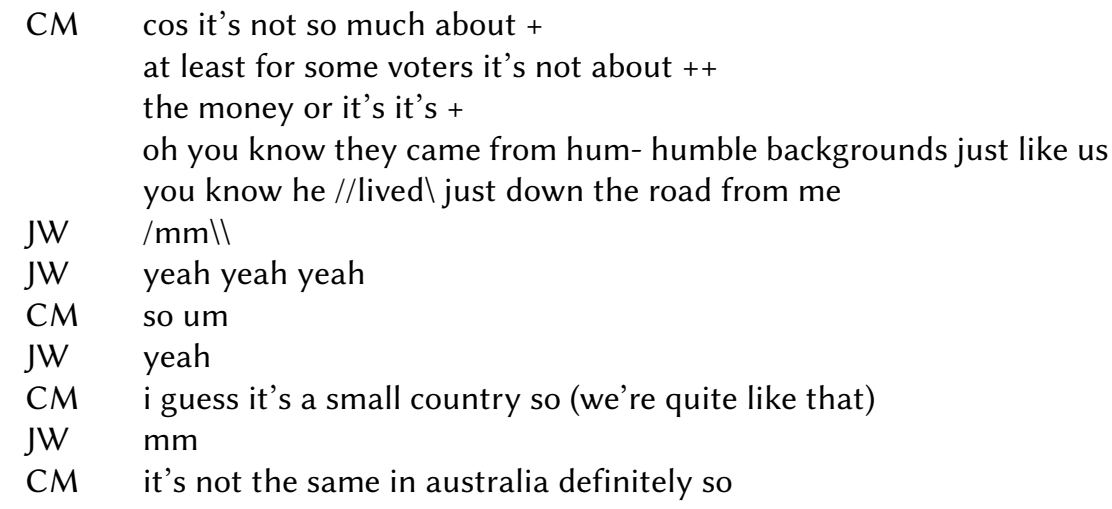

The context helps to determine to which sense of small the participant is referring. In Excerpt 6.2, Cate's use of the noun country (line 10) and comparison to australia (line 12) suggests that she is either indexing the physical connotation of small (line 10) or New Zealand's relatively small population. This is complicated by the fact that context indicates she is concerned with a feeling of neighbourliness and 'everyone knows everyone' (see Chapter 8) that she states is valued by some voters, evidenced in her utterance you know he lived just down the road from me (line 5). The referent of the small country 
discourse is therefore ambiguous, as the label small country can simultaneously index multiple meanings of small. Nevertheless, the ambiguity is introduced through the medium of discourse, and the physical structures indirectly indexed by her utterance, whatever they may be, remain. Again, this is in the context of political stancetaking, as she evaluates Labour voters and thus positions herself.

Christen, in Excerpt 6.3, provides again a clearer physical usage of small within the small country discourse, and repeats the observation that New Zealand is in 'complete isolation' (Siegfried, 1914, p. 3).

\section{Excerpt 6.3}

Christen Page-Brown, 18-22 year old NZ European/Pākehā female Setting: Wellington café (outside)

Context: We have been talking about the politics and global influence of the United States.

Time: 51:06.0-51:25.5

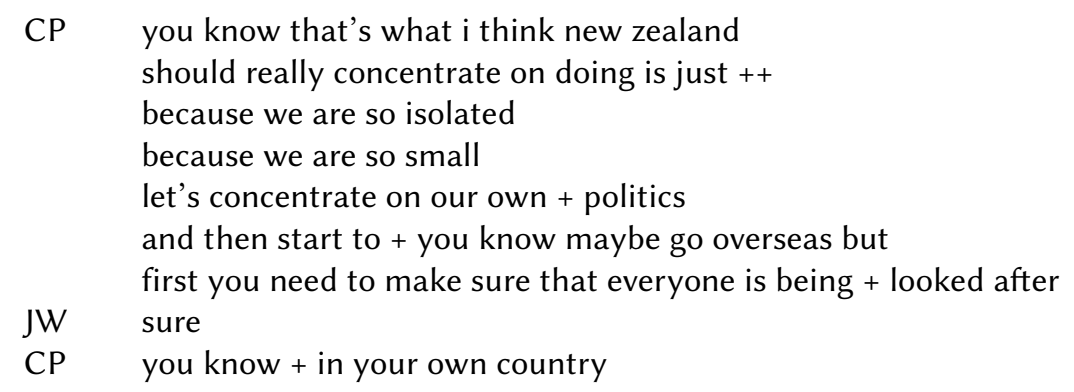

Christen uses small (line 4) alongside isolated (line 3) which indicates that the referent is, at least partially, the country's physical geography. The context of the discussion is talk about the influence of the United States, so discursive ambiguity is again introduced: small could possibly refer to population size or even global political clout. What this suggests is that extra-discursive referents are only indirectly implicated; Christen indexes a discourse (small country) which then in turn indexes its extra-discursive reality.

What the above excerpts indicate is that participants' use of small has the potential to index various discourses, depending on the wider interactional context, which in turn point to extra-discursive referents. A critical realist approach stresses the fact that while ambiguity is introduced by participants in interaction, and meaning negotiated in situated context, the extra-discursive referents remain 
unchanged, whether it is physical geography or more social referents such as population or economics (Sayer, 2000). In the case of the above excerpts, the referents indirectly accessed by the participants, whether geographical, demographic or economic, have real existence beyond the discourse which calls them forth. This has implications for the way in which identity is generated on-the-ground, as explored further in Chapters 9 and 10.

The next section shifts focus to more social aspects of structure, that is, the historical and political structures that inform the understandings of inequality in New Zealand, a topic which is of concern to several of the participants.

\subsection{THE REALITY OF INEQUALITY}

Poverty and inequality, most often manifested in interactional discourse in this study as acknowledgement of an income gap in New Zealand society, have structural aspects that transcend the discursive (Houston, 2001). The way in which discourses of inequality reference these extra-discursive referents varies depending on the situational context. In this section, these structural influences are examined as they are indirectly accessed by the participants in the context of their political stancetaking.

On 21 February 2002, New Zealand's then Prime Minister and leader of the Labour Party, Helen Clark, told an audience at the London School of Economics that

Our nation's modern history has been one of relative decline. From the contentment and prosperity of the early 1950s, New Zealand failed to innovate and renew its economy and institutions. Change when it came from 1984 lacked balance, produced growing inequity, failed to deliver a turnaround, and lacked popular support. (Clark, 2002; also cited in Nolan, 2007, p. 119)

Clark's reference to New Zealand's 'relative decline' is framed in terms of her government embarking on a series of progressive reforms after the outcomes of the market-oriented reform agenda of the Labour government of the mid-eighties, popularly known as 
'Rogernomics.'4 The 'golden days' of the 1950s had evaporated and Clark positioned her government to continue picking up the pieces.

The notion of decline in Clark's terms is broad and ill-defined, though given her audience the assumption can be made that her primary reference point was economic. Economic issues include concerns with income, and if decline is viewed in terms of deepening income inequality, then it has indeed been sharp: the gap between the rich and poor in New Zealand has widened dramatically since 1984 (Podder \& Chatterjee, 2002; Rashbrooke, 2013). Income inequality is important not only because it strikes at the heart of our value of fairness, as propagated through the egalitarian discourse (Chapter 7), but also because a high level of income inequality is associated with lower social cohesion, poorer health and reduced economic growth, all of which affect the whole of a society, not just the poor (see Rashbrooke, 2013; Wilkinson \& Pickett, 2010). A UMR Research survey, carried out in 2013 for the Labour Party, found that

Only 24 per cent of New Zealanders now believe that New Zealand is an egalitarian society, 71 per cent believe the gap between the rich and poor is widening and 78 per cent believe that the overall effects of the widening gap between rich and poor have been bad. (UMR Research, 2014)

There is no doubt that New Zealand faces challenges with increasing income inequality and poverty. This is a complex topic that is presented clearly and accessibly in Rashbrooke's (2013) edited volume, 'Inequality: A New Zealand Crisis'. In terms of its relevance to the topic of this thesis, the extra-discursive aspects of poverty and inequality in New Zealand, including the state of material deprivation and the associated social and political structures that contribute to its relative permanence (Houston, 2001), provide a foundation and extra-discursive reference point for the discourses drawn on by the participants, and again form part of the structural context in which identities are generated.

4 Rogernomics is named for the then Minister of Finance, Roger Douglas. It involved opening New Zealand's markets and privatising state-owned assets (see Walker, 1989). 
In light of the increasing levels of inequality in New Zealand, a general sentiment of decline arises in the discussions. The fact that inequality seemed to concern many participants, and also the simple fact that the growing presence of inequality is treated as a decline at all, strengthens sociocultural orientations to egalitarianism and characterisation of its erosion (see Chapter 7). Below are some examples that demonstrate how participants oriented to inequality and poverty in conversation in the context of their political stancetaking. In Excerpt 6.4, Joe, in direct reference to the egalitarian discourse, links wealth and poverty to the erosion of egalitarianism and frames this in terms of decline.

\section{Excerpt 6.4}

Joe Branstad, 78-82 year old NZ European/Pākehā male Setting: Joe's living room

Context: Joe has told me how NZ used to be an egalitarian society.

Time: 48:53.7-49:09.3

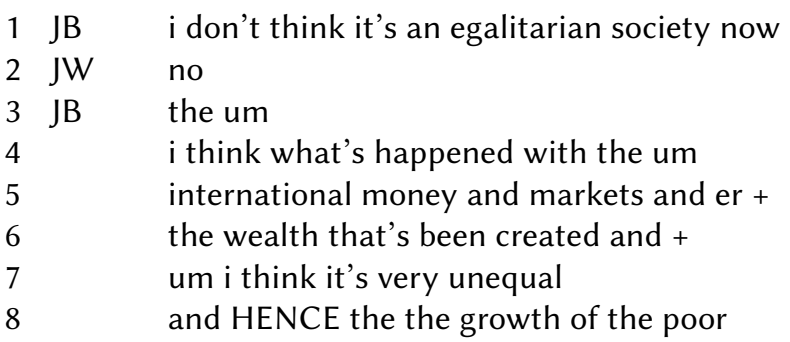

Joe makes direct reference to inequality with very unequal (line 7) and the growth of the poor (line 8). He attributes this to the wealth disparity brought on by economic reforms which opened New Zealand up to international money and markets (line 5) and as a result the wealth that's been created (line 6). The notion of decline arises from his comparison between the New Zealand he knew growing up to that of today, stating that $i$ don't think it's an egalitarian society now (line 1). How decline is conceptualised in this case seems to be rooted in the materiality of inequality, in other words, the deprivation of the poor. ${ }^{5}$ His concern with economic structures also indicates another set of extra-discursive referents that are indirectly accessed in his

5 Defining poverty is difficult, as it can be viewed in absolute or relative terms (Foster, 1998; Notten \& de Neubourg, 2011). In either case, the critical realist view is that it is underpinned by structures that exist outside discourse (Houston, 2001). 
talk. An extended version of this excerpt is analysed in more detail in Chapter 7 in reference to Joe's conceptualisation of egalitarianism as equality of opportunity.

Two participants in particular discussed poverty in detail. Michael talked about his own experience of growing up poor and Elizabeth talked about poverty in her area. Excerpt 6.5, from the discussion with Michael, shows how his experience of poverty affects the way in which he engages with politics, indicating how these structural influences are related to his political identity genesis.

\section{Excerpt 6.5}

Michael Teoh, 18-22 year old NZ Asian male

Setting: Wellington café

Context: I have asked Michael what the most important issue for him is besides the environment.

Time: 14:59.4-16:26.6

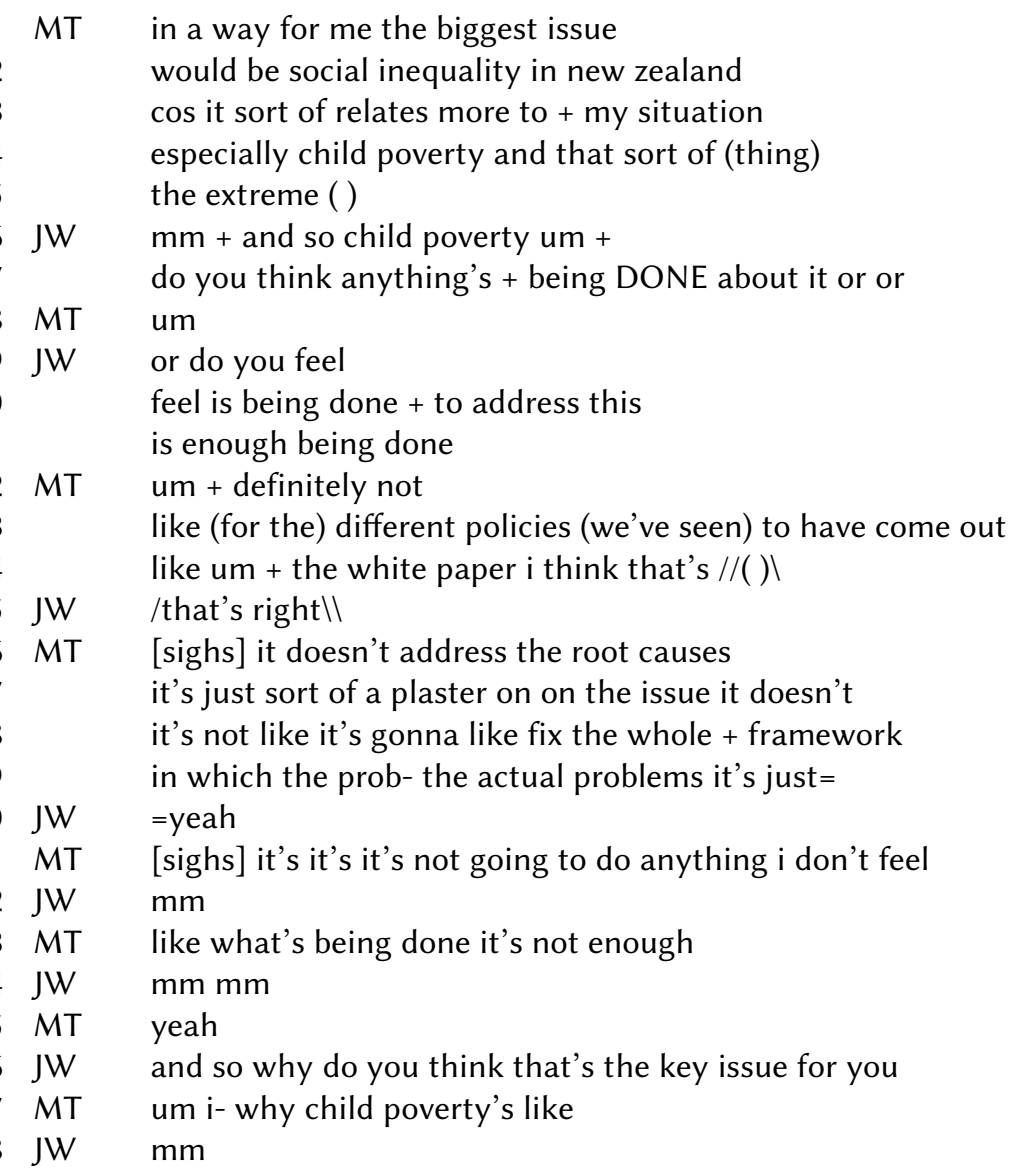




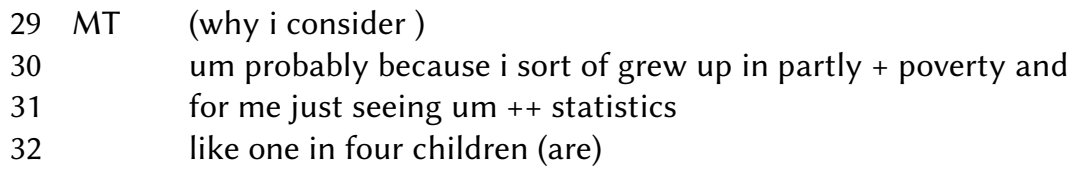

Michael mentions both social inequality (line 2) and child poverty (line 4) and cites his own experience as the motivator for his interest in these issues. He mentions that the white paper (line 14) is just sort of a plaster on on the issue (line 17) and argues that these political policies and documents do little to address structural inequality, it's not like it's gonna like fix the whole + framework (line 18). Michael appears to adopt a governmental register, reflected in his word choice: white paper (line 14), root causes (line 16), framework (line 18) and his citation of statistics, one in four children (line 32). This indicates a level of political awareness which is corroborated by his personal involvement in an international political organisation. His more formal phrasing could also be due to his relatively high level of discomfort due to my use of a more structured and visible questionnaire during his interview (see Chapter 5).

A critical realist reading of his utterances indicates a struggle on his behalf with the structural nature of inequality and the inability of political policies to make change, driven by his own experiences in childhood. The extra-discursive aspects of poverty are inextricably bound up in discourse, as poverty has numerous definitions and measurements (Piachaud, 1987) which are relative to context. The reality remains that poverty is a state of deprivation, whether economic, social, political or cultural (United Nations Development Programme, 1997), and these structures appear to have a level of extra-discursive permanence and hence causal efficacy (Bhaskar, 1979; Collier, 1994). They also clearly affect the way in which Michael portrays his political self.

Elizabeth also mentions poverty and inequality in New Zealand, though without a link to her own experience as in Michael's case. She does however locate her concerns to Wellington, highlighting that poverty occurs uncomfortably close to home. This is outlined in Excerpt 6.5.

\section{Excerpt 6.5}

Elizabeth Blake, 23-27 year old Māori/Pākehā female 
Setting: University library

Context: I have asked Elizabeth what issues matter to her the most.

Time: 8:51.9-9:47.2

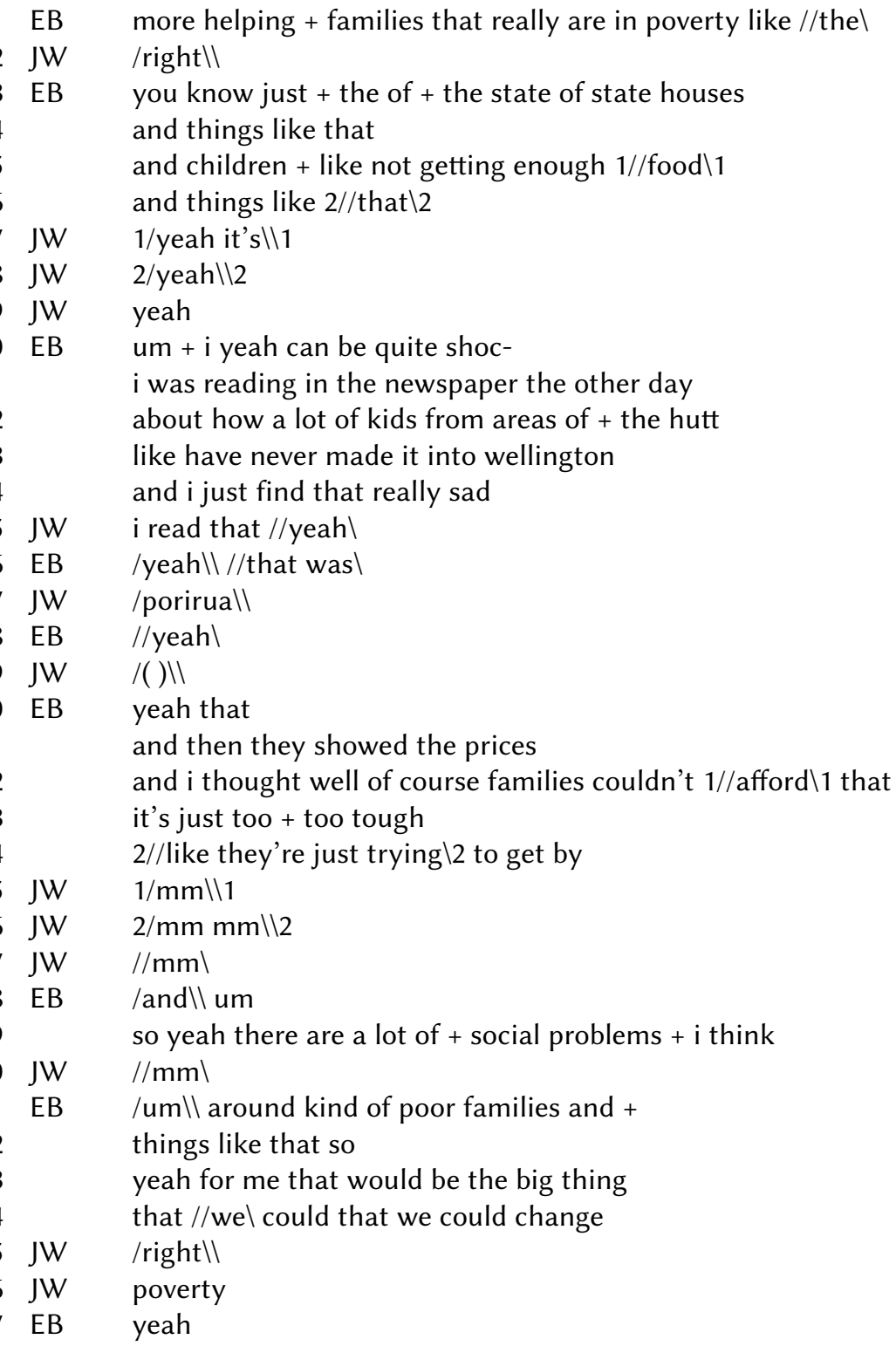

Elizabeth shows concern with families that really are in poverty (line 1) and their material circumstances, such as the state of state houses (line 3), referring to primarily Government-owned housing provided to those on low incomes, and children + like not getting enough food (line 5). She brings this somewhat abstract concern home by providing 
a narrative that functions to link her concern to the Wellington region, beginning with $i$ was reading in the newspaper the other day (line 11) and ending with her evaluation and i just find that really sad (line 14). Her finding that a lot of kids from areas of + the hutt like have never made it into wellington (lines 12-13) is quite shoc- [shocking] (line 10), considering that Wellington is only twenty minutes by train from Lower Hutt. I align with her, i read that yeah (line 15), and based on my recollection of the article, which I thought had not been in reference to the Hutt Valley, I suggest porirua (line 17), another town to the northeast of Wellington. ${ }^{6}$ This also indicates that the town names carry meaning for both of us in terms of their relationship to relative socioeconomic status.

While not as personal an experience as Michael's, Elizabeth's concern relates to her desire to see poverty eradicated, yeah for me that would be the big thing that we could that we could change (lines 33-34). Her concern about poverty again points to an extradiscursive, material state which structures the way in which she talks about it and therefore the political stances that comprise her identity. For example, the discourse of poverty in the New Zealand context is held in her mind to be linked to poor quality housing (line 3), nutritional deprivation (line 5) and financial difficulties (line 22). Again, certain social and political structures, each with their own causal mechanisms, also contribute to the structural reality of poverty in New Zealand to which Elizabeth indirectly orients.

Poverty and inequality are salient referents within the discourse of participants and as such influence wider sociocultural discourses, particularly that of egalitarianism, which are discussed further in Chapter 7. They are unfortunately growing social issues in New Zealand which some argue need urgent political attention (see, for example Boston, 2014; Boston \& Chapple, 2014; Rashbrooke, 2013). One important first step in addressing such inequality through discourse analytic work is to give theoretical support to structure, which critical realism provides (Houston, 2001), and which can then lead on

6 I was born and raised in the Hutt Valley which suggests a level of defensiveness on my behalf in this exchange. This is due to my past experience of a degree of general disdain and condescension from some Wellingtonians towards the Hutt Valley and its inhabitants. It is often hedged in terms of humour, though nevertheless still entails an element of 'othering' (Riggins, 1997). 
to emancipatory research designs (Chouliaraki \& Fairclough, 1999). In terms of this study, critical realist inspired research of structural factors sheds lights on the referents of individuals' identity work.

The following section explores the cultural composition of New Zealand and the important issues of biculturalism and multiculturalism which again are associated with extra-discursive structural touchstones. These are indirectly accessed by several of the participants during their political stancetaking.

\subsection{BICULTURALISM AND MULTICULTURALISM}

The influence of population on discourse has already been mentioned in terms of its connotation within the small country. The related issues of ethnicity and culture in New Zealand have a complicated and controversial history and it is necessary to acknowledge that they have an important influence on the discourse and stancetaking of the participants. This section seeks to examine how they are referenced in talk and why bi/multiculturalism can be considered to be, in part, extra-discursive.

Henry Demarest Lloyd, an American journalist visiting New Zealand at the turn of the last century, wrote in his 1901 work Newest England that

Its isolation protects it from tidal waves of heat, cold, immigration, fashion, speculation, or invasion. The people are likely to remain what they are-the most homogeneous Anglo-Saxon blend, the most harmonious constituency of our race there is anywhere-English predominant, Scotch next, Irish third. There is practically no other blood; the foreigners and Maoris are too few to colour the strain. (pp. 3-4)

Lloyd's main focus during his trip was progressive political policies such as public ownership and compulsory arbitration (which he wrote about at length in A Country Without Strikes, 1900). His opinion of the ethnic composition of the colony, which from today's perspective reflects hegemonic colonialism (see Smith, 1999), demonstrates a popular view of the time and is echoed in the title of his work: New Zealand was the Newest England; as a colony it was treated as an 
extension of, or 'political laboratory' for, Great Britain (Lloyd, 1900, p. vii). Lloyd's visit coincided with the low point in Māori population, as disease had brought their number down to around 42,000 in the 1896 census (Hawke, 1985, pp. 20-21), whereas Pākehā had risen to over 703,000 (Registrar General's Office, 1897). Swept away as Lloyd was by the notion of a newly-founded Anglo-Saxon paradise, he would have likely been unable to predict how both Māori and Pākehā would shape Aotearoa New Zealand's national identity in the century to come.

The general consensus amongst archaeologists is that Māori have been in Aotearoa since the late thirteenth century (Anderson, 1991; McGlone \& Wilmshurst, 1999; Smith, 2008; Walter \& Jacomb, 2008), some 600 years prior to Lloyd's visit. In 1769, Captain James Cook estimated the Māori population to be approximately 100,00o (Pool, 1991), and at the signing of the Treaty of Waitangi in 1840, Māori 'outnumbered the 2000 Pākehā... by something like 40:1' (Pool, 1991, p. 58). Despite dismissing Māori as no threat to Anglo-Saxon blood, which happens to ignore the historically high levels of intermarriage between the two groups (Wanhalla, 2008, 2013), Lloyd held the Māori in high esteem and commended them for their 'strength, bravery and intelligence', noting that their influence 'has left deep marks and beneficent ones on the social institutions of the country' (Lloyd, 1901, pp. 6-7). From today's perspective, Māori influence extends much further than the original designs of New Zealand's institutions. Howe (2008) notes that Māori culture has played an important role in national identity, distinguishing New Zealanders from the colonists of other countries, particularly in reaction to an emergent Australian outback frontier identity. Howe observes that 'intellectuals... [plundered] Māori culture for national emblems which they embedded in painting, literature, and music' (p. 169) and goes on to say that while New Zealand failed in being branded as 'Maoriland' in the early twentieth century due to a preference for displaying 'prowess in rugby and war', it is the case that

many remnants of a public symbolic celebration of New Zealand's Polynesian heritage remain, such as on coins and banknotes, the koru emblem on the tails of Air New Zealand planes, and aspects of Maori protocol in public events such as a haka before an All Black rugby game, or 


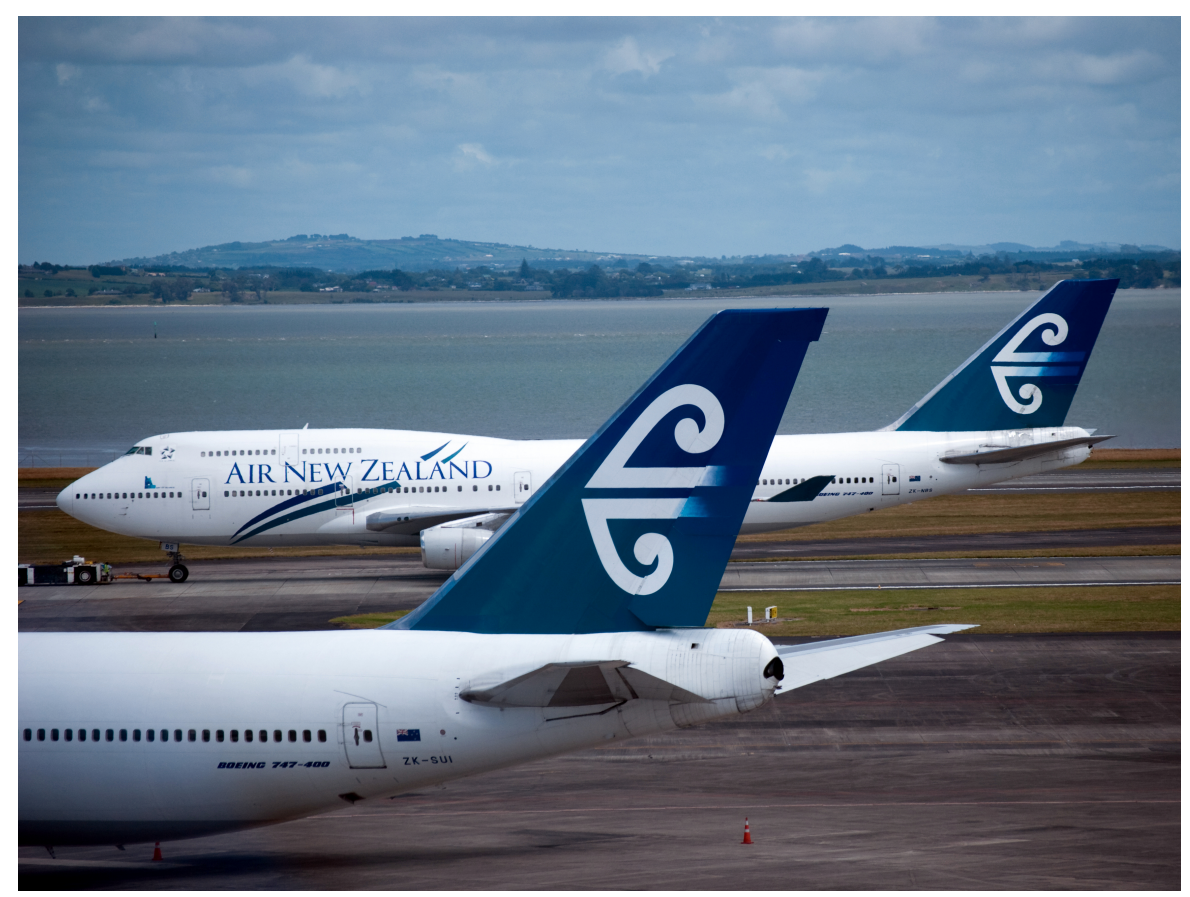

Figure 5: Air New Zealand 747-400 aeroplanes displaying the koru.

challenges and welcomes to visitors on civic ceremonial occasions. (Howe, 2008, p. 171)

Such uses of Māori cultural symbolism, as depicted in Figure 5, have been labelled the neoliberal appropriation of indigenous culture (Smits, 2014; see also MacLean, 1999), but there is no doubt that Māori culture is a core aspect of what it means to be from Aotearoa New Zealand particularly in light of the fact that today over 598,00o people identify as Māori, making up 14.9 per cent of the population (Statistics New Zealand, 2015a).

The question for New Zealand has been, and continues to be, whether it defines itself as a bicultural or multicultural nation (Hill, 2010; Pearson, 2000). This is a contentious issue which Fleras (2011, p. 127) summarises is the result of a tension between two views; one side argues that the language of multiculturalism can background the role of Māori as tangata whenua [indigenous people], and the other that biculturalism can be dismissive of immigrant cultures (Mulgan, 1989; Smits, 2011). Both are salient points, the latter highlighting the historical marginalisation of some immigrant cultures; as Lloyd (1901, 
p. 357) observed, 'Asiatics are outside the law. The Australasian has no "open door" for the Chinese.' Today, New Zealand is composed of other large ethnic groups: in 2013, those of Asian descent numbered over 471,000 and Pasifika 295,000 (Statistics New Zealand, 2015b). Perhaps a satisfactory compromise to the language of bi/multiculturalism is the adoption of 'binationalism' alongside multiculturalism (Mulgan, 1989). Mulgan (1989, p. 9) succinctly notes that New Zealand can be most accurately described as 'one nation, two peoples, many cultures.' Questions remain about how this relates to the Treaty of Waitangi, an agreement between Māori and the Crown, and how it affects issues such as minority language policies (May, 2002, 2004).

The social, political and cultural structures that have endured across New Zealand's history inform the way in which we think and talk about bi/multiculturalism today. Particularly relevant to this study is their influence on the way in which national identity is generated in New Zealand (Liu et al., 2005). But they also have an extra-discursive existence, as do the institutionalised relations between different groups, which appear to have causal mechanisms of their own and thus constrain the discourse of race relations in the country. Below is a selection of excerpts that demonstrate how the binational Māori/Pākehā reality of Aotearoa New Zealand was referenced in the talk of participants, and which in turn point from indexed sociocultural discourses to these relatively enduring structures (Bhaskar, 1979). Again, this occurs in the context of political stancetaking.

In Excerpt 6.6, Jacqui compares New Zealand to Australia, informed by her experience living there.

\section{Excerpt 6.6}

Jacqui Cooper, 18-22 year old NZ European/Pākehā female

Setting: Wellington café

Context: Jacqui has been describing how she witnessed racial discrimination while living in Australia.

Time: 42:08.8-42:41.8

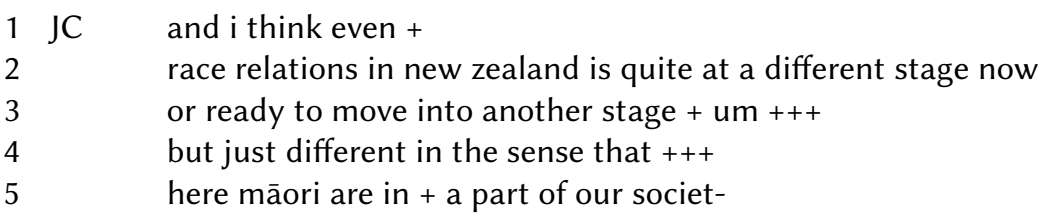




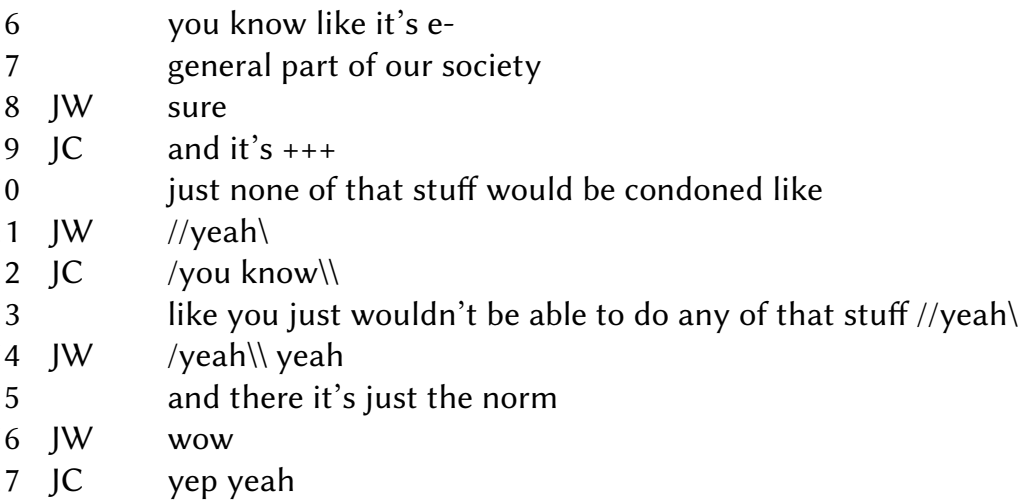

Jacqui raises the issue of race relations (line 2) and compares New Zealand to Australia in arguing that new zealand is quite at a different stage now (line 2). A narrative she tells immediately prior to this excerpt recounts her experience while she was living in Australia of witnessing an Aboriginal Australian subject to public abuse. This leads her to conclude that here māori...general part of our society (lines $5^{-7}$ ), which appears to have elements of a Māori 'other' in contrast to her Pākehā identity, and her repeated use of pronoun our (lines 5 , 7) indicates also an Australian 'other' in contrast to New Zealanders (Riggins, 1997). She then states that what she witnessed would not occur in New Zealand, just none of that stuff would be condoned (line 10). She ends her comparison by noting that there it's just the norm (line 15). It is evident that the social and historical context of relations between Māori and Pākehā underpin Jacqui's utterances in this excerpt. The extra-discursive referents that this indirectly points to are likely the sociopolitical structures and relations between people and institutions that have led to and sustain race relations discourse in New Zealand. These have an effect on the way in which Jacqui makes political evaluations throughout our conversation and thus has implications for her political identity.

These themes are also present in discussion with May, as shown in Excerpt 6.7.

\section{Excerpt 6.7}

May Potter, 18-22 year old NZ European/Pākehā female

Setting: May's kitchen

Context: May has mentioned that Scandinavian countries are monocultural societies so they do not have as many challenges as we have in New 


\section{Zealand.}

Time: 35:28.2-37:25.8

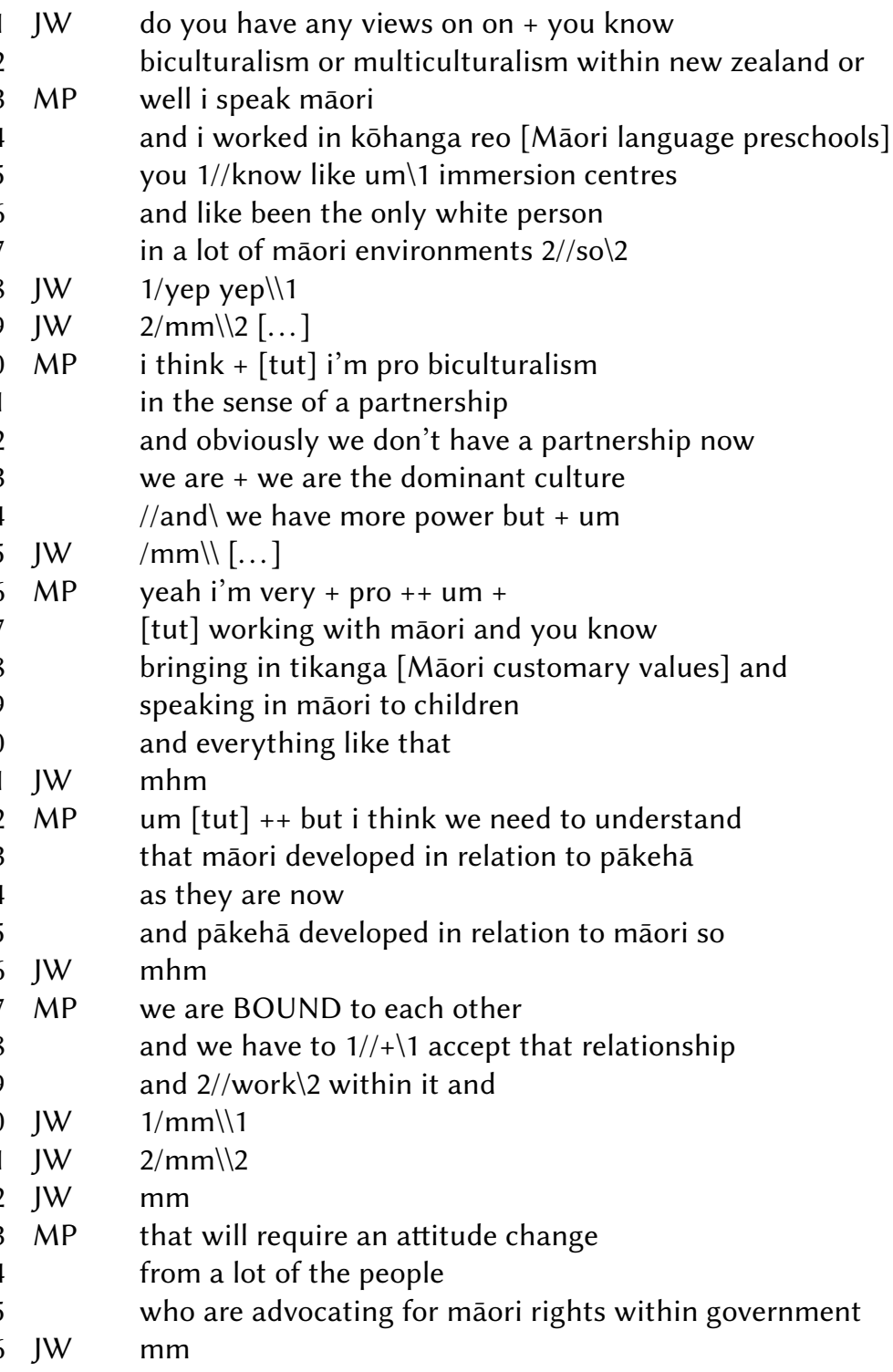

This very detailed and sophisticated discussion on May's part is again underpinned by the sociocultural and historical context of the country, underlain by a structural foundation. May provides her credentials at the beginning, noting that i speak māori (line 3) and that $i$ worked in kōhanga reo (line 4) and describes her experience as like been the only white person in a lot of māori environments (lines 6-7). Her particular view is pro biculturalism in the sense of a 
partnership (lines 10-11) and she continues on to eloquently state her view that māori developed in relation to pākehā as they are now and pākehà developed in relation to māori so... we are BOUND to each other (lines 23-27). This echoes the sentiments of Jacqui in that Māori and Pākehā are of the same society yet more work must be done; in May's case, she states that will require an attitude change (line 33). Perhaps not only a change in attitude is required to improve race relations in New Zealand. A critical realist reading suggests that a structural change must occur as well. In order for this to happen the social and political structures that sustain certain discourses must be identified and exposed (Houston, 2001). For example, a close critical examination of public or private institutional discourse may uncover systemic racism, which can then be challenged and changed. Again, the extra-discursive factors indirectly referenced in May's talk are the sociopolitical and institutional structures of the country, such as education and government, which influence her particular conceptualisation of the Māori and Pākehā partnership. They also appear to contribute more broadly to aspects of race relations discourse in New Zealand. Her own political stancetaking and identity is generated in light of these factors.

Biculturalism is clearly an important consideration in researching political identity in New Zealand. Multiculturalism is also raised by participants; for example, Chelsea makes explicit mention of Wellington as a multicultural city. This is discussed further in Chapter 8 as it appears to occur within the context of salient subnational discourses that relate to the nature of Wellington city within which many of the participants located their political stancetaking.

New Zealand as a bi/multicultural country appears to influence interaction in the data set particularly because of the political implications of the topic. As discussed in this section, there is a long and complex history and a contentious political background to the issue (Fleras, 2011; Hill, 2010; Mulgan, 1989; Spoonley \& Pearson, 2004) which informs the references made by participants. From this complex historical background, in which Māori experienced war, disease and colonisation (Pool, 1991), a set of relatively enduring social structures and relations has emerged. They have an extradiscursive reality which influences the discourse of race relations in 
New Zealand and thus the political identities of the participants in fundamental ways.

6.5 SUMMARY

A discourse analysis which ignores extra-discursive referents can only hope to provide a partial explanation. The analysis in this thesis is carried out with an awareness of the presence of these referents and as such brings another dimension to the analysis of the negotiation of meaning in interaction and the genesis of identities. The nature of the extra-discursive is however not always clear because we can only come to know it through the medium of discourse. They remain indirect references (Ochs, 1992, 1993), channelled through various sociocultural discourses, and obscured in their nature and origin. A critical realist approach suggests that even though we may know something through discourse it does not follow that it is entirely discursive. The discourses of small country, inequality and bi/multiculturalism discussed in this chapter all point, at least in part, to the extra-discursive, whether the physical geography of the country, material states of deprivation or the sociopolitical structures of relations between two peoples. These all provide a structural foundation for identity genesis in New Zealand and demonstrate the utility of critical realist analysis which takes these factors into account.

The extra-discursive underlies all analysis of discourse throughout this thesis. As the spotlight and analytical focus moves into the realm of discourse in the later chapters, the extra-discursive does not disappear. If humans, and hence discourse, were to disappear from the Earth overnight, the islands of what is known as Aotearoa New Zealand would remain. 
Even though it is a relatively 'young' democratic country (Liu et al., 2005), New Zealand has developed a set of sociocultural discourses that are reflected in the speech of many of its inhabitants and seem to transcend immediate local and individual contexts. Evidence for this is provided by my insider status as a member of the community in focus and is substantiated through exposure to popular media and social commentary. One such discourse that arose in the data set is that of egalitarianism, a distinctive ethos that has defined the country since its colonial origins (Lipson, 1948/2011, p. 457; Nolan, 2007). The analytical spotlight falls on this discourse and its supporting mechanism tall poppy, a levelling discourse which encourages humility and promotes the avoidance of overt displays of high status (Peeters, 2004a, 2004b). This chapter seeks to identify them as they appear in talk, providing further insight into the context of New Zealand political identity generation.

Sociocultural discourses have an important influence on the genesis of national identities. Wodak and Meyer (2009) view the nation as an 'imagined community' (Anderson, 2006), and national identity as a form of social identity that is negotiated in discourse (Wodak \& Meyer, 2009, p. 3). They define national identity as

a complex of similar conceptions and perceptual schemata, of similar emotional dispositions and attitudes, and of similar behavioural conventions, which bearers of this 'national identity' share collectively and which they have internalised through socialisation. (p. 4)

This recalls van Dijk's (2006b, p. 116) definition of an ideology, or shared beliefs that define a social identity, and as such is related to Bourdieu's notion of 'habitus', which is 'a kind of deeply structured cultural grammar for action' (Swartz, 1997, p. 102). Wodak and Meyer (2009, p. 29) argue that habitus forms a sort of 'national common sense' which is acquired through educational systems of the country. The 
sociocultural discourses identified in this chapter contribute in many ways to a 'New Zealander' or 'Kiwi' identity and its reproduction and transformation. They are also an important contextual factor in stancetaking, as explored in Chapters 9 and 10. This chapter focuses on the structure of these salient discourses.

The first section of this chapter outlines the historical context that gives rise to egalitarianism in New Zealand. From this background a model of the conceptual structure of the discourse is presented and then tested against the data. Egalitarianism is indexed by participants directly, in phrases such as egalitarian society, and it is also identified as being enacted in less overt ways, for example by orienting to the mitigation of hierarchy or authority. The supporting tall poppy discourse is then discussed, the historical background also providing evidence for its continuing influence in the country. Tall poppy appears to act as a levelling mechanism that sustains New Zealand's egalitarian 'myth' (Nolan, 2007), and the two discourses, as they are intertwined in complex historical context, appear to affect much of the political talk and thus identity work in this study.

\subsection{NEW ZEALAND EGALITARIANISM}

Egalitarianism is one of the central sociocultural discourses indexed in my data set and it thus forms an important component of the political stancetaking and identities of the participants. In order to demonstrate how the discourse of egalitarianism developed and gained its unique character it is necessary to start with the historical literature which documents a time when it was a particularly salient topic of discussion and interest in the country. This section lays the groundwork for the model of the discourse of egalitarianism which is presented in the following section.

Egalitarianism served as a particular point of difference for the young colonial nation of New Zealand. Colonists escaping the shackles of a relatively rigid class system in Britain embraced a land where class struggles were less pervasive (McLeod, 1968). By the early 2 oth Century, New Zealand's distinct version of egalitarianism served as a defining aspect of national identity in contrast to the 'Old World' (Olssen, Griffen \& Jones, 2011, p. 181). Prompted by the progressive reforms of the Liberal government (1891-1912), New Zealand was the 
first nation in the world where women won the right to vote (1893), the first to implement a system of compulsory arbitration (1894) and the first in the British Empire to introduce old-age pensions (1898; Hamer, 1988; Reeves, 1903a, 1903b). The Liberal reform programme resulted in New Zealand being viewed as 'a laboratory for social scientists' and attracted academics from around the world who came to bear witness to New Zealand's development (Hawke, 1979, p. 379; Phillips, 2014). Visiting French academic André Siegfried (1914, p. 48) observed 'that the little English Colony of the Antipodes has become the chosen land of the most daring experiments' and praised it for its 'absence of all aristocracy of birth, of title, or of wealth.' English Fabian socialists Beatrice and Sidney Webb, visiting in 1898, commented that 'it is delightful to be in a country where there are no millionaires and hardly any slums, among a people characterised by homely refinement, and by a large measure of vigorous public spirit' (Webb \& Webb, 1959, p. 54).

Leslie Lipson, American political scientist and author of The Politics of Equality: New Zealand's Adventures in Democracy (1948/2011), arrived in 1939 to a country that lacked the sharp divides in wealth that he had witnessed in the United States and Britain. Acknowledging that New Zealand's early 'lack of resources' may have inhibited the creation of vast wealth, Lipson nevertheless credited government policy as being a key driver of the egalitarian reality in New Zealand: graduated taxation, generous social welfare and widespread access to education, prompted by the early Liberal reforms, meant that differences in income were much narrower than other countries at the time (pp. 5-6). Perhaps Lipson's most famous, if rather simplistic, contention was that a democratic country could focus on either equality or liberty, with emphasis on one often being at the expense of the other (see also Fischer, 2012). Lipson noted that in contrast to the United States, where freedom is symbolised by their Statue of Liberty, New Zealand has a very different ideal:

In New Zealand, if any sculptured allegory were to be placed at the approaches of Auckland or Wellington harbor, it would assuredly be a statue of Equality. For equalitarianism is there regarded as the core of the democratic doctrine. If something good is to be had, then, the New Zealander will argue, let it be spread as widely as possible. 
The more who can participate, the better. Indeed it is undemocratic for any to be excluded from a share in the benefits that others enjoy. (Lipson, 1948/2011, p. 7)

Lipson noted that egalitarianism, or 'equalitarianism' in his terms, had thoroughly taken hold in one hundred years of nationhood, cementing itself as a core value of its citizenship and government. He argued that it was a trait which dominates and regulates everything that happens in the community (p. 449). Lipson's observation that an emphasis on equality meant a necessary restriction of liberty was borne out in a distrust of those that stood out from the crowd, with individual needs placed secondary to the goal of achieving and maintaining an egalitarian society. Lipson did not neglect these negative aspects of an egalitarian society, and identified the discourse commonly referred to as tall poppy, which is discussed further in Section 7.2.

Certain segments of society were however neglected in the country's egalitarian story; in particular, Māori and women are seldom mentioned (Nolan, 2007). The gender differential in egalitarian New Zealand was also picked up by Lipson in passing: 'There is no underdog, nor is anybody exploited-unless it be the housewife and mother' (p. 450). Nolan (2007) argues that the reason for such neglect is that New Zealand egalitarianism is based on the white male breadwinner model (p. 127) and Māori and women fit uneasily into this conceptual framework (see Nolan, 2000). Nolan further argues that today, amongst a backdrop of rising inequality (see Chapter 6), New Zealand's fascination with and pride in its egalitarian origins has become a sociocultural 'myth', or somewhat more pejoratively by other scholars, a form of 'delusional egalitarianism' (BönischBrednich, 2008, p. 7). Nolan (2007, p. 127) states that

Countries exude powerful self-images; New Zealand's particular attachment has been to an ideal of its own egalitarianism and consensus. Typically, this self-image draws upon a rich amalgam of truth and myth. Yet the realities have changed. Over the past century inequality has grown, and a new nostrum might now apply: once egalitarian does not mean always egalitarian. 
This calls for a close examination of the egalitarian concept. How does the egalitarian myth sustain itself today alongside rising social inequality? Part of the reason for this apparent contradiction is the fact, noted by economist Gary Hawke (personal communication, 21 January 2015), that the concept of egalitarianism has changed over time, from 'a focus on relationships among people from different occupations and social groupings', as present in the work of Lipson (1948/2011, p. 457), to 'the modern preoccupation with distribution of personal incomes', exemplified in the work of journalist Rashbrooke (2013). The social aspect of egalitarianism, which focuses largely on classlessness, appears to have drifted into myth and is replaced by an economic version focused on wealth. Widening income gaps are thus treated as an erosion of egalitarianism. These two aspects are apparent in the data, as discussed in Section 7.1.2.

One approach to clarifying the relationship between the social and economic aspects of egalitarianism is provided by the work of New Zealand and Australian sociologists. Pearson (1980, p. 170) argues that 'egalitarianism does not necessarily clash with visible inequalities, provided one is sensitive to how the "myth" is conceptualised.' In conceptualising egalitarianism for his study of Johnsonville, a small New Zealand township close to Wellington, Pearson (1980) draws on the work of Oxley (1974), who investigated the notion of mateship in small-town New South Wales, Australia. Oxley treats egalitarianism as an ideology, 'a set of ideas which guide action in terms of some basic concept of the human condition and destiny' (p. 44), and argues that it has two distinct subtypes: 'equal opportunity' and 'intrinsic equality'. As with any other ideology, it may be comprised of components that are 'logically distinct', as is the case with these two subtypes, which, as Oxley (1974, p. 45) notes, are inherently doomed to conflict. Equal opportunity, the first subtype, 'is only meaningful in the context of unequal rewards' and can sometimes be called upon to justify excessive stratification. Oxley $(1974$, p. 45) explains that a doctrine of equal opportunity 'is potentially compatible with any inequality not ascribed at birth; winners can have riches and losers rags so long as they raced from the same starting point.' In an equal opportunity system, people openly compete in the political, economic and social spheres; bringing winners and losers to the same level is not a concern as long as they have the equal opportunity to compete with 
one another. Intrinsic equality has a different emphasis in viewing people as inherently the same which suggests that equal rights to compete should be denied. Oxley $(1974$, p. 45) explains this further by noting that in effect [intrinsic equality] demands that the more and less able be unequally protected and unequally restricted.' In other words, the winners should be brought down and the losers raised up in order to preserve equality. This conceptualisation is evident in New Zealand's levelling mechanisms, helping those less well-off through social welfare support (McClure, 1998) and limiting those who are wealthy or successful through graduated taxation, all of which is mediated by discourses such as tall poppy. Intrinsic equality provides the bulk of the conceptual underpinning for the myth to which New Zealanders orient. In this thesis, the unqualified term 'egalitarianism' refers primarily to this subtype. However, as explored in the next section, equal opportunity has a significant influence in the modern age which makes a clear-cut conceptualisation of the term difficult.

Some historians (Olssen et al., 2011) have made similar observations to sociologists, contrasting both egalitarian subtypes and affirming the New Zealand concern with intrinsic equality:

The American belief in 'rags to riches' did not exist, and the fall from 'riches to rags' (from aristocratic rank in Britain to a menial position in the colony) attracted much more interest. Even the idea of equality of opportunity has rarely been proclaimed, partly (no doubt) because of the widespread belief that everyone is more or less on the same level, and the equally widespread desire to live in a society with no very rich and no very poor. Fairness, rather than freedom, has been central to our political culture. (Olssen et al., 2011, p. 20)

However, modern free-market capitalism after the neoliberal Rogernomics reforms (Walker, 1989) has seen an increase in competition which on the face of it is opposed to intrinsic equality and causes possible tension in the country's narrative (see also Larner, 1997; Nairn, Higgins \& Sligo, 2012). New Zealanders are able to consider themselves still living in an egalitarian country because both open competition and intrinsic equality are conceptually 'able to coexist under the same banner of equality because of their common 
opposition to inherited privilege' (Oxley, 1974, p. 45). Pearson, the author of the Johnsonville study cited above, who asserted that egalitarianism and visible inequalities can be reconciled (p. 170), explains his understanding further:

Egalitarianism is basically an equal opportunity model, but this is always hedged by ideas about who you think are inside these boundaries-and such models, of course, are based on a core assumption of competition. There is concern about equal conditions for the runners in the race, assuming you have the right credentials to compete, but there are always winners and losers. (D. Pearson, personal communication, 4 April 2014)

Pearson's argument seems at odds with that of Oxley (1974), who treats the term egalitarianism as reference to the intrinsic subtype, and also contrasts with Olssen et al. (2011) and Lipson (1948/2011, p. 457), who argue for New Zealand's historical emphasis on fairness over freedom (see also Fischer, 2012). This demonstrates firstly the tension that exists between the two subtypes as they struggle for dominance and the resulting difference in understanding across individuals. Secondly, it is indicative of the degree of scholarly disagreement further complicated by the fact that there has been little explicit academic focus on the structure of egalitarianism in the New Zealand context (D. Pearson, personal communication, 15 April 2014). Thirdly, historical developments in the understanding of egalitarianism have further muddied the picture. Such complexities necessitate a clear model in order to provide a solid basis from which to theorise about how the discourse influences the speech of individuals in New Zealand and in doing so contributes to their stances and identities.

\subsubsection{Conceptualising Egalitarianism}

The discourse of New Zealand egalitarianism arose spontaneously in conversation and was identified as a fruitful item of focus at the analytical stage helped by my ethnographic understanding of the study context. The clues that aided its identification were participant (and researcher) reference to issues such as equity and fairness, talk of income and wealth gaps, concern with inequality and poverty and 
also explicit and spontaneous discussion of New Zealand's history as an egalitarian society. The discourse was more salient than others and permeated the majority of conversations held.

In addition to the two subtypes of egalitarianism identified in the previous section, there are two main directions participants take in talk: a concern with its social aspects and concern with the economic. The data suggests that growing income inequality is increasingly viewed as an erosion of egalitarianism (see also Rashbrooke, 2013), which, as mentioned in the previous section, appears to neglect its historical origins and its position as a 'myth' that relates to having equitable social relationships (Nolan, 2007).

The conceptual model, presented in Table 6, arose through my ethnographic understanding of the study context and a literature review which confirmed the importance of egalitarianism in the New Zealand context. The model was tested against the participants' own conceptualisations, the results of which are presented in the following section. ${ }^{1}$

The model treats egalitarianism as an umbrella term which can be understood in terms of four primary components organised along two main dimensions. The first is the 'conceptual', concerning the ways in which participants orient to the two aforementioned conceptual subtypes of egalitarianism. The second dimension is the 'interactional', concerning the ways in which participants talk about egalitarianism. Both can be grouped vertically based on their differing ideological emphases; for ease of reference I have chosen the labels 'equality' and 'equity', the former referring to equal rank or privilege, and the latter to fairness and even-handedness (Deverson \& Kennedy, 2005). The two terms highlight the different emphases: equality emphasises equal rights with one another, and equity stresses fairness. A society with winners and losers may be equal, as people can enjoy equal rights and be free from discrimination, but it may not be considered equitable, as the existence of soaring wealth and grinding poverty can hardly be considered fair.

There is overlap between items across all dimensions due to the conceptual complexity of egalitarianism provided in part by its rich

1 This is an example of retroductive reasoning in practice (see Chapter 5), as the hypothetical model of egalitarianism was posed after preliminary analysis and then its explanatory power tested against the data. 


\begin{tabular}{|c|c|c|}
\hline & EQUALITY & EQU ITY \\
\hline CONCEPTUAL & $\begin{array}{l}\text { Equal Opportunity } \\
\text { Participants tend to } \\
\text { orient to equal } \\
\text { rights, winners and } \\
\text { losers, success and } \\
\text { failure (wealth), } \\
\text { achievement }\end{array}$ & $\begin{array}{l}\text { Intrinsic Equality } \\
\text { Participants tend to } \\
\text { orient to helping } \\
\text { the disadvantaged, } \\
\text { fairness }\end{array}$ \\
\hline INTERACTIONAL & $\begin{array}{l}\text { Economic } \\
\text { Participants } \\
\text { mention income } \\
\text { disparity, modern } \\
\text { poverty and wealth, } \\
\text { health and } \\
\text { wellbeing, measures } \\
\text { of inequality }\end{array}$ & $\begin{array}{l}\text { Social } \\
\text { Participants } \\
\text { mention } \\
\text { classlessness, } \\
\text { principles and } \\
\text { values }\end{array}$ \\
\hline
\end{tabular}

Table 6: A model of New Zealand egalitarianism (the conceptual dimension is drawn from the work of Oxley, 1974).

history. For example, one may conceptualise egalitarianism as intrinsic equality yet index economic concerns (see next section). What is clear from more detailed interactional analysis, provided in the next section, is that participants vary in their conceptualisations. For example, Joe places egalitarianism within an economic frame by treating it along the equality dimension, Peter appears to orient to equity by focusing on classlessness rather than income, and Desmond draws on both equality and equity. Their strategies however remain similar as all three appear to convey a sense of decline. This all occurs in the context of their political stancetaking, highlighting the influence of real structures on talk.

In relating the model to the literature on egalitarianism discussed in the previous section, the overriding ideological emphasis in New Zealand across history seems to be on the dimension of equity. However, the competing stress on equality, and the reformulation of egalitarianism as a focus on income concerns, brings about a tension that becomes apparent when analysing talk about this topic. The 
explanatory power of the model is examined further in the following section.

\subsubsection{Egalitarianism in Interaction}

Perhaps not surprisingly, given the historical antecedents discussed, explicit talk about egalitarianism occurred in conversation with the older participants, particularly Desmond (73-77), Joe (78-82) and Peter (63-67). The excerpts chosen for further analysis in this section come from discussions with these three men and constitute exchanges which demonstrate their explicit concern with the topic. The purpose served in mentioning egalitarianism varied for each participant and is examined in further detail alongside each analysis.

Desmond, in Excerpt 7.1, describes egalitarian New Zealand of the past in reference to education. He then gives some indication as to why this may have changed.

\section{Excerpt 7.1}

Desmond Morain, 73-77 year old NZ European/Pākehā male Setting: Desmond's living room

Context: We have been talking about my research experience on the building site.

Time: 4:46.1-5:37.1

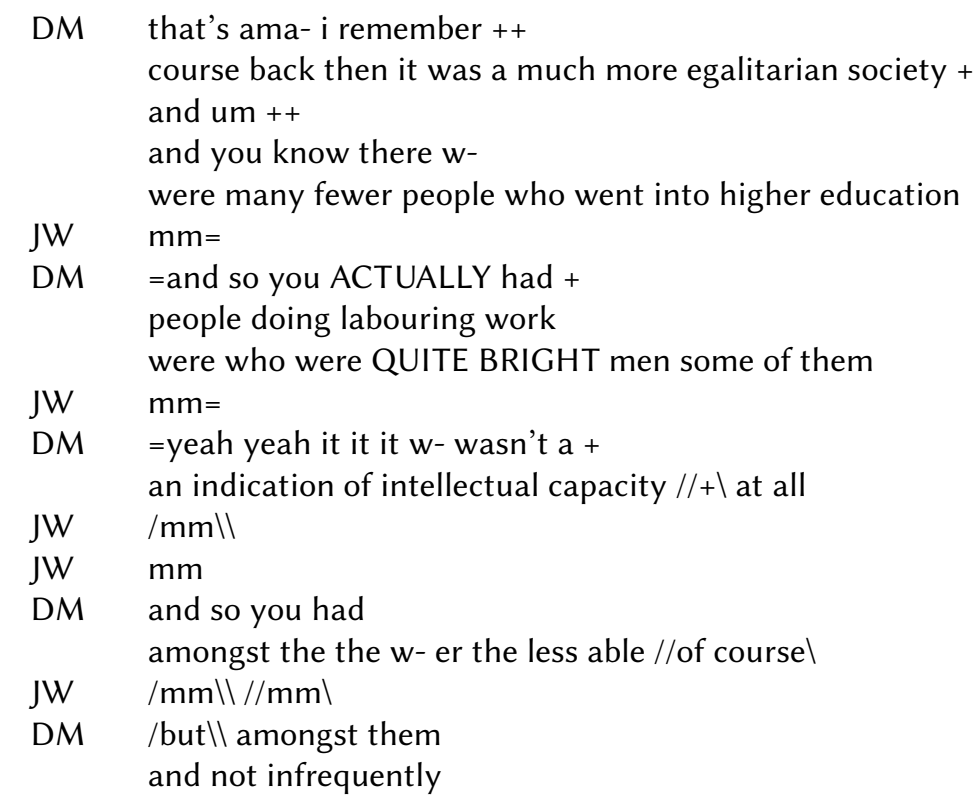




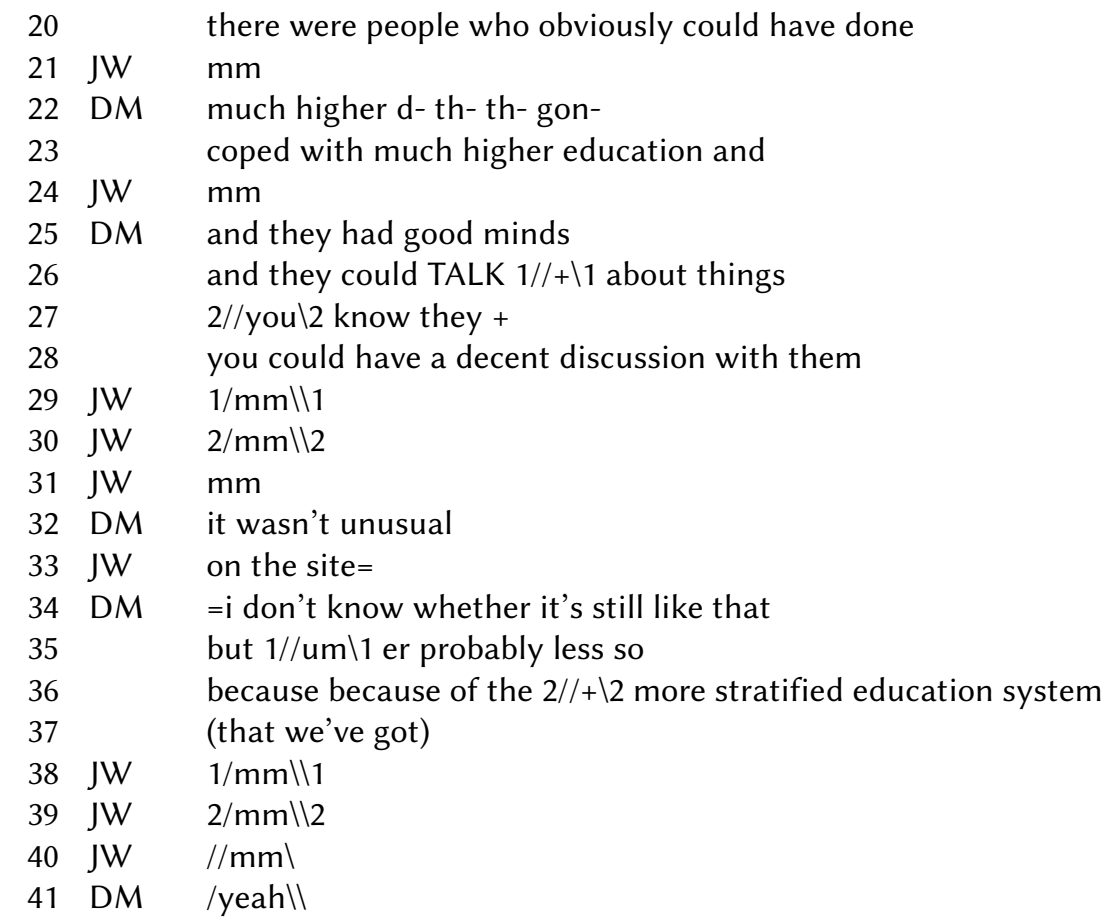

The main function of this exchange appears to be to contrast New Zealand's egalitarian society back then (line 2) with the situation today, linking it explicitly to higher education. To Desmond, in the 1930s (he mentions the date in the following excerpt), labouring work was a suitable means of employment for all regardless of intellectual capability as he notes that people doing labouring work were who were QUITE BRIGHT men some of them (lines 8-9). Desmond indexes egalitarianism in a general sense through his own experience, course back then it was a much more egalitarian society (line 2), and simultaneously compares this to today, where implied from his statement such 'bright men' would be at university were they to be in the same position now. Desmond's understanding of an egalitarian society being related to access to higher education (lines 2-5) indicates a conceptualisation which seems to relate primarily to social relationships between different groups, specifically in the form of a classless society: people of all intellectual abilities worked in labouring jobs in those days and hence no one was better than another. The more stratified education system (line 36) he observes today challenges this view and his implication is that the construction site may now be viewed as unsuitable for intellectual individuals. The picture 
he paints of today's situation contrasts with his conceptualisation of egalitarianism which seems to centre on classlessness and thus equity.

The linguistic features of Desmond's talk substantiate the view that his concern is with comparing the past to the present. He begins with $i$ remember (line 1 ) which frames the excerpt as a narrative of personal experience (Labov \& Waletzky, 1967), indicating that he is drawing on his past experience to inform his evaluations. The rest of the excerpt does not however follow the structure of a typical narrative of personal experience (as in the case of the narrative provided by Steven in Chapter 10; cf. Labov, 1997; Labov and Waletzky, 1967), as Desmond reformulates to narrate the past from a general perspective which is reflected in his pronouns that refer back to nonspecific nouns (i. e., men, the less able, people): some of them (line 9), amongst them (line 18), they had good minds and they could talk (line 25-26) and you could have a decent discussion with them (line 28). Drawing on his time working in both labouring and higher education, Desmond seems to opt for general referents as a means to achieve a broad generalisation about egalitarianism in New Zealand and to illustrate how it has changed. This exchange has Desmond move from past to present to create an image of New Zealand, influenced by the discourse of egalitarianism, which could be placed within a frame of general decline. However, there is no explicit evaluative language that indicates Desmond's stance in relation to the perceived shift in the egalitarian society. The full dialogic context does, however, indicate that Desmond is somewhat nostalgic for pre-Rogernomics New Zealand and interpreting this exchange as conveying decline aligns with this view. Economics could also be a possible reason for the shift in the characteristics of labouring personnel; perhaps labouring paid better in relative terms than it does now which could explain why QUITE BRIGHT men (line 9) have moved into higher education. This explanation indicates the possible effects of other structural mechanisms which should be taken into account. Desmond's views are no clear window onto the nature of the mechanism at work, though they do provide further support for the explanatory power of the model of egalitarianism provided in the previous section.

Excerpt 7.2, from later in the discussion with Desmond, shows egalitarianism embedded within an economic frame. As mentioned 
above, Desmond has an interest in New Zealand in the 1930s, contrasting it with the vast differences in wealth apparent today. The exchange demonstrates clearly how both aspects of egalitarianism can be drawn upon in the same conversation to highlight decline within an economic frame, focusing on the extra-discursive nature of inequality in much more explicit terms than in the previous excerpt.

\section{Excerpt 7.2}

Desmond Morain, 73-77 year old NZ European/Pākehā male

Setting: Desmond's living room

Context: Desmond has been talking about how the modern Labour Party differs from that of the 1930s.

Time: 28:48.9-29:27.4

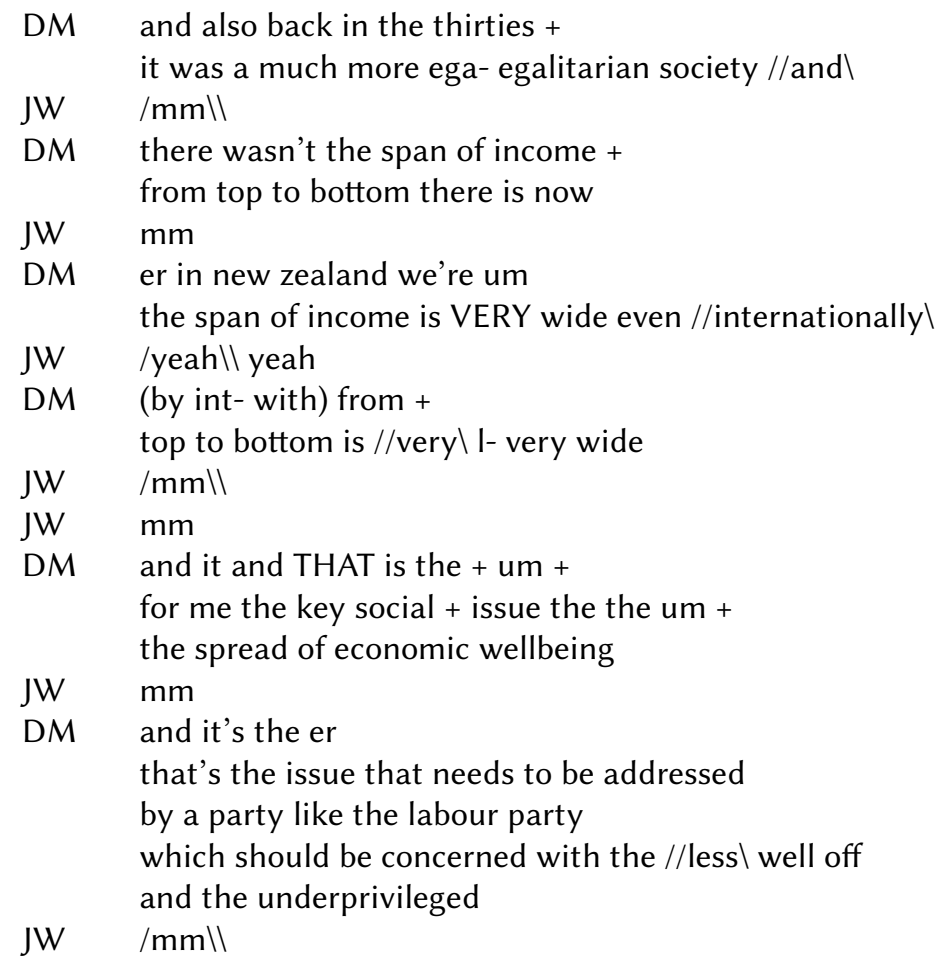

In this excerpt, Desmond explicitly indexes the discourse of egalitarianism, it was a much more ega-egalitarian society (line 2) and refers to its decline through a modern-day economic frame. This is indicated by his concern with income disparity (lines $4^{-5}$ ), New Zealand's poor international standings, the span of income is VERY wide even internationally (line 8) and his mention that his key issue 
is the spread of economic wellbeing (line 16). The function of this excerpt appears to be to provide historical context for how the modern Labour Party differs greatly from that of the 1930 s and provides context for his apparent pro-Labour political identity. Desmond indirectly indexes the extra-discursive referents of income inequality in order to show how, in his mind, egalitarianism has been eroded. Compared to Excerpt 7.1, Desmond appears to be more concerned with income as an indicator of the erosion of egalitarianism. This provides further evidence for dual social and economic concerns and also indicates that an individual, depending on context, can draw on different conceptualisations within a short space. Egalitarianism is multi-dimensional, implicating both social relationships and income inequality, and Desmond appears to view it as such.

In Excerpt 7.3, Joe also uses narrative as a device to explain his own experiences of egalitarianism and he appears to do so within the conceptual dimension of equality.

\section{Excerpt 7.3}

Joe Branstad, 78-82 year old NZ European/Pākehā male

Setting: Joe's living room

Context: Joe was talking about Kim Dotcom ${ }^{2}$ and how it is his business how he spends his money.

Time: 48:15.4-49:11.0

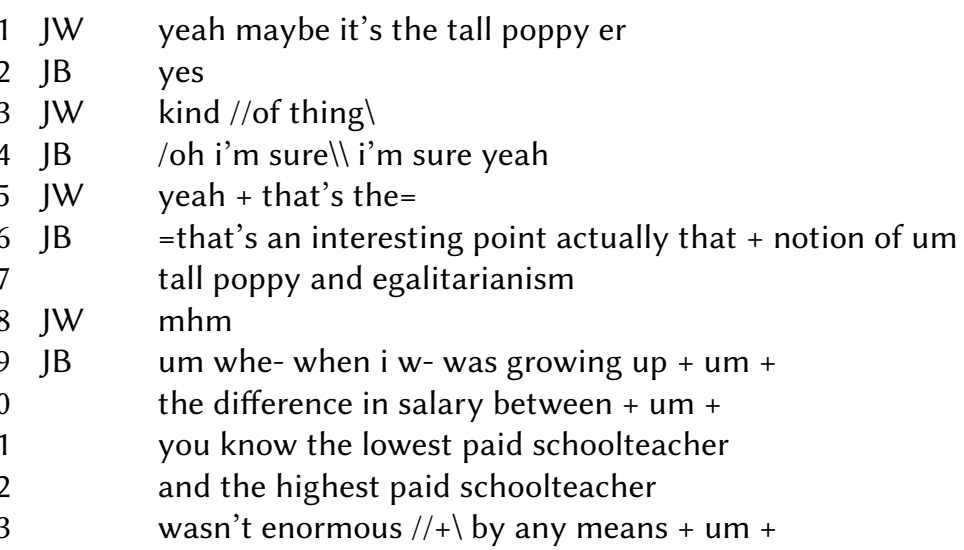

2 Kim Dotcom, a German entrepreneur and New Zealand permanent resident, was at the time the focus of a police investigation at the behest of United States authorities for his involvement with copyright infringement allegedly carried out through his website, Megaupload. The New Zealand courts had frozen his assets and allowed him access to limited sums for living expenses. 


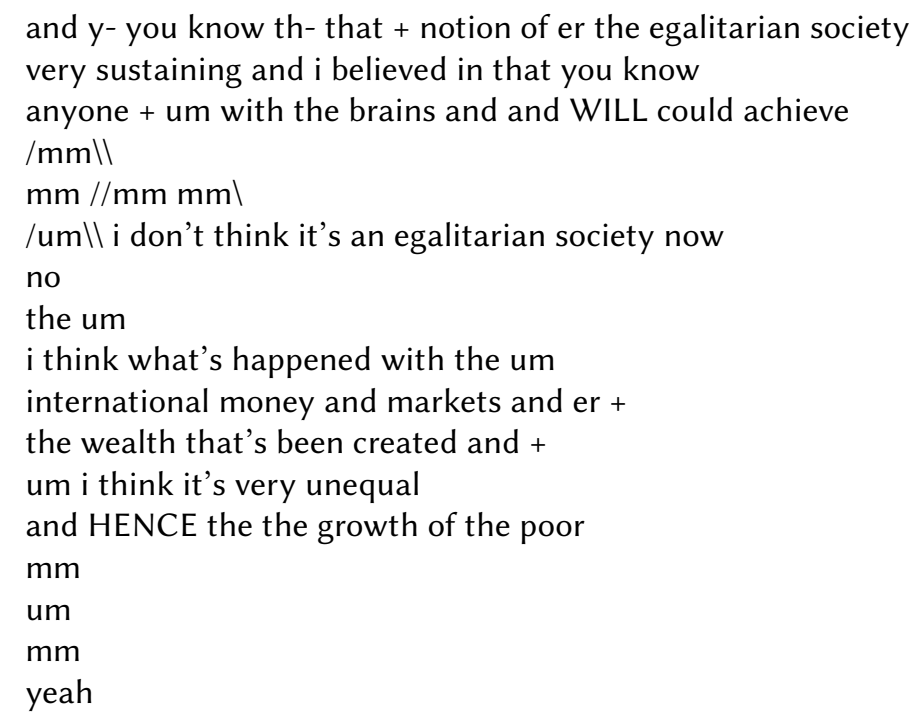

Joe ties income disparity to the decline of the egalitarianism in much the same way as Desmond, though he seems to orient more closely to the equality dimension. He also indexes it alongside tall poppy (line 7) which is examined in Section 7.2. Joe begins a narrative of personal experience marked by a series of false starts, um whe-when $i w$-was growing up (line 9). In addition to having more personal reference than Desmond in his discussion of the past, indicated through Joe's use of the pronoun $i$, he also talks in slightly more specific terms, referring to the lowest paid schoolteacher and the highest paid schoolteacher (lines 11-12) compared to Desmond's nonspecific pronoun use. This also demonstrates that income concerns are central to his definition of egalitarianism. Conceptually, Joe appears to draw on the equal opportunity doctrine as demonstrated in his utterance anyone $+u m$ with the brains and and WILL could achieve (line 16). He also indexes, via a discourse of inequality, its extra-discursive referents, um ithink it's very unequal and HENCE the the growth of the poor (lines 25-26). Joe's orientation to the equal opportunity model is interesting as it seems at odds with the historical conceptualisation of egalitarianism as equity. Related to this is his focus on income over social aspects, though this could be due in part to our lead-up to the topic that focused on Dotcom's financial issues (discussed in Section 7.2). It also provides further evidence for the complexity of this sociocultural discourse. 
A historical perspective was taken by another participant, Peter, who immigrated to New Zealand from England in the 1970s. Peter is an interesting case, as his initial 'outsider' perspective meant he was less embedded in the prevalent New Zealand discourses that had shaped the country. Peter also had a direct line of comparison to his home country which strongly informs his opinions. His labelling of himself as a 'socialist' influences his evaluation of egalitarianism throughout the interaction and is a clear link to his political identity. At the outset it is very clear that he evaluates egalitarianism positively, as shown in Excerpt 7.4.

\section{Excerpt 7.4}

Peter Baxter, 63-67 year old NZ European/Pākehā male

Setting: Peter's living room

Context: Peter has been describing how living in New Zealand differed from and affected his opinion of England.

Time: 27:29.6-28:03.0

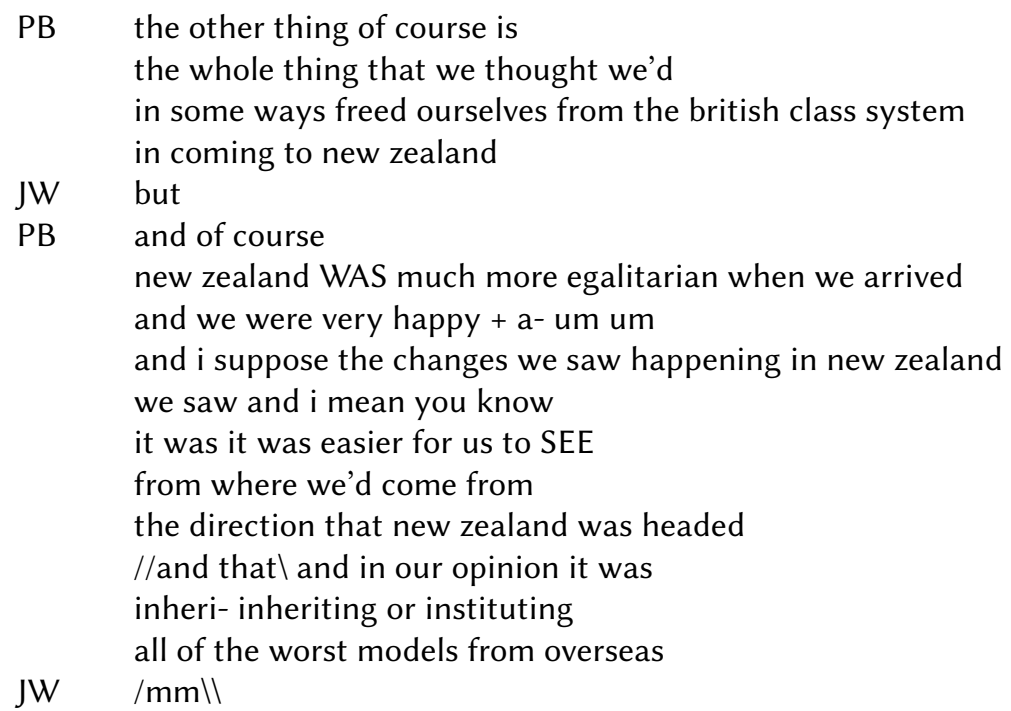

Peter evaluates egalitarianism as a positive, classless social system which was instrumental in his own past happiness (lines 7-8). He frames egalitarianism within a general sentiment of decline, indicated by his use of the stressed past tense, new zealand WAS much more egalitarian when we arrived (line 7) and his explicit mention of a metaphorical journey the direction that new zealand was headed (line 13) towards a negative outcome, instituting all of the worst models from 
overseas (lines 15-16). Given Peter's experiences I further explore his thoughts on the notion of egalitarianism, presented in Excerpt 7.5.

\section{Excerpt 7.5}

Peter Baxter, 63-67 year old NZ European/Pākehā male

Setting: Peter's living room

Context: We have been discussing egalitarianism in New Zealand and comparing it to the English class system.

Time: 31:21.1-32:18.5

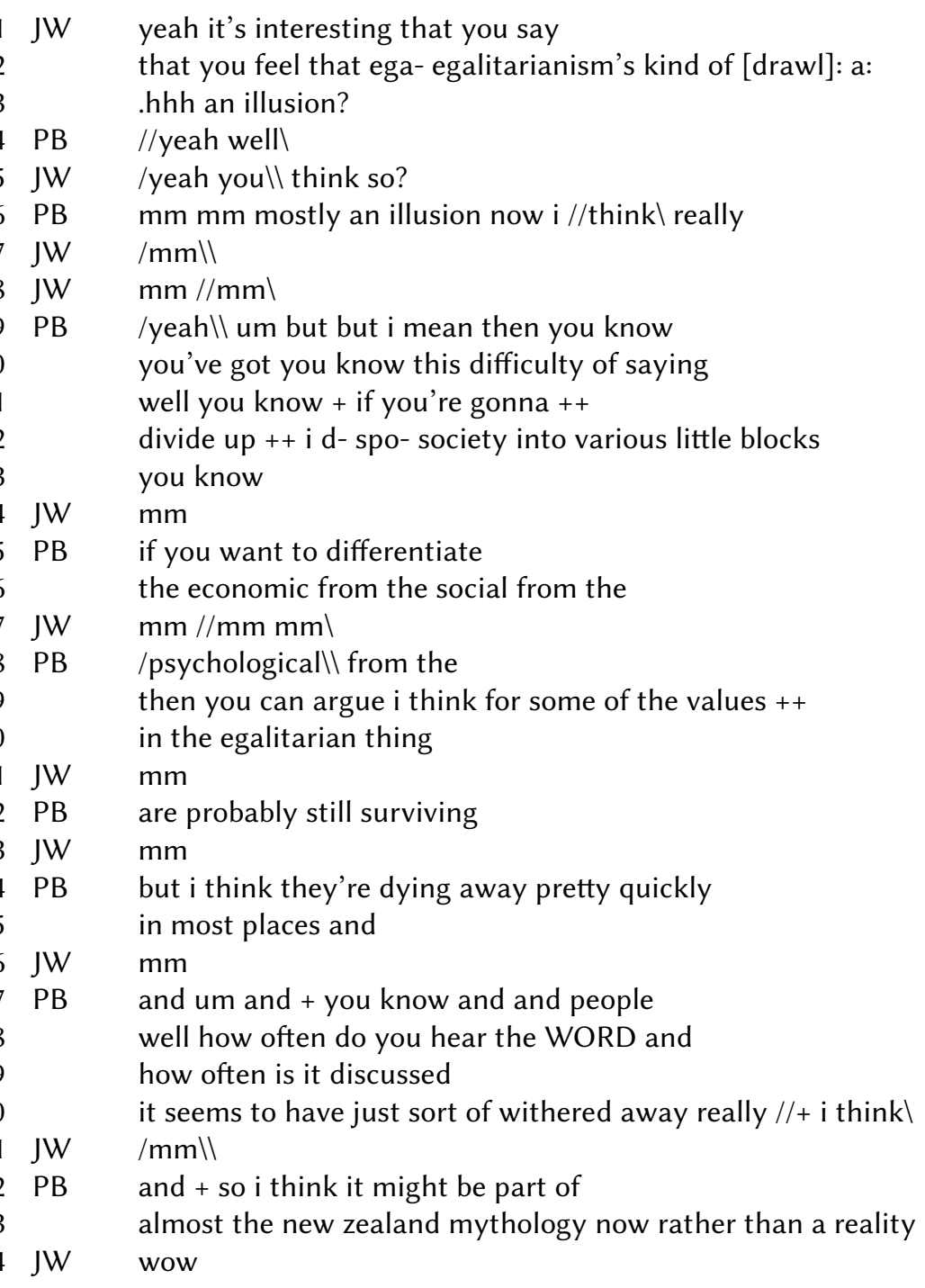

At the start I pick up on an earlier comment Peter made about egalitarianism (lines $1-3$ ), effectively giving him the opportunity to 
expand on his views. I am therefore contributing to the formation of his stance: I orient to the discourse of egalitarianism and mark it as something worthy of further discussion. Noteworthy is my formulation of the question. My false start, drawl and long intake of breath suggest that I am buying time to formulate the question, and my hedge, kind of (lines 2-3), seems to function here as an 'adaptor', where 'the speaker has selected an approximative lexical item, which may be negotiated' (Fetzer, 2010, p. 53). My mention of an illusion (line 3 ) in this negotiable frame provides Peter the opportunity to disagree with or modify my use of the term, or more specifically, my description of his earlier characterisation of egalitarianism. This would explain his hedged response, $\mathrm{mm} \mathrm{mm}$ mostly an illusion now $i$ think really (line 6). Peter then provides a sophisticated view of egalitarianism. He understands it as having multiple dimensions, the economic from the social from the...psychological (lines 16-18), and states that in some of these aspects egalitarianism is probably still surviving (line 22 ) but it is dying away pretty quickly (line 24). In answering my question and expanding on his views, Peter explicitly places egalitarianism within a frame of decline with metaphors of life and death, surviving and dying (Kövecses, 2010; Lakoff \& Johnson, 1980), and appears to do so without reference to income inequality. This indicates that his concern is likely with the social over the economic aspects of the discourse. Echoing Nolan (2007), Peter also explicitly mentions that it is part of the new zealand mythology now rather than a reality (line 33). How he conceptualises this reality is ambiguous, but it appears that he orients to the equity dimension through his clear concern with social class.

These three men, Desmond, Joe and Peter, demonstrate a striking concern with egalitarianism which could be attributed to the fact that, particularly in Desmond's and Peter's cases who mentioned it explicitly elsewhere in the discussion, the 1984 'Rogernomics' reforms occurred in their lifetimes. Peter appears to conceptualise egalitarianism along the equity dimension of the model, whereas Joe aligns with the equality dimension. Desmond is more ambiguous in his conceptualisation, drawing from aspects of both. This indicates that understandings of egalitarianism differ even within a small selection of participants and it follows that egalitarianism may have meant different things to different people across history (G. Hawke, 
personal communication, 21 January 2015). It is a complex discursive construct, underlain by extra-discursive factors, and these findings raise questions as to what exactly New Zealanders mean when describing their society as egalitarian. What is clear, however, is that egalitarianism is an important sociocultural discourse that has implications for the way in which New Zealanders' D-identities are recognised.

Younger participants seem more concerned with the presence of inequality and the poor rather than discussion of the egalitarian myth itself. Nairn et al. (2012), for example, discuss the discourses and identities of the post-1984 'neoliberal generation' in New Zealand, finding that they tend to orient to discourses of individual responsibility and free choice. This appears to be largely in contrast to the older participants of this study. However, as shown in Excerpt 7.6, a younger participant, Isaac, orients to the discourse of egalitarianism in an explicit fashion and draws attention to its decline in similar ways to the older participants.

\section{Excerpt 7.6}

Isaac Quinn, 23-27 year old NZ European/Pākehā male Setting: Wellington café

Context: Isaac has been talking about the ACT Party and right-wing media commentators.

Time: 42:24.7-42:45.0

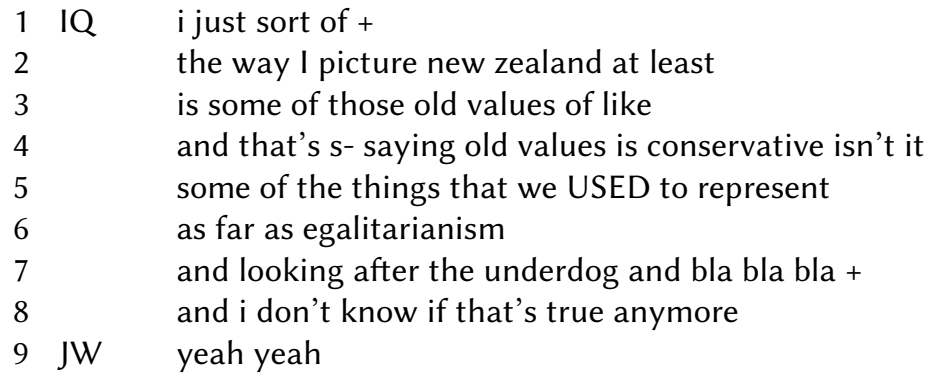

Isaac refers to egalitarianism as old values (line 3), an interesting utterance when considered alongside the fact that it is the older participants who most frequently provide explicit reference to egalitarianism in the data set. Isaac then hedges by noticing that this phrase may index conservative ideology, and that's s-saying old values is conservative isn't it (line 4), something he has spent much of the 
conversation rallying against. I suggest that this example indicates a stance 'crisis' in which certain linguistic items may index ideologies or discourses that are at odds with the speaker's personal values (cf. Jaffe, 2009a, p. 4; Ochs, 1992, on the 'non-exclusive' nature of stance). His statement that egalitarianism comprises looking after the underdog (line 7) suggests that he conceptualises it along the equity dimension. Isaac questions whether egalitarianism actually exists in the present day in much the same way as the older participants, again evaluating its status in terms of decline, which is indicated by past tense and stress, some of the things that we USED to represent (line 5) and his comment and $i$ don't know if that's true anymore (line 8).

The structures that sustain egalitarianism may no longer exist and the sociocultural discourse appears to be undergoing change and renegotiation in response. Given the constitutive and dialectical relationship between interaction and wider discourses (Fairclough, 1992; Ochs, 1992), this is a process that can be held to occur on-theground in interactions such as these, where stancetaking and identity work can both shape and be shaped by the discourses that surround us. The next section focuses on the enactment of egalitarianism in the form of mitigation of power and hierarchy which became relevant to many of the participants in various ways.

\subsubsection{Mitigation of Power as Egalitarian Equity}

Informality is valued in New Zealand, particularly in the workplace (e. g., Holmes et al., 2011; Kennedy, 2008). It is has been ranked low in 'power distance' by a GLOBE study of New Zealand culture, evidenced in the use of first names in many professional and academic contexts, which is consistent with orientation to egalitarianism through flattened hierarchies (Jackson, 2008; Kennedy, 2008, p. 409). Such forms of informality, tied to the mitigation of power, authority or status, can thus be considered symbolic egalitarianism within the New Zealand context. The vignettes below present descriptions of the discussions which attempt to provide brief insight into the nature of this social norm.

1. BRENT: In New Zealand, calling a teacher 'sir' is weird and creepy. People start to get upset about it here. [59:15.4] 
2. LINDA: Would knock on the door of the CEO of the ministry in which she worked to say she wants something. [22:57.2]

3. CATE: In New Zealand we're so close to our politicians that we can watch them debate. John Key and David Shearer are always pottering around. [27:13.0]

4. ISAAC: In New Zealand, more so than other places, there are not many degrees of separation from politicians. Politicians are not up on a pedestal; they are normal people. [4:15.6]

5. DANIEL: Likes that John Key seems down-to-earth. [10:44.6]

6. EDITH: John Key was on the front page with barbecue prongs in his hand. He wants to be the good Kiwi bloke that you can trust. [29:54.7]

7. Christen: John Key is awful and slimy. People say he's a nice guy but he isn't. There's an idea that he's a New Zealand bloke that has jandals and stubbies and has barbecues with his family. He's also got a five million dollar holiday home. He's not an accurate representation of New Zealanders. [31:50.0]

All of the vignettes display examples of the ideologies, in van Dijk's (2006b) sense, that permeate the data set of this study. Vignettes 1 and 2 indicate the necessity of informality at school and the workplace; Brent mentions that compared to Japan, using honorifics to address teachers is odd in New Zealand, and Linda mentions walking directly into the CEO's office at her former workplace. These both show one sense in which power is mitigated by cultivating informal relationships with those of higher status (as in the New Zealand workplace, see Holmes, Marra and Schnurr, 2008 and Kennedy, 2008) and also the way in which such behaviours and shared beliefs are central to social identity (van Dijk, 2006b). Vignettes 3 and 4 refer to the ability of New Zealanders to have access to their politicians; Cate mentions watching politicians debate in the public gallery, and Isaac, in reference to his time working as a journalist, notes that politicians are not placed on a pedestal in New Zealand and access to them is comparatively easier than in other countries. These two examples suggest informality of a similar kind, in that politicians are deserving 
of informal relationships, and both Cate and Isaac seem to orient to an egalitarianism of equity in that access to politicians should be almost the same as access to anybody else. The remaining vignettes, 5, 6 and 7, refer to Prime Minister John Key specifically. Daniel positively evaluates Key by describing him as 'down-to-earth', whereas Edith and Christen are negative in their evaluations but nevertheless index the same relaxed image of the Prime Minister. Edith mentions Key's barbecuing in the context that likeability should not be a factor in determining the ability to run a country and Christen is strong in her negative evaluation of Key as 'awful', 'slimy' and disingenuous in his cultivation of the image of a 'good Kiwi bloke.' These three vignettes demonstrate that a likeable and relaxed persona seems valued in the New Zealand context, even though two of them evaluate John Key, through the lens of their Green political beliefs, in negative terms for his enactment of the informal and accessible leader. ${ }^{3}$

One participant had a negative view of New Zealand's informal culture, criticising it as 'false egalitarianism', as shown in vignette 8 .

8. Peter: New Zealand has a class system but it is not as overt as England. You could meet a captain of industry here and be on first name terms from the first meeting. This doesn't mean that they're not doing the same things as overseas, but we have a more casual approach over here. In some ways this fools people into a false sense of mateship and egalitarianism when it's not really there. [28:22.5]

Peter's point about being on a first name basis is similar to that of Brent above. Peter however links this to a form of false egalitarianism, in that the use of informal salutations and friendly relations hide the fact that New Zealand is no longer an egalitarian or classless society. This aligns with Peter's orientation to the decline of egalitarianism, as discussed in the previous section.

3 It is perhaps no surprise in light of these examples that Prime Minister John Key opted for a barbecue with reporter and broadcaster John Campbell of TV3's Campbell Live as part of the series At Home With the Leaders (7 April 2014). My experience suggests that barbecues index informality and the quintessentially relaxed Kiwi summer holiday and it therefore appears to be an effective strategy of mitigating his own powerful position as Prime Minister and conveying an egalitarian 'man of the people' self. 
These vignettes attempt to show how mitigation of powerful positions can be considered the symbolic enactment of equitable egalitarianism within the New Zealand context. Using informal terms of address and appearing accessible and reachable serves to demonstrate orientation to the egalitarian myth. However, there is a reason that such humility is made necessary, as there is the risk of negative consequences for any who rise too high. The mitigation of authority sketched in this chapter occurs with reference to another salient sociocultural discourse, that of tall poppy, where those who are seen to boast about their achievements are 'cut down to size.' Tall poppy appears to contribute to sustaining the egalitarian myth in New Zealand and is examined further in the next section. It is a structure which, like egalitarianism, has far-reaching consequences for stancetaking and identity in New Zealand.

\subsection{TALL POPPIES IN NEW ZEALAND}

There has thus far been a general concern amongst the participants with the decline of egalitarianism in New Zealand, which perhaps implies that some of them view it as a point of pride. It is, however, not entirely associated with positive sentiment. The reason for this is indicated by Lipson's (1948/2011) observation that the inevitable result of a society stressing fairness is a restriction of liberty. He notes succinctly of New Zealand that 'in its anxiety to raise minima, the country has deemed it necessary to lower maxima' (p. 452). This gives rise to what is now known as tall poppy.

A society with an egalitarian disposition necessitates a means of sustaining the equity (or equality) of its people. In New Zealand, initiatives that aim to level-up, such as redistributive government policies and generous social supports (McClure, 1998; Reeves, 1903a, $1903 \mathrm{~b})$ are complemented by a levelling-down mechanism. Lipson $(1948 / 2011$, p. 453$)$ observed that the existence of this mechanism in New Zealand meant that those who did not follow the group standard were met with hostility and argued that the resulting lack of tolerance was characteristic of early New Zealand society. He notes that this proclivity has implications for talent. In New Zealand, the most successful seem to be those who are humble and self-effacing, that 


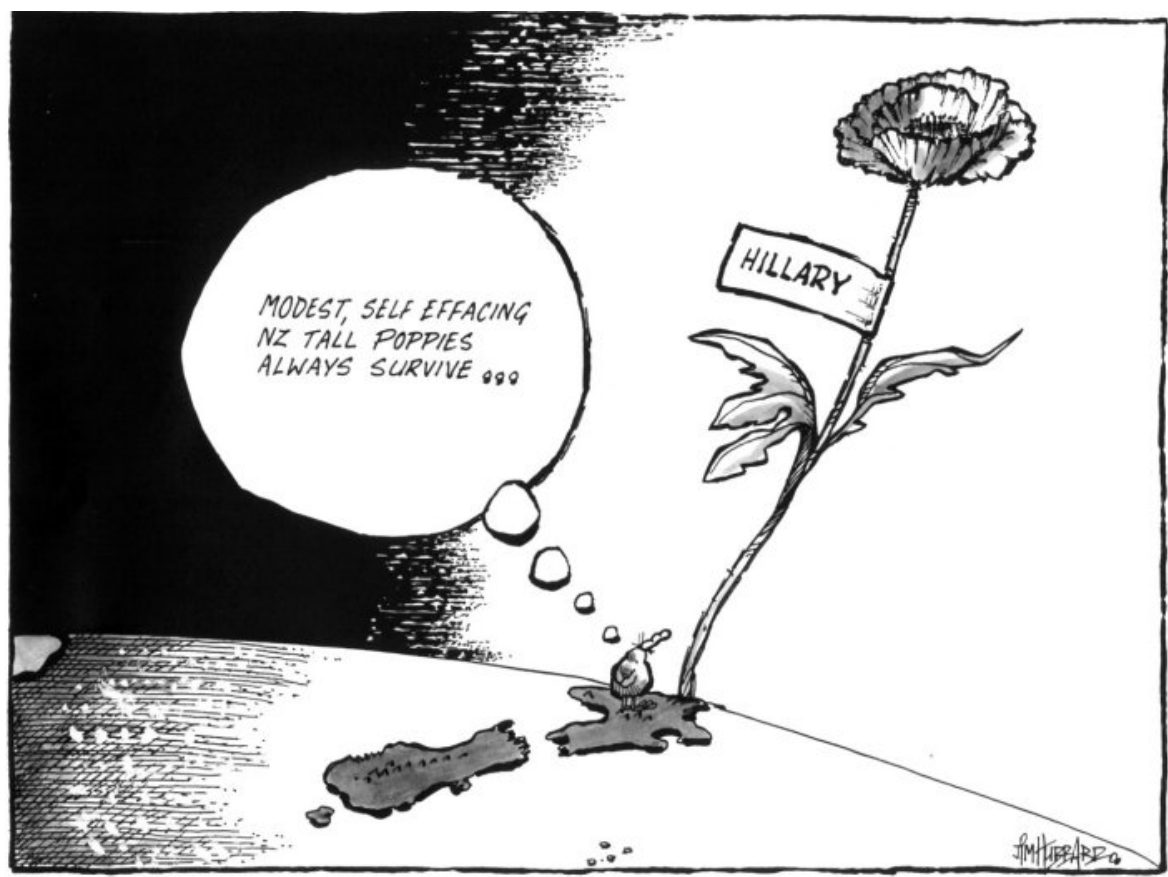

Figure 6: Edmund Hillary cartoon by James Hubbard, 22 January 2008.

is, not boastful (Bönisch-Brednich, 2008, p. 9). As Lipson eloquently states,

Democracy itself can imitate the policy of Periander the Greek and remove the heads that stand above the crowd. There is a tendency for the idolaters of equality to sacrifice talent on the altar of their god. (Lipson, 1948/2011, p. 8)

Edmund Hillary's 'we knocked the bastard off' in reference to his pioneering ascent of Mount Everest illustrates the Kiwi propensity to downplay success (Bönisch-Brednich, 2008, p. 8; Kennedy, 2008, p. 407). This could be attributed to the distinctive Kiwi trait of ducking Periander's blade (Felton, 1998) which, when followed, can still lead to success and achievement, as depicted in Figure 6.

As Lipson $(1948 / 2011$, p. 8) identified, the origin of tall poppy can be traced to the Greek story of the tyrant Periander. When imported into Roman culture, the original wheat fields of the Greek story were replaced with Roman gardens due to their importance to Roman life, and these were often planted with poppies (Rutland, as cited in 
Felton, 1998, p. 44). The flower also carries the ancient symbolism of sleep or death due to its narcotic characteristics and its distinct head enhances the image of decapitation (Felton, 1998, pp. 44-45). Perhaps the symbolic baggage attached to the flower gives rise to its use in a negative sense in tall poppy. However, some scholars have suggested that tall poppy only relates to achievement in a general sense, those 'people who are conspicuously successful or who have high status by virtue of their achievement, rank or wealth' (Feather, Volkmer \& McKee, 1991, p. 85). In New Zealand, success in itself does not seem to invite tall poppy levelling, as the culture of 'performance orientation', demonstrated by the cases of Hillary, Rutherford, Batten and others, is widely valued (Kennedy, 2008, pp. 406-407). The definition of Feather et al. (1991) lacks the key factor of hubris, self-aggrandisement or boasting which others agree is necessary in order to be a target of tall poppy (Kennedy, 2008, p. 407; Peeters, 2004a, 2004b). In either case, the negative connotation of cutting tall poppies has resulted in it referred to as the tall poppy syndrome, a metaphorically pathological ailment which afflicts New Zealand society, and which is captured in Figure 7 (see also Kirkwood, 2007; Mouly \& Sankaran, 2000). The conceptual image produced by tall poppy, with its focus on removing, cutting, lowering or reducing, gains further negativity through the cognitive metaphor BAD IS DOWN (Lakoff \& Johnson, 1980). As a negative phenomenon, it has been blamed for holding the country back in business terms (Kirkwood, 2007) and is very often a topic of focus in the media; a recent controversy involving a prominent New Zealand author raised questions of tall poppy and anti-intellectualism (Flood, 2015). ${ }^{4}$

Similar discourses exist in other countries. Australia is the subject of the highest volume of explicit research into tall poppy as a social norm (Feather, 1989; Feather \& McKee, 1993; Feather et al., 1991; Peeters, 2004a, 2004b), while in comparison the research carried out in New Zealand generally has a more restricted focus (Harrington \& Liu, 2002; Kirkwood, 2007; Mouly \& Sankaran, 2000). In Scandanavia,

4 The controversy was sparked in late January 2015 by Man Booker Prize winning author Eleanor Catton when she stated in an interview, amongst other things, that she is uncomfortable being an ambassador for New Zealand when the Government is not doing what it could for the literary arts (Mint, 2015). She later referred to her critics' attacks as forming part of a 'jingoistic national tantrum' (Flood, 2015). 


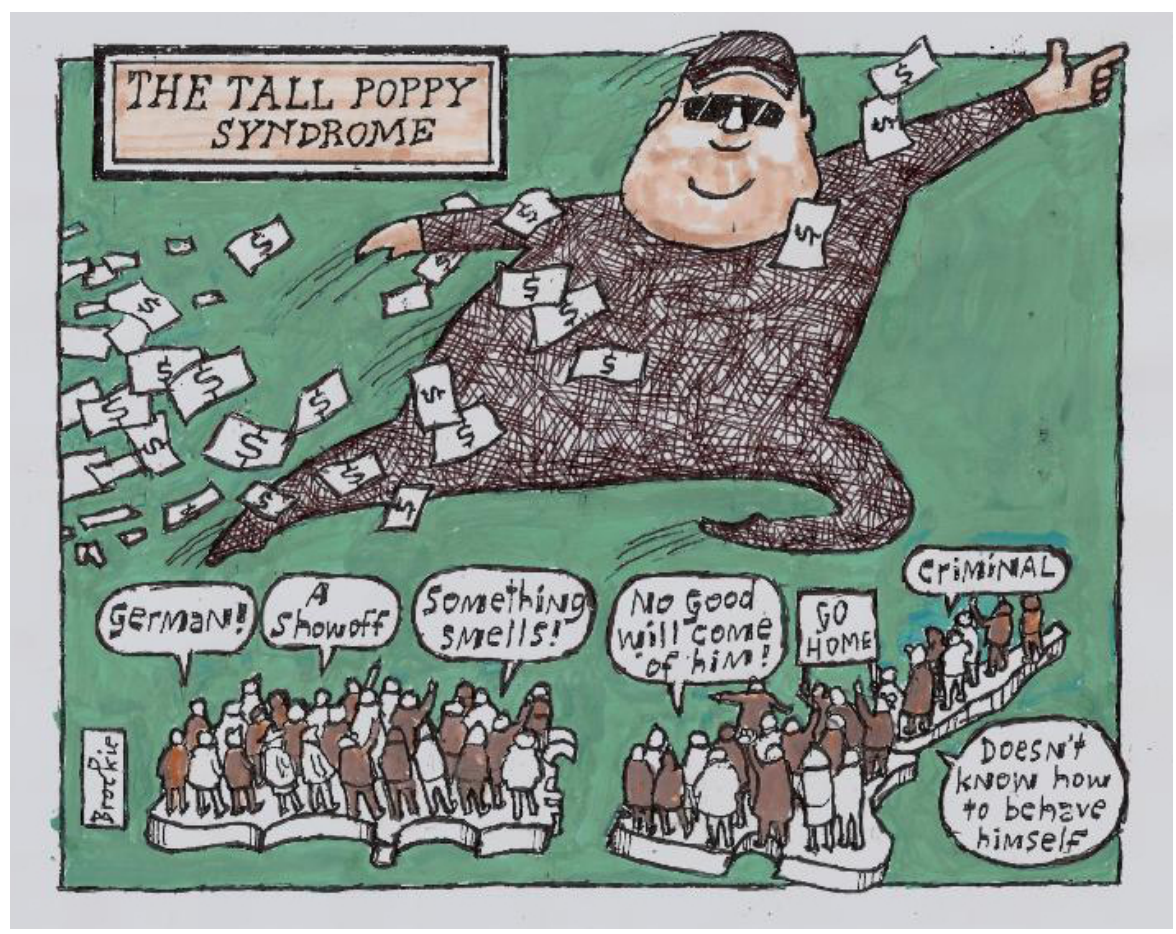

Figure 7: Kim Dotcom cartoon by Bob Brockie, 25 January 2013.

fanteloven [the Law of Jante] promotes humility and conformity (Ahlness, 2014; Bromgard, Trafimow \& Linn, 2014); in Japan, the proverb 'the nail that sticks up gets pounded down' likewise stresses conformity (Feather \& McKee, 1993); and in the Philippines, 'crab mentality', referring to crabs in a bucket pulling down those that try to climb out, relates to a sense of envy in which 'another's gain is our loss' (Licuanan, 1994, p. 40). Tall poppy, like these similar overseas discourses, is cemented in the particular historical and sociocultural developments of the country. One notable aspect is that the red poppy is a symbol of the remembrance of Commonwealth war dead and paper versions are attached to lapels around the country to commemorate Anzac Day. In 1921, the red poppy was selected as a symbol by the British Legion because it was the first plant to grow in the mud after battles in France and Belgium during the First World War (Iles, 2008). Tall poppy and the remembrance poppy are perhaps connected by nothing more than name, especially as the former is particularly negative, but there is at least the possibility that the two discourses interact when indexed in interaction in New Zealand. 
Explicit talk on the topic of tall poppy was not as frequent as that of egalitarianism, perhaps due to the time and place at which the discussions took place (if, for example, they had taken place during the aforementioned Catton controversy, discussion of tall poppy would have been more topical). Tall poppy did, however, arise alongside talk of egalitarianism in the discussion with Joe, as shown in Excerpt 7.7, whose talk was prompted by my mention of the phenomenon. This occurs just prior to Excerpt 7.3.

\section{Excerpt 7.7}

Joe Branstad, 78-82 year old NZ European/Pākehā male

Setting: Joe's living room

Context: Joe has been talking about how investigative journalists' focus on politicians' spending is intrusive but acknowledges that it holds them to account.

Time: $47: 51.9-48: 20.5$

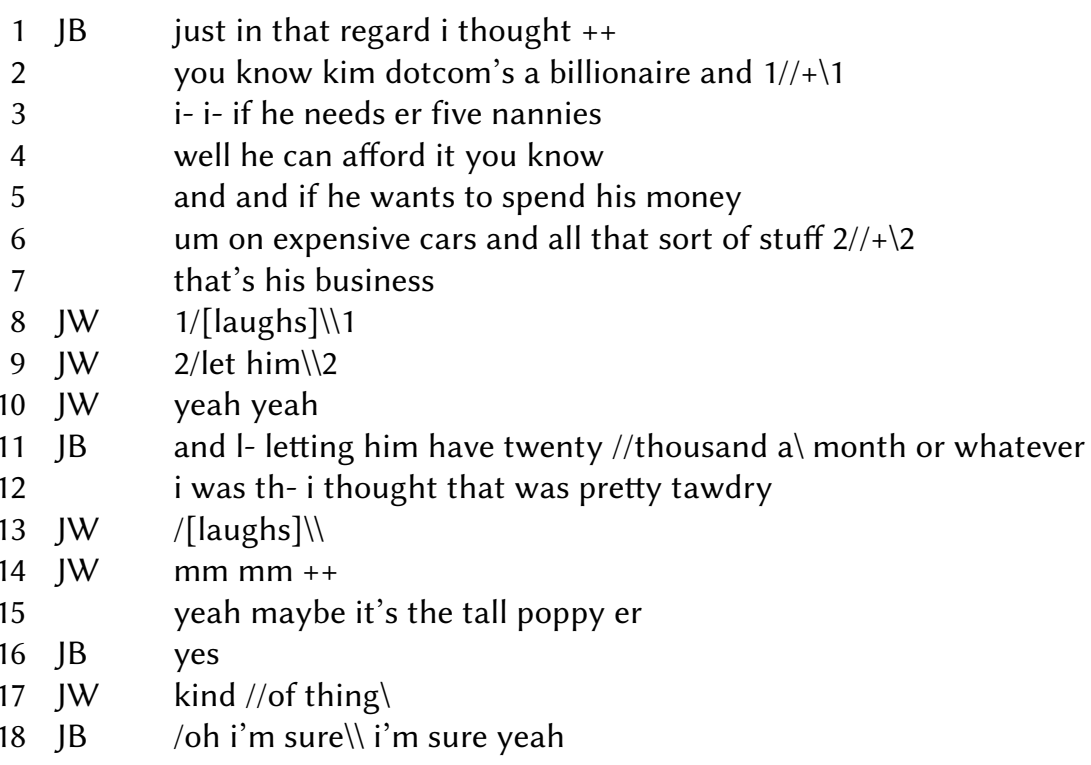

In this excerpt Joe criticises the courts which restricted Dotcom's spending, letting him have twenty thousand a month or whatever...i thought that was pretty tawdry (lines 11-12). Joe orients to a sense of fairness through his conceptualisation of egalitarianism as equalityin Joe's view, Dotcom can do what he wishes with his money, well he can afford it you know (line 4) and that's his business (line 7). Joe does not criticise Dotcom for his wealth or negatively evaluate him in any 
way, which would be expected if he was enacting tall poppy. Instead, Joe takes the opportunity to demonstrate his disapproval of Dotcom's treatment. I index tall poppy as an explanation for the court's actions (line 15) with which Joe agrees. He then uses it as a prompt to talk about egalitarianism, mentioned in the previous section, indicating that the tall poppy and egalitarian discourses are closely related in his mind. It also shows how our talk about Dotcom and his wealth served to frame Joe's subsequent view of egalitarianism which perhaps affected his conceptualisation along the equality dimension and his concern with income. Therefore, these conceptualisations, while salient in situated context, may shift when the context changes. If we had entered discussion of egalitarianism after talking about social class then perhaps Joe's subsequent conceptualisation would have differed. Furthermore, my own view is implicated in the outcome of this exchange. After the discussion of Dotcom's money, I raise the topic of tall poppy (line 15) and in doing so place the subsequent conversation within an economic frame. Drawing on different aspects of discourses, whether equality or equity in the case of egalitarianism, is clearly an intersubjective achievement that can be understood only in reference to the wider context and aided by reflexive analysis.

Explicit indexing of the tall poppy discourse through the phrase 'tall poppy' was not the only way in which it appeared in the data. It is also enacted in talk. In the discussion with Cate, shown in Excerpt 7.8 , the 'cutting down' of a successful Wellingtonian is established collaboratively.

\section{Excerpt 7.8}

Cate Mclver, 18-22 year old NZ European/Pākehā female

Setting: Wellington café

Context: Cate tells me some gossip about an MP.

Time: 18:27.4-19:00.8

$\begin{array}{lll}1 & \text { CM } & \text { i didn't know [politician's name] was [religious] } \\ 2 & \text { JW } & \text { really } \\ 3 & \text { CM } & \text { //yeah } \backslash \\ 4 & \text { JW } & \text { /is shell } \\ 5 & \text { CM } & \text { yeah + it threw me a curve ball } \\ 6 & \text { JW } & / / \text { where'd you find that from } \backslash \\ 7 & \text { CM } & \text { /i used to think she was } \backslash \text { um }+ \\ 8 & & \text { my friend's dad }+ \\ 9 & & \text { [name] }\end{array}$




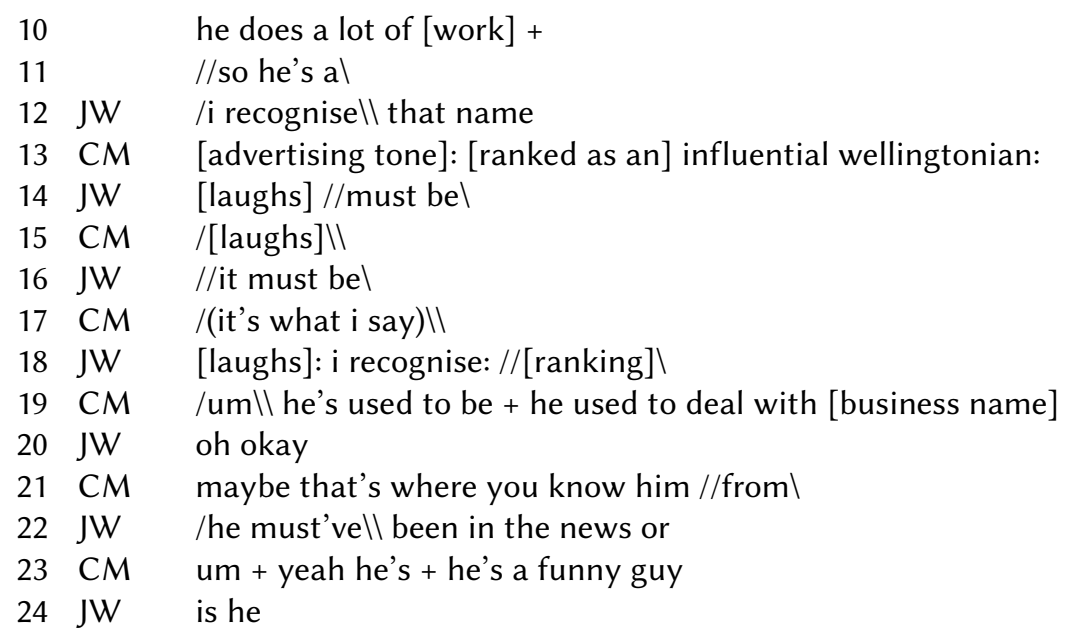

This excerpt demonstrates a collaborative enactment of tall poppy as Cate and I discuss a well-known Wellingtonian. This is prompted by my recognition of his name (line 12) and Cate's tone when explaining why I might have heard of him (line 13). I have labelled it 'advertising' for lack of a better descriptor: Cate's tone indexes television advertisements or 'infomercials' in which the positive characteristics of certain products are presented. In this context it indexes sarcasm and as such elicits laughter from me (lines 14, 18). Cate goes on to provide more details, including the work he does (line 19), to help me remember where I had heard his name. Cate's final evaluative stance, he's a funny guy (line 23), refers in context to the man's strong political opinions which for her are a source of entertainment; again, a hint of sarcasm is indexed through her use of funny.

Tall poppy in this extract is enacted collaboratively. Firstly, Cate could be interpreted as mitigating the fact that she knows a wellknown person through her tone (line 13), which serves to soften any sense of bragging or boasting through gentle sarcastic mockery. Our laughter throughout (lines 14, 15 and 18) indicates that there is humour present and contributes to affirming the evaluation of the man in question. Cate's final evaluation also serves to minimise the man's influence by referring to him as funny (line 23) rather than, say, influential or important. Whether Cate thinks he is a braggart is not clear, though her description of his characteristics elsewhere in the discussion, withheld for confidentiality reasons, suggests that he 
does indeed 'stand out from the crowd.' This excerpt presents a very subtle example of tall poppy in action and again demonstrates the importance of ethnographic data and knowledge of the wider dialogic context in interpretation.

Egalitarianism and tall poppy discourses do not seem to operate in isolation. They are tied closely to one another, with egalitarianism providing a sociocultural schema through which New Zealand society can be organised and tall poppy providing a mechanism through which egalitarianism can be maintained. From a critical realist perspective, tall poppy can be broken down into three distinct aspects:

- TALL POPPY AS IDENTITY

- A boastful high achiever who has been cut down

- A D-identity which is generally ascribed by others (Gee, 2000)

- tall poppy as Discourse

- A sociocultural discourse

- Related to the discourse of egalitarianism

- Has an associated 'levelling' mechanism

- TALL POPPY AS MECHANISM

- Associated with its structure (i. e., tall poppy discourse)

- A critical realist mechanism that results in an event (which can be experienced in the form of 'levelling-down'; see Chapter 2)

These three aspects serve to differentiate product versus process and help to clarify what is meant when referring to 'tall poppy' in research.

The discourses of egalitarianism and tall poppy are analytically salient in the data set. Given the evidence from the literature discussed in the previous sections, and supported by the ethnographic data, the two discourses are considered to have important influence within the New Zealand context. Both are not only indexed through explicit mention with their direct indexical labels, they are also enacted in less direct ways, whether through the mitigation of a powerful position 
or through the subtle 'cutting down' of a well-known Wellingtonian. This all provides structure for the way in which political identities are generated in conversation.

\section{$7 \cdot 3$ SUMMARY}

New Zealand's rich historical context gives rise to a discourse of egalitarianism through which people are viewed primarily as intrinsically equal to one another. In light of modern developments, particularly the rise of inequality, the discourse of egalitarianism has shifted, resulting in different interpretations appearing in interaction. This chapter introduces a model that seeks to clarify the conceptual nature of egalitarianism in New Zealand, and drawing on the literature and ethnographic knowledge of the study context, divides egalitarianism into two general components that focus on either equality or equity. When tested against the data, the model provides support for the different ways in which the participants conceptualise egalitarianism in interaction. Closely related is the discourse of tall poppy, which is broken down into product, process and discourse, all of which act to sustain the egalitarian myth. Those that achieve are not necessarily cut down by tall poppy, unless they are seen to boast or do not display a level of self-effacement or humility. These two discourses have substantial influence on the talk of the participants in this study and therefore their stancetaking and eventually identities. While similar discourses have been identified around the world, egalitarianism and tall poppy within New Zealand appear to have unique characteristics. Sociocultural discourses may constrain or influence our talk but they are also open to transformation (Fairclough, 1992). The apparent shift in the meaning of egalitarianism from social to economic concerns is one such example. The interactions collected for this study likely contribute to the situated reinterpretation and negotiation of these wider discourses, a process which occurs in reference to the shifting extra-discursive circumstances that underpin them. 

In this chapter the analytical spotlight shifts to a more situated form of sociocultural discourse. These are the subnational discourses which affect the way in which we interact in particular contexts. The chapter explores political identity as it is generated in Wellington and examines how the context of this particular city influences the way participants articulate their political selves. This local focus is supported by research that is concerned with more bounded geographical identities; from a general discourse perspective, researchers have examined identities in particular places such as Hong Kong (Tsang \& Wong, 2004; Zhang \& Mihelj, 2012), Washington, D.C. (Modan, 2007) and four African cities (Bekker \& Leildé, 2006). These studies are supported by work in environmental psychology on the notion of 'place identity' (Dixon \& Durrheim, 2000; Proshansky, 1978; Proshansky, Fabian \& Kaminoff, 1983; Twigger-Ross \& Uzzell, 1996). That is, 'cognitions about the physical world in which the individual lives' (Proshansky et al., 1983, p. 59) and is 'the process by which, through interaction with places, people describe themselves in terms of belonging to a specific place' (Hernández, Hidalgo, Salazar-Laplace \& Hess, 2007, p. 311). The discourses identified in this chapter can therefore be considered to contribute to the genesis of a 'Wellingtonian' identity in which inhabitants interact with the material and discursive features of the city.

Four salient subnational discourses arise in the data that relate to the characteristics of the capital city: the political town; the leftwing nature of the politics within it; the small town 'everyone knows everyone' discourse, related to the small country discourse and extradiscursive referents discussed in Chapter 6; and a discourse of difference, that is, Wellington contrasted to other places in New Zealand, which positions the city and its inhabitants as different to the rest of the country. Through investigation of these subnational discourses, which are underpinned by the extra-discursive referents and framed within the sociocultural discourses explored in Chapter 7 , this chapter 
seeks to provide insight into the nature of the rich context that surrounds political stancetaking within Wellington.

\subsection{POLITICAL IDENTITY IN WELLINGTON}

A brief introduction to Wellington is provided in Chapter 6 which outlines the physical prominence of politics in the city and the nature of political support within it. This unique context became salient in speech, as participants often referred to Wellington's characteristics and people in their political talk, providing evidence for subnational discourses influencing their political stancetaking. In addition to the local discourses circulating within Wellington, such as its political and left-wing nature, the local context includes an important realist component in the form of its physical makeup in much the same way as the small country: for example, the arrangement of the city at times becomes salient to the participants. The data highlights the prominence of this character and this chapter outlines its subsequent influence on the way participants generate their political selves.

Wellington, shown in Figure 8, is the location of the New Zealand Parliament and has conferred upon it the title of capital city despite it being only the third largest city by population in the country (Statistics New Zealand, 2015b). It was not always this way. Parliament, and the title of capital, was moved south from Auckland to Wellington in 1865 due to the increasing population and associated economic influence of the Southern provinces, and also to allay fears from Southern MPs regarding the long journey to Auckland (Martin, 2004, p. 40). Today, Wellington likes to style itself as the cultural capital of New Zealand, having a rich arts, café and restaurant scene, a thriving film industry and buzzing nightlife (Wellington City Council, n.d.). Lonely Planet (2010) described Wellington as 'the coolest little capital in the world', a phrase which the local council tourism office and the Mayor have taken up with enthusiasm (Partnership Wellington Trust, 2015). The phrase has even found a place on the cruise ship terminal near the entrance to the city, reformulated as the 'coolest little cruise capital.'

Siegfried (1914, p. 251) admired Wellington for its natural scenery, though criticised it for being 'characterless and inelegant' due to its rapid early development. He noted that it is hardly likely that it will 


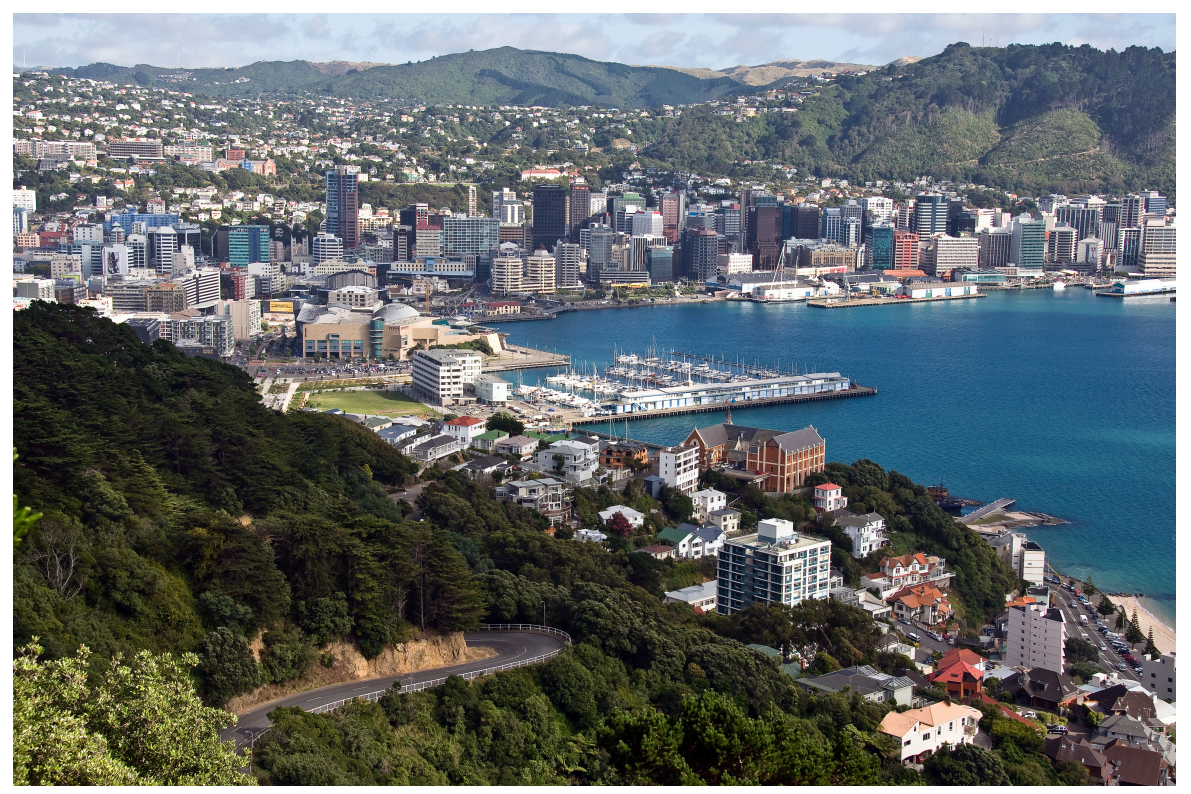

Figure 8: A view of Wellington from Mount Victoria.

ever be for New Zealand what Sydney is for New South Wales, or what London is for England-a predominant and unrivalled centre' (pp. 251-252). Siegfried was largely correct in his prediction if viewed in light of the statistics; Auckland is the economic powerhouse of New Zealand with a population that overshadows Wellington by a magnitude of degrees (Statistics New Zealand, 2015b). Nevertheless, there is a palpable sense of pride that many Wellingtonians feel about their city, demonstrated through the tireless determination of the local authorities to enhance the profile of the city and the positive references made by many of the participants in this study. Its location at the bottom of the North Island guarantees a 'central' character at least geographically, and despite Auckland's economic dominance, the unrivalled centre of New Zealand in the eyes of many Wellingtonians will always be the capital.

Four salient subnational discourses are identified through analysis as being particularly relevant to the participants. They vary in form and occur amongst a host of other discourses, but most broadly, Wellington is characterised as a political city; left-wing and liberal; a small town where 'everyone knows everyone'; and existing in a 'bubble' in contrast to other places in the country. The first two 
discourses appear to be more overtly 'political', and the second two related to the physical or material. All, however, contribute to the context-bound genesis of identities.

The following sections explore each discourse in detail, presenting excerpts from the participants that highlight their orientation to each and investigating their possible contribution to identity genesis.

\subsection{THE POLITICAL TOWN}

It is perhaps unsurprising that Wellington, the centre of government, was characterised as a political city in the conversations with participants. The physical environment of Wellington in terms of the placement of political buildings also became relevant in the context of this discourse (see Chapter 6). Its status as a subnational discourse is indicated by its salience in the participants' speech and supported by the ethnographic data set. It is a socially accepted way of thinking (Gee, 2014) about the local context that is relatively enduring and widespread, and is signalled in interactional discourse through various linguistic, pragmatic and discursive features. The following discussion in Excerpt 8.1 provides an example of this discourse in action.

\section{Excerpt 8.1}

Steven Wheeler, 43-47 year old NZ European/Pākehā male Setting: Wellington café Context: I have just explained the aims of my project.

Time: 0:14.9-0:34.5

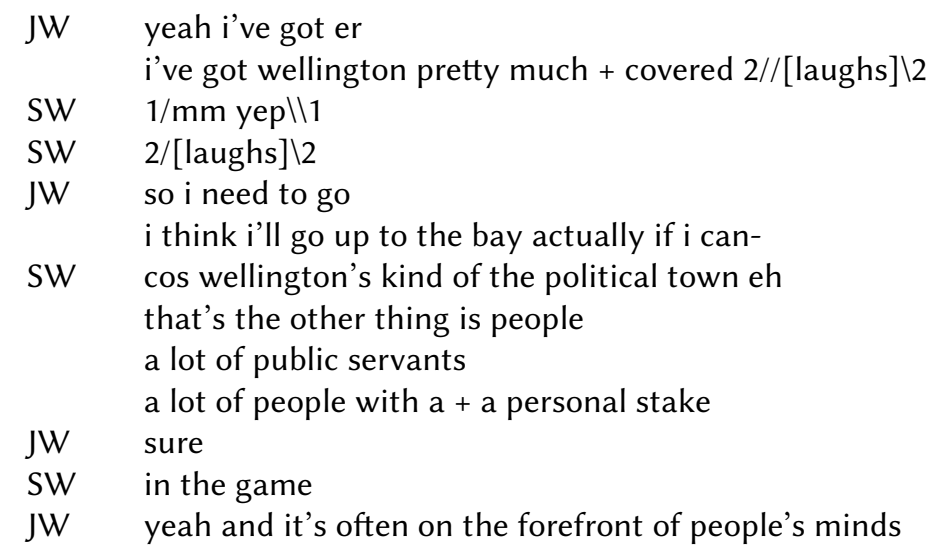


so they yeah

I explain to Steven the progress of my research at a time when I was aiming to talk to people outside of Wellington. In response to this, Steven notes that wellington's kind of the political town eh (line 7), directly indexing the political city discourse, and using the characteristic New Zealand English pragmatic tag $e h$ at the end of this clause (Meyerhoff, 1994). In accessing the political city discourse, Steven refers to a lot of public servants (line 9) and those with a personal stake (line 10), which could refer to aspiring politicians, lobbyists or union officials, or even those with strong personal interest in New Zealand politics, further accessing the discourse through less direct means. I align with Steven's stance by evaluating Wellington the same way, providing positive feedback sure (line 11) and agreeing and elaborating yeah and it's often on the forefront of people's minds (line 13). Both Steven and I are cooperatively characterising Wellington and its inhabitants as particularly political, aligning our stances with each other by demonstrating that our understandings of the city are compatible. This also has the effect of generating our Wellingtonian identities by mutually indexing socially accepted aspects of this discourse (Gee, 2014; Silverstein, 2003).

Steven continued to draw upon this discourse throughout the conversation, reaffirming our initial stance alignment and identities, as shown in Excerpt 8.2.

\section{Excerpt 8.2}

Steven Wheeler, 43-47 year old NZ European/Pākehā male

Setting: Wellington café

Context: Steven has just finished signing the consent form.

Time: 6:45.0-7:13.0

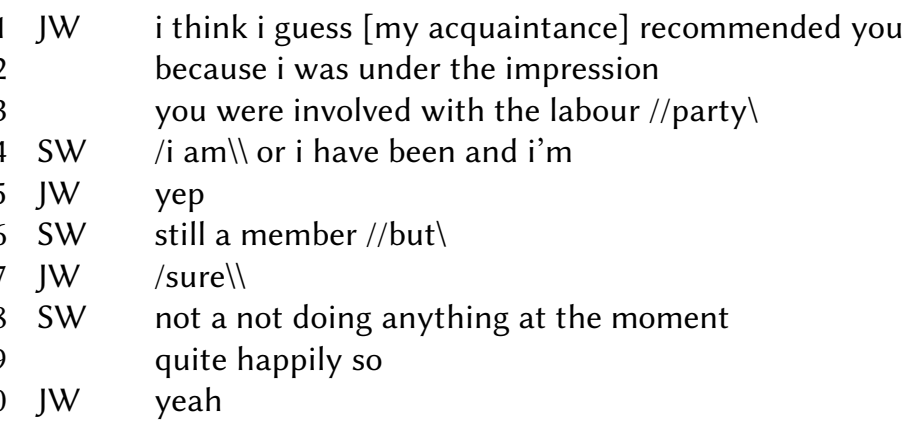




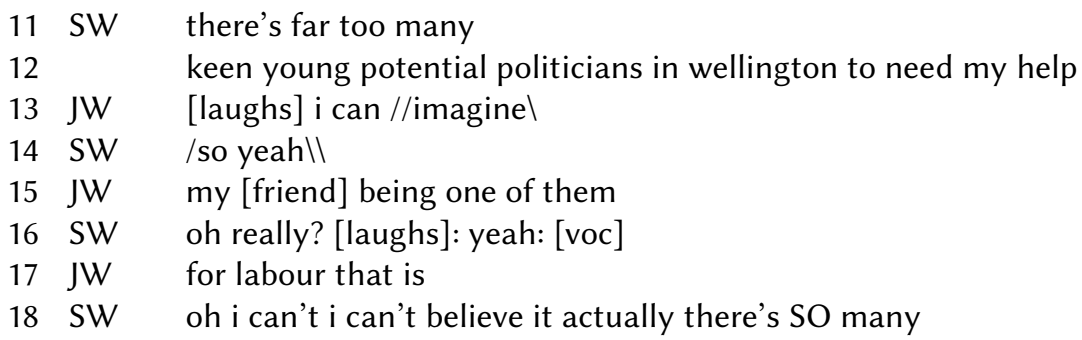

I begin the discussion by mentioning our acquaintance's recommendation of him as a candidate for this research (lines 1-3). Steven mitigates the stance I attribute to him, you were involved with the labour party (line 3), by diverging in alignment, not doing anything at the moment quite happily (lines 8-9). His mitigation of my identity ascription is linked to his dissatisfied Labour member identity, also evident elsewhere in our conversation, which relates to Labour's then poor performance in the opinion polls. Steven then elaborates his reasoning behind this by mentioning that there's far too many keen young potential politicians in wellington to need my help (lines 11-12). I align with Steven's view of Wellington being full of potential Labour politicians by providing evidence that $\mathrm{I}$, in fact, know someone who fits this description, my [friend] being one of them... for labour that is (lines 15-17). Steven finds this an amusing confirmation of his original point (line 16) and returns to strengthen his point with emphatic stress, oh i can't believe it actually there's SO many (line 18), which carries within it elements of evaluation, perhaps negative, through his tone of (mock) disbelief (Manusov \& Trees, 2002). Throughout this exchange, Wellington is characterised as both political and Labour, a discourse that is indexed by other participants and which is discussed further in the following section.

In Excerpt 8.3, Steven explains how Wellington is unique in terms of the political engagement of its citizens, in comparison to those in the rest of the country. He sets up a city/provincial divide, a form of us/them polarisation (van Dijk, 1998, 2006a), that contributes to the contrast of Wellington to other places in the country.

Excerpt 8.3

Steven Wheeler, 43-47 year old NZ European/Pākehā male Setting: Wellington café

Context: Steven has mentioned that he has witnessed low political 
interest in provincial New Zealand.

Time: 21:31.4-21:49.0

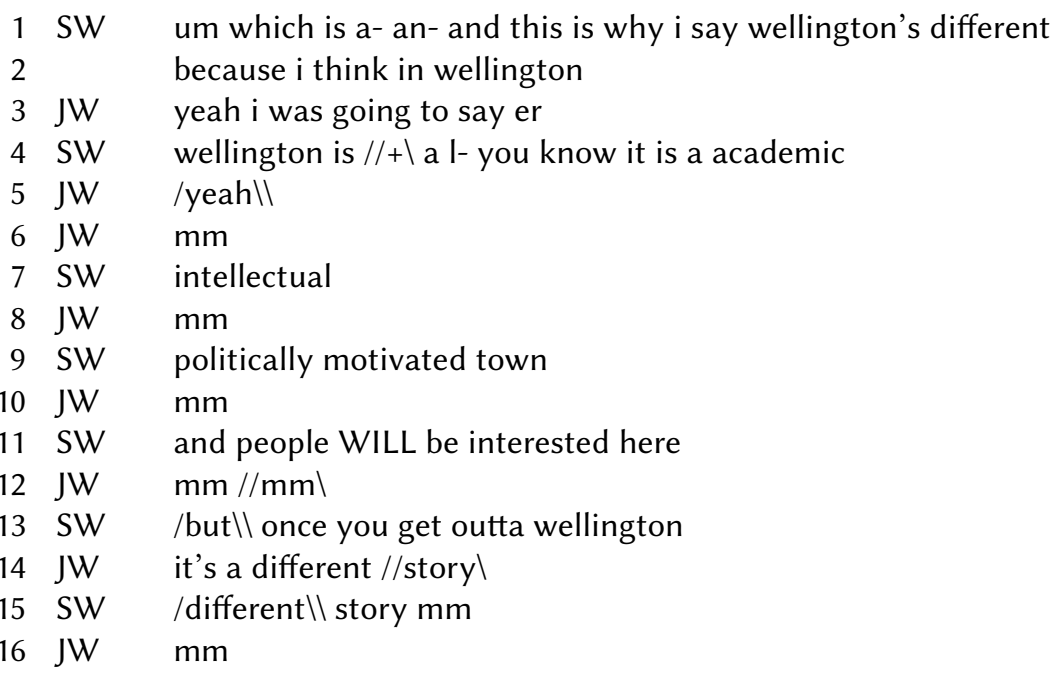

Steven describes Wellington as different (line 1) in comparison to the provinces, and expands on this with the adjectives academic, intellectual and politically motivated (lines $4^{-9}$ ). Taken in context, Steven is comparing Wellington to the provincial North Island towns in which he used to work with the Labour Party and where he attended numerous town hall meetings. According to him, in Wellington people WILL be interested [in politics] here (line 11), a view he outlines with particular emphasis. The opposition Steven sets up between the provinces and the city continues to be referred to throughout his talk and functions to characterise Wellington as particularly politically engaged. Steven's stress on WILL (line 11) underlines this point. My minimal response throughout provides acknowledgement and signals my engagement (Coates, 2013; Gardner, 1997). I join in at the end, aligning with his stance by pre-empting his utterance it's a different story (line 14) which he then overlaps with and echoes (line 15). Again, our Wellingtonian identities are being strengthened in relation to the provincial 'outsider.'

Steven provides a clear example of how being in political Wellington influenced interaction, particularly through explicit characterisation of the city. Steven was not the only participant to portray Wellington in this way. In Excerpt 8.4, Cate sets up an opposition between Wellington and Christchurch (a city in which she had spent 
some time), likewise contributing to the discourse of contrast (see also the 'ideological square' of van Dijk, 1998).

\section{Excerpt 8.4}

Cate Mclver, 18-22 year old NZ European/Pākehā female Setting: Wellington café

Context: Cate has been comparing Wellington to Vancouver where she earlier lived.

Time: 19:59.0-20:50.3

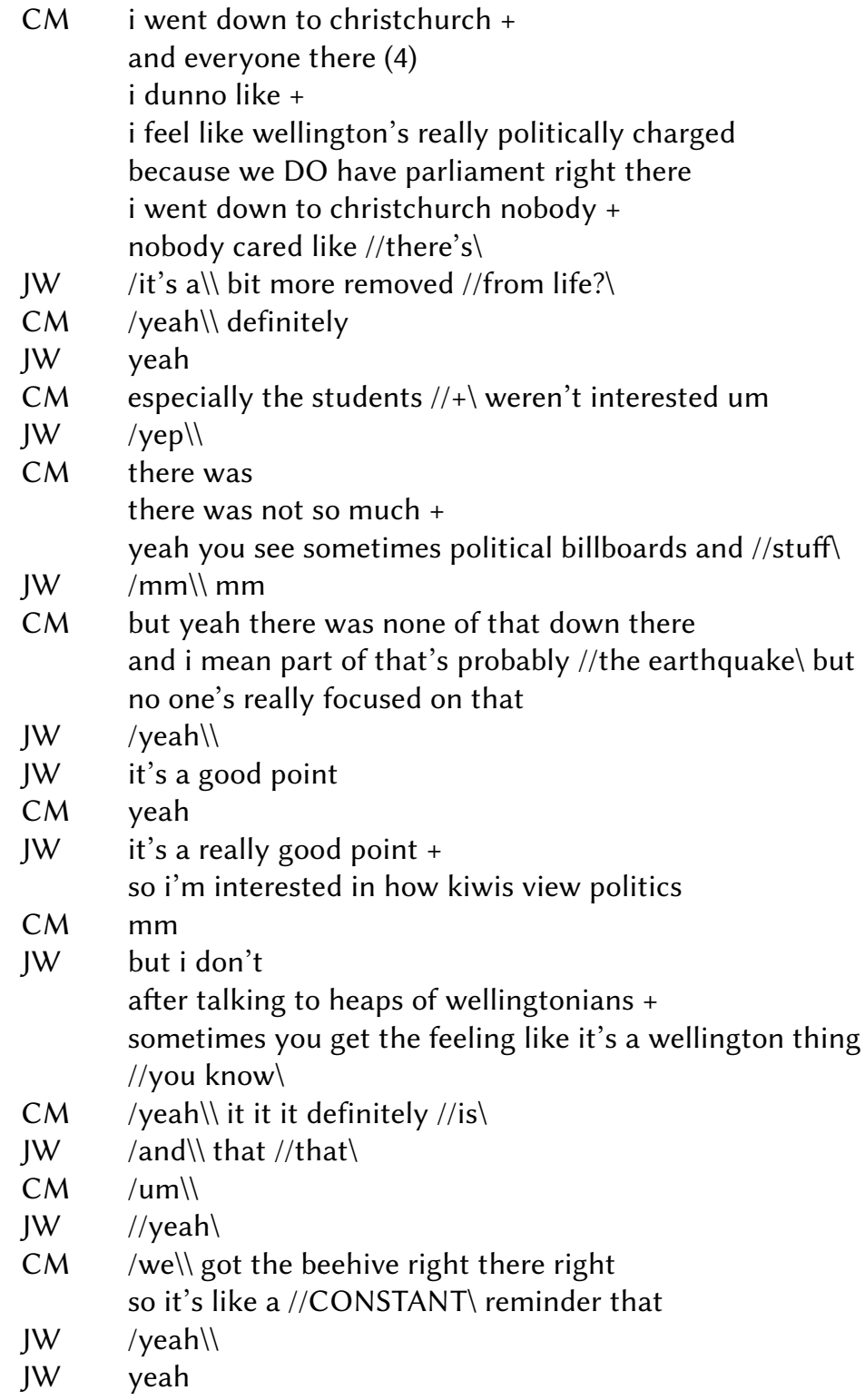


38 CM they're lurking

39 JW yeah yeah

Cate, like Steven, sets up an opposition between Wellington and, in her case, Christchurch, by describing Wellington as really politically charged (line 4) and giving examples that contrast this to Christchurch, students + weren't interested (line 11) and you see sometimes political billboards and stuff... there was none of that down there (lines 15-17). The physical extra-discursive setting becomes relevant as Cate orients to the presence of Parliament in downtown Wellington: we DO have parliament right there (line 5) and her tongue-in-cheek observation we got the beehive right there right so it's like a CONSTANT reminder that...they're lurking (lines 34-38). Cate's pronoun use indicates a different kind of division between us (Wellingtonians) and them (the politicians; see, for example, Leudar, Marsland and Nekvapil, 2004, p. 246; Baxter and Wallace, 2009, pp. 417-418). Her use of humour at the end of the excerpt, they're lurking (line 38), demonstrates her personal view of politics and politicians as somewhat untrustworthy or cunning, and even at times laughable, evaluations which are further developed throughout our discussion. Evaluation is a central component of any stance act and therefore her stancetaking has the potential to influence the ongoing genesis of her political identity.

The political Wellington discourse was also indexed in less direct ways. Joe, in Excerpt 8.5, characterises Wellington as political and couples it to the small town discourse.

\section{Excerpt 8.5}

Joe Branstad, 78-82 year old NZ European/Pākehā male

Setting: Joe's living room

Context: Joe was explaining what he takes being 'political' to mean.

Time: 1:45.2-2:05.0

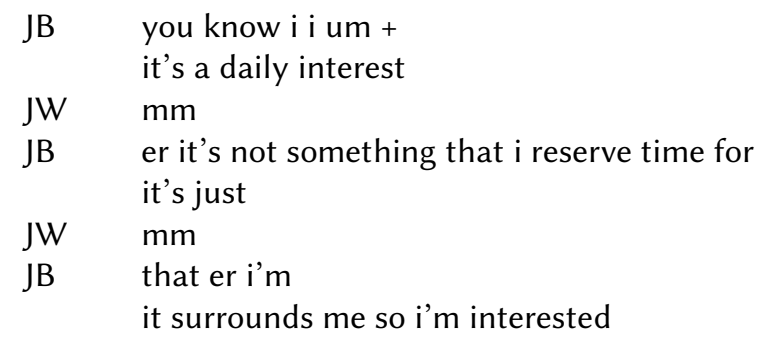




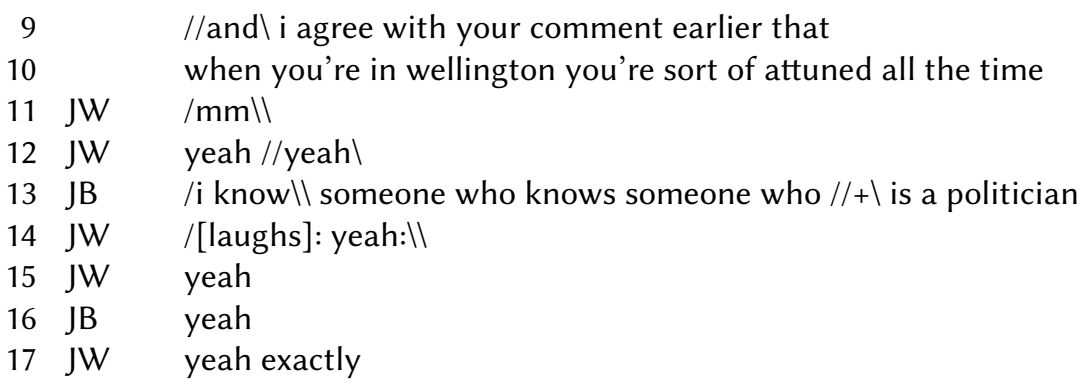

Joe first describes politics as a daily interest (line 2) but then states $i t$ 's not something that $i$ reserve time for (line 4 ). He could be referring to politics in Wellington as somewhat unavoidable, indexing the political town discourse, and providing the reason for him not devoting time to it. Joe's following utterance, it surrounds me so i'm interested (line 8) supports this interpretation. This functions to align him with my earlier index of the political town discourse that occurred before the recorder was turned on, during the signing of the forms (this was the first discussion that I held and I was not yet aware of the importance of switching the recorder on as early as possible; see Chapter 5). During my explanation of the project, and before Wellington discourses had arisen as a salient analytical category, I mentioned that Wellington was a good place to carry out this sort of research due to participants being generally 'clued in' to political goings on. Joe explicitly aligns with me in reference to my earlier utterance, i agree with your comment earlier that when you're in wellington you're sort of attuned all the time (lines 9-10). He elaborates by coupling it to the small town discourse, $i$ know someone who knows someone who + is a politician (line 13), a variant of 'everybody knows everybody', explored in Section 8.4. To Joe, Wellington is clearly a political place due to its status as the political heart of the country and enhanced by the fact that there is a high likelihood of coming across politicians in everyday life in the city.

In Excerpt 8.6, Michelle refers to the visibility of politicians as being a defining feature of Wellington, again in contrast to other places in the country.

\section{Excerpt 8.6}

Michelle Dempsey, 18-22 year old NZ European/Pākehā female

Setting: Wellington café

Context: I have asked Michelle if she thinks Wellington is different to 
other places in NZ.

Time: 18:42.1-19:38.2

MD well [laughs] two weeks ago

2 i was just in [shop]

3 at the [brand] counter

and winston peters [leader of NZ First] walked past me like where else in new zealand

are you gonna get that sort of good value entertainment //you knowl

JW /do you work \\ there or

$\mathrm{MD}$ no

JW oh ()

MD just just standing there [laughs]

12 oh winston + hi

yeah + um i know you can go and

you know obviously do the protests

if you so desired

much more easily than anyone else could

um ++ yeah $1 / /+\backslash 1$

it's just [laughs] how it is and all the people

um you know lobbyists and $2 / /+\mid 2$ stuff down here

$3 / /$ so they're trying $\backslash 3$ to get into that scene

JW $1 / \mathrm{mm} \backslash 1$

JW $2 / \mathrm{mm} \backslash 12$

JW 3/so you reckon $\backslash 3$

JW so you reckon politics is probably a bit more visible down here than the rest of the country or

MD probably on part

i mean auckland

i haven't really lived in auckland so i wouldn't know

but $i$ imagine you would see + a number of people and um

JW mm

MD political things happening up there $1 / /+$ as $\backslash 1$ well but + you know i like to think that because the [laughs]: beehive's here: you see it and you kind of go oh $2 / /+\backslash 2$ politics [laughs]

JW $/ \mathrm{mm} \|$

JW /yeah \I

JW yeah

MD [laughs]

8 JW yeah

39 MD on the bus

40 JW [mock awe]: centre:

41 MD [mock awe]: politics:

42 JW yeah

$43 \mathrm{MD} / /[$ laughs $] \backslash$

44 JW /[mock awe]: capital:॥ [laughs] 
Michelle uses narrative to present Wellington's politicians as readily visible, introducing it with discourse marker well (line 1; Schiffrin, 1987) and then orienting to past time, two weeks ago (line 1; Labov and Waletzky, 1967). Michelle describes her experience, $i$ was just in [shop] at the [brand] counter and winston peters walked past me like (lines 2-4). A positive evaluation of the experience follows, where else in new zealand are you gonna get that sort of good value entertainment (lines 5-6), followed by coda you know (line 7; Labov and Waletzky, 1967). The narrative told in this context has the pragmatic function of responding to my line of questioning by portraying Wellington as a political place through a narrative of personal experience (Labov \& Waletzky, 1967). It also draws on the small city discourse, in that she mentions seeing politicians in local shops, which is discussed further in Section 8.4. She then returns to her story, which she finds humorous, just just standing there [laughs] (line 11), and then simulates an exchange with Winston Peters, oh winston + hi (line 12), an example of direct speech in a narrative frame (Baynham, 1996; Coulmas, 1986) which serves to introduce her own voice into the story (Tannen, 1986).

Michelle follows with further examples of Wellington as political, stating that $i$ know you can go and you know obviously do the protests if you so desired (lines 13-15), which appears to contain an element of negative evaluation through if you so desired (line 15). She then presents a similar view to that of Steven, all the people um you know lobbyists and + stuff down here so they're trying to get into that scene (lines 18-20). My line of questioning, so you reckon politics is probably a bit more visible down here than the rest of the country or (lines 2425) prompts Michelle to compare Wellington to Auckland, though she hedges by stating $i$ haven't really lived in auckland so $i$ wouldn't know (line 28), which leads in to her hypothetical comparison, but i imagine you would see + a number of people and um...political things happening up there + as well but (lines 29-31). She then makes a statement similar to Cate's mention of the physical arrangement of the city, $i$ like to think that because the [laughs]: beehive's here: you see it and you kind of go oh + politics [laughs] (lines 32-33). This again indicates the importance of the extra-discursive referents of this discourse. The tone here is light-hearted and we have a humorous exchange at the end of the excerpt where we collaboratively joke in mock awe of 
Wellington's political buildings and capital status, which functions to align us further (lines 40-44). Clearly, then, this discourse is important in our intersubjective stancetaking (Chapter 9) and identity genesis.

Wellington is clearly a political city to many of the participants in this study. This constitutes a subnational discourse which provides a way of thinking about the city and appropriate ways of talking about it, indexed most directly through adjectives such as 'political' and 'politically charged', and also in more subtle or complex ways, such as through narrative or humour. The political context of this discourse is also relevant to the genesis of political identities. It exists alongside and is intertwined with the other subnational discourses that are explored in the following sections.

\subsection{LEFT-WING WELLINGTON}

Wellington was not only characterised as political but a particular stripe of political, that of the liberal left-wing. Wellington voters have elected a Labour Party candidate to the seat of Wellington Central at every election since 1999 (Electoral Commission, 2015). In its neighbouring electorate, Rongotai, which encompasses Wellington's eastern suburbs and the Chatham Islands, Labour MP Annette King has been elected at every general election since 1996 (Electoral Commission, 2015). While the majority party vote often oscillates between Labour and National at general elections, there is a strong perception arising from the participants that Wellington is a left-wing city, possibly due to the large population of public servants working at the many ministry offices around the city and the high number of university students, two groups who are generally characterised as being more sympathetic to left-wing politics. In Excerpts 8.7a and $8.7 \mathrm{~b}$, Steven provides an example of left-wing Wellington in the form of high levels of support for Labour, which is underpinned by the extra-discursive voting patterns of its inhabitants, followed by explicit description of the city within the bounds of this discourse.

Excerpt 8.7a

Steven Wheeler, 43-47 year old NZ European/Pākehā male

Setting: Wellington café

Context: We have been talking about centre and centre-right Labour 
support in parts of New Zealand.

Time: 10:30.0-10:38.4

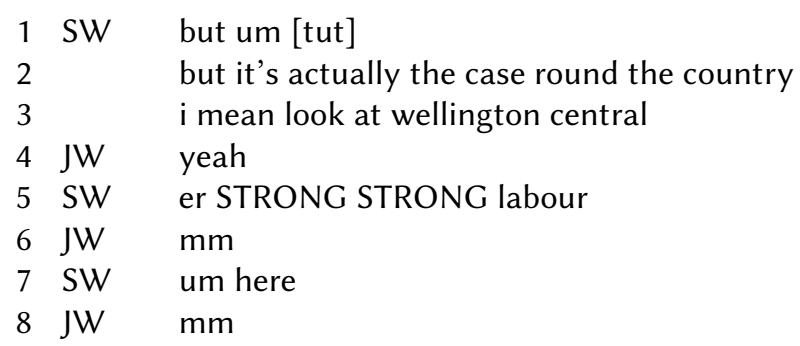

\section{Excerpt $8.7 \mathrm{~b}$}

Context: I have asked Steven if he knows anyone else who would be keen to talk to me, particularly those with right-wing views.

Time: 46:54.5-46:59.5

1 SW it's a it's a left wing town to a large //extent \

$2 \mathrm{JW} /$ it is $\backslash / /$ yeah

3 SW /it's $\backslash$ the bloody p s a [Public Service Association] for you

4 JW yeah

5 SW er [laughs]

In Excerpt 8.7a, Steven explicitly describes Wellington central as STRONG STRONG labour (line 5), his emphasis underscoring the perception (and reality) of the electorate aligning with Labour Party candidates (Electoral Commission, 2015). After the end of this excerpt, he goes on to say that it is mainly young professionals with few children voting Labour in Wellington, people who in his view would be traditional National or ACT supporters. This perhaps indicates that rather than coming from students and public servants, Labour support in Wellington comes from a broader range of people than would be expected. Later in the interaction, in Excerpt $8.7 \mathrm{~b}$, he provides a related stance, stating explicitly that Wellington is a left wing town to a large extent (line 1). Steven indicates an orientation to the general understanding of Labour as a left-wing party given his previous mention of their predominance in the city. I align with Steven, it is yeah (line 2), and he attributes this humorously to the PSA (line 3), the union representing public servants in New Zealand, the headquarters of which is based in Wellington. I do not immediately pick up Steven's attempt at humour, it's the bloody $p$ s a for you (line 3), as I am perhaps confused by his statement; his identity as 
a Labour supporter, in my view, entails positive evaluation of the PSA. My misunderstanding is indicated in straightforward agreement, yeah (line 4), before a hesitation and laugh from Steven (line 5) which serves to mark his prior utterance as an attempt at humour which trades on the incongruity of his utterance (Berger, 1976; Meyer, 2000; Morreall, 1983, 2009). Steven's evaluation of Wellington as left wing (line 1) is followed by this humour perhaps to enhance solidarity and rapport between us (Vine, Kell, Marra \& Holmes, 2009) and to end the discussion on a positive and light-hearted note. It also serves to build on Steven's dissatisfied and critical Labour supporter identity, as discussed in Chapter 10. His drawing on this discourse could be a way of ratifying the place in which he chooses to live due to its alignment with his party political support.

Wellington's left-wing nature also arose in conversation with other participants. In Excerpt 8.8, Chelsea comments explicitly on her perception of the political leaning of the city.

Excerpt 8.8

Chelsea Brentwood-White, 18-22 year old NZ European/Pākehā female

Setting: Wellington café

Context: I asked whether she grew up in Wellington and we talked about her high school and the high number of single-sex schools in the city.

Time: 57:49.6-58:27.5

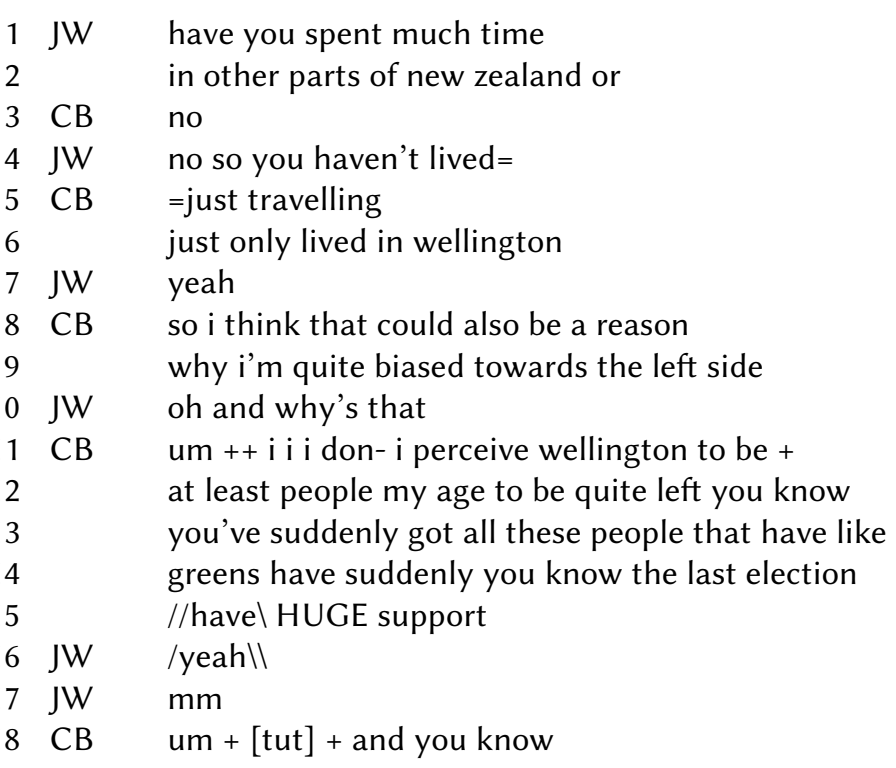




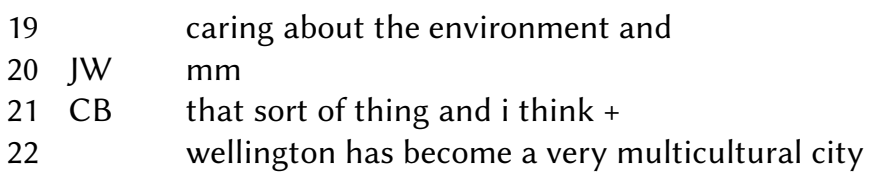

Chelsea, a Labour voter, mentions that she has spent the majority of her time in Wellington, citing this as the reason for being biased towards the left side (line 9). Her use of the term biased indicates that she is aware of other ways of approaching political thinking, though appears comfortable with her use of left indexing a left-wing political identity. Chelsea conceptualises left-wing to mean caring about the environment (line 19) and being multicultural (line 22), and then goes on after the end of this excerpt to elaborate with a narrative about witnessing multiculturalism in the city. Chelsea mentions that $i$ perceive wellington to be...quite left (lines 11-12) which confirms that, in her mind, Wellington has a clear political ideological proclivity toward the left-wing, likely comprising the Green and Labour parties, and that living in the city influences its inhabitants' political views. Chelsea hesitates, including false starts, $u m++i i$ idon- (line 11), her use of both filled and unfilled (silent) pauses (Maclay \& Osgood, 1959) likely an indicator of increased cognitive load as she chooses a way to answer my question (Corley \& Stewart, 2008, p. 590). She then provides evidence supporting her view, you've suddenly got all these people that have like greens have suddenly you know the last election have HUGE support (lines 13-15), her use of emphatic stress underlining her point and concluding her argument. In the same way as Steven, the left-wing town discourse aligns with her own political identity.

Similar sentiments are echoed by Cate. In both Excerpts 8.9a and 8.9b, Cate portrays Wellington as 'liberal' (in this context related to the centre-left, see discussion below). This removes the emphasis from partisan politics as conveyed by the term 'left-wing' and focuses attention on social issues, in this case, same-sex marriage (or marriage equality), a topic that was undergoing Parliamentary debate when our discussion took place.

Excerpt 8.9a

Cate Mclver, 18-22 year old NZ European/Pākehā female Setting: Wellington café 
Context: Cate has mentioned that the majority of people are in favour of marriage equality and those who are against it should accept it in the spirit of democracy.

Time: 9:01.0-9:07.4

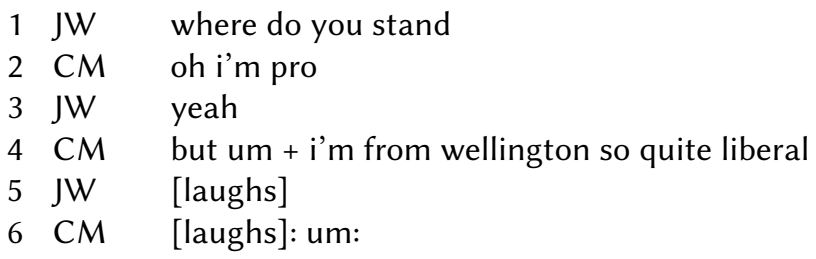

\section{Excerpt 8.9b}

Context: Cate has been talking about a National supporter friend of hers who may like to participate in the project.

Time: 1:13:23.3-1:13:35.1

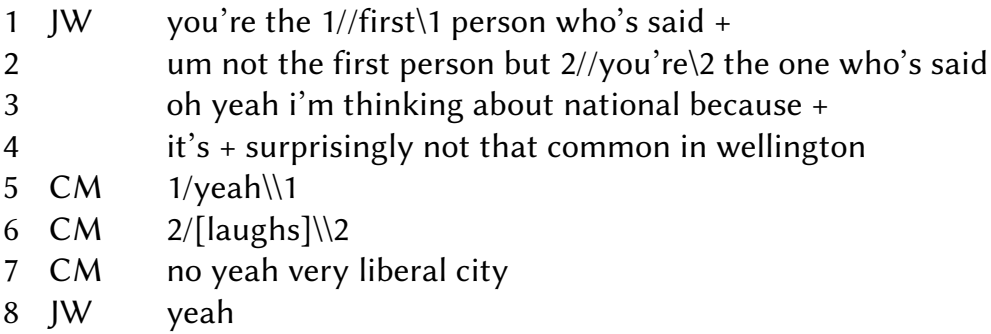

Cate uses the label liberal to characterise firstly herself then Wellington in both excerpts (lines $4 / 7$ ). As suggested by the wider context, her reference is likely to social liberalism rather than classic liberalism (the latter of which is represented in New Zealand by the ACT Party of which Cate had earlier been highly critical). There are two indicators of her understanding of the term 'liberal' which support this interpretation. In Excerpt 8.9a, Cate notes that she is supportive of marriage equality, an issue that at the time was closely associated with the centre-left-wing, having been raised in Parliament through the member's bill of Louisa Wall, a Labour MP. In Excerpt 8.9b, I mention that Cate is one of only a few who have explicitly told me they are considering voting National, to which she replies no yeah very liberal city (line 7). In other words, Wellington, in her mind, is not centre-right or conservative, the implication being that it is a leftwing city. I also contribute to this by indexing the same discourse, it's + surprisingly not that common in wellington (line 4 ). 
In Excerpt 8.9a, Cate shows clearly how the discourse of left-wing Wellington affects her political stancetaking: she is pro [marriage equality] (line 2) which is treated as a given because she is from wellington so quite liberal (line 4), a statement which evokes mutual laughter (lines $5^{-6}$ ). This is an example of the discourse interacting with a participant's own social views and used as an explanation for such, again resembling Chelsea's argument about her leftist 'bias' being due to influence of the city. It also demonstrates that social issues may be more important to Cate as a liberal even though she later notes that she sympathises with National's financial and economic policies.

Excerpt 8.9b provides more evidence of Cate drawing on the same discourse as she again uses the adjective liberal (line 7) to characterise Wellington. As Cate voted National at the 2011 election her earlier personal characterisation as liberal is particularly interesting yet not entirely unsurprising; in New Zealand, supporting a centre-right party does not preclude socially liberal beliefs, a high profile example of which being the leader of the National Party and Prime Minister, John Key, who voted in favour of marriage equality at all three readings of the bill (Parliamentary Library, n.d.). This suggests that to Cate, left-wing and liberal are perhaps not entirely synonymous, as the former may relate to political support and thus a label that she would not apply to herself whereas the latter may refer to socially liberal views evidenced in her support of marriage equality. She does, however, index a similar discourse to Steven and Chelsea of Wellington as a left-wing town, at least partially through her concern with social issues, and in less direct terms. This provides evidence for the many ways in which discourses can be indexed; while Cate chooses 'liberal', a term which aligns with her political views, the others gain access through 'left wing' which is suitable given their statuses as Labour and Greens supporters and the alignment of this term with their respective political identities.

The excerpts presented in this section demonstrate a general orientation to Wellington as a left-wing city. This relates to different issues for each participant: union presence, as mentioned by Steven; environmentalism and multiculturalism, in Chelsea's case; and for Cate, support for marriage equality. The participants use either 'left wing' or 'liberal' to index a similar discourse in more or less direct 
ways (Ochs, 1992, 1993). It is apparent that Wellington city itself, whether its physical or social composition, has a strong influence on the political views of its inhabitants and therefore on the way in which their political identities are generated in this context.

\subsection{EVERYONE KNOWS EVERYONE}

As discussed in Chapter 6, Wellington is a geographically contained area, lying between hills and the sea. The city has a compact downtown area that is easily walkable but many of its suburbs are located on inclines, making it known for its narrow, winding streets. Wellington is a capital city with the feeling of a large town, and as a result, finding mutual acquaintances with those just met is a common experience. A refrain often heard in the city, as in the smaller towns and townships of New Zealand, is that 'everyone knows everyone' (Kennedy, 2008, p. 406). This adage is frequently borne out in my own experience. Besides its clear advantages in snowball method recruiting (Chapter 5), the small size of Wellington city is a salient feature of the discourse of participants used to characterise the local context of the study. It is more 'material' in nature than the above two discourses but still forms an important part of the discursive and structural context in which identity genesis takes place.

As shown in Excerpt 8.1, Steven refers to Wellington city as kind of the political town eh (line 7). Technically, the term 'town' is generally reserved for places with fewer than 50,000 inhabitants (Statistics New Zealand, n.d.), though the population of Wellington city is around 191,000 (Statistics New Zealand, 2015b). Steven's reference to Wellington as a town contributes to the small town discourse and may be a marker of affectionate familiarity perhaps influenced by the collocations 'small town' or 'home town.' Joe, in Excerpt 8.5, mentions that $i$ know someone who knows someone who + is a politician (line 13), linking the small town discourse with the political city discourse. Michelle, in Excerpt 8.6, offers a narrative that highlights the experience of those who live in small town Wellington, recounting being in [shop] at the [brand] counter and winston peters walked past $m e$ (lines 2-4). This is evidently a salient subnational discourse (with material referent) that is indexed in talk about the city. 
The small town discourse was especially prominent for Maryam and Ali, an Iranian couple who immigrated to New Zealand over twenty years ago, who were accustomed to the much larger cities of their homeland. In Excerpt 8.10, the experience of living in a small city is borne out as members of the small group of participants realise that they know a person in common. The small town discourse, indexed by the phrase 'everyone knows everyone', is used afterwards to evaluate the exchange.

\section{Excerpt 8.10}

Maryam Hassani and Ali Ahmadi, 68-72 year old Iranian couple Also present are two Iranian acquaintances known to the researcher and participants, Ariana (AR) and Yasmin (YA)

Setting: Maryam and Ali's living room

Context: We have finished talking about politics and are chatting about life in Wellington.

Time: 1:03:37.0-1:04:49.8

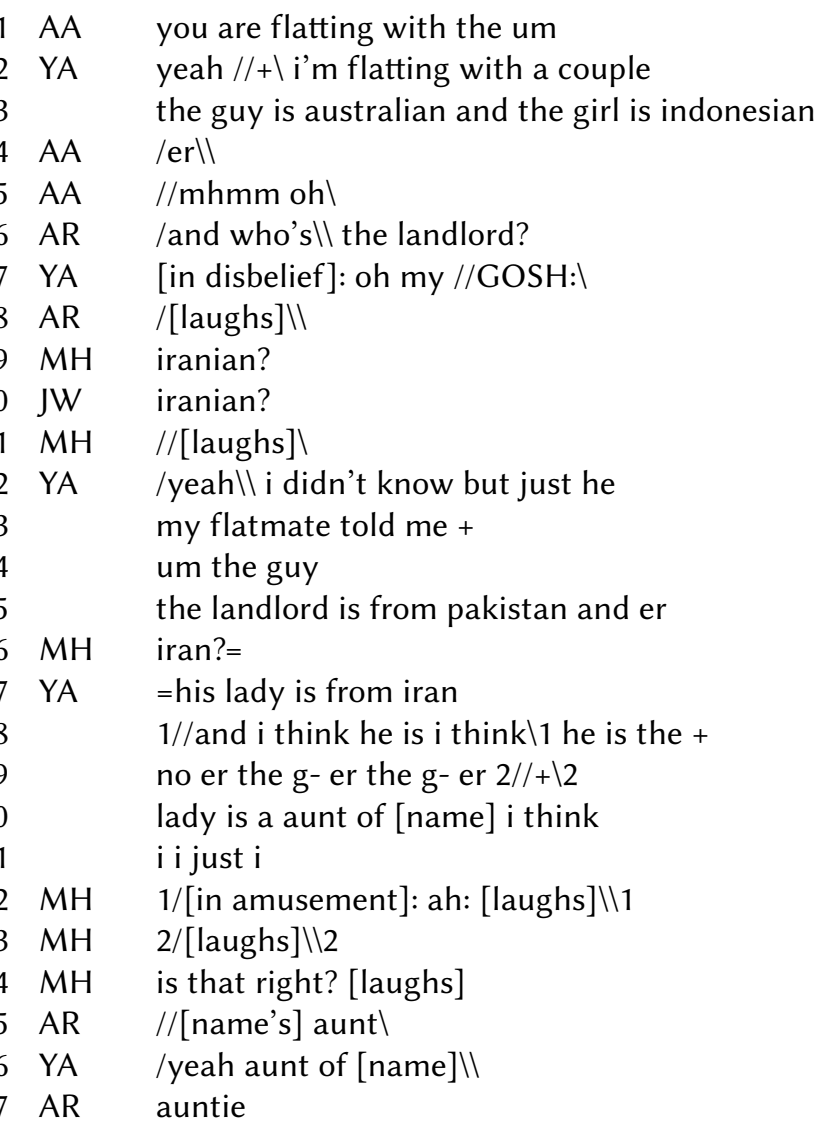




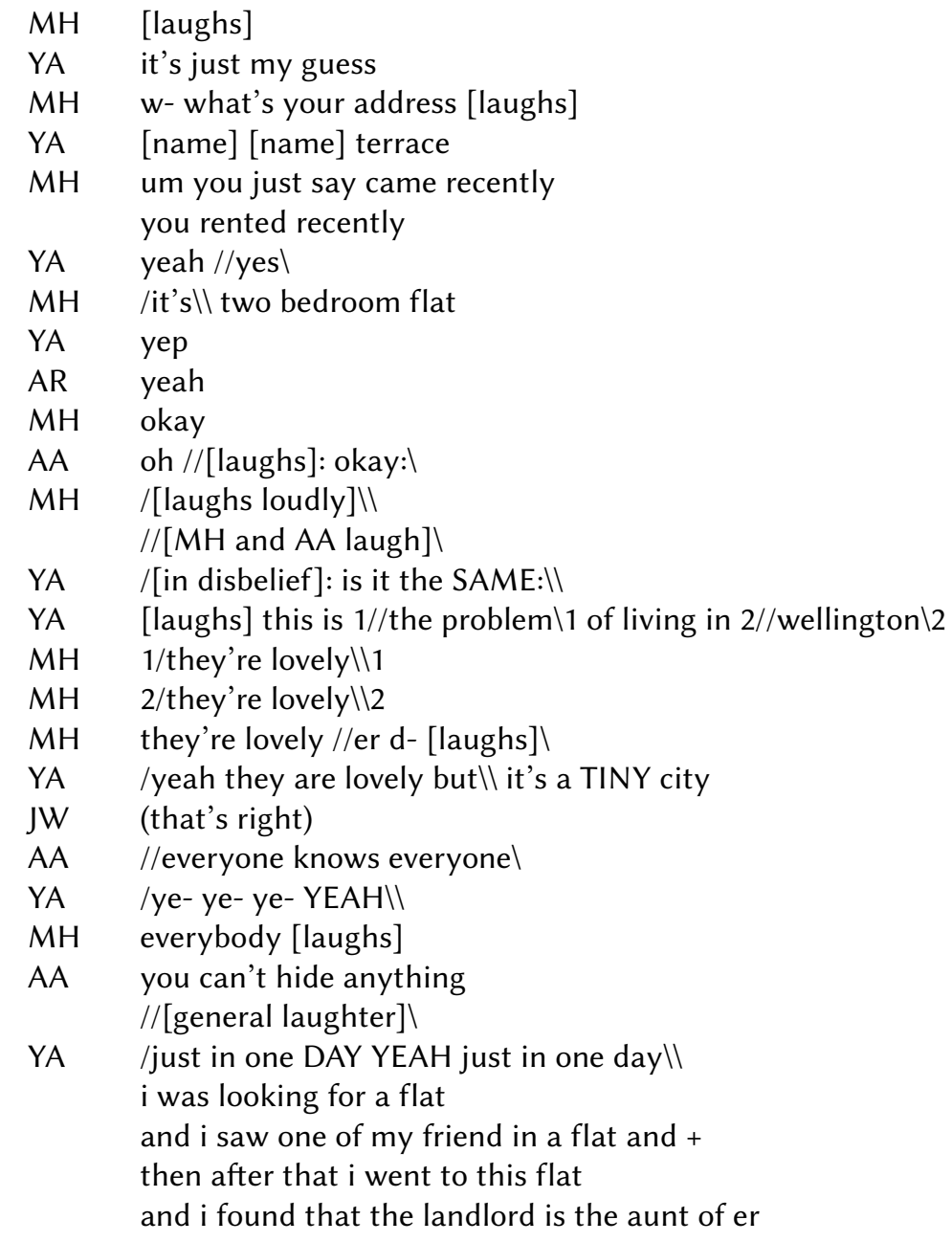

Yasmin responds to Ali's question about her flatting arrangement (lines 2-3) and they then find amusement in the fact that the landlord is also Iranian, oh my GOSH (line 7), followed by laughter (lines $8,11)$. Maryam keeps a straight face while giving details about the flat, it's two bedroom flat (line 35), and from there Ali realises that Maryam in fact knows the woman in question oh [laughs]: okay: (line 39). Maryam then indicates, with hearty laughter (line 40), that she knew all along. Yasmin's reaction, is it the SAME (line 42), leads into a spontaneous example of the small town discourse in action, this is the problem of living in wellington (line 43). This excerpt captures the moment where everyone realises that Maryam knows who Yasmin is talking about and the amusing aftermath of this realisation (line 41-58). This exchange is shot through with humour and the copious 
laughter indicates the entertainment the small town provides. The humour is notable as it indicates that 'everyone knows everyone' is not a negative phenomena; in fact, it is a source of amusement and can even be valued, as discussed in relation to Excerpt 8.11. From my own experience, exchanges like this occur regularly in Wellington. After the realisation that they indeed know the same person, the participants orient to the small town discourse in an evaluation of what just happened. Yasmin mentions that it's a TINY city (lines 47) and Ali adds to this everyone knows everyone (line 49) and further contributes to the humour by joking that you can't hide anything (line 52), his implication that Yasmin may have something to hide prompting laughter from everyone (line 53). Yasmin then tells a short narrative summarising her experiences, in which she saw her friend and an aunt of another friend in the same day of flat hunting (lines 55-58). The narrative here serves to further substantiate her earlier evaluation while drawing again on the small town discourse. This experience is further enhanced by the small size of the Iranian population in Wellington, comprising only 222 individuals, $6.9 \%$ of the total Iranian population in New Zealand (Statistics New Zealand, $2015 \mathrm{~b}$ ). As a result the community is particularly close-knit, meaning that their social network is more dense and multiplex (Milroy \& Milroy, 1985; Milroy, 1987b; Milroy \& Milroy, 1992). An Iranian meeting another in the city has a high likelihood of either knowing them or being familiar with someone in common. This is in addition to the reality of Wellington as a small town which likely magnifies the frequency of such encounters.

In excerpt 8.11, Maryam and Ali exhibit an orientation to the small town discourse and its extra-discursive referents.

\section{Excerpt 8.11}

Maryam Hassani and Ali Ahmadi, 68-72 year old Iranian couple

Also present are two Iranian acquaintances known to the researcher and participants, Ariana (AR) and Yasmin (YA)

Setting: Maryam and Ali's living room

Context: Maryam and Ali have been talking about their choice between living in Australia or New Zealand.

Time: 1:10:37.4-1:11:07.7

$1 \mathrm{AA}$ we had the chance to go there 


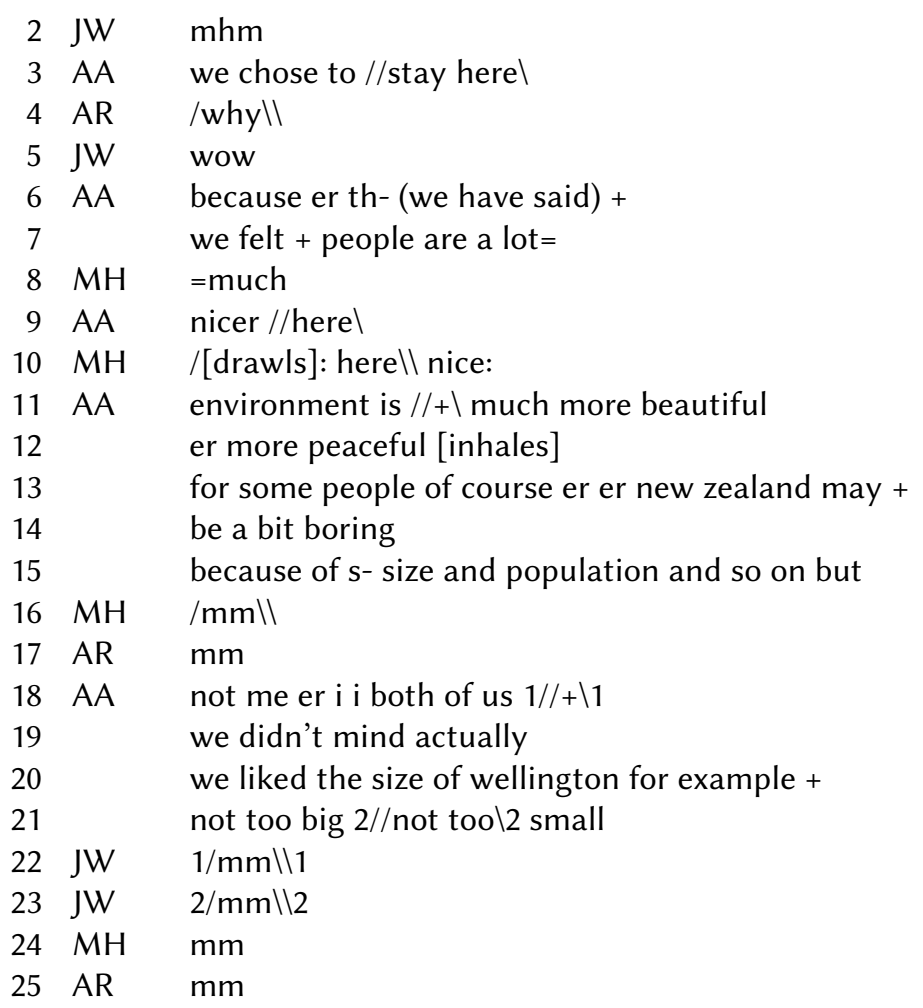

Ali tells the story of their family's choice between settling in New Zealand or Australia. The characteristics that convinced them were the people, we felt + people are a lot... nicer here (lines 7-9), the scenery, environment is + much more beautiful er more peaceful (lines 11-12) and the size, particularly Wellington, we liked the size of wellington for example + not too big not too small (lines 20-21). The comparatives nicer (line 9), more beautiful (line 11) and more peaceful (line 12) provide a direct contrast to Australians and Australia and as such function as a positive evaluation of New Zealand and its people which appears to contribute to their proud New Zealander identities. Ali orients to hypothetical criticisms of the small country as being a bit boring because of $s^{-}$size and population (lines 14-15) but notes that this did not bother them in their choice of New Zealand as their home, we didn't mind actually (line 19). His positive evaluation of Wellington, signalled by the affective stance we liked (line 2o), occurs within the frame of the wider small country discourse and extradiscursive constraint. This is indicated by his mention of size and population (line 15); his initial mention of size in this context likely 
does not appear to refer to population given its subsequent mention; rather, Ali is likely referring to the physical setting of the city. He then references the size of the city again, though ambiguous as to whether he is referring to population or physical size, we liked the size of wellington for example + not too big not too small (lines 2021). Ali's positive evaluation indicates that the apparent trappings of a small city that played out in Excerpt 8.10, where everyone knows everyone, are either accepted or, perhaps, appreciated. This seems to be a characteristic of the small town discourse as it is often drawn upon in amusing situations where you find a mutual acquaintance with a stranger and, as shown in Excerpt 8.10, the tone is often light-hearted, humorous and occasionally shot through with feigned exasperation. At least for Ali and Maryam in Excerpt 8.11, the small city's physical reality is a positive feature and one of the reasons why they chose to settle there.

This kind of exchange also occurred in discussion with Cate where we realised that we were both familiar with the same person, following directly after the tall poppy excerpt discussed in Chapter 7. Again, the small town discourse is drawn on and acts as a discursive resource through which we mutually explain the occurrence.

\section{Excerpt 8.12}

Cate Mclver, 18-22 year old NZ European/Pākehā female

Setting: Wellington café

Context: Cate and I have been talking about an influential Wellingtonian.

Time: 19:01.1-19:12.0

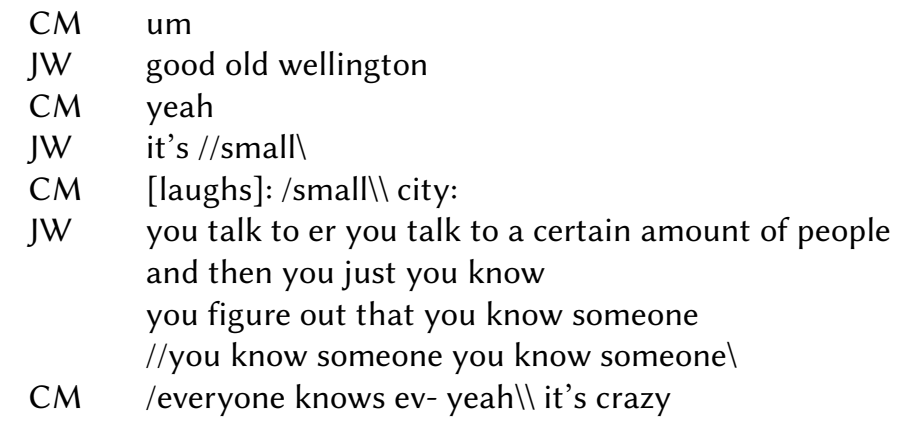

Even though I do not know Cate's acquaintance personally this is enough to invoke the small town discourse. The exchange leads me 
to draw on the discourse, good old wellington...it's small (lines 24), an evaluation of positive familiarity that Cate aligns with, yeah (line 3), and then indexes the discourse herself, small city (line 5). I go on to elaborate from my own experience undertaking research in Wellington, you talk to a certain amount of people... you figure out that you know someone you know someone you know someone (lines 6-9). Cate again aligns with me by using the truncated phrase everyone knows ev-yeah (line 10). Her evaluation of the effects of small town as crazy (line 10) is a further example of appearing annoyed and exasperated with the small city like Yasmin, yet, at least in my case, it being something that I do in fact appreciate for much the same reasons as Maryam and Ali.

The phrase 'everybody knows everybody' is not used solely to characterise Wellington. New Zealand is made up of many towns and smaller townships where it is even more likely that walking down the main street will result in seeing a friend or acquaintance. Steven, in Chapter 10, evaluates another province in New Zealand with 'everybody knows everybody', which indicates that this subnational discourse has variants in other parts of New Zealand. This raises the question of how widespread subnational discourses are around the country and how specific they are to Wellington. It also indicates the fuzziness and permeability of the border between sociocultur$\mathrm{al} /$ subnational discourses; it is likely that the small town discourse contributes to the small country discourse discussed in Chapter 6. Hence the way in which Wellington is characterised in this section could be 'expanded' to affect inhabitants' ways of thinking about New Zealand. In some ways, Wellington acts as a discursive microcosm of the entire country.

Wellington is a small capital city by international standards and its geography physically constrains the spread of the city limits. An outcome of this is a limited population size and the demographic and geographical reality is reflected through the small town discourse, drawn upon by the participants and negotiated in various ways. The discourse can often evoke exasperation, particularly if you see someone you would rather avoid. However, the sense of community that inevitably flows from seeing acquaintances around town can be, for some, a comforting and reassuring social aspect of living in a small city like Wellington. 


\subsection{WELLINGTON IN CONTRAST}

According to the participants, Wellington is a political, left-wing, small town where everyone knows everyone. The final salient subnational discourse identified in the data is a discourse of difference, or Wellington contrasted to other places in the country, which appears to function to draw attention to the uniqueness of the city. Although less obviously related to politics, this discourse is an important aspect of how Wellingtonians view themselves.

This chapter has already presented examples of Wellington as different: in Excerpt 8.3, Steven states explicitly that wellington's different (line 1) as it is academic... intellectual...politically motivated (lines $4^{-9}$ ) and also that once you get outta wellington... different story (lines 13-15). In Excerpt 8.4, Cate compares Wellington to Christchurch by saying that wellington's really politically charged (line 4) and continues on to give examples. This discourse of contrast is evident elsewhere in the data, with Wellington further characterised as different to other parts of the country. These examples are presented in this section.

In Excerpt 8.13, May and I collaborate in drawing on the discourse of contrast which functions to differentiate the capital from elsewhere.

\section{Excerpt 8.13}

May Porter, 18-22 year old NZ European/Pākehā female Setting: May's kitchen

Context: May has mentioned that we may be more conservative than we think in NZ.

Time: 12:19.2-12:51.9

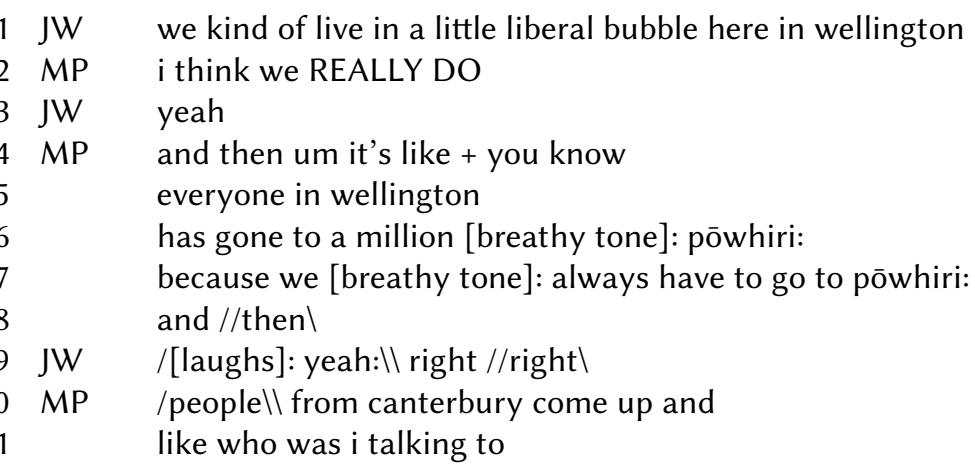




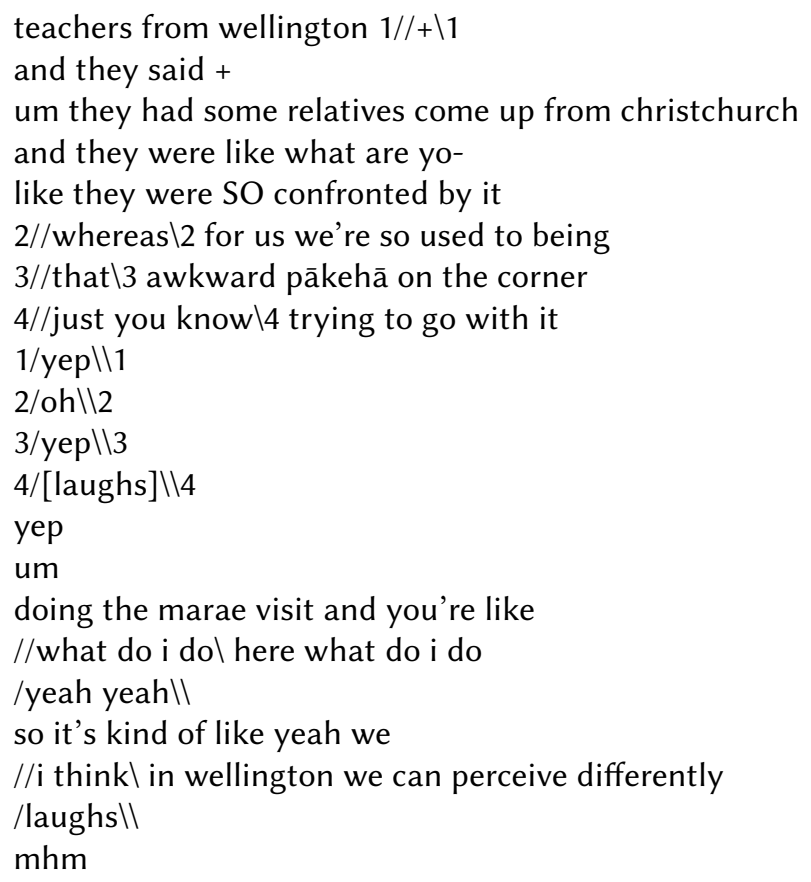

In this excerpt I mention that we kind of live in a little liberal bubble here in wellington (line 1) with which May emphatically agrees, $i$ think we REALLY DO (line 2). My stance characterises Wellington as both different and somewhat isolated by this difference, indexed by the metaphorical use of bubble (line 1). My utterance also draws on the left-wing Wellington discourse, which indicates the intertwined nature of the two discourses in the local context and their relevance to situated stancetaking. May follows by aligning with me and drawing on the discourse of contrast by explaining that Wellingtonians have exposure to Māori customs, everyone in wellington has gone to a million [breathy tone]: pōwhiri: [welcome ceremonies] (lines 5-6). She then compares this to people from canterbury (line 10) and provides a narrative that functions to compare the two, teachers from wellington... they had some relatives come up from christchurch... like they were SO confronted by it (lines 12-16). In her view, Pākehā Wellingtonians have much more experience with Māori cultural situations than those from Christchurch, such as at pōwhiri and marae visits, as we're so used to being the awkward pākehà on the corner just you know trying to go with it (lines 17-19). This also reiterates the observation made by Holmes et al. (2011) that Pākehā in Māori workplaces can feel like a minority, a point that May further expands 
upon later in the discussion. The breathy tone noted in the transcript appears to be a caricature of Pākehā who have to attend pōwhiri and could be a way of portraying those Wellingtonian Pākehā as having a potential condescending perspective, when, in her view, such token participation is not appreciated (demonstrated through her later mention of the use of te reo Māori and pōwhiri being tokenistic at her university [35:23.0]). I align with May's previous utterance by providing my own example, doing the marae [meeting house] visit and you're like what do $i$ do here what do $i$ do (lines 2627), indicating again that we are collaborating in our stancetaking. The bicultural lens is used to contrast Wellingtonians with those who are from Christchurch in the South Island where the Māori population is lower (Statistics New Zealand, 2015b). The discourse of difference in this case, then, arises in reference to the structures of the bicultural nation, discussed in Chapter 6. May's final statement, $i$ think in wellington we can perceive differently (line 30), reorients the talk to the characterisation of Wellington and Wellingtonians as different to the rest of the country and functions to return and align with my earlier bubble (line 1) comment.

In the data set there are prominent comparisons with New Zealand's two largest cities, Auckland and Christchurch. Christchurch is the city of comparison in conversation with May, and Cate also uses it as a point of contrast, particularly in substantiating Wellington's political town discourse (Excerpt 8.4). Auckland was also a point of contrast for some of the participants. In Excerpt 8.14, Chelsea contrasts Wellington to Auckland, making reference to multiculturalism (as briefly discussed in Chapter 6).

\section{Excerpt 8.14}

Chelsea Brentwood-White, 18-22 year old NZ European/Pākehā female

Setting: Wellington café

Context: Chelsea has been talking about Wellington being a multicultural city.

Time: 1:00:31.7-1:01:58.9

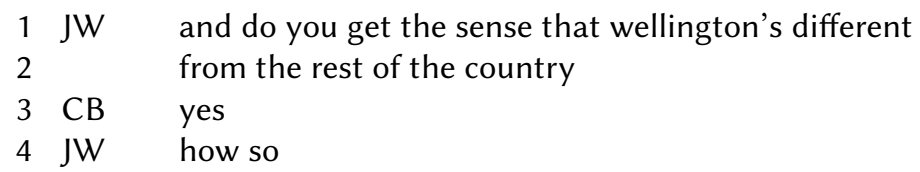




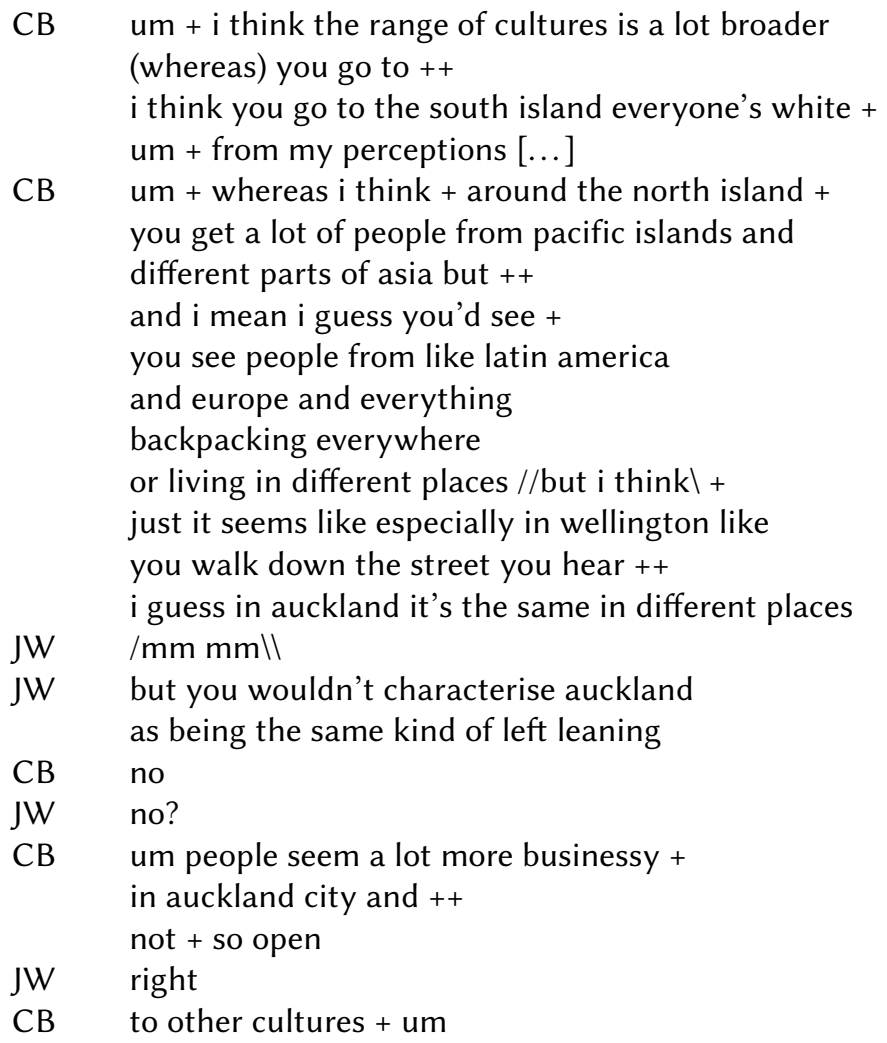

Chelsea characterises Wellington as multicultural, the range of cultures is a lot broader (line 5), in contrast to the South Island, where everyone's white (line 7), echoing a similar point expressed in a different form by May. Her answers are prompted by my line of questioning, and do you get the sense that wellington's different (line 1), which in itself indicates an orientation to the discourse of contrast. Chelsea follows her initial response with a general characterisation of the multicultural North Island as a whole, $i$ think + around the north island + you get a lot of people from pacific islands and different parts of asia (lines 9-10), and she begins to make a case for the uniqueness of Wellington, just it seems like especially in wellington like you walk down the street you hear (lines 17-18). She then halts her line of thinking by stating that $i$ guess in auckland it's the same in different places (line 19). I provide her the option to continue with her contrast along political lines by drawing on the political town discourse and revisiting her earlier characterisation of Wellington as left-wing (Excerpt 8.8), but you wouldn't characterise auckland as being the same kind of left leaning (lines 21-22). This provides Chelsea 
another opportunity to index the discourse of difference and she answers that people seem a lot more businessy + in auckland city and ++ not + so open...to other cultures (lines 25-29). Her use of comparative phrases, a lot more businessy (line 25) and not + so open (line 27), serve to index the discourse of contrast by providing direct comparison between Wellington and Auckland. Chelsea's point is supported by research into attitudes to (perceived) regional varieties of New Zealand English where Auckland is characterised as 'businessspeak' and Wellington as 'official' and 'sophisticated' (Nielsen \& Hay, 2005). This attitudinal data can affect the way in which individuals orient to stereotypes and generate their own regional identities.

Anti-Auckland sentiment is also present in the data set. My ethnographic understanding indicates that this is a common communicative topic within Wellington (and also many areas outside Auckland) that can function to enhance solidarity with non-Aucklanders through mutual light-hearted opposition. In fact, when preparing this chapter, a DJ on the Wellington radio station Radio Active noted that:

It's very much rat-race in Auckland. Auckland is very much: What do you drive? Where do you work? Where do you live? In Wellington it's more like: What's your favourite band? Where do you drink coffee? (DJ Don Luchito, Amplifier Show, Radio Active 88.6 FM, 5 May 2014)

These views contribute to the discourse of contrast by presenting Wellington and Auckland as different and in some ways in opposition (van Dijk, 1998, 2006a). Similar sentiment is indeed present in the conversations with several participants, as shown in Excerpts 8.15a and $8.15 \mathrm{~b}$.

Excerpt $8.15 \mathrm{a}$

Chelsea Brentwood-White, 18-22 year old NZ European/Pākehā female

Setting: Wellington café

Context: We have been talking about the construction of a major new road north of Wellington.

Time: 1:12:20.0-1:12:26.3

1 JW [feigned enthusiasm]: roads: 


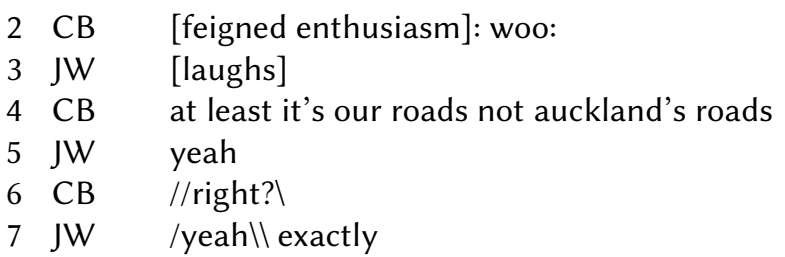

Excerpt 8.15b

Sushanti Vikram, 18-22 year old Indian female

Setting: Wellington café

Context: We have been discussing Prime Minister John Key's comment that Wellington is a 'dying city.'

Time: 35:34.2-35:44.0

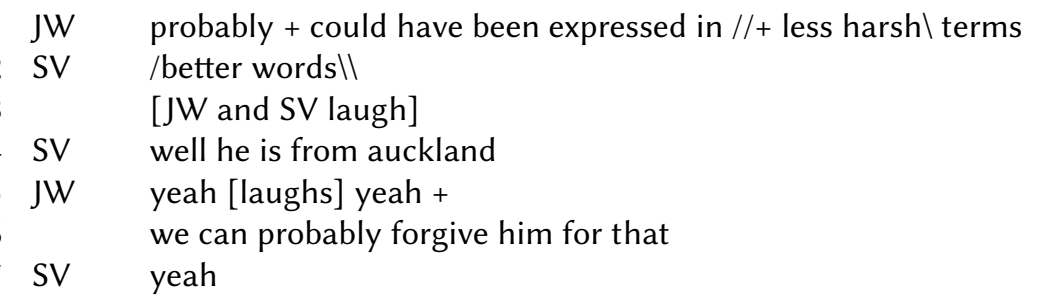

In Excerpt 8.15a, I signal feigned enthusiasm, roads (line 1), which invites a similar tone from Chelsea in reaction, woo (line 2). These utterances are in keeping with Chelsea's identity as 'left' and also signal my own divergent alignment away from policies that support the building of roading infrastructure, thus indicating my own political stance as critical of the Government's current spending decisions. Chelsea's following joke, at least it's our roads not auckland's roads (line 4) sets up an opposition between us, Wellington, and them, Auckland (van Dijk, 1998, 2006a). This division is reflected in the pejorative slang term JAFA (Just Another Fucking Aucklander), which is commonly used throughout New Zealand (see Baker \& Crellin, 2004; Grant, 2012, p. 171; Orsman, 1999). Auckland often demands the attention of politicians particularly due to its notorious traffic issues which attract large roading projects (e. g., Anderson, 2000). Chelsea's joke has the function of building solidarity between us (Hay, 2000; Holmes, 200ob, 2006b), demonstrated in our collaborative reactions right? (line 6) and yeah exactly (line 7), and also serves to strengthen our respective Wellingtonian identities through which our political allegiances are portrayed. 
In Excerpt 8.15b, the exchange arises in reaction to the Prime Minister John Key's offhand comment that Wellington is a 'dying city' (APNZ, 2013). Labelling the city as such had strong reverberations at the time, prompting media coverage which was inevitably drawn into interaction within Wellington. After our discussion about Key's comment, which Sushanti earlier mentions that she does not necessarily disagree with, I diverge from her stance slightly defensively by calling to question the harshness of Key's statement, probably + could have been expressed in + less harsh terms (line 1), again contributing to my identity as a proud Wellingtonian. Sushanti then makes a joke at the expense of Auckland, perhaps as a tension release after our discussion (Meyer, 2000; Morreall, 1983, 2009). She draws on antiAuckland sentiment in an effort to build solidarity with me, well he is from auckland (line 4), the humorous implication that being from Auckland means being less tactful with words. I end the exchange by laughing and stating that we can probably forgive him for that (lines $5^{-}$ 6), implying that it is understandable for an Aucklander to behave in such a way, which serves to acknowledge Sushanti's joke and realign with her. This kind of anti-Auckland sentiment is not however unique to Wellington as it also arises in discussion with Ashley, who is from the Coromandel, as discussed in Chapter 9.

In many of the participants' eyes, Wellington differs from other places in the country, be it due to our bicultural experiences, multicultural composition or positioning in contrast with other New Zealand cities and regions. These have been grouped under a discourse of contrast, through which Wellington is broadly characterised as different or unique. Various features, such as narrative (Excerpt 8.13), comparative language (Excerpt 8.14), humour (Excerpts 8.15a and $8.15 \mathrm{~b}$ ) and direct indexical tokens (e. g., 'different'), function to index this discourse. Indeed, the discourses addressed in this chapter gain their power through comparison to other contexts. For example, the political town discourse likely gains credibility when compared to other cities where politics is less physically prominent. Nevertheless, emphasising Wellington's uniqueness through contrast appears to be a candidate for a subnational level discourse, albeit broader, that holds particular salience for the participants. It also has ramifications for the way in which their political selves are generated in local context. 


\subsection{SUMMARY}

Subnational discourses overlap with the sociocultural, for example in the case of small town and its apparent relation to small country, though the discourses identified in this chapter all appear to have components particularly unique to the situated context of the capital city. Wellington is referred to as the political town, which is oriented to the presence of government and Parliament in the city alongside its politically-engaged inhabitants. Wellington is also referred to as a leftwing or liberal city, which implies alignment primarily, though not exclusively, with the Labour and Green parties. These two discourses have obvious political content which is relevant to participants' political stancetaking.

Bearing similarity to the extra-discursive aspects of small country and its associated discourse, as discussed in Chapter 6, Wellington appears to act as a symbolic microcosm of New Zealand as a small country when referred to as a small town. The participants draw on this discourse through phrases such as 'everybody knows everybody' in evaluation of instances where Wellington's small nature becomes apparent. The city is also often characterised as different to other places in New Zealand, contributing to a discourse of contrast which appears to provide the mechanism through which the other subnational discourses gain their comparative meanings. These two discourses are more politically 'neutral' but, like Chapters 6 and 7 , provide insight into the structural context in which the participants carry out identity genesis.

As demonstrated in this chapter, the nature of the Wellington 'bubble' affects the articulation of political selves in talk. How this is achieved at the micro-level of stancetaking is the subject of the following two chapters. 

INTERSUBJECTIVITY IN STANCETAKING

\subsection{INTRODUCTION TO THE CASE STUDIES}

The focus of the analytical spotlight in the case studies presented in this chapter and the next is moment-by-moment interaction, or the linguistic and discursive features that index various levels of context (Gumperz, 1999, 2001, 2009). The interactional nature of political identity, as it comprises stancetaking, is contextualised within the 'higher' (Blommaert, 2007) or broader discursive phenomena explored in previous chapters, investigation of which creates a fuller and richer picture of identity genesis in context.

I present a detailed case study in this chapter and the next in order to explore different and salient processes of stancetaking that have arisen from analysis. The first, the subject of this chapter, examines 'intersubjectivity' (Du Bois, 2007; Du Bois \& Kärkkäinen, 2012; Kärkkäinen, 2006), a term which encompasses 'co-construction' and 'negotiation' (Englebretson, 2007, p. 19). I examine the stance acts of the conversational participants, myself included, as we interact with one another over the course of an entire discussion. The second case study, presented in Chapter 10, investigates stance 'multiplicity' (Jaffe, 2009a, p. 19), where I focus on the potential for numerous stances and disparate identities to be articulated alongside one another. Both processes work together in stancetaking and as such are not considered discrete phenomena, though the case studies I have selected are particularly prominent examples of each respective process in action. The general aim of these case studies is to explore the contribution that interactional discourse analysis can make when situated within both sociocultural and subnational context and a wider critical realist frame. 
As argued in Chapter 3, stance is central to both interaction and identity. Considering that we 'do not merely act, but interact' (Kärkkäinen, 2006, p. 704), the stances we take during conversation can be viewed as an intersubjective achievement (Du Bois, 2007; Du Bois \& Kärkkäinen, 2012; Englebretson, 2007; Kärkkäinen, 2006). Subjectivity, which presupposes intersubjectivity (Du Bois, 2007, p. 159), is defined as the encoding of our perspectives into our utterances (Kärkkäinen, 2006, p. 702). Subjectivity is central to the function of positioning on the stance triangle (see Chapter 4; Du Bois, 2007, pp. 152-158). Individual subjectivities react to others in interaction which also makes it a central component of alignment, another core function of stancetaking ( $\mathrm{Du}$ Bois, 2007, pp. 159-162). All stancetaking is intersubjective in nature and the case study in focus in this chapter serves to examine this in the context of political identity genesis.

From a discourse and identity perspective, intersubjectivity is what is generally referred to when stance is described as 'jointly constructed, negotiated, and realized in and through interaction' (Englebretson, 2007 , p. 19). I am the main conversational partner of the participants in this study and thus my own subjectivities are inextricable ingredients of the discourse context and have an effect on participants' stancetaking, and vice versa (Jacoby \& Ochs, 1995; Kärkkäinen, 2006). The case study in focus, my discussion with Ashley, explores precisely how our stances are enacted intersubjectively at the interactional level. The salient topical focus is the development of political affiliation across the conversation. I investigate the nature of Ashley's stance acts, alongside my own, as they develop and convey sympathies for particular political parties and policies. In stance triangle terms (Du Bois, 2007), positive evaluation of a political party or their policies positions the individual which in turn can index a social identity (e. g., conservative, liberal, and so on) and its associated discourse. Participants can also display a degree of convergence or divergence along the scale of alignment which has important intersubjective implications, as examined in this chapter.

The conversation with Ashley is chosen for closer analysis because it provides a very concentrated example, just over twenty minutes long, which is largely due to the limited amount of time that she 
had for a lunch break during her working day. This, in combination with my limited interaction with her before our meeting, means that a 'clearer' initial stance slate is provided at the outset compared to some of the other participants with whom I had communicated prior. Ashley's case is also particularly useful as I have the ability to track our entire interaction from the point of first contact via email to the final follow-up. Considering that an exploration of stance requires a grasp of the broader dialogic context (Du Bois, 2007), the analysis of my full interaction with Ashley provides a view of this context in its entirety.

\subsubsection{Stage One: First Contact}

Ashley and I had exchanged a series of emails in order to set up our first meeting. Even at the point of our initial contact the opportunity for stancetaking is provided through the medium of written communication. In her initial email to me, Ashley mentions that $a$ ) a mutual acquaintance (referred to hereafter as Jane) had passed on my details to her; $b$ ) the fact that she works in government; and $c$ ) that due to the nature of her work she would require anonymity. From this brief initial point of contact I had gained some detailed information about her and made a series of tentative stance inferences, listed as follows:

- I know that Jane has particular loyalty to the Green Party which, given that Ashley and Jane are friends, provides the first indication of where Ashley's political loyalty could possibly lie.

- Since Ashley works in government, I judge that she has insider knowledge and experience with politics in New Zealand. Her mention of this in her email also serves the function of displaying what she views as her qualifications to take part in the project; i. e., she is positioned to be able to talk about politics and political issues.

- Ashley's desire to remain anonymous opens up a couple of possibilities: that she is sensitive about what she says being leaked into her working domain, or that she is critical of the current Government, a further possible indication of her party political leanings. 
These are tentative, subconscious inferences which remain ambiguous and unconfirmed until stancetaking is realised in conversation. As becomes apparent later in our conversation, Ashley's political leaning matches closely with what I had inferred from this first point of contact.

Stances need not be taken up explicitly to have an effect on interaction (Du Bois, 2007; Du Bois \& Kärkkäinen, 2012, p. 438). Stances and identities can also be attributed to (or imposed on/ascribed upon) others without them being present (as discussed in the cases of I- and D-identity in Chapter 3; Gee, 2000). In Gee's (2000) terms, preconceived ideas about what 'kind of person' my conversational partner is can affect how we relate at initial face-to-face contact. For example, if a mutual acquaintance had told me that 'Ashley is a friendly person', then that attributed D-identity can, in context, influence how I enter into stancetaking with her, likely affecting the establishment of common ground and rapport (Kecskes, 2014; Kecskes \& Zhang, 2009; Spencer-Oatey, 2000). I may not be as reserved or nervous in this case as opposed to if she had been characterised as an angry person. From our initial contact via email I had inferred her likely political persuasion and hence anticipated the way she would evaluate certain topics. This background information about her possible identities undoubtedly influences my judgement when choosing to mention certain issues during at least at the early stages of our face-to-face discussion (Kecskes, 2014; Kecskes \& Zhang, 2009). This process of testing the conversational water at the beginning of an interaction, tentatively searching for indications of stancetaking particularly as it relates to potentially controversial subjects, is clearly displayed in my discussion with Ashley. The next section examines how we first relate and gauge each other's trustworthiness through the medium of small talk.

\subsubsection{Stage Two: Talking Small}

Far from being a waste of time, small talk has many social purposes: it can enhance solidarity and social cohesion, smooth relations and frame the conversation 'proper' (Coupland, 2000, 2003). In New Zealand, it is common practice at the start and end of the working day and before and after meetings (Holmes, 2000a; Holmes \& Marra, 
2004; Holmes et al., 2011). In the context of identity genesis, small talk provides the opportunity to take up initial, if relatively vague, stances. The small talk that occurs at the beginning of the discussion with Ashley is particularly interesting in this sense. Ashley and I know little about one another, other than that we have friendship with Jane in common. Jane therefore functions as a relatively safe bet as an initial conversational topic (and an example of establishing common ground, see Kecskes, 2014; Kecskes and Zhang, 2009).

The small talk phase of our interaction lasts for just over four minutes in total, a substantial amount of time (a fifth of the entire conversation) which occurs mainly while Ashley is signing the consent form. The amount of time dedicated to relational practice at the beginning of the interaction, which includes small talk, indicates the particular importance placed on building conversational rapport or solidarity in this context (see, for example, Coupland, 20oo; Holmes \& Marra, 2004; Locher \& Watts, 2008; Mullany, 2006; Pullin, 2010; Spencer-Oatey, 2000). During these four minutes we cover topics such as our respective relationships with Jane, Ashley's work, my study and supervisors, my time at conferences and Ashley's experience of public seminars. These are relatively uncontroversial topics that we have in common which also provide information about our backgrounds. As shown in Excerpt 9.1, our small talk also contains important stance content.

\section{Excerpt 9.1}

Ashley Braithwaite, 18-22 year old NZ European/Pākehā female

Setting: Wellington café

Context: Ashley is taking a lunch break from her job and has just sat down with me.

Time: 0:00.0-0:47.8

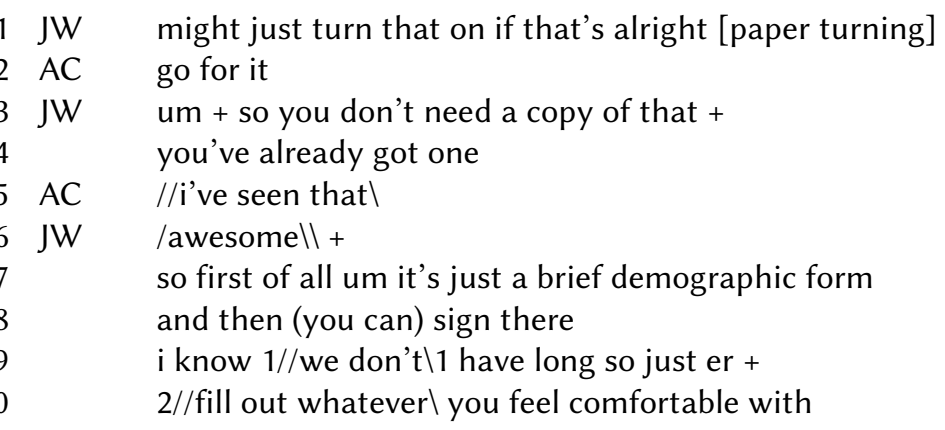




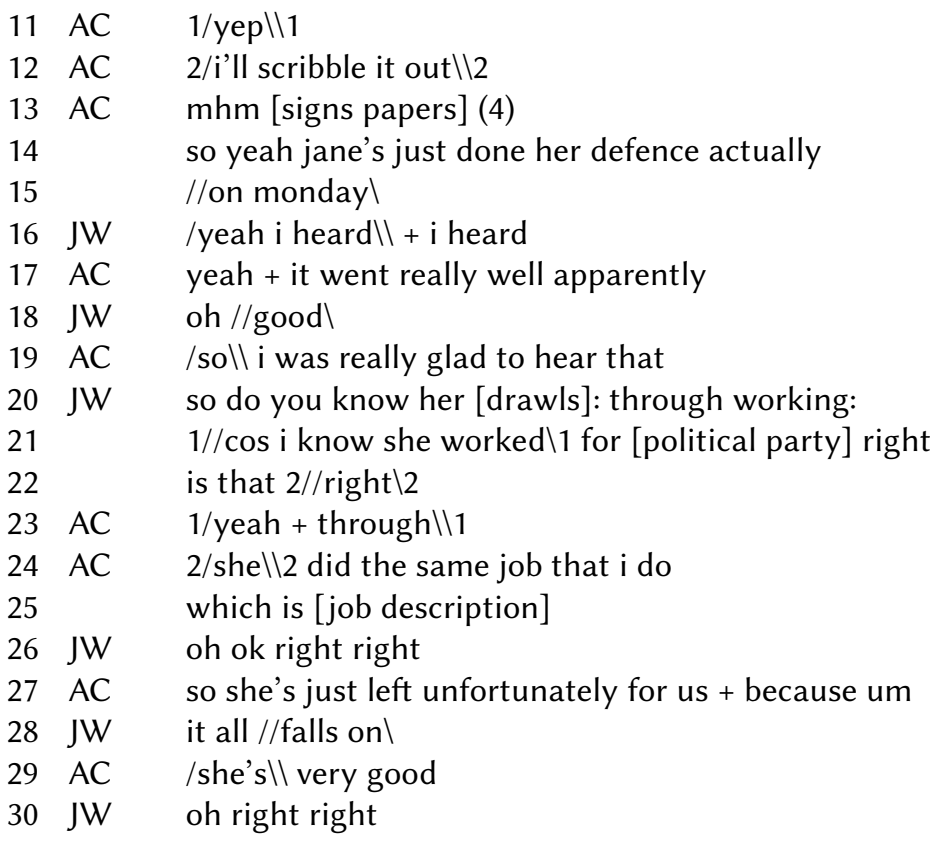

After the recorder is turned on we talk briefly about the information sheet, demographic survey and consent form, focusing solely on transactional talk (lines 1-13; Holmes, 1995). Ashley then transitions to relational talk by offering some insider knowledge about our acquaintance, so yeah jane's just done her [thesis] defence actually on monday (lines 14-15). I confirm that I know the same piece of information, yeah $i$ heard $+i$ heard (line 16), and Ashley goes on to elaborate yeah + it went really well apparently (line 17). This exchange functions to establish common ground and ratify one another as trustworthy conversational partners by focusing on the one topic we have in common, our relationship with Jane, and displaying our knowledge about certain aspects of Jane's life. I then ask how Ashley knows Jane, so do you know her [drawls]: through working: (line 20), and Ashley follows by providing more detail about her job (lines 24-25). Ashley interrupts my offered reason for the fact that Jane's departure was unfortunate, it all falls on [you] (line 28), instead complimenting her, she's very good (line 29), which acts as a positive evaluation of our acquaintance. It also functions as a potential disagreement with my completion of her sentence, hedged within a positive stance act, which can be interpreted as aligning with me through our shared connection to Jane. 
Throughout this exchange there is relational work being carried out as evidenced in the use of intensifiers in the clauses really well (line 17), really glad (line 19) and very good (line 29; Holmes and Marra, 2004). The affective content of Ashley's speech (well, glad and good) indicates that she is taking a positive affective stance of friendship towards Jane (Du Bois, 2007; Du Bois \& Kärkkäinen, 2012; Ochs, 1996). Stating so $i$ was really glad to hear that (line 19) positions Ashley as someone who would be concerned with how Jane's thesis defence went and in doing so strengthens her friendly stance towards her. The use of intensifiers also promotes Ashley's connection to Jane by suggesting a degree of emotional investment in her wellbeing (Argaman, 2009; Tagliamonte \& Roberts, 2005). Throughout this exchange we align with one another by displaying our mutual friendly stances towards Jane; my utterances yeah $i$ heard $+i$ heard (line 16) and oh good (line 18) move towards the convergence end of the alignment scale (Du Bois, 2007) as does the repetition of yeah across multiple turns, functioning as acknowledgement tokens the first of which is associated with topical shift (Gardner, 1998; Jefferson, 1984): so yeah jane's just done... (line 14), yeah $i$ heard + $i$ heard (line 16) and yeah + it went really well apparently (line 17). Ashley's use of so (line 14) in this context functions as the preface of an 'other-attentive topic' (Bolden, 2006), shifting the focus to Jane. There is also a degree of collaborative parallelism as we repeat yeah across turns (Du Bois, 2007, p. 160). This linguistic evidence points to an alignment of our stances on the relatively uncontroversial subject of Jane's life.

We display degrees of alignment through various structures and stance acts which appear to have an interpersonal function that serves to enhance solidarity between us (Holmes, 1995). This is done in the knowledge that the reason we are meeting is to discuss politics (Chapter 5) and building rapport beforehand pre-empts the possible face threat of controversial topics which could arise later (Brown \& Levinson, 1987; Spencer-Oatey, 2000). Even at this very early stage it is clear that my subjectivity interacts with hers which affects the interactional discourse context in fundamental ways. Ashley's political stances do however remain somewhat ambiguous throughout the small talk phase and my earlier inferences therefore remain largely unchanged. Ashley's friendly affective stance towards Jane functions 
to provide slightly more evidence for my belief that they both support the Green Party. This is not solid evidence however, as Jane's political sympathies may not be shared by Ashley. Nevertheless, given the stance information accumulated thus far, my hunch is that Ashley has Green Party political sympathies, which, as shown in the following sections, influences how the conversation plays out.

\subsubsection{Stage Three: A Balanced Approach}

Ashley pushes the conversation along by suggesting a degree of time pressure, so we conclude small talk and enter what is considered the interview 'proper' (Milroy \& Gordon, 2003, p. 62). In Excerpt 9.2 we broach the topic of her political engagement and talk about the ongoing social welfare reforms. During this stage Ashley remains balanced and nonpartisan in her evaluation of certain issues, likely remaining guarded of her full political views given we are relatively new acquaintances.

\section{Excerpt 9.2}

Context: We have been engaged in small talk about work and study.

Time: 4:13.0-5:14.0

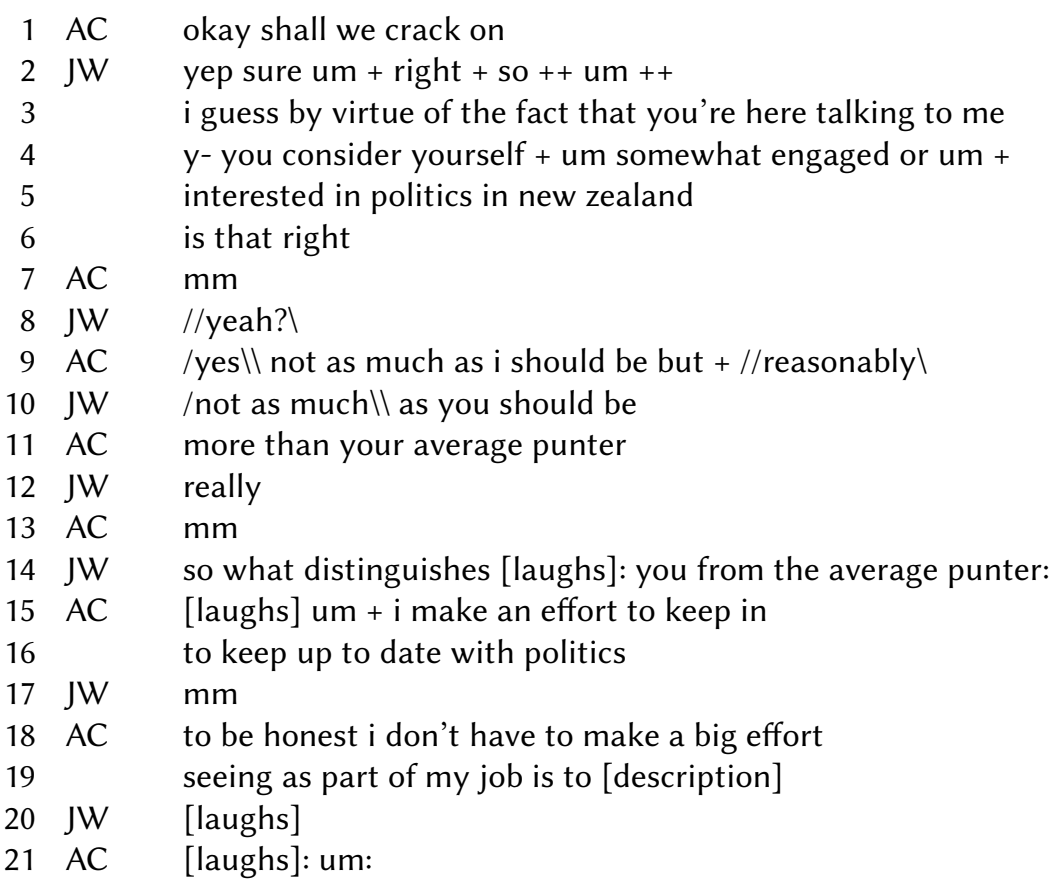




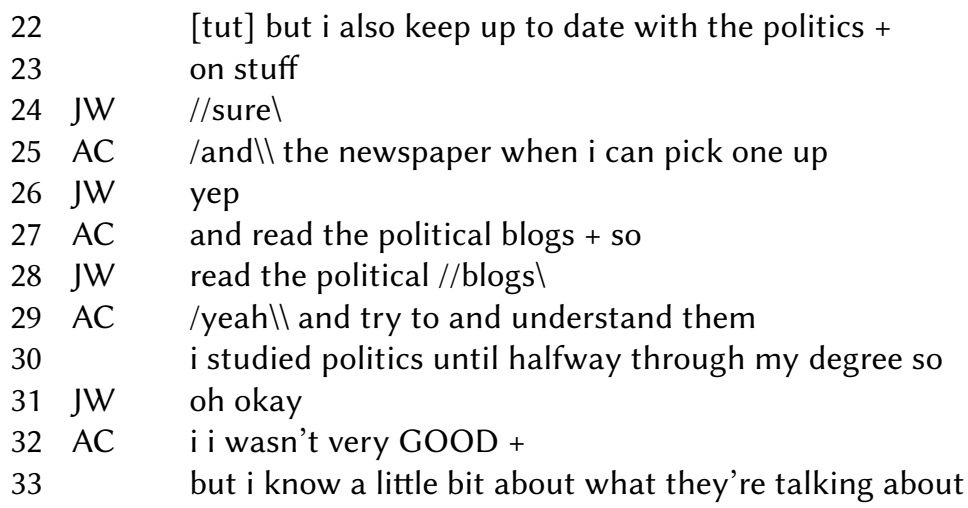

At the start of Excerpt 9.2, Ashley initiates the conversation with a clear boundary marker ending the relational talk phase, okay shall we crack on (line 1), which recognises the anticipated structure of the interaction. It also recalls the difficulties with using the term 'interview' in that a clear structure is often expected (Milroy \& Gordon, 2003, p. 62). I use the fact that she agreed to meet as an indication that she is willing to discuss political issues, asking the first question about her level of political interest (lines 3-5). She answers yes not as much as i should be but + reasonably (line 9), indicating a sense of obligation in being informed about politics, though whether this obligation arises from work or for personal reasons is unclear. It also functions as a justification of her role as an 'interviewee', showing that she is able to engage with me about the topic to a reasonable level. Ashley then compares herself to the general public, more than your average punter (line 11), which I find humorous, indicated by laughter in my follow up where I ask her to expand on what she means, so what distinguishes [laughs]: you from the average punter: (line 14). Ashley expands on why this is the case, explaining that since she works in politics she does not have to make a great effort to be informed (lines 18-19), though she does mention reading new websites; stuff (line 23), in reference to the Fairfax Media news website Stuff.co.nz, reading newspapers (line 25), blogs (line 27) and also studying politics herself (line 30). The New Zealand Oxford Dictionary (2005) defines 'punter' as a person who gambles or bets, or in a colloquial sense, a customer, client, member of an audience or a prostitute's client. Ashley's use of the word appears to refer in general terms to a member of the public, though my laughter (line 14) and hers (line 15) indicate that we find her use of this word humorous, perhaps 
because my interpretation of the term suggests a subtle connotation of naivety.

This excerpt shows Ashley taking up various epistemic stances (Ochs, 1996). Her utterance yes not as much as $i$ should be but + reasonably (line 9) is a sophisticated epistemic stance act which displays her level of knowledge about politics in tentative, measured terms and also conveys a sense of obligation to being informed. Her following turns function to elaborate on this epistemic stance by placing herself more accurately on the epistemic scale (Du Bois, 2007), in that [I am] more [engaged in politics] than your average punter (line 11). After explaining how she keeps informed about politics, Ashley then downplays her knowledge by stressing that she can only try to understand them [the political blogs] (line 29) and mitigates her utterance $i$ studied politics until halfway through my degree so (line 30) by mentioning $i$ wasn't very GOOD + but $i$ know a little bit about what they're talking about (lines 32-33). Ashley, who it subsequently appears is very knowledgeable about politics (which she goes on to display clearly only a few turns later), humbly diminishes the fact that she studied politics. Indicating that $i$ know a little bit (line 33) at the end of her turn could be interpreted as her stressing that despite this she does indeed know something and can thus productively engage in conversation about the topic. Her self-deprecating stances of limited ability and knowledge also seem to be an example of the sociocultural egalitarian discourse in action (Chapter 7 ), as she attempts to 'keep her head down' by avoiding an overt display of expertise. It is in interactions such as these where this discourse is shaped and structured on-the-ground; Ashley wants to convey the fact that she knows about politics (she knows at least a little bit) but simultaneously does not want to appear boastful in case she is caught in the sights of tall poppy. This is evidence for the benefit to be gained from a critical realist exploration of the wider context. She is also unaware of my level of political knowledge and her mitigation can be viewed as giving a reason why she may not be able to answer my anticipated questions.

In Excerpt 9.3, Ashley displays her detailed knowledge of political issues which provides a contrast to the humble epistemic stances she had earlier taken. 


\section{Excerpt 9.3}

Context: Ashley has just told me what her degree was in.

Time: 5:21.2-6:15.8

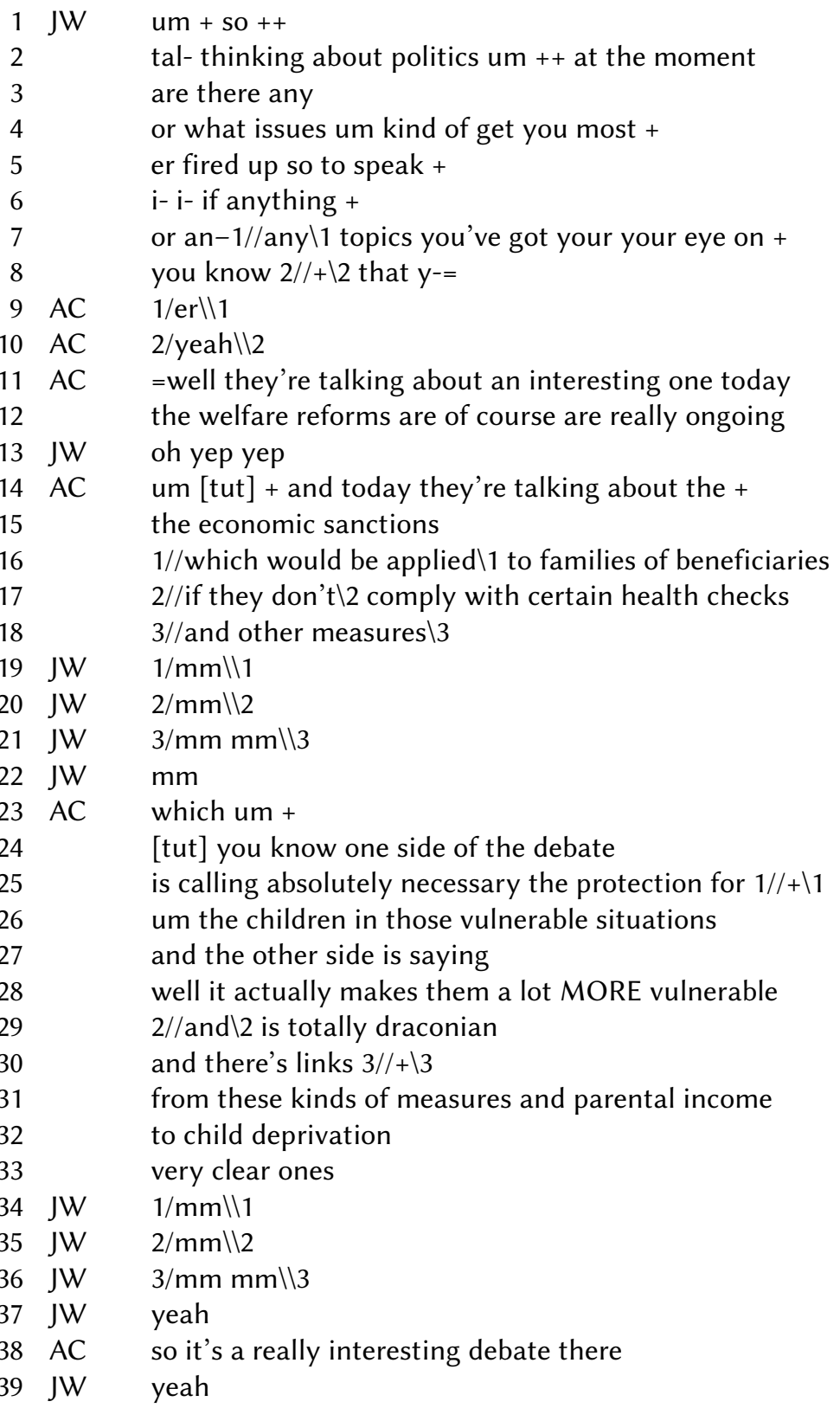

I hesitate quite markedly in the initial questioning about Ashley's interest in certain political issues. I am aware that asking such a question is a potential face threat and to remedy this I search for 
an appropriate means to convey my question, reformulating the structure of the question multiple times (lines 1-8). Ashley cuts me off and offers the initial topic, the welfare reforms are of course are really ongoing (line 12), which she evaluates rather neutrally as an interesting one today (line 11). The term interesting (line 11) indicates some degree of personal engagement with the issue and functions as a nonpartisan evaluation of a topic that was, at the time, highly divisive. Ashley demonstrates that she is knowledgeable about the topic, suggesting that the epistemic stance on politics she had taken previously, i know a little bit (Excerpt 9.2, line 33), may not have told the whole story. She remains balanced in her evaluation by presenting both sides of the debate (lines 24-33) and she is careful not to let me know where she lies in terms of agreement or disagreement, merely stating that social welfare reforms are an interesting topic for her (lines 11,38). Nevertheless, her selection of social welfare as a discussion topic shows that she has at least some level of interest in it which in itself functions as an implicit indicator of her stance; the Labour Party's historical association with the welfare state (McClure, 1998) is perhaps enough to infer a tenuous left-wing stance in this case. An ambiguous referent in the pronoun they're talking (line 11) appears to further serve her balanced purpose.

Her presentation of both arguments, in the form of one side of the debate (line 24) and the other side (line 27), without reference to who comprises either group, provides more evidence for a level of measured detachment. This structure likely functions as a way of her avoiding the attribution of stances to certain political figures which could serve to prevent a debate if I were to disagree with her. It also provides a measure of indeterminacy and deniability in her stancetaking which, as Jaffe (2009a, p. 18) notes, can be used to mitigate accountability for them. This structure also helps Ashley attend to the potentially face-damaging atmosphere brought about by discussion of a controversial issue (Brown \& Levinson, 1987). Managing this is particularly important given the high level of media coverage and public concern that surrounded social welfare reforms at the time.

Despite Ashley's attempts at remaining nonpartisan, there are subtle indicators of the side of the debate with which she sympathises. In combination with my inference that she is a Green Party supporter 
and my own knowledge of the Green Party's social welfare policy, I judge that Ashley is likely against economic sanctions for beneficiaries. This is supported by her use of emphatic stress and an intensifier in the clause a lot MORE vulnerable (line 28), the intensification and affective content of totally draconian (line 29) and an intensifier in very clear ones (line 33), all of which she associates with those on the other side [of the debate] (line 27). Compared to the argument that she attributes to one side of the debate (line 24), which lacks comparable stress and intensifiers, with the exception of absolutely necessary (line 25), and in addition to my ethnographic understanding of the ongoing public debate, I interpret the ambiguous referent of her utterance the other side (line 27) to include the Green Party, its supporters and now, tentatively, Ashley. She then returns to her more balanced stance by repeating her evaluation of the debate as interesting (line 38), a final word which perhaps functions to underscore her desire to remain nonpartisan and only indicate in a neutral manner her view of an issue that is of interest.

My role in this exchange is an important aspect of what occurs in terms of stance. As mentioned above, I hesitate in formulating the initial question which perhaps influences Ashley's subsequently balanced manner; in other words, the way in which I formulated the question, such as any topics you've got your your eye on (line 7), which in itself begs a neutral answer, may have led Ashley to adopt a stance of interesting (line 11) rather than one that is more emotionally invested. My earlier attempted question what issues um kind of get you most + er fired up so to speak (lines 4-5) had the opposite intention, as it was aimed at eliciting an emotional response, the affective metaphorical content of fired up (line 5) implying anger and frustration through the conceptual metaphor ANGER IS HEAT (Kövecses, 1986; Lakoff \& Johnson, 1980). It was aborted after I had gained little reaction from Ashley and also due to its higher likelihood of eliciting a face-threatening answer. If, for example, Ashley had answered with 'I am totally against welfare reform', then the interpersonal stakes would be higher in that there is the potential for me to strongly disagree with her emotionally invested stance. Had my fired up (line 5) line of questioning been pushed it is possible that rapport may have been threatened (Spencer-Oatey, 2000), particularly as it is relatively early in the conversation and we 
have yet to develop a degree of solidarity as conversational partners. While my initial questioning sequence perhaps influences how the subsequent exchange plays out, it is more likely that Ashley's desire to remain nonpartisan overrides the constraint of my questioning. Nevertheless, this is a clear indication of the intersubjective nature of stance in a discussion between 'interviewer' and 'interviewee.'

During Ashley's talk about the detail of the social welfare reforms (lines 16-18), I offer a high frequency of responses in the form of $\mathrm{mm}$ (lines 19-22). These minimal responses appear to function as weak engagement or acknowledgement tokens (Gardner, 1997; Lambertz, 2011). My use of $\mathrm{mm}$ is particularly interesting in this case, as 'unlike Yeah, Mm does not have positive-negative polarity' and is thus semantically 'empty' (Gardner, 1997, p. 132). It also has 'reduced visual message' with closed lips and no jaw movement (p. 132). The neutrality of $\mathrm{mm}$ is thus particularly useful in the context of balance and detachment as I respond to Ashley's nonpartisan stance by avoiding an indication of where my own thoughts lie on the issue. The high frequency of $\mathrm{mm}$ that overlaps with Ashley's turns in lines $19^{-21}$ and $34^{-36}$ indicate that I place particular emphasis on acknowledging her contribution across these turns, appropriately 'doing listenership' in this context (Holmes, Marsden \& Marra, 2013).

\subsubsection{Stage Four: Strengthening Inferences}

The conversation moves further into potentially controversial territory as Ashley raises another prominent political topic, state asset sales. At the time the Government was asking people to register their interest in purchasing shares of a state-owned electricity company which they had designated for partial sale (see Ahmed, Balzarova \& Cohen, 2014). Ashley's discussion of this issue provides me with further stance information which functions to strengthen my inferences about her political party support. This is outlined in Excerpt 9.4.

\section{Excerpt 9.4}

Context: Continues from the end of Excerpt 9.3.

Time: 6:15.9-7:10.2

1 AC um other than that

2 the asset sales is always interesting 


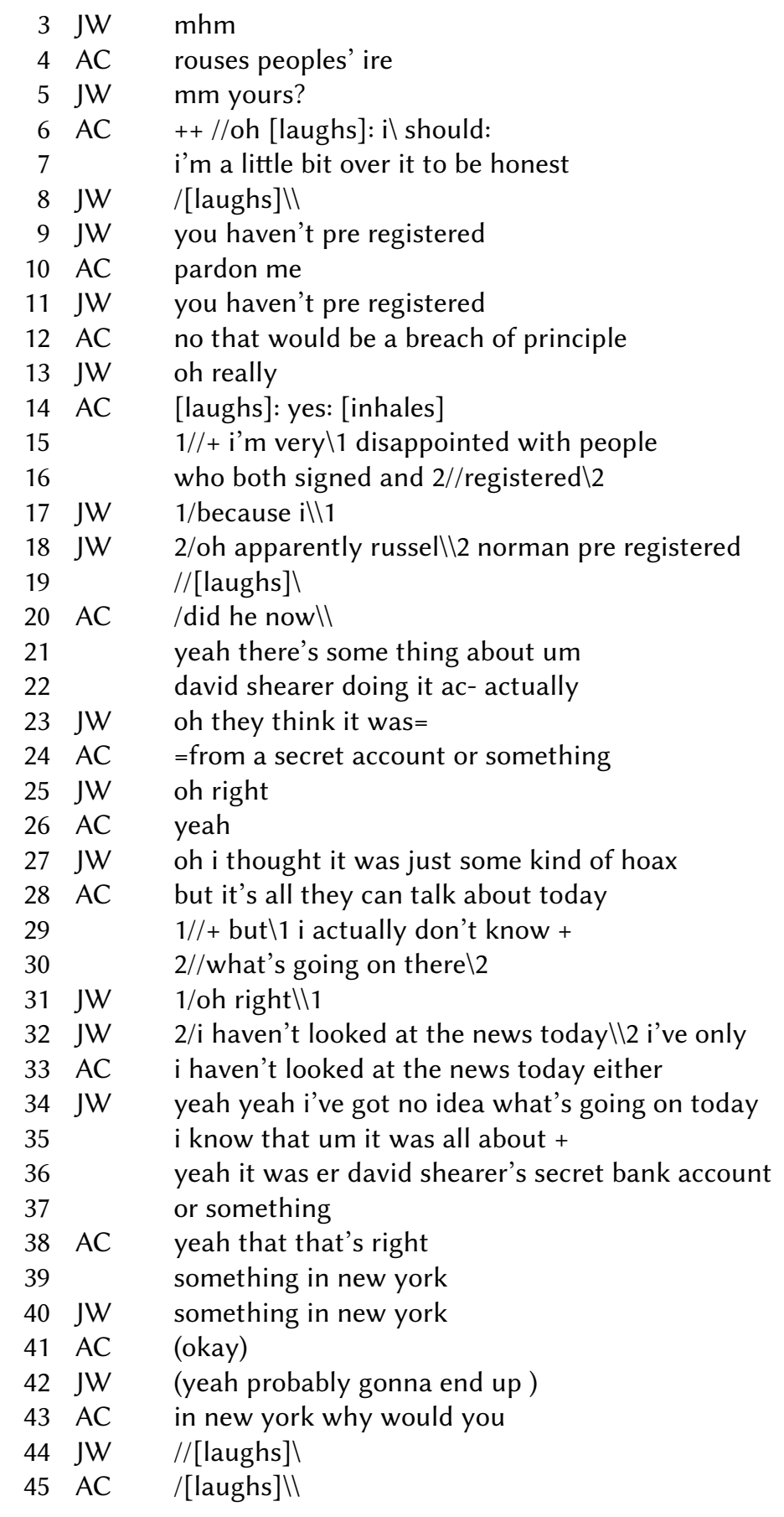

Ashley begins again with an evaluation of asset sales as interesting (line 2), continuing on from her engaged yet balanced stance set down earlier in reference to social welfare reform. The situation changes 
rapidly however as she mentions first i'm a little bit over it to be honest (line 7), likely due to the heavy media coverage dedicated to the issue and large street protests against asset sales throughout 2012 and 2013 (the largest of which I had attended myself, see Chapter 5). My question you haven't pre registered (line 11) is a first attempt at getting a partisan reaction from Ashley which is partially successful. She responds by giving an explicit hint as to where her political loyalty lies by stating that registering for the share sale would be a breach of principle (line 12). Her statement $i$ 'm very disappointed with people who both signed and registered (lines 15-16) indicates that she is against state asset sales, her disappointment intensified by very in negatively evaluating those that have taken part. Ashley's reference to signed (line 16) refers to those that signed the petition against asset sales and thus indicates, in her view, a level of hypocrisy on their behalves. Asset sales was a highly partisan issue at the time, with the National Party and other minor governing parties in favour, and the Labour, Green and NZ First parties in vocal opposition. Ashley's stancetaking in this excerpt clearly aligns her with the parties that oppose the sale and in doing so positions her as sympathetic to the Opposition, at least on this particular issue. My mention that apparently russel norman pre registered (line 18) is a cheeky challenge of her inferred loyalty and can be viewed as an attempt at humour. Russel Norman is the Green Party co-leader ${ }^{1}$ and it was revealed that a member of the public had signed up for the share float in his name, along with David Shearer, then leader of the Labour Party. In raising the topic of Norman's registration for purchasing shares I am effectively asking Ashley whether she is also disappointed in him. She acknowledges my comment briefly, did he now (line 20), and then goes on to mention Shearer's registration (lines 21-22). This topic leads to the discussion of another scandal in the newspaper that day where Shearer was found to have an undisclosed bank account in New York containing a substantial sum of money which forms the topic of the remaining turns in this excerpt.

Ashley more explicitly displays her views on this particular political issue but there is still a level of detachment in that she refrains from explicitly evaluating both asset sales and the news regarding

1 In 2015, Norman announced his resignation which is to take effect at the 2017 election. 
Norman and Shearer. She does however adopt an implicit stance against asset sales in displaying her disappointment at those interested in buying shares of a state-owned company which further strengthens my inferences as to her political identity. This exchange functions as the most concrete evidence so far as to where her political loyalties lie, or at least how she evaluates a highly partisan political issue. Coupled with Ashley's subtle stances on the social welfare issue and the accumulated inferences I had earlier made, I am at this stage close to convinced that she is either a Labour or Green Party supporter.

There is also a degree of parallelism and stance alignment that occurs in the excerpt (Du Bois, 2007). Ashley takes an epistemic stance but $i$ actually don't know + what's going on there (lines 29-30) in reference to the news about Shearer. I respond by mentioning that $i$ haven't looked at the news today i've only (line 32) and Ashley follows with an almost exact repetition $i$ haven't looked at the news today either (line 33). Du Bois (2007, p. 161) notes that, 'the word either...serves to index a specific intersubjective relation between two speakers engaged in dialogic interaction.' If 'either' was not present in this context, Ashley's utterance would sound strange; its necessity in this sort of construction indicates its importance to intersubjective stancetaking. In other words, Ashley is indexing my immediately prior epistemic stance with her use of the term. Du Bois (2007, p. 161) terms my utterance the 'stance lead' and hers the 'stance follow'. In effect, these two turns are an example of the process of alignment in action and highlights it as an intersubjective achievement (p. 162). I then follow up with yeah yeah i've got no idea what's going on today (line 34) which repeats and aligns with Ashley's initial epistemic stance $i$ actually don't know + what's going on there (lines 29-30). Further repetition and alignment occurs at the end of the excerpt, with yeah that's right something in new york (lines 38-39), something in new york (line 40) and in new york why would you (line 43). The high level of converging stance alignment in this segment and instances of humour (lines 18, 43) and laughter (lines 6, 8, 14, 19, 44, 45) serve to indicate that we are both successfully negotiating the thorny issue of a close-to-explicit admission of Ashley's political convictions and that we are steadily establishing good rapport (Spencer-Oatey, 200o). 


\subsubsection{Stage Five: Establishing Credentials}

In this section, Ashley begins to establish her credentials in the form of talking about her background and engagement with politics. Excerpt 9.5 builds upon Excerpt 9.2, where Ashley displays an epistemic stance regarding her knowledge of politics. My repetition of average punter in Excerpt 9.5 indexes Ashley's earlier stance, calling it and its contextual entailments back into the conversation.

\section{Excerpt 9.5}

Context: We have been talking about marriage equality and the minimum wage.

Time: 8:56.8-10:12.1

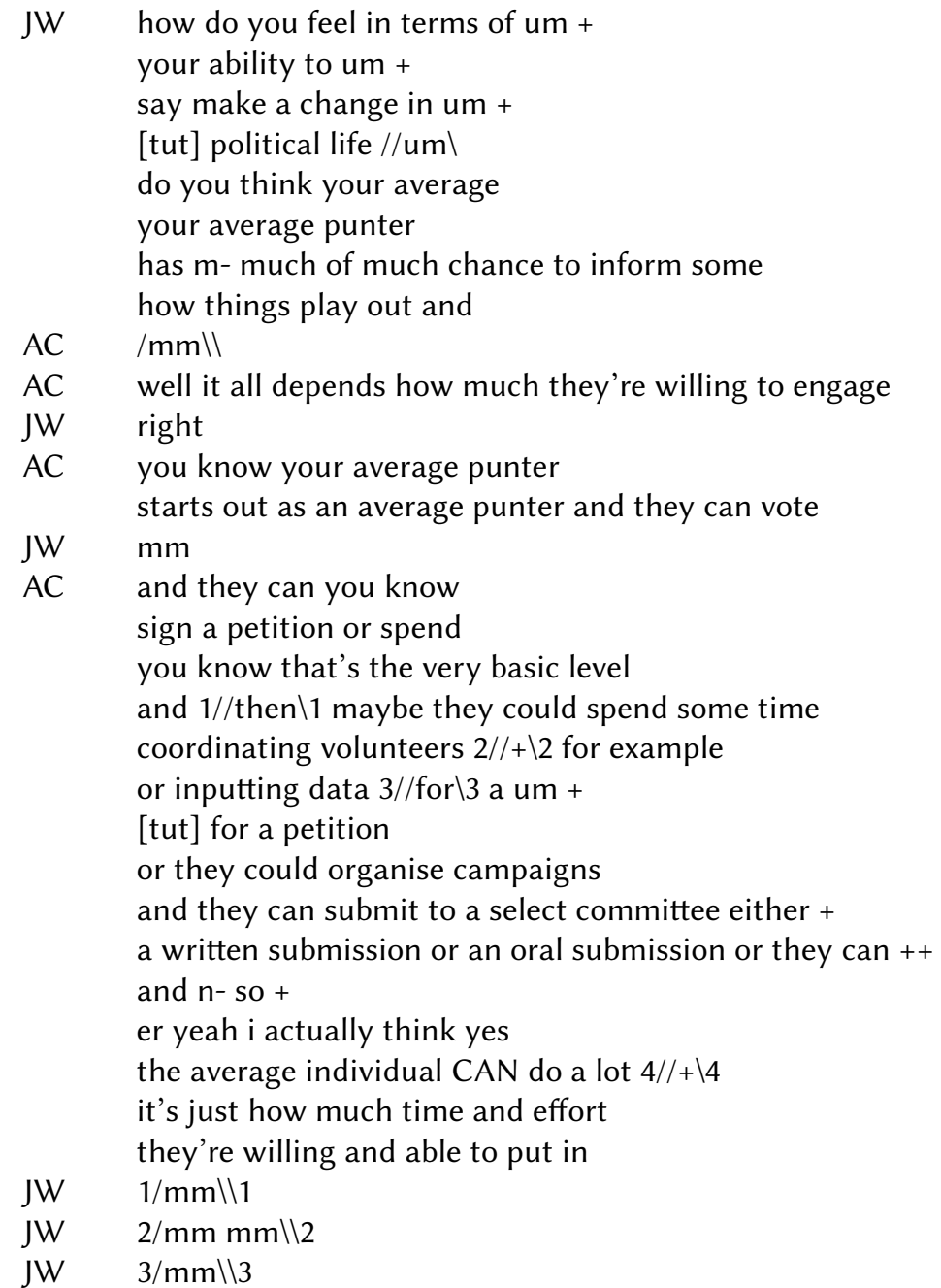




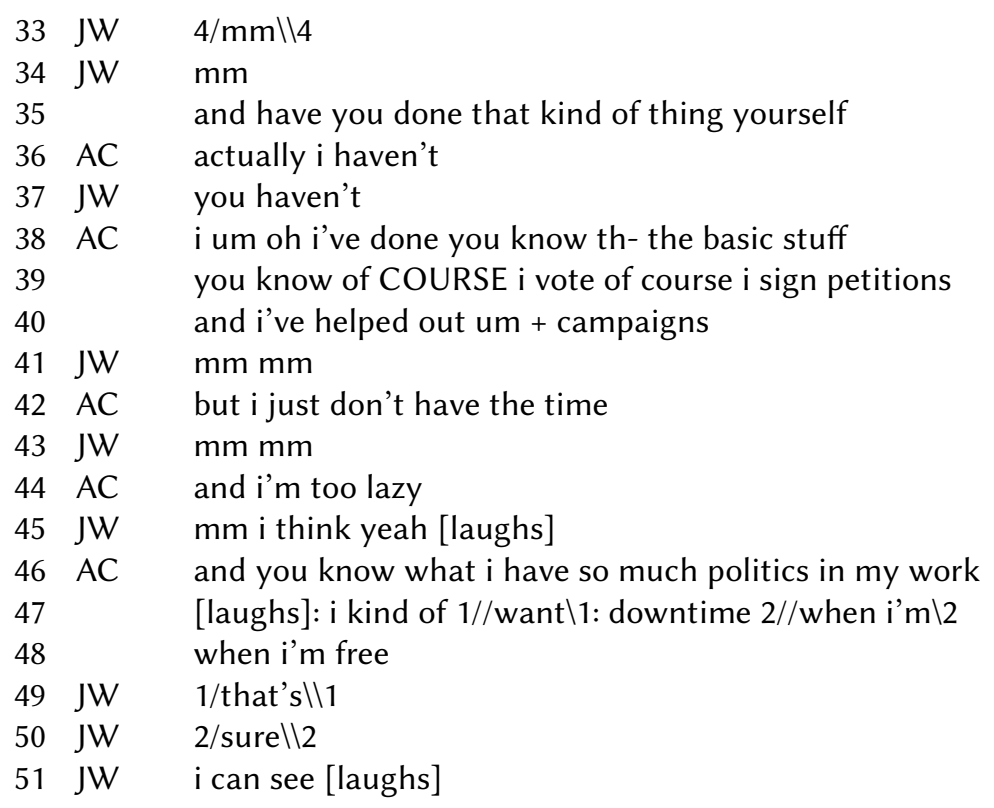

As mentioned above, I index Ashley's earlier epistemic stance from Excerpt 9.2 by repeating her term average punter (line 6), linking to the earlier stance act encoded in her earlier utterance, [I am] more [engaged in politics] than your average punter (Excerpt 9.2, line 11). She then repeats this at the beginning of her explanation, you know your average punter starts out as an average punter and they can vote (lines 12-13). Ashley goes on to describe the ways in which a person can engage in politics, going into some detail about the many methods of political involvement, including sign a petition (line 16), coordinating volunteers (line 19), inputting data (line 20), organise campaigns (line 22) and submit... a written submission or an oral submission (lines 23-24). She links this to the amount of time and effort they're willing and able to put in (lines 28-29), but when I question her level of engagement in reference to these criteria she admits that it is limited, taking a less engaged stance, but $i$ just don't have the time... and i'm too lazy (lines $42^{2-44}$ ). Then, explaining her self-description as lazy, she provides the reason, and you know what $i$ have so much politics in my work...i kind of want downtime... when i'm free (lines 46-48).

On the face of it, Ashley seems to be contradicting her earlier stance where she characterises herself as engaged more than your average punter (Excerpt 9.2, line 11). Ashley now admits that in fact she does 
not engage to the level she has just described. In assigning herself a label, and i'm too lazy (line 44), Ashley essentially characterises herself as being engaged to the same level as her 'average punter.' She then explains that this is due to her work, a fact which in essence distinguishes her level of political knowledge from others. This is perhaps the reason why, when asked if she were engaged or interested in politics earlier, she answered yes not as much as $i$ should be but + reasonably (Excerpt 9.2, line 9). The sense of obligation in her use of the modal should appears to arise from her knowledge that she has the ability to engage with politics further but refuses to do so due to the nature of her work. The negative force of the adjective lazy (line 44), in reference to herself, is perhaps precluding a possible stance attribution on my behalf; in other words, I could have attributed 'lazy' to her after she admits not taking part in all the activities she lists. In effect, by assigning the negative label to herself, she has taken away the ability for it to be imposed on her by another, preventing the possibility of a face-attack (Austin, 1990).

Throughout the conversation we move from the 'interview' into relational talk and back as a means of managing our interpersonal needs (Holmes, 1995; Holmes \& Marra, 2004). In Excerpt 9.6, we talk briefly about my recent holiday to Coromandel, a region in the North Island of New Zealand where Ashley grew up. The relational function of Excerpt 9.6 is also within a transactional context: her upbringing is used to explain her political background and thus has a more referential function than the small talk examined in Excerpt 9.1.

Excerpt 9.6

Context: Continues from the end of Excerpt 9.5.

Time: 10:12.2-11:22.6

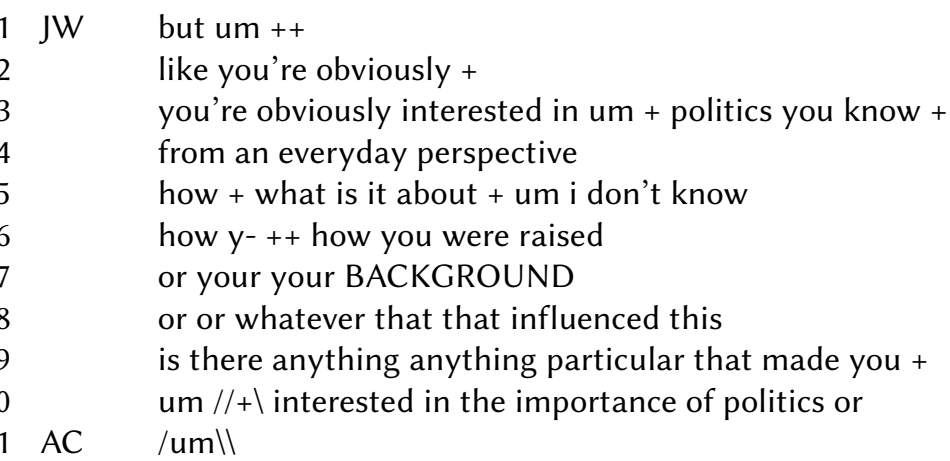




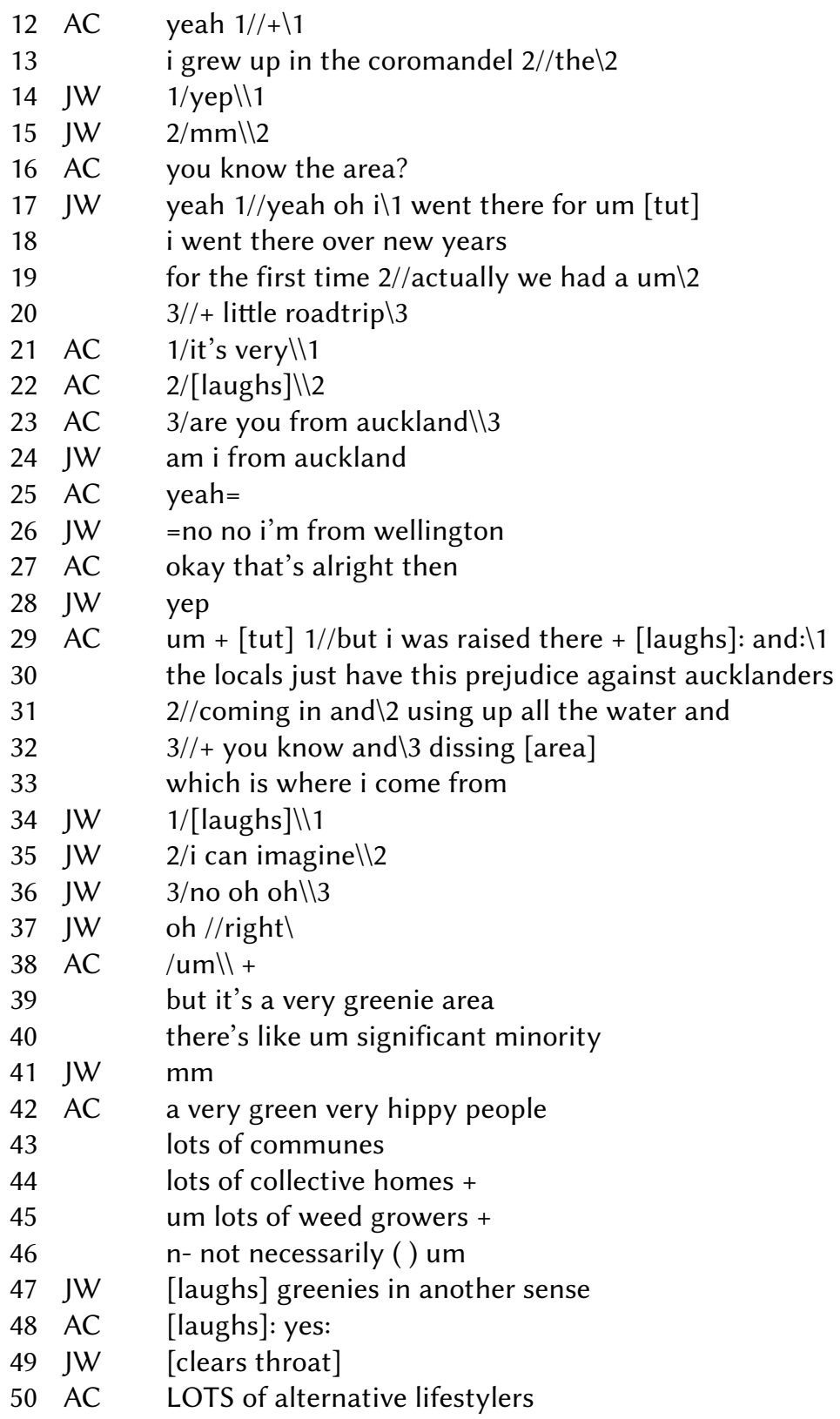

The hesitation in my line of questioning at the start of Excerpt 9.6 is similar to that displayed in Excerpt 9.3. Again, in this excerpt I am aware that asking a rather personal question about Ashley's background could be a potential face threat and as a result hesitate and reformulate my question (lines 1-10). It also gives her the opportunity to save face by allowing her the chance to tell me about her 
engagement with politics in a different way. When viewed in context of suffering a possible loss of face when she earlier described herself as lazy (Excerpt 9.5, line 44), my purpose of raising this question is an attempted repair and positive attribution attending to rapport and her face needs, you're obviously interested in um + politics (line 3; Brown and Levinson, 1987; Goffman, 1955).

Ashley begins answering my question by raising the topic of the place in which she grew up, the Coromandel region (line 13), which is stereotypically associated with 'hippies' and Green Party supporters, further evidence for the indexical value of place names in New Zealand and the salience of subnational discourses (Chapter 8). My minimal feedback signals to her that I am familiar with the region (line 15) and as a result she asks you know the area? (line 16). I then tell a 'small story' (Bamberg, 2006; Bamberg \& Georgakopoulou, 2008; Georgakopoulou, 2006) about my little roadtrip (lines 17-20) which seems to contain for her connotations of a holidaying Aucklander, indicated by her laughter (line 22) and which prompts her question are you from auckland (line 23). I appear to be taken aback by her accusation, demonstrated in my repetition of the question, am i from auckland (line 24). Ashley appears to be establishing my identity here which may affect the way in which she chooses to respond to my story. I disagree, no no i'm from wellington (line 26), and being a Wellingtonian means I get a free pass in Ashley's eyes, okay that's alright then (line 27). This functions to align with me and to evaluate Auckland negatively in a humorous frame. Ashley then returns to an earlier line of conversation where she is discussing where she is from, but $i$ was raised there (line 29), but is interrupted by my overlapping laughter prompted by her earlier strong reaction (line 34), which I indeed find amusing, and to which she also responds with laughter (line 29). She treats my behaviour as a prompt to further explain her reaction, the locals just have this prejudice against aucklanders coming in and using up all the water (lines 30-31). Her mention of the locals (line 30) serves to distance herself from the group, as a pronoun such as the inclusive we would have emphasised her membership in this community (Înigo-Mora, 2004). Perhaps such distancing is a form of mitigation given the face-threatening nature of her allegation in the Wellington context and could also be interpreted as Ashley generating a Wellingtonian identity in order to align with me. 
This segment of the exchange appears to be similar to the antiAuckland sentiment in Wellington, as discussed in Chapter 8. There is a degree of alignment between our stances here as she likely infers, due to the subnational discourse of contrast, that being a Wellingtonian I may share a similar negative evaluation of Auckland. She then returns to her earlier point and further describes the Coromandel region as a very greenie area there's like um significant minority... a very green very hippy people (lines 39-42). The intensifier very stresses and strengthens her evaluations (Hunston, 2011, p. 1). In reference to her utterance lots of weed growers (line 45) I make an attempt at humour, greenies in another sense (line 47), referring to marijuana growers rather than Green Party supporters, which functions to maintain rapport and release tension (Meyer, 2000; Morreall, 1983, 2009). This prompts laughter from her (line 48) and she then returns to her earlier point in summary, LOTS of alternative lifestylers (line 50).

Ashley's description of the region confirms in my mind the Coromandel stereotype and locates our interaction in subnational context. After this excerpt we continue to talk further about her family background and experiences as a child, not presented here for confidentiality reasons, which leads into a discussion about political representation in the region, as shown in Excerpt 9.7. Talk about her home region demonstrates that a sense of place and origin is important to Ashley in defining her political self. Coromandel appears to have shaped her political leaning much like Wellington has for the participants in Chapter 8. This provides further evidence for the importance of considering subnational discourses and extradiscursive referents alongside stancetaking as they have the potential to leave significant impressions on who we are as political beings.

In Excerpt 9.7, I ask Ashley about the MP that currently holds the Coromandel seat.

\section{Excerpt 9.7}

Context: Ashley has been talking about her family background and exposure to politics and politicians in the Coromandel region.

Time: 13:00.2-13:58.7

1 JW so the um $\mathrm{m} \mathrm{p}$ up there is a national $\mathrm{m} p$ now

2 AC that's right um

$3 \mathrm{JW}$ is that 


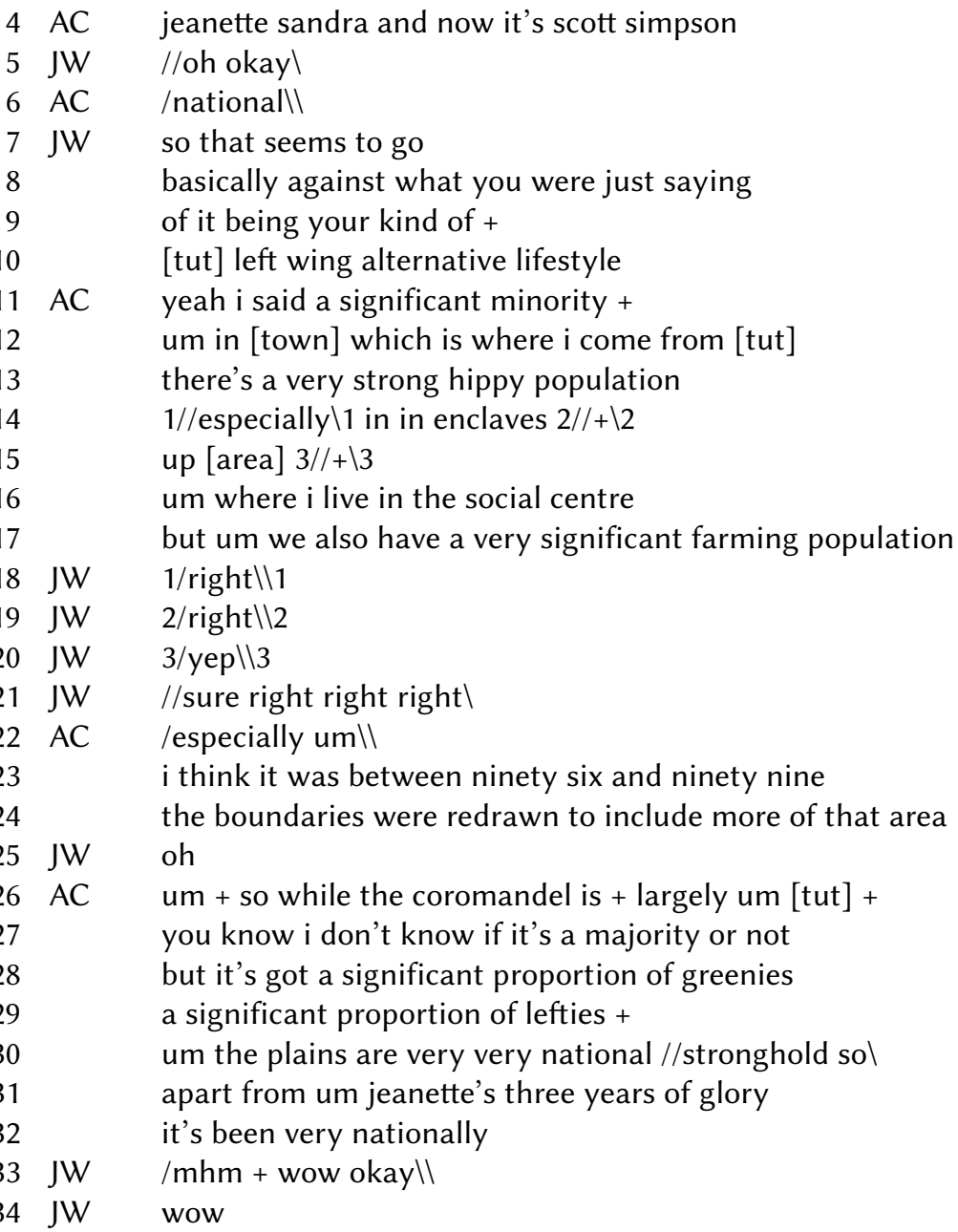

My first utterance, so the um $m p$ up there is a national $m p$ now (line 1), signals an opportunity for Ashley to expand. I question why a National Party MP, Scott Simpson, represents Coromandel when it is stereotypically a hippy and left-wing area, so that seems to go basically against what you were saying of it being your kind of + [tut] left wing alternative lifestyle (lines 7-10). However, Ashley earlier stated that the greenies were only a significant minority (Excerpt 9.6, lines 39-40). Ashley corrects, yeah $i$ said a significant minority (line 11), stressing her earlier characterisation and stating that in fact we also have a very significant farming population (line 17). Talk about farming in New Zealand has strong indexical links to more conservative politics, indicated by rural voting patterns in New Zealand that overwhelmingly tend to favour the centre-right National 
Party (Electoral Commission, 2015). Ashley's choice of pronoun we (line 17) in this utterance also includes her within the Coromandel community (Înigo-Mora, 2004). She then goes on to explain why National holds the seat, due in her mind to the electoral boundaries shifting. In her explanation she creates an opposition between the greenies (line 28) and lefties (line 29) versus national (line 30), and uses a POLITICS IS WAR metaphor to do so through the use of stronghold (line 30; see Lakoff and Johnson, 1980; Semino and Masci, 1996; Woodhams, 2011).

Ashley's reference to jeanette's three years of glory (line 31) is further evidence for her Green Party support through positive evaluation. The reference is to Jeanette Fitzsimons, the only Green MP to secure an electorate in the 1999 election. At the 2002 election Fitzsimons lost her seat to Sandra Goudie, a National MP (Electoral Commission, 2015). A sense of familiarity is created through Ashley's use of politicians' first names, jeanette sandra (line 4) and jeanette's (line 31). This appears to relate to New Zealanders' tendency to mitigate hierarchy and operate on an informal basis, and indicates the influence of sociocultural norms as discussed in Chapter 7 .

This exchange displays a stance clash where my stereotypes of the Coromandel region do not hold up against the fact that a $\mathrm{Na}-$ tional MP represents it in Parliament. Ashley negotiates this apparent contradiction by repeating the fact that she was originally referring to only a minority of left-wingers and is hence not responsible for my misunderstanding. She then goes on to provide evidence for this by characterising a split between Coromandel's hippy enclaves (line 14) scattered throughout the region and the plains (line 30) which are held by National-voting farmers, attributing to the latter the political influence which was enough to carry a National MP to Parliament. Reference to the physical characteristics of the land is also an indication of the existence of extra-discursive referents, as explored in Chapter 6.

Much like the previous excerpt, Excerpt 9.7 indicates that place of origin is very important to Ashley as it helps to situate her within the national context. She clearly aligns with the groups she has characterised as being greenies and lefties (lines 28-29), which is evidenced in her positive evaluation of Jeanette Fitzsimons alongside her likely Green supporter identity. Again, regional information, such 
as Coromandelite or Wellingtonian identities, provides tentative indexical clues about likely background and opinions based on regional stereotype (and can also draw on the aforementioned attitudes to perceived regional dialects in New Zealand, as highlighted by Nielsen and Hay, 2005). We both orient to these stereotypes, and having them challenged and explicitly raised as a discussion topic provides the opportunity for an insider to explain to an outsider why the region is characterised in this way.

At this point Ashley has established her political identity based largely on where in New Zealand she was raised. This has again strengthened my inferences to the point that confirming her Green Party support at this stage is a mere formality. This is where the conversation leads at the next stage.

\subsubsection{Stage Six: Explicit Confirmation}

At this point of the conversation we are comfortable enough with each other to ask questions that may have been considered facethreatening at the start of the interaction. We have spoken about more personal topics, such as family background and place of origin, which has served to establish common ground and make us surer of the validity of our stance inferences. This allows me to ask Ashley directly about her political leaning. Excerpt 9.8 shows how this unfolds.

\section{Excerpt 9.8}

Context: Continues from the end of Excerpt 9.7.

Time: 13:58.8-14:24.5

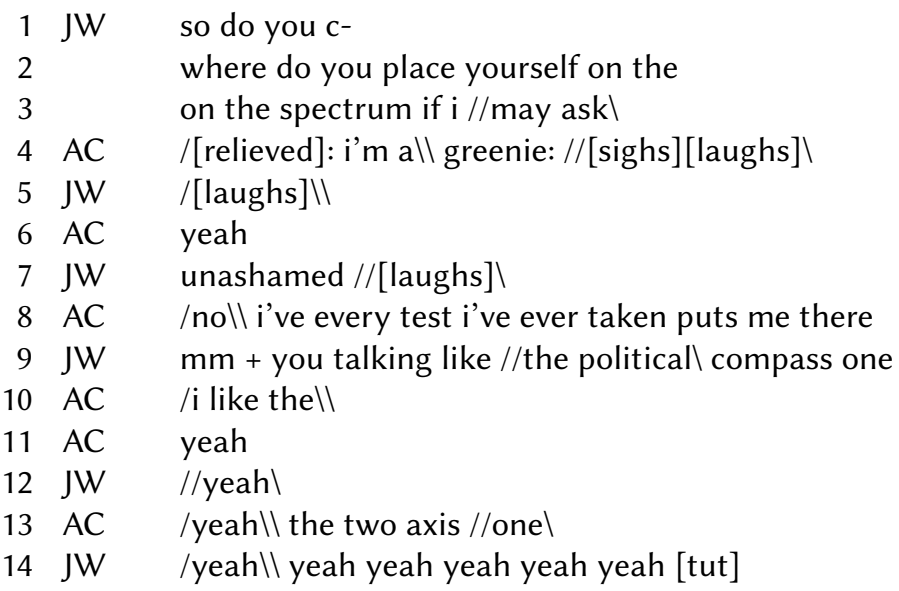




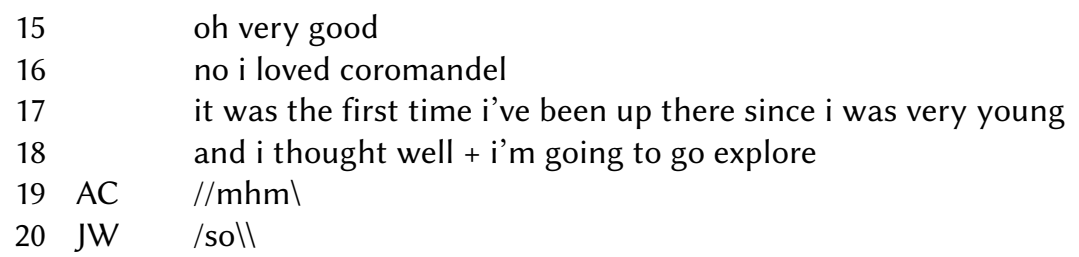

In this excerpt, I broach the topic of Ashley's political alignment explicitly. I do however still attend to face by using the polite tag if $i$ may ask (line 3). The tone of her voice in answering, [relieved]: i'm a greenie: [sighs][laughs] (line 4), suggests relief, a breathy quality followed by a sigh and laughter, which indicates that she is glad to have finally confirmed this point. It is perhaps a question that she had expected and been prepared for, given the nature of the recruitment and the aims of the project as explained on the information sheet. Ashley provides explicit confirmation by indexing the social identity greenie (line 4), a term which has arisen previously in reference to the Coromandel, and which functions to simultaneously align her with both the greenie identity and her home region. The regional identity which she has sketched for me earlier provides evidence as to her conceptualisation of the content of the greenie identity; in other words, part of being a greenie, at least in Coromandel, involves very hippy people lots of communes lots of collective homes (Excerpt 9.6, lines $4^{2-44}$ ). Ashley's conceptualisation of the structure of this identity is likely one that she is comfortable aligning with given her Coromandel upbringing.

The word 'greenie', referring to those concerned with environmental issues, often has derogatory undertones in New Zealand English (Deverson \& Kennedy, 2005). This also appears to be the case in Australia (see Whitehouse, 2014; Whitehouse \& Evans, 2010). It seems at least in Ashley's case that the word has been reclaimed (or 'reappropriated', see Galinsky et al., 2013) and serves as an indexical label which links to an identity with which she desires to be associated. Perhaps using greenie rather than other terms (e. g., left-wing, Green) serves as a mitigation on her part by using a diminutive form in an attempt to play down her allegiance and thus attend to the possibly controversial nature of her utterance. This is particularly important considering that at this point I have not explicitly confirmed my own political allegiance, though it is more than likely that she has arrived at a similar point regarding my loyalties through inferential processes. 
Her use of greenie does however mirror the form of the term lefties (Excerpt 9.7, line 29) and may be an idiosyncratic way of referring to left-wing political support. The term indexes multiple categories in New Zealand, such as environmentalism and conservationism (Haggerty, 2007), in addition to Green Party support.

Despite the strength of my prior inferences, explicit confirmation of her belonging to this group has implications for both the A-identity (in the form of a more a global set of environmentalist 'greenies') and I-identity (Green Party supporter) aspects, and is therefore an important step in the evolution of the discussion. It clears the air, allowing her to converge more explicitly with the characteristics of a person who belongs to the indexed identity groups. This is demonstrated in the subsequent excerpts.

The laughter between turns in Excerpt 9.8 serves to defuse the tension of my potentially face-threatening question and she mitigates the potential controversial nature of baldly stating political persuasion in New Zealand by ending her turn with laughter (line 4). I join in even though there is nothing overtly humorous, unashamed [laughs] (line 7). My use of the term unashamed is curious in that until now Ashley had not overtly confirmed her Green Party support and hence it seems unwarranted in this context. Its function appears to be to call attention to the fact that she seems to make no apology for the fact that she is a greenie, suggesting that her explicit statement of affiliation is a marked action in the New Zealand context. It also perhaps signals that it is not necessary for Ashley to mitigate her identity claim any further. However, Ashley appears to interpret it as a challenge of sorts which implies that she may not have provided adequate evidence for her alignment with the greenie identity. This is addressed in her following response, no i've every test i've ever taken puts me there (line 8), giving evidence for her political persuasion along more quantifiable (and perhaps more academic) lines. In this context Ashley signals that she does not blindly align with a political identity and has substantive evidence for why she indexes membership of the group. Presenting evidence in this way could also be a response to my identity as an academic researcher and her belief that I may require some kind of quantitative 'proof' or external verification of her ideological leaning. I demonstrate knowledge of a particular online test of political ideology, you talking like the political compass 
one (line 9), perhaps strengthening in her mind my academic identity, and Ashley confirms her knowledge of the test I mention, yeah the two axis one (line 13), converging in alignment in the process.

I then return to talking about Coromandel, the topic that immediately preceded this excerpt, with yeah yeah yeah...oh very good no $i$ loved coromandel (lines 14-16). This is an abrupt segue, quickly orienting away from the face threatening atmosphere brought up by overt discussion of political identity and returning to the 'safer' topic of my trip around her home region. Its appropriacy as a conversational topic at this point is perhaps due to the Coromandelite and greenie identities having been explicitly linked throughout the conversation; Ashley's indexing of greenie in this exchange indexically calls down Coromandelite as part of its indexical field (Eckert, 2008). It also functions as further alignment with her through my positive evaluation of her home region, $i$ loved coromandel (line 16), likely attending to her face needs directly after the high-stakes exchange regarding the potentially face-threatening issue of her political persuasion (Brown \& Levinson, 1987). The structure of my utterance in switching to this topic is also notable as it follows a broad 'yeah...no' structure. According to Burridge and Florey (2002), yeah no can function as a resumptive topic marker which provides coherence and in this case connects to a topic which has earlier proven useful for maintaining rapport.

After Ashley has explicitly confirmed her political allegiance, she begins to take more partisan stances. This is examined in the next section.

\subsubsection{Stage Seven: Identity Reinforcement}

With being a greenie confirmed, Ashley now has the opportunity to provide stances containing stronger evaluations and more explicit positionings, as apparent in Excerpt 9.9.

Excerpt 9.9

Context: We talk further about my trip around Coromandel and engage in small talk.

Time: 15:12.4-16:41.4

1 JW so um i guess er + 
how do you feel +

[tut] um the government's performing at the moment at the moment?

$\mathrm{mm}$

well [sighs]

[laughs]

[laughs] +

well i think they're doing appallingly um +

[tut] particularly in the matter of democracy

local and at a higher level //um \ [tut]

they seem to think the three

once every three year mandate +

gives them the right to do whatever they like um=

/okayll

=sure

particularly + um

things such as the ecan commissioners bill +

which is um [tut]

the way they're going about it now with +

reinstating com-temporary commissioners //for christchurch】

$/ \mathrm{mm} \backslash \backslash \mathrm{mm}$

is a direct contradiction of what they promised //earlier

$/ \mathrm{mm} \backslash \backslash \mathrm{mm} \mathrm{mm}$

um and there's + in you know

in total opposition to local democracy

and they've been challenged over it

by the human RIGHTS commission for $1 / /$ example 1

but it's still going ahead

um ++ [tut] and what was the other major one

oh the $2 / /+\backslash 2$ charter schools thing is JUST RIDICULOUS

ABSOLUTELY not mandated by an election or anything since and of course asset sales $3 / /$ which $\backslash 3$

you you can make a fair case for $4 / /+\backslash 4$

having an electoral mandate

but you can't really make a case for

trying to block a a referendum

$1 / \mathrm{mm} \backslash \backslash 1$

$2 /[$ laughs] $\mid 12$

$3 / \mathrm{mm} \backslash 3$

$4 / \mathrm{mm} \backslash \backslash 4$

$\mathrm{mm}$

because that is the CHECK that's

//that's put on that in a sensel

$/ \mathrm{mm}+\mathrm{mm} \backslash \backslash$

$\mathrm{mm} \mathrm{mm} / / \mathrm{mm} \backslash$

/soll you know i just think it's characterised by

a fair amount of dirty dealing and //(under)handedness $\backslash$

i don't think should be present 
$50 \mathrm{JW} \quad / \mathrm{mm} \backslash$

$51 \mathrm{JW} \quad \mathrm{mm} \mathrm{mm}$

At the start of Excerpt 9.9, I open the floor to Ashley to provide more detail about her views as she has now established herself as a greenie. The most obvious topic for initial comment is the performance of the current Government, how do you feel $+[$ tut] um the government's performing at the moment (lines 2-3). Ashley's initial reaction to my question, well [sighs] (line 6) perhaps indicates frustration at the Government's poor performance, preparing herself to enter into emotionally invested stancetaking. The discourse marker well in this case appears to be a delay device in which Ashley is thinking about her answer (Jucker, 1993) and her second use (line 9) may simply be an interactional response marker (Schiffrin, 1987).

Tension is mitigated by our mutual laughter (lines 7-8). Ashley then has no problem providing strongly negative evaluative stances against the National Government, indicated in heavily critical words such as appallingly (line 9), and implying that they are antidemocratic at a local and at a higher level (line 11) and arrogant in thinking a once every three year mandate + gives them the right to do whatever they like (lines 13-14). She provides examples of this in relation to the Government's 2012 extension of the earlier appointment of Environment Canterbury (ECan) commissioners, placing the Government in direct contradiction of what they promised earlier (line 23), and hence not trustworthy. ${ }^{2}$ The Government is further characterised as anti-democratic with Ashley's evaluation of their approach to Christchurch as being in total opposition to local democracy (line 26).

Ashley switches tack by introducing another Government policy, the ACT Party's private charter schools policy, which she strongly and emphatically condemns, the + charter schools thing is JUST RIDICULOUS ABSOLUTELY not mandated by an election or anything since (lines 31-32). This also furthers her negative stance against the Government, characterising them as anti-democratic in implement-

2 After the 2010 review of the Canterbury Regional Council (known as ECan), the Government replaced the democratically elected council members with commissioners in order to address issues of poor performance. In 2012 this was extended to 2016 in the context of the rebuild after the devastating 2010-2011 Canterbury earthquakes (Department of Internal Affairs, n.d.). 
ing policies that in her mind do not have the support of the electorate. The exchange also indexes a democratic identity in that she shows concern with democratic process through a series of implicit prodemocracy stances. Ashley is more moderate in the case of asset sales given the Government campaigned on the very issue during the 2011 general election, thus you can make a fair case for + having an electoral mandate (line 34-35). However, the Government's attempts to stymie a citizens initiated referendum is not acceptable to Ashley in the same sense, furthering her democratic identity (line 36-37). This contrasts with her earlier and more neutral evaluation of asset sales as interesting (Excerpt 9.4, line 2) and her mention that i'm a little bit over it to be honest (Excerpt 9.4, line 7); she clearly has more invested views than she earlier indicated. She finishes by summarising the behaviour of Government in this case as being characterised by a fair amount of dirty dealing and (under)handedness $i$ don't think should be present (lines 47-49).

The evaluative stances in this excerpt are in stark contrast to the more measured evaluations of the Government and the ambiguous referents present earlier in the conversation (e. g., one side, the other side; Excerpt 9.3, lines 24, 27). Considering we are nearing the end of our conversation and we have both shared information about ourselves, rapport between us is at a point where such topics can be safely aired. Ashley is also building on the greenie identity she indexed earlier as these strongly negative evaluations are in line with this identity; by criticising the Government she converges in alignment with the Green Party whilst simultaneously diverging from the National-led Government and its policies.

Excerpt 9.10 further demonstrates Ashley's negative evaluation of the Government in light of her greenie identity.

Excerpt 9.10

Context: Continues from the end of Excerpt 9.9.

Time: 16:41.5-17:08.3

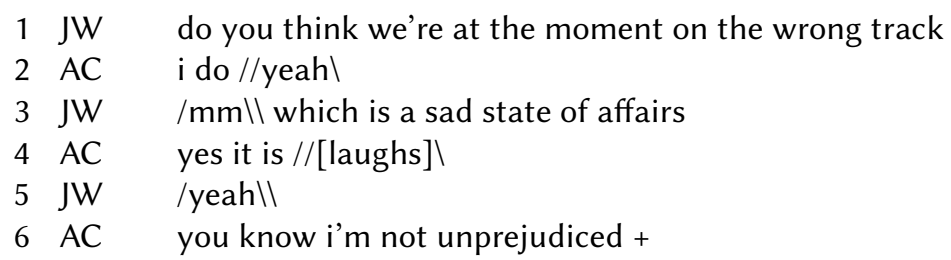




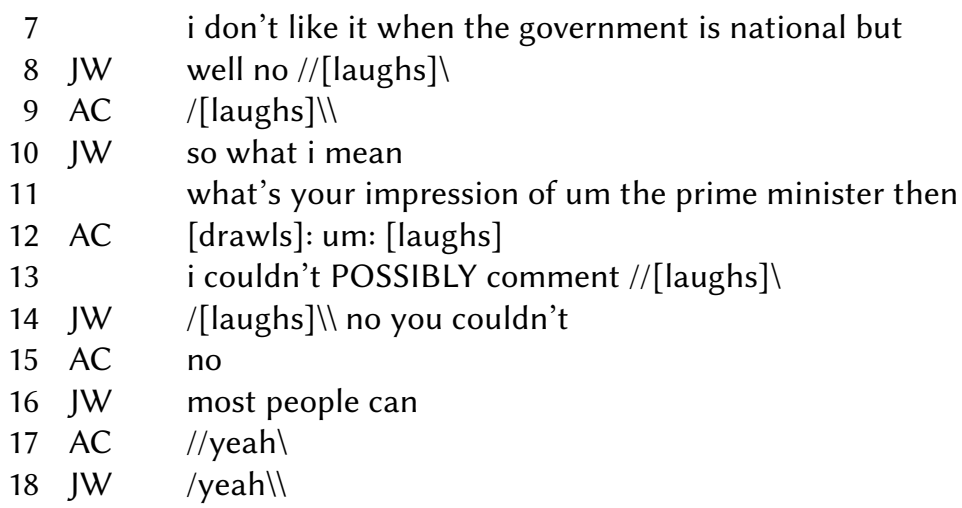

Carrying on from the previous excerpt, this exchange shows Ashley's most explicit negative evaluation of the National Government. She states that i'm not unprejudiced $+i$ don't like it when the government is national (lines 6-7). She essentially casts aside any pretence of balance, as displayed earlier in the conversation, and has now taken up a highly partisan approach implying that she is prejudiced against all governments which are led by the National Party. My utterance, $\mathrm{mm}$ which is a sad state of affairs (line 3), could be interpreted as an implicit alignment with Ashley's anti-Government stance, or it could be taken at face value as an alignment solely with her agreement that we're at the moment on the wrong track (line 1). Either way, my utterance functions as stance alignment with her (Du Bois, 2007), supporting her in her condemnatory comments.

My next question, what's your impression of um the prime minister then (line 11) prompts an interesting response from Ashley, [drawls]: um: [laughs] i couldn't POSSIBLY comment [laughs] (lines 12-13). This could be a method of declining to answer through referencing the 1990 British television series House of Cards in which the fictional politician Francis Urquhart often uses the phrase 'You might very well think that; I couldn't possibly comment.' I miss Ashley's reference and appear somewhat confused by her response given her strong condemnation of the National party only a few turns earlier, and I respond [laughs] no you couldn't (line 14), prompting her to reconsider. She flatly denies to do so no (line 15) and in my confusion I note that most people can (line 16), in the sense that most people I have talked to have been able to clearly articulate their opinions about the Prime Minister. Sensing that I have misunderstood, the topic quickly shifts to discussing the 2014 election after the end of this excerpt. It is not 
until the very end of our discussion, when we are saying goodbye, that Ashley states that she will email me her views on the Prime Minister. Perhaps having these opinions audio recorded or aired in a public space could be a potential threat to her employment which implies that her view of Key is likely to be critical. It also shows that to some extent she is beginning to monitor her speech, at least in this part of our conversation.

The discussion now moves to a close, as Ashley's time limit approaches. The next section examines how Ashley strengthens her greenie identity before the conversation ends.

\subsubsection{Stage Eight: Ending the Conversation}

After Ashley's strongly negative evaluations of the Government we continue on to talk about her views of the Labour Party and the internal workings of the Green Party. As shown in Excerpt 9.11, Ashley ends the conversation on a greenie note as she displays indepth knowledge of the Green Party and also positions herself more strongly as a democrat.

\section{Excerpt 9.11}

Context: Ashley and I have been talking about the Labour Party.

Time: 18:30.6-19:51.3

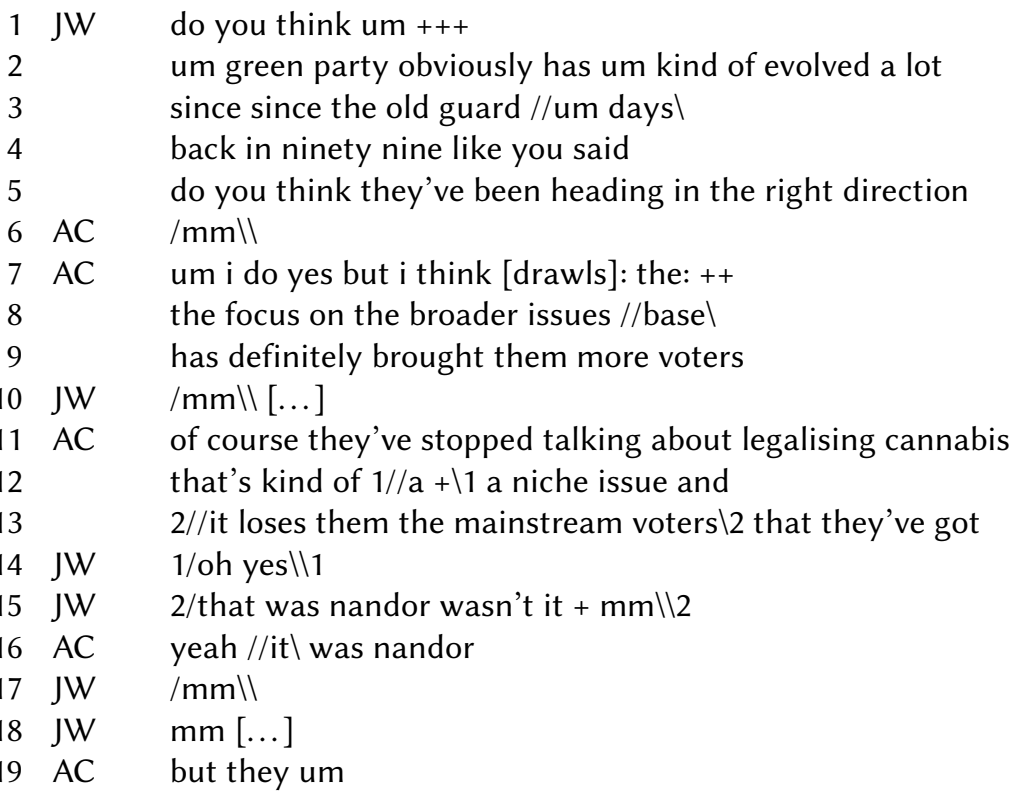




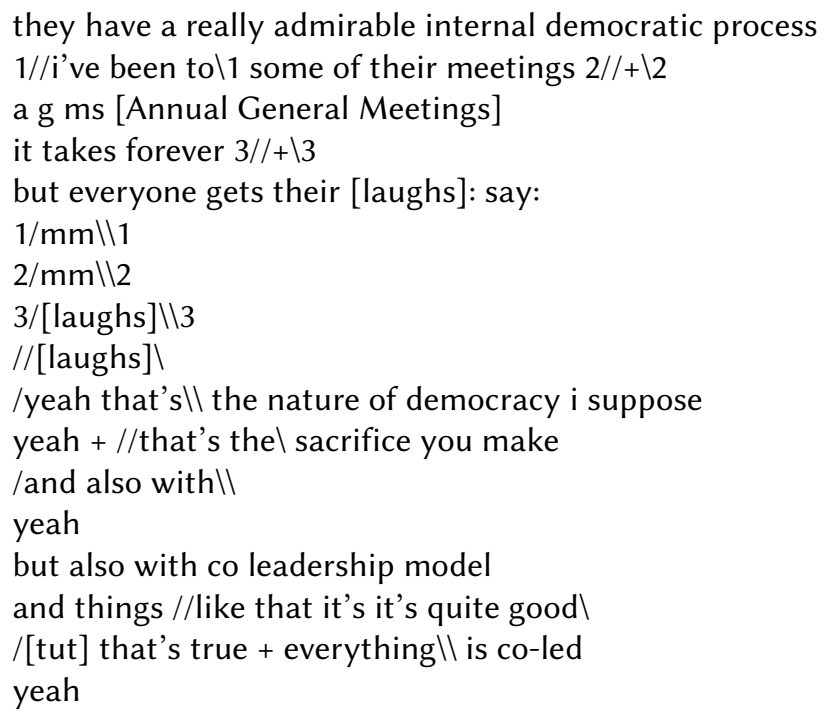

Describing the Green Party as having a really admirable internal democratic process (line 20) is an explicit contrast with her earlier criticism of National's lack of democratic practice (Excerpt 9.9, lines 9-11). The earlier stance contrasts directly with her view of the Green Party where everyone gets their [laughs]: say: (line 24) as opposed to National which is in total opposition to local democracy and they've been challenged over it by the human RIGHTS commission (Excerpt 9.9, lines 26-28). This indicates that Ashley is also building on her identity as a democrat through her accumulated stancetaking. Negative evaluation of National's alleged flouting of democratic principles is in direct contrast to the Green Party's admirable (line 20) commitment to the democratic process and this is provided as an implicit reason why the Green Party has Ashley's support.

There is a journey metaphor present in my question do you think they've been heading in the right direction (line 5) which echoes my earlier metaphorical utterance, do you think we're at the moment on the wrong track (Excerpt 9.10, line 1). The metaphorical journey I have characterised has two paths provided by Ashley: the wrong direction, associated with the National-led Government, and the right direction, which is provided by the Green Party (see also Woodhams, 2011, 2012). Throughout this excerpt I demonstrate knowledge of the old guard um days (line 3), mention ex-Green Party MP Nandor Tanczos that was nandor wasn't it (line 15) and also mention co leadership model and things like that it's it's quite good (lines 33-34). This demonstrates that 
I know something of the Green Party's internal workings and history which both positions me as someone who is knowledgeable about them and functions to align with Ashley's greenie identity throughout the entire exchange. My evaluation of the Green Party's co-leadership model as quite good (line 34) is an explicit positive evaluative stance which Ashley could infer to mean they also have my political support. This alignment towards the end of the conversation functions to reiterate the fact that we are both 'on the same page' (Kecskes, 2014; Kecskes \& Zhang, 2009). It may also serve to show that she can trust me with the information that she has provided throughout the discussion, especially as some of it was strongly condemnatory and potentially controversial. The conversation then ends quickly as Ashley mentions that her time is up. We wrap up and I mention that it was nice to meet her and thank her for her time.

\section{$9 \cdot 3$ DISCUSSION}

Through a complex process of inference and contextual presupposition due to both the initial email contact between us and the preliminary small talk at our first meeting, I had built a picture of Ashley's likely political persuasion even before we engaged in the main body of talk. Ashley's political alignment is not explicitly confirmed until much later in the conversation, but by that point it is merely a formality as I had attributed to her positive stances towards the left of the political spectrum, more specifically, the Green Party. This is determined by a combination of contextual presupposition (e. g., through her friendly relationship with Jane) and inference (e. g., from her family background and topical interests). Ashley's initial reluctance to engage in a partisan manner, even when discussing highly divisive topics such as state asset sales, contrasts with her later more invested stances against the National Party and its policies, culminating in the strong assertion i'm not unprejudiced $+i$ don't like it when the government is national (Excerpt 9.10, lines 6-7). This highly partisan stance is preceded by the explicit confirmation of her political allegiance where she self-labels as a greenie (Excerpt 9.8, line 4), a term originally derogatory (Deverson \& Kennedy, 2005) but reclaimed as an identity marker which aligns her closely with environmentalism, conservationism and the Green Party. The label also indexes her 
earlier evaluations of her place of origin, the Coromandel, which in her words is known for its significant greenie population.

The intersubjectivity of stancetaking is highlighted when my stances are analysed alongside Ashley's. I am privileged as an analyst of this conversation as I have access to the inferences I had made prior to and throughout the conversation. With this in mind, it is possible to gain deeper insight into how my subjectivity played a role in negotiating political identity genesis in this context. I am however not privy to the inferences Ashley made and can only hypothesise as to their nature based on evidence arising from the discourse context.

A monolithic political identity is not unproblematically displayed in interaction as multiple identities are indexed through our cumulative stancetaking (Eckert, 2008, p. 469; Rauniomaa, 2003, as cited in Bucholtz \& Hall, 2005, p. 596), particularly in the case of Ashley's alignment with the I- and A-identity aspects of greenie ${ }^{3}$ and her supporting identity as a democrat. Had Ashley foregone face-saving conventions and indexed greenie identity at the outset of the conversation, in addition to being a face-threatening act in itself, Ashley's identity claim would only be tentative until such time that her stances could support it. In other words, Ashley would not be a greenie until she is recognised as such in discourse, through the recognition process of D-identity. Accumulation of stances over subsequent interactions then has the potential to solidify her being seen as this certain kind of person. Granted, this conversation was short, and further interaction with Ashley could very well change the analysis provided here. It seems unlikely however that Ashley would contradict her indexing of the greenie identity or condemnation of the Government, as all contextual information points to her strong Green Party allegiance. Further interaction with her could provide more information as to her trajectory of stancetaking across time and space (Jaffe, 2009a, p. 19). It may also indicate her particular conceptualisation of the structure of the greenie identity and perhaps give

3 The NIDA model (Chapter 3) allows for indexical ties between certain labels and multiple aspects of identity. As mentioned above, within I-identity (institutional), aspects of 'greenie' may refer to membership of the Green Party. A-identity (affinity) may relate to a more global environmentalist movement. $\mathrm{N}$-identity (nature) is not apparent in this example but from a realist viewpoint still present, and D-identity (discourse) is the channel through which all of these aspects are recognised. 
insight into possible relations between aspects of her stancetaking. Nevertheless, the analysis in this chapter suggests that consideration of the full discursive and structural context alongside the intersubjective relations between conversational participants is necessary to gain a better understanding of identity genesis in discourse.

Ashley indexes multiple identities throughout our conversation alongside her greenie self, including democrat and Coromandelite. The focus in Chapter 10 shifts to this 'multiplicity' of stance and examines in detail the many ways in which stancetaking can index multifarious identities in discourse. 
The analysis of my discussion with Ashley in Chapter 9 focuses on the intersubjective nature of stancetaking, that is, how my stancetaking interacts with hers in numerous ways and affects the interactional context in which her political identities are generated. Less focus is paid however to the fact that an individual can take multiple stances that index various identities at any point in a conversation (Jaffe, 2009a). As Bucholtz and Hall (2005, p. 598) argue, in reference to their principle of relationality, identities are never autonomous or independent but always acquire social meaning in relation to other available identity positions and other social actors.' In Ashley's case, her greenie identity and its related stance acts intertwine with other identities and their associated stances such as environmentalist, government worker, democrat and Coromandelite, along with my own stances as her conversational partner. The case study examined in this section, my discussion with Steven, focuses in more detail on this process of stance multiplicity as it occurs within structural and discursive context (see also Damari, 2010; Jaffe, 2000; McIntosh, 2009; Moita-Lopes, 2006).

The discussion with Steven is different to that of Ashley for a number of reasons. Firstly, Steven and I spend roughly an hour in conversation which gives us more time to develop more complex intersubjective stances. Secondly, Steven was an acquaintance of mine whom I had met on a few previous occasions in informal contexts. The stance slate was therefore not as clear as it had been with Ashley. For example, I knew Steven's political allegiance to Labour prior to our meeting and also knew of his professional identity as a church minister. This was, however, the first time I had engaged with him in detail about his political views.

In contrast to Chapter 9, I make use of selected aspects of my discussion with Steven in order to best highlight stance multiplicity 
in action. Steven's case is chosen for analysis primarily due to his two major identity threads, that of the political and religious. This does not discount that, like Ashley, Steven has multifaceted identities and related stances that are analytically salient. In this case the two selected are useful examples of how different identities interact, particularly within the sociocultural context which influences the relationship between politics and religion. Steven's management of these multiple aspects of his identity and their associated stance acts makes for a rich case study of stance multiplicity in action.

\subsubsection{Political Affiliation}

The history behind the relationship between religion and the state in New Zealand has an important influence on the way in which Steven generates his political and religious selves. New Zealand has historically favoured 'pragmatic secularism' in its political affairs, reflected in its secular education system (Ahdar, 2006). In fact, as Matheson (2006, p. 178) points out, New Zealand has never had an established or state church. The Supreme Court clarified this very fact in a ruling in 1910 which stated that while the Anglican Church was then large, it had no special legal rights over any other denomination (Ahdar, 2006, p. 622). This led to a 'grand narrative' of secularism which has tended to dominate histories of New Zealand and which some scholars have criticised as erasing the legacy of Christianity in Aotearoa (Stenhouse, 1998; Stenhouse \& Wood, 2005). While growing in its secular nature in the current day, New Zealand has historically oriented to a de facto nondenominational or 'generic' Christianity (Ahdar, 1998) which is still reflected symbolically in, amongst other things, the Christian prayer that opens proceedings in the House of Representatives and the national anthem, God Defend New Zealand (Ahdar, 2006, pp. 631-632). The de facto status of Christianity is arguably losing influence in light of the growing acknowledgement of Māori spirituality and minority religions (Ahdar, 1998, 2006). It is also reflected in the increasing number of people reporting no religious affiliation (from $34.6 \%$ of the population in 2006 to $41.9 \%$ in 2013 ; Statistics New Zealand, 2015a). This tension in its history and ongoing redefinition of religion in New Zealand provides the sociocultural and historical context in which Steven's identity work takes place. 
As indicated in Chapter 8, Steven's allegiance to the Labour party is made explicit after roughly six minutes. Excerpt 10.1 shows his more general political leaning becoming apparent soon after the recorder is switched on.

Excerpt 10.1

Steven Wheeler, 43-47 year old NZ European/Pākehā male

Setting: Wellington café

Context: Continues from the end of Excerpt 8.1.

Time: 0:34.6-0:53.3

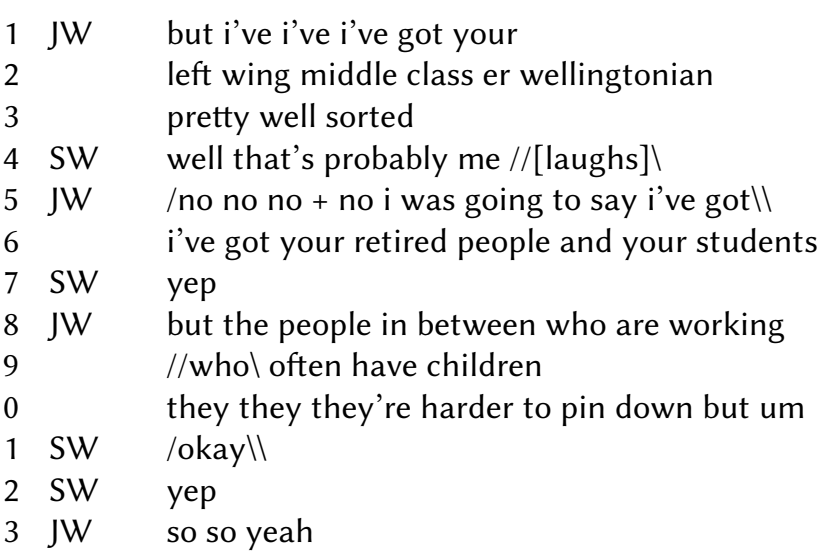

My mention of the method of recruitment I was following at the time, i've got your left wing middle class er wellingtonian pretty well sorted (lines 1-3), leads Steven to immediately assign the description to himself, well that's probably me [laughs] (line 4). This is the first political stance act by Steven in this conversation which functions to orient me to the fact that he is politically left-wing and simultaneously confirms my prior knowledge of his Labour allegiance. His utterance functions as an attempt at humour which is indicated by his subsequent long turn at laughter. His use of humour in this context may be in response to the implication of my previous utterance, that he may not be considered a good choice for participation in the study given I had already talked to many people of similar political backgrounds (see Chapter 5). My immediate answer, rather than responding to the humour with laughter, is to assure him strongly that he will make a valuable contribution, no no no + no $i$ was going to say i've got... (lines $5^{-10}$ ). My answer suggests that the humour in this context is not serving as an indicator of amusement, instead, it is 
more likely nervous laughter or tension release (Glenn, 2003). This is understandable at the early stages of the interview; even though we are acquainted with one another a level of rapport still needs to be achieved (Abbe \& Brandon, 2014; DiCicco-Bloom \& Crabtree, 2006; see also Duncombe \& Jessop, 2012).

Steven has been politically active, particularly throughout a prior Labour Party election campaign. He goes on to describe his campaign experiences in detail in Excerpt 10.2, taking up stances which further contribute to the political aspect of his identity.

Excerpt 10.2

Context: Steven has just explained that Labour has a difficult time in the provinces and I ask for more detail.

Time: 7:55.0-8:21.1

\begin{tabular}{|c|c|}
\hline JW & so you were you were working as the \\
\hline \multirow[t]{3}{*}{ SW } & i was the chair of the I- of the I e c \\
\hline & so the local electorate committee \\
\hline & $1 / /$ the labour $\backslash 1$ electoral committee $2 / /+\backslash 2$ for [place] \\
\hline JW & 1/okay \\
1 \\
\hline JW & $2 /$ yeah $\backslash \backslash 2$ \\
\hline JW & oh yeah yeah yeah yeah \\
\hline \multirow[t]{4}{*}{ SW } & and before that i'd been $+u m+[$ tut $]$ \\
\hline & i wasn't wasn't involved when i was in [place] \\
\hline & um cos the church is very nervous \\
\hline & about people being involved in //politics $\backslash$ \\
\hline JW & /yeah $\backslash \mathrm{i}$ was wondering about that \\
\hline SW & $\begin{array}{l}\text { and b- but before that i had been the chair of um [tut] } \\
\text { er the [place] electorate }\end{array}$ \\
\hline JW & sure \\
\hline SW & so \\
\hline
\end{tabular}

Steven actively builds on his political identity by outlining his position during a Labour Party campaign. He references his past job title as a Labour Electorate Committee (LEC) chair. This label indexes a particular identity; from an I-identity perspective it is a title authorised by the Labour Party which implies a certain level of insider knowledge (Gee, 2000). Steven then provides an indication of his experience of the relationship between religion and politics, the church is very nervous about people being involved in politics (lines 10-11). I confirm that this is a topic of discussion that I am interested in, yeah $i$ was wondering about that (line 12). The fact that Steven raises religion 
while discussing politics and his past campaign roles is the first suggestion that in his view they are closely related.

In addition to his political identity, there is a multifaceted professional identity drawn upon in this interaction. Steven is a full-time church minister and previously a LEC chair. His professional identities have therefore included both relatively high-profile religious and political aspects, a combination which was considered inappropriate by the Church of one particular electorate where Steven notes that he did not work in politics to the same extent as other regions (line 9). This indicates that in that particular context the requirements of his professional identity as a minister took precedence over aspects of his political identity as a Labour campaigner. The next section examines this intersection of religion and politics within Steven's identity in more detail.

At the end of the conversation, Steven underlines his political identity by indexing certain identity categories. This is demonstrated in Excerpt 10.3.

Excerpt 10.3

Context: Steven has offered to put me in touch with one of his acquaintances.

Time: 47:50.6-47:58.3

1 JW [laughs]

2 SW loony lefties like myself

3 JW [laughs]

4 SW um bleeding heart liberals

5 JW [laughs]: yeah:

Steven applies the phrases loony lefties (line 3) and bleeding heart liberals (line 5) to himself in a light-hearted and self-deprecating manner, eliciting laughter from me throughout. There is a possible link to the notion of tall poppy (Chapter 7), as Steven attends to humility by using loony in reference to himself, a term defined in New Zealand English as 'crazy, silly' (Deverson \& Kennedy, 2005), and as such an example of self-deprecating humour (see Dynel, 2009; Holmes, 2007a; Lampert \& Ervin-Tripp, 2006). There is a perhaps an indication of an apologetic or 'downplaying' function in this exchange as such labels may act to mitigate the invested political views Steven had made clear throughout our conversation. Likewise, 
Steven uses bleeding heart liberals (line 5) in reference to himself. The phrase 'bleeding heart' is defined as 'a dangerously soft-hearted person' (Deverson \& Kennedy, 2005). There are also possible links to the bleeding heart depicted in some Christian religious iconography (e. g., Morgan, 2008), though the phrase 'bleeding heart liberal' is perhaps too widely used to make strong claims about the overt religious currency it may or may not have in this context. It is nevertheless an interesting coincidence that Steven, both religious and political, uses a phrase with the connotations of both to describe himself.

As indicated in the above analysis, Steven's political identity is closely related to his religious and professional identities. The next section examines this relationship in more detail.

\subsubsection{Religious Intersections}

A highly salient aspect of Steven's identity is that of his professional capacity as a church minister. His professional identity intersects with his religious one, as a Christian, which in turn interacts in complex ways with the political aspects of his identity. This intersection and its implications for stancetaking form the focus of this section.

In light of the relationship between religion and the state in New Zealand (Ahdar, 1998, 2006; Matheson, 2006; Stenhouse, 1998; Stenhouse \& Wood, 2005), I am particularly interested in hearing from Steven how political affiliation is treated by the Church. In Excerpt 10.4, I move the questioning towards the explicit discussion of this topic.

\section{Excerpt 10.4}

Context: Continues from the end of Excerpt 10.2.

Time: 8:21.2-9:10.1

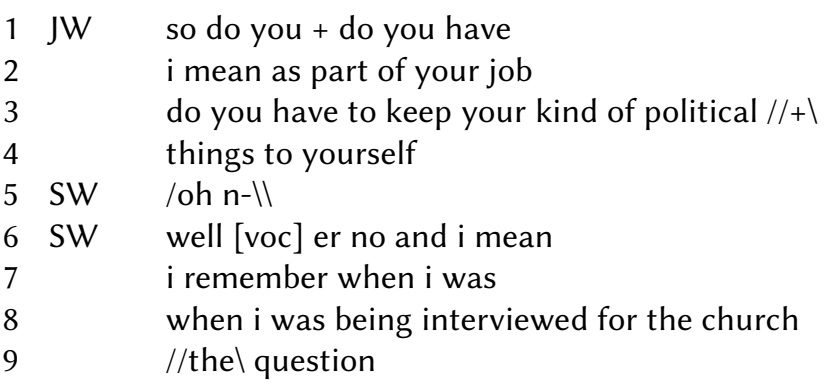




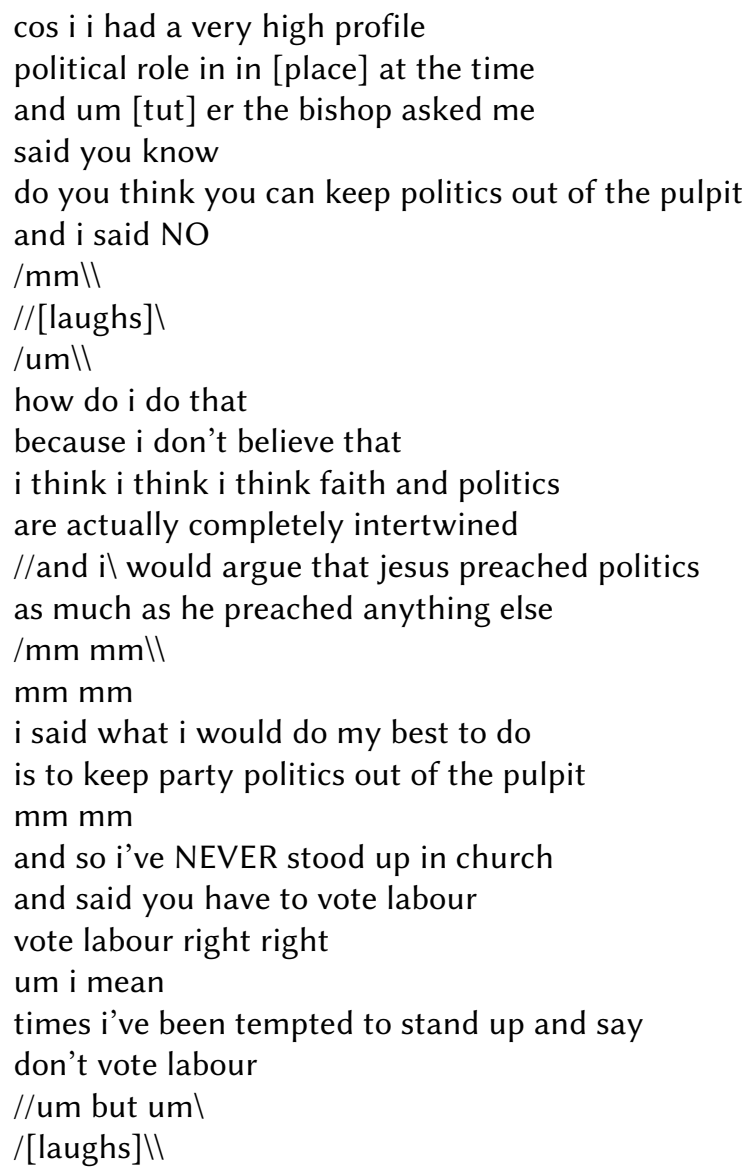

Steven notes in response to my initial question that he does not in fact have to keep political issues to himself in the Church context, well [voc] er no (line 6) despite the fact that the church is very nervous about people being involved in politics (Excerpt 10.2, lines 10-11). He follows this answer with an explanatory narrative (lines 7-15) which confirms his earlier point. I align with Steven by pre-empting his likely answer, how do $i$ do that (line 19), joining in with the creation of his story and aligning with the fact that his religious and political identities appear inseparable. Steven then continues, evaluating and providing a resolution (lines $20-31$ ). This narrative fits broadly into the classic Labovian structure (Labov \& Waletzky, 1967):

1. Orientation: $i$ remember when $i$ was when $i$ was being interviewed for the church (lines 7-8) 
2. Complication: and um [tut] er the bishop asked me...out of the pulpit (lines 12-14)

3. Evaluation: because i don't believe that... preached anything else (lines 20-24)

4. Resolution: $i$ said what $i$ would do my best to do... have to vote labour (lines 27-31)

5. Coda: times i've been tempted to stand up and say don't vote labour (lines 34-35)

The nature of the semi-structured interview, with generally short questions and longer answers, invites structured narratives of this kind (Labov, 1972b; Labov \& Waletzky, 1967). The purpose of the narrative in this case is to outline the conflict Steven went through in negotiating his professional and political selves. The question he was asked by the bishop, do you think you can keep politics out of the pulpit (line 14), indicates that there is concern at the higher levels of the Church about the role of politics within it. This highlights a conflict between the institution that authorises his I-identity as a minister and other aspects of his identity such as his I-identity Labour membership or even A-identity Labour movement member. Steven continues with a sophisticated answer to address this complicating factor, tying religion and politics closely together which provides the basis for the intersection within his own identity: $i$ think faith and politics are actually completely intertwined (lines 21-22) and jesus preached politics as much as he preached anything else (lines 23-24). Returning to the first part of his narrative, Steven provides a resolution by noting that he told the bishop that he would keep party politics out of the pulpit (line 28). Here Steven appeals to the distinction between the two kinds of politics, state governance and more abstract power and authority, as discussed in Chapter 4; Steven accepts that party issues and partisan interests have no place in the religious domain, though more general political issues remain an important concern. The coda comes at the end of the narrative in the form of humour. This arises through the incongruity in Steven stating he is not always loyal to Labour (lines 34-35) in light of his confirmed party membership. This elicits laughter from me (line 37) and functions to return us to the flow of the questioning in present time (Labov \& Waletzky, 1967). 
The evaluation section of the narrative acts as evaluation in a stancetaking sense. The epistemic stance token $i$ think (line 21) (Aijmer, 1997; Kärkkäinen, 2003) indicates a stance that evaluates the intertwining of faith and politics within his professional context but also within himself as a feature of his identity, particularly when taken in context with his subsequent stancetaking. The falling intonation of his repeated $i$ think indicates that Steven is expressing confidence (Coates, 1987, p. 116) and as such is an example of 'deliberative' rather than 'tentative' I think (Holmes, 1985). This stance also positions Steven as both religious and political and serves to diverge from those who would argue that the two should be kept completely separate, as is the implied stance of the bishop in the case of Steven's narrative.

Steven's religious and professional identities thus inform his political choices at a fundamental level. Less clear so far is why he supports the Labour Party. In Excerpt 10.5, Steven explicitly links his political support to that which he perceives as the moral political party, by making explicit reference to the Bible. This provides context which suggests that Steven's understanding of what is ethical or moral is influenced by his religious identity.

\section{Excerpt 10.5}

Context: Steven has mentioned that NZ politics is a battle for the 'middle ground.'

Time: 30:21.8-30:48.9

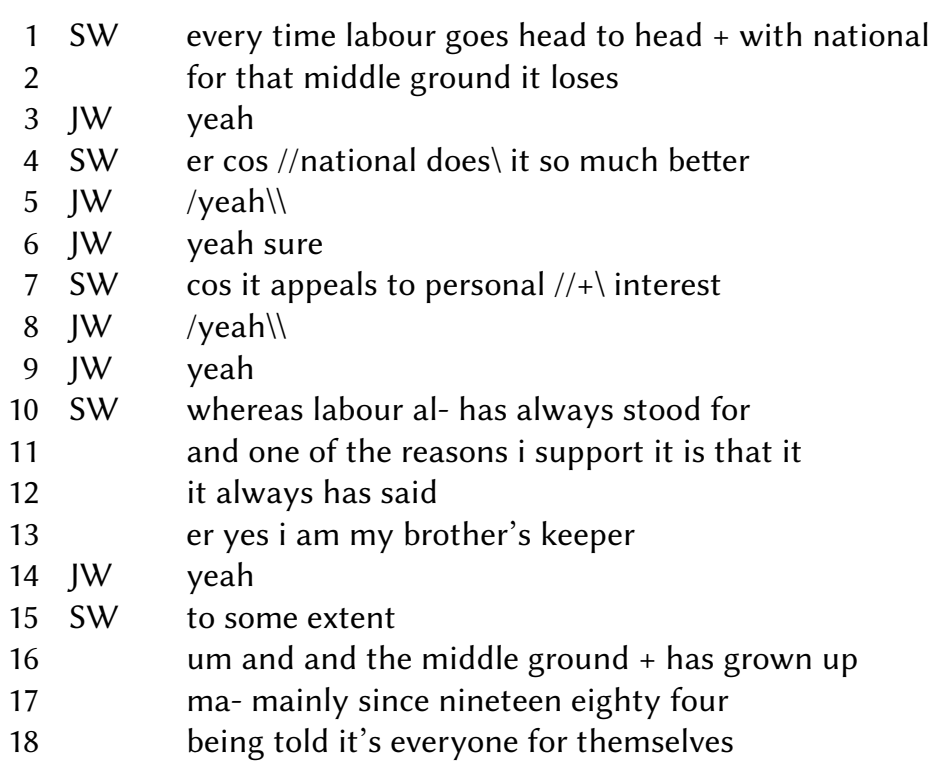


19 JW yeah sure $=$

$20 \mathrm{SW}=$ so

In this exchange Steven talks about the strategic successes of National, explaining that it wins the middle ground (line 2), a reference to an important portion of New Zealand voters who have a generally centrist political orientation, Steven's view being that National is successful cos it appeals to personal + interest (line 7). He uses a biblical phrase in describing Labour's socialist nature, and one of the reasons $i$ support it is that it it always has said er yes i am my brother's keeper (lines 11-13). In doing so he creates an opposition between National's apparent appeal to individuality and Labour's perceived concern for others. Steven, in using the phrase $i$ am my brother's keeper (line 13), makes reference to the Bible and specifically Cain's question 'Am I my brother's keeper?' which is used in Christian discourse to refer to having responsibility for another (Genesis 4:9, New International Version). This exchange provides a more explicit link between Steven's political and religious identities than elsewhere in the conversation.

Steven then moves into an analytical frame concerned with political ideology more explicitly, arguing that since the 1984 market deregulation in New Zealand (Walker, 1989), those who constitute the 'middle ground' have been told that it's everyone for themselves (line 18). This links the success of National in the polls at the time to the apparent selfishness and individualism of the post-1984 generation. The exchange also highlights the composition of Steven's personal values, contrasting personal + interest (line 7) with being your brother's keeper (line 13), the latter of which is linked closely to his support for Labour.

I next introduce a line of questioning aimed at eliciting Steven's view on the interaction of religion and politics in the New Zealand context in particular. In Excerpt 10.6, Steven demonstrates detailed knowledge about the various faith-based parties across New Zealand's political history and paints the picture of religion and politics having had a strained relationship.

Excerpt 10.6

Context: We have been talking about tertiary study in New Zealand. Time: 35:19.1-36:11.2 


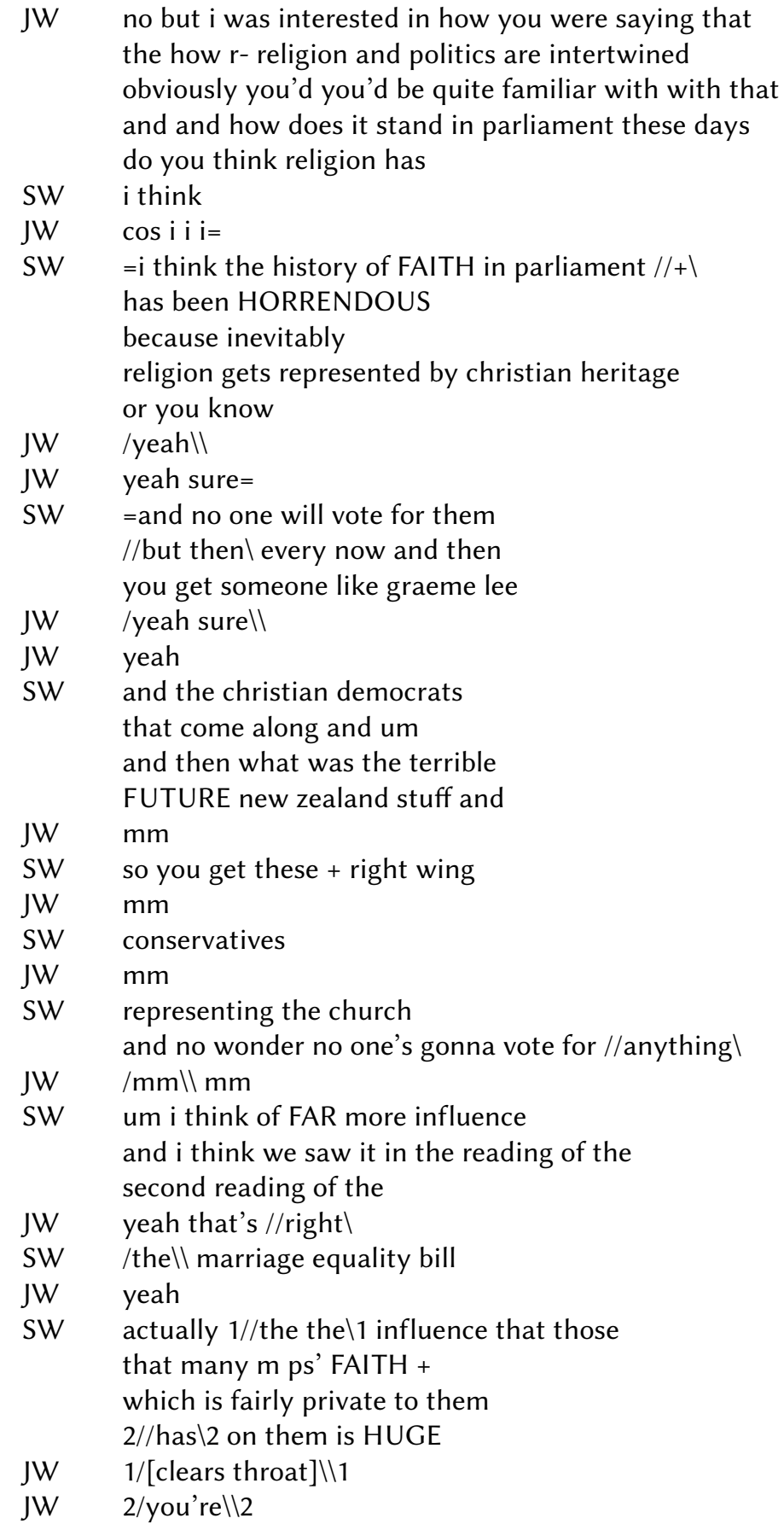

This exchange illustrates the large amount of shared political knowledge Steven and I possess which demonstrates how the ethnographic data allows me to contribute appropriately in this context (see 
Chapter 5). At the beginning of the exchange, I return to Steven's earlier evaluation of religion and politics as being bound together, indexing his earlier stance by reusing the word intertwined (line 2). The exchange serves to further refine Steven's religious identity through a series of evaluative stance acts that criticise political parties associated with right-wing conservative Christians. In doing so, Steven aligns with the brother's keeper (Excerpt 10.5, line 13) style of religion and politics which is associated with his Labour identity. The stance acts in this excerpt serve to diverge Steven in alignment from conservative Christians and implicitly align with more progressive Christian ideals. He initially sets this up by providing an epistemic stance act evaluating religion in New Zealand political history, $i$ think the history of FAITH in parliament + has been HORRENDOUS (lines 89). He elaborates on this stance by citing an example, religion gets represented by christian heritage (line 11), referring to a now defunct political party whose leader, Graham Capill, was jailed for sexual abuse of children. Steven then provides further evidence for his stance by mentioning other socially conservative Christian parties which no longer exist, such as the Christian Democrat Party (later renamed Future New Zealand) and its leader Graeme Lee (lines 17-23), who was known for his vocal opposition to the Homosexual Law Reform Bill of 1985. Steven negatively evaluates this party, terrible (line 22), and explains that it is the right wing...conservatives (lines 25-27) which in his opinion give the Church a bad public image, and no wonder no one's gonna vote for anything (line 30). As a more moderate Christian, Steven appears to view religious conservatives as his rivals in much the same way as National is his political adversary.

After elaborating on his stance that diverges in alignment from socially conservative Christians and their political bodies, Steven then switches tack to argue for the hidden influence of more mainstream religion within politics in New Zealand, um i think of FAR more influence (line 32). He notes that religion is a very influential factor for mainstream MPs particularly in the context of the Marriage Amendment Bill which was ongoing legislation at the time, the influence that those that many $m$ ps' FAITH + which is fairly private to them has on them is HUGE (lines 38-41). In doing so, Steven acknowledges the generally secular nature of politics in New Zealand but argues that the 
religious beliefs of many MPs still have significant influence (Ahdar, 1998, 2006).

The evidence Steven provides in this excerpt addresses my initial line of questioning by elaborating upon the intertwined nature of religion and politics in New Zealand. Not only is this reflected within Steven's own identity, as he draws on religion-informed values in his political life, but religion is also implicated in the decisions of many well-known MPs and is not solely the domain of socially conservative right-wing Christians. This bolsters Steven's own religious identity and its importance to his political self.

In Excerpt 10.7, Steven contributes to the stances taken up in Excerpt 10.6, further discussing the role of faith in politics. He essentially argues for it as being an important consideration in political thinking and in turn justifies the same linkage within his own identity.

\section{Excerpt 10.7}

Context: Steven has mentioned that conservative lobby groups have gone too far and alienated some politicians who would otherwise be amenable to their viewpoint.

Time: 37:56.8-39:19.6

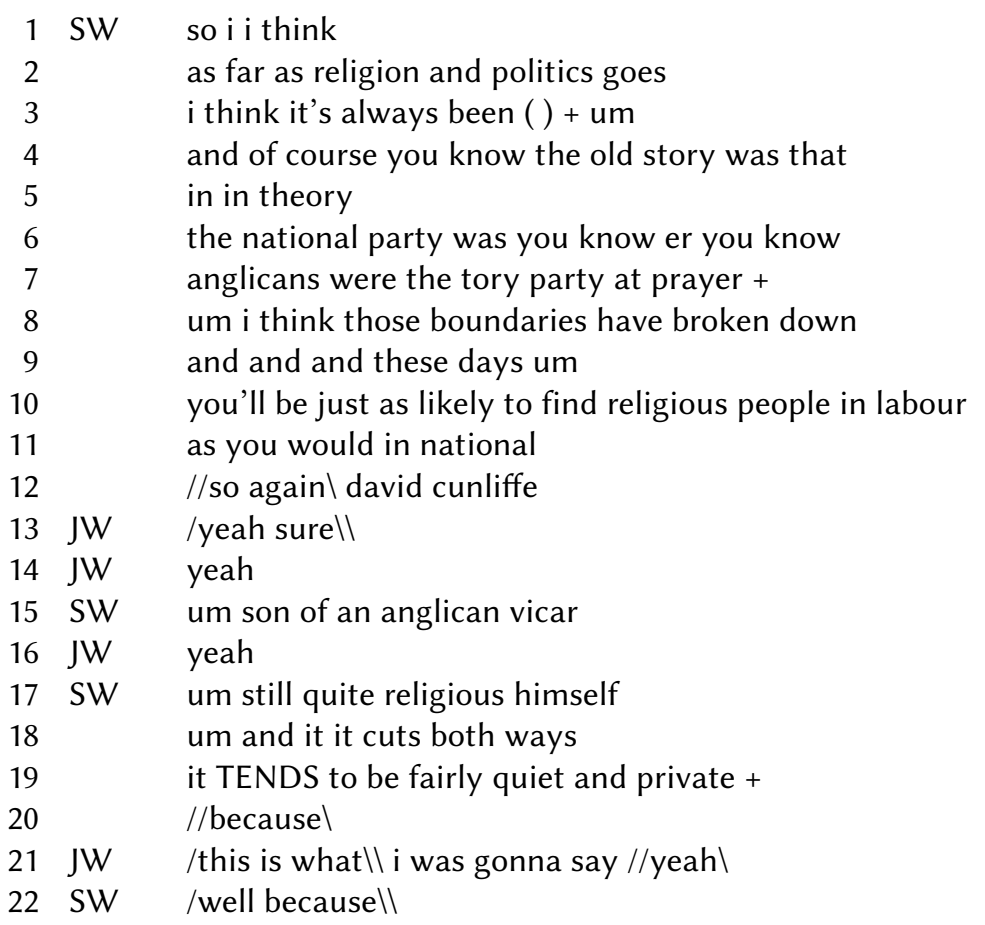




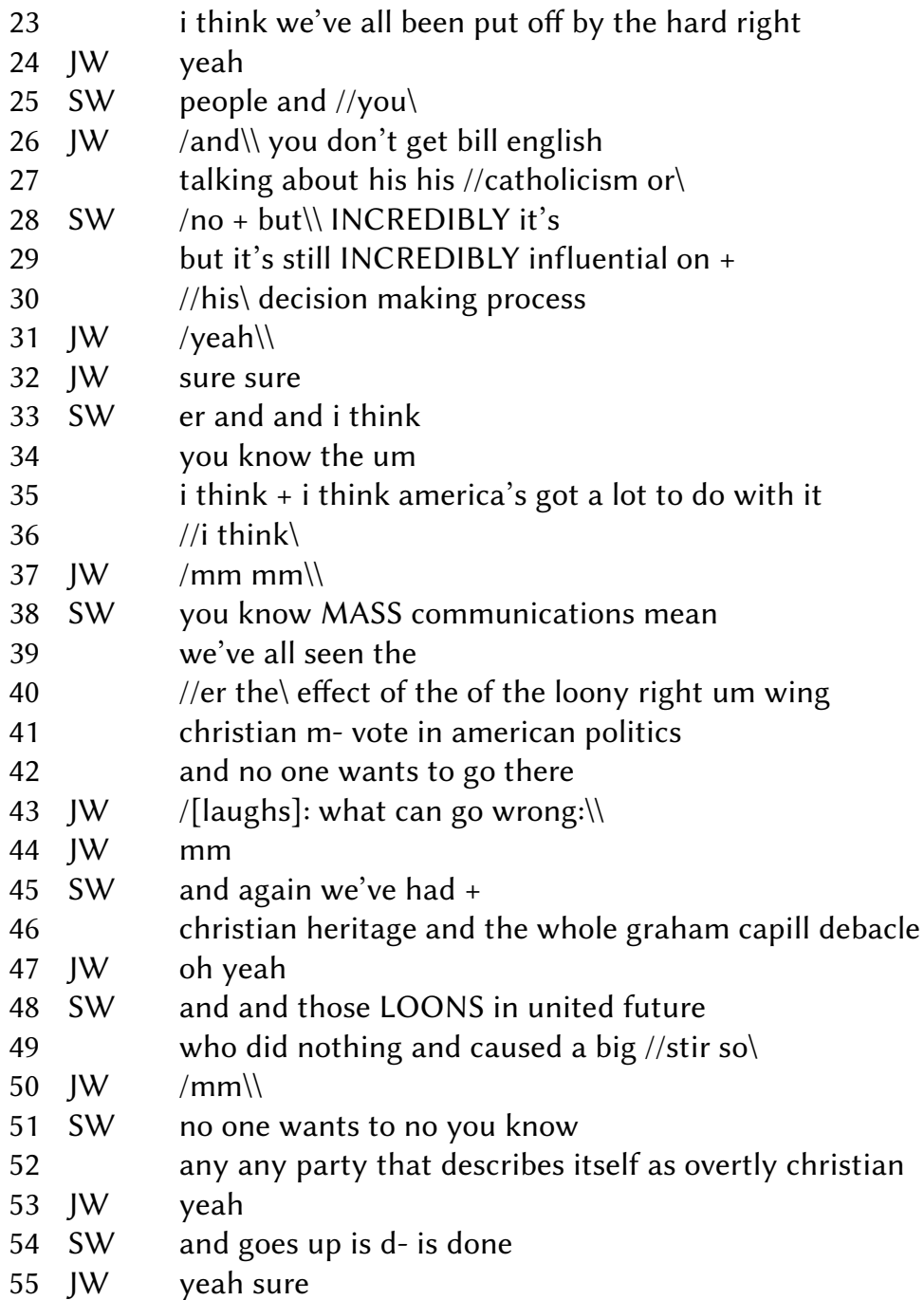

In this exchange Steven provides further evidence for his 'intertwined' stance, presenting a detailed argument for religion having an influence on not only the politically conservative, who may be considered the traditionally religious, but those on the left as well, these days um you'll be just as likely to find religious people in labour as you would in national (lines 9-11). Again, Steven repeats his earlier point that it TENDS to be fairly quiet and private (line 19) but provides a reason for why this may be in the form of an epistemic stance, $i$ think we've all been put off by the hard right (line 23). His negative evaluation of the hard right strengthens both his religious and political stances, positioning himself as left-wing on both the political and religious 
spectra. His pronoun use, we've all (line 23), could be interpreted as inclusive, in reference to both Steven and I as part of the wider New Zealand community, or perhaps exclusive, in reference to Steven and others, who could perhaps be his fellow ministers or Christians (İñigoMora, 2004; Pennycook, 1994; Quirk, Greenbaum, Leech \& Svartvik, 1985; Wales, 1996, pp. 63-67). In either case, the pronoun functions to distance Steven from conservative Christians and to make reference to a sizeable opposition.

Steven continues by suggesting that the reason that such extreme views are disliked in New Zealand could be due to the United States, $i$ think america's got a lot to do with it (line 35). He explains by mentioning that due to MASS communications (line 38) New Zealanders are able to witness the outcomes of the complex relationship between religion and politics in the United States (see, for example, Wald \& Calhoun-Brown, 2014; Wilcox \& Robinson, 2010). Steven argues that no one wants to go there (line 42) and in doing so attributes a stance to New Zealanders that diverges from hard right (line 23) Christian views and the United States in general. This situates the issue within a global context and acknowledges that there are forces at play that reach beyond the immediate New Zealand environment. It also highlights the potential of globalisation to affect the articulation of identities in modern New Zealand (Liu et al., 2005; see also Blommaert, Collins \& Slembrouck, 2005; Blommaert \& Dong, 2010).

Steven brings it back to New Zealand by again referencing the aforementioned graham capill debacle (line 46) and those LOONS in united future who did nothing and caused a big stir (lines 48-49), furthering his stances from Excerpt 10.6 in which he pinned the blame for Christian electoral failure on individuals and parties such as these. He then sums up explicitly, any any party that describes itself as overtly christian... and goes up is $d$ - is done (lines 52-54), providing further context for his earlier point regarding the tendency of politicians to keep their religious views to themselves. Nevertheless, Steven believes that religion has a strong influence on politicians which reiterates the points of scholars who argue for the importance of Christianity in New Zealand across history (Ahdar, 1998, 2006; Matheson, 2006; Stenhouse \& Wood, 2005). Steven's argument is further outlined in Excerpt 10.8. 
Excerpt 10.8

Context: Steven has mentioned his experience in the Labour election campaign, specifically about the need to balance the public perception of candidates' religious and political identities.

Time: 39:49.2-40:03.2

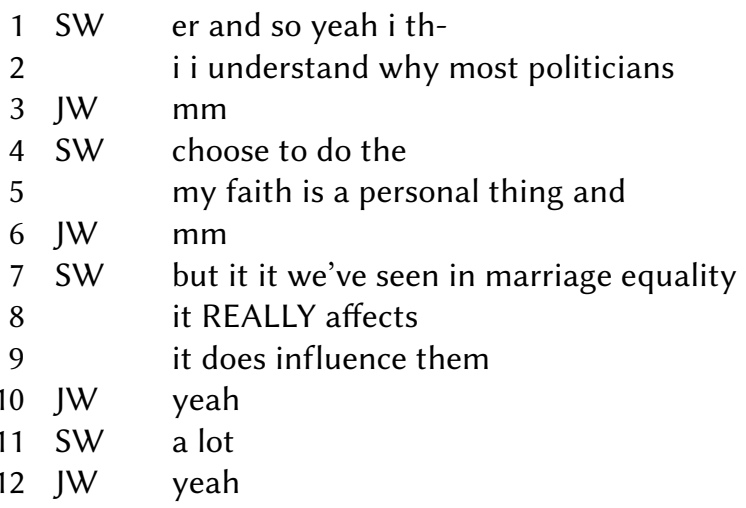

In this exchange, Steven notes that due to the unfavourable climate for overt Christianity in Parliament, many MPs keep it to themselves, $i$ understand why most politicians...choose to do the my faith is a personal thing and (lines 2-5). Even though it is somewhat silent, faith has an important role to play in his eyes. He brings up again the topical issue of marriage equality to illustrate his point (line 7), and emphatically underscores that it REALLY affects it does influence them... a lot (lines 8-11). The final stance he adopts in this excerpt serves to underline his argument that while it may be electorally unpopular to be overtly Christian, it has a significant influence on MPs and thus New Zealand politics and law-making. In presenting this argument he essentially validates his own identity which appears to explain why Steven is particularly keen to stress this point.

Steven's stances accumulate throughout our discussion and contribute to the intertwining of identities. Religion has heavily influenced Steven's political choices and beliefs to the degree that his political affiliation with Labour is almost inseparable from his identity as a Christian and church minister. His resultant stance acts are thus complex and varied and exist in the context of New Zealand's 'intertwined' religion and politics.

As a point of comparison to Steven, it is helpful to see how stance multiplicity works in discussion with other participants. Briar presents an initially disengaged or apolitical view of politics through 
which she claims to have limited knowledge. Her stance is later reformulated to position her as a (kind of) political person. This example is provided in Excerpt 10.9.

\section{Excerpt 10.9}

Briar Murphy, 48-52 year old NZ European/Pākehā female

Setting: Briar's workplace

Context: We have just been talking about the nature of her work.

Time: 8:30.4-8:50.7

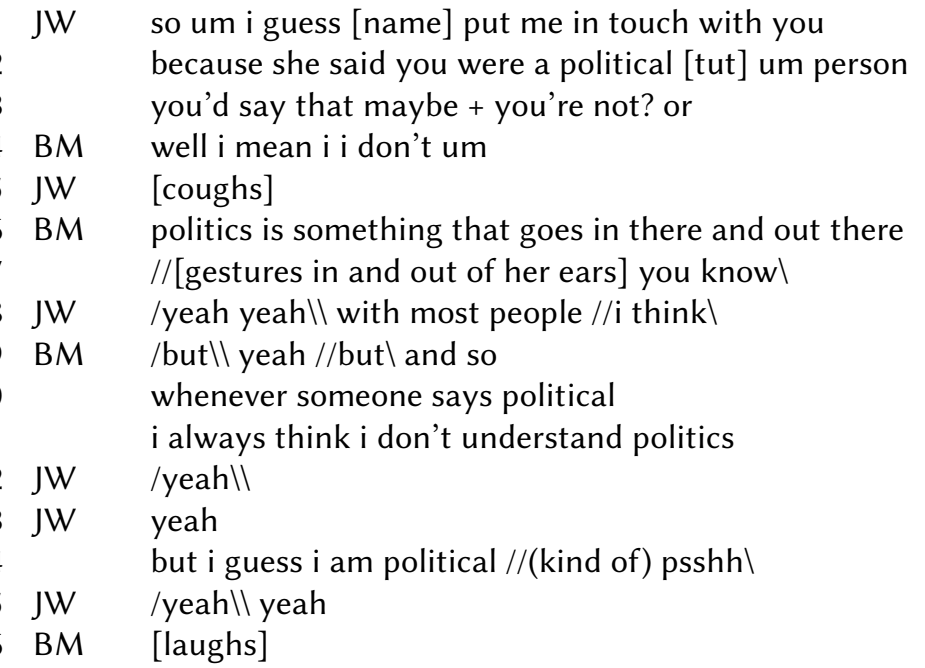

I initially assign an epistemic stance to Briar through an indirect report of her knowledge about politics that I had gained through an acquaintance, thereby positioning her on the epistemic scale (Du Bois, 2007, p. 143), she said you were a political [tut] um person (line 2). Immediately she contests this stance through a facial expression, which I attend to in my questioning, you'd say that maybe + you're not? or (line 3). In response she moves down the epistemic scale and diverges in alignment from the stance I have assigned her, well $i$ mean $i$ i don't um (line 4). Briar also substantiates her disengaged stance with a gesture (line 7). Up to this point, Briar's stancetaking appears to be indexing an 'apolitical' identity. Then, after her explanation, whenever someone says political $i$ always think $i$ don't understand politics (lines 10-11), Briar appears to reformulate her previous stance by adopting a new stance that positions her further up the epistemic scale, but $i$ guess $i$ am political (kind of) (line 14). This exchange shows an instance of stance conflict (and unwanted attribution), mitigation 
(through explanation) and resolution (resulting in a more nuanced stance of political engagement), all within the space of a few lines. This highlights both intersubjectivity as her stances are adopted in response to my questioning and multiplicity in the various degrees of apolitical/political that each stance indexes.

\subsection{DISCUSSION}

Steven's (and Briar's) stancetaking is multifaceted and dynamic, shifting throughout the course of our conversation depending on the context which includes both my line of questioning and the development of the topics raised. It is important to note that while the analysis in this chapter focuses on two of Steven's salient identities, other identities exist alongside them; for example, Steven and I align our regional identities at a point in the conversation, discussing a provincial city with which we are both familiar, and Steven generates an academic identity by discussing his own studies and interest in political philosophy and history. For analytical clarity, only Steven's most salient identities are discussed in this chapter, though this does not disregard the fact that myriad identities are indexed through complex stancetaking in any conversation (Bucholtz \& Hall, 2005; Jaffe, 2009a).

Steven's initial argument is that both religion and politics are closely related which is reflected in the nature of his resultant stancetaking. My line of questioning guides Steven to provide his explicit opinion on the relationship between the two, influenced by the history of the relationship between religion and the state in New Zealand. Therefore, to treat political and religious stancetaking as separate phenomena overlooks the analytical gains that can be made in examining their intersections. If religion and politics are so intimately related within Steven's own identity then stancetaking in relation to one can imply stancetaking in relation to the other. This recalls again the principle of relationality in which identities are articulated in reference to other identity positions (Bucholtz \& Hall, 2005), and demonstrates the utility of a focus on stance multiplicity.

The cumulative stancetaking present in the conversation between Steven and I likely contributes to the formation of his more durable identities. Steven's position as a church minister can be viewed as an 
I-identity, authorised by the Church as an institution. His religious stancetaking can therefore be considered to primarily contribute to his I-identity, with an indirect indexical link existing between the discursive realisations of his stancetaking and this identity (Ochs, 1992). Steven's political support and its associated stances could be viewed as indexing and contributing to his A-identity as he is affiliated with a global Labour movement. It could also be considered an index of I-identity in terms of being an authorised member of the New Zealand Labour Party. Likewise, Steven's identity as a Christian could also be viewed from both A- and I-identity indexical perspectives and his religious stancetaking could contribute to both his Christian and professional identities, which are in themselves closely related. These are all channelled through discursive recognition and aspects of Steven's D-identity. What is clear is that there is no one-to-one relationship between a stance and an identity; indeed, one stance may index many multi-levelled identities, and many stances may index one particular identity (Bucholtz \& Hall, 2005; Jaffe, 2000, 2009a; McIntosh, 2009; Moita-Lopes, 2006; Ochs, 1992, 1993).

Multiplicity is clearly an important part of stancetaking and identity genesis in interaction. Its function appears to be to manage multifaceted identity work, but as Jaffe (2009a, p. 18) notes, it can be in a sense more strategic:

Using linguistic variables that index multiple stances makes all of those stances potentially available to be claimed after the fact by the stance taker. Conversely, speakers can exploit indeterminacy to take up deniable stances, or in some way mitigate or mediate the extent to which they are held accountable for them.

There is no express indication that the multiplicity of Steven's stancetaking as outlined in this chapter serves the functions of deniability or mitigation of accountability. However, it is important to acknowledge that multiplicity is not always a straightforward and neatly bounded phenomenon. As Jaffe (2009a, p. 19) again notes, in some cases 'speakers themselves are fundamentally conflicted, and stance multiplicity and indeterminacy expressively mediates that conflict.' In Briar's case, as shown in Excerpt 10.9, there is no claim made for internal conflict, but the usefulness of such indeterminacy is somewhat 
clearer than in Steven's case. Briar can effectively switch between apolitical and political stances in response to factors within our discussion, possibly giving her some level of deniability (i. e., 'I can't answer that question due to my aforementioned apolitical stance'), which likely also functions as a face preserving measure (Goffman, 1955, 1967). Multiplicity is thus an important and sometimes strategic factor in the social realisation of many shades of our discursive selves.

The social psychological view of 'role' and 'role identity' (Ashforth, 2001; Burke \& Reitzes, 1981; Callero, 1985; Stets \& Burke, 2000) relates to the socially structured positions of individuals and their effect on identities. Steven's positions as a minister, campaign manager and Labour Party member are, according to this body of work, roles, as they are general '[positions] in a social structure' (Ashforth, 2001, p. 4). This recalls the notion of 'subject position' which was briefly discussed in Chapter 2. The associated concept of 'role identity' refers to the 'goals, values, beliefs, norms, interaction styles, and time horizons that are typically associated with a role' (Ashforth, 2001, p. 6). Steven's role as a minister is thus associated with an identitya socially generated identity-that includes negotiated discursive resources for its enactment. These concepts are subsumed within the model of identity adopted in this thesis, as outlined in Chapter 3, particularly that of D-identity. From this perspective, roles are broken down into their institutional or affinitive interactional resources associated with I- and A-identities respectively (Gee, 2000), though it is important to recognise that roles do have a structured and hence extra-discursive component.

My interaction with Steven occurs within a rich discursive and structural system. The sociocultural level heavily influences his religiopolitical stancetaking; for example, his view of the need to keep religion quiet in political roles orients to the largely secular nature of New Zealand politics and perhaps also to tall poppy. Subnational discourse becomes relevant at the point where Steven refers to the characteristics of Wellington and its inhabitants, outlined in Chapter 8, where he draws upon the left-wing and political town discourses. At the interactional level, stancetaking is carried out through various linguistic means, such as the use of epistemic stance tokens, evaluative language and extended narrative sequences. The interplay between the different levels of the discursive system is particularly 
evident in Steven's case which demonstrates the productive gains that can be made when approaching identity from a multi-layered discourse perspective. 

We are all political people operating in a world of myriad influence and constraint. This thesis attempts to unpack the levels of context surrounding those in Wellington, New Zealand, demonstrating how articulations of self are contextually bound, multiple and intersubjective in their making. For linguists, this thesis presents a picture of the micro level of identity genesis; the minutiae of our political selves as they appear in talk, embedded in features such as narrative structures, pronouns, evaluative language, comparatives, discourse markers, colloquialisms and indexical tokens. At a more general level, this study seeks to provide a better grasp of how materiality, discourse and context is implicated in the genesis of self.

Critical realism may not offer more, in the sense that the analysis presented in this thesis may not appear radically different from constructionist analyses, particularly in light of the points of compatibility between the two approaches. Rather, I contend that critical realism offers a more disciplined approach to discourse analysis that provides an alternative way forward for the field. Demonstrating exactly how this philosophy adds to the constructionist paradigm is a difficult task, considering the foundational level at which philosophy naturally operates. This study seeks to address this in more explicit terms, and I aim to provide at least an indication of how realism and its concern with the physical world around us can be taken seriously in discourse analytic study and practice.

The following sections outline the potential philosophical, theoretical, methodological and analytical contributions of this study in more detail, and discuss their specific implications for discourse analysis.

\subsection{PHILOSOPHICAL CONTRIBUTION}

The philosophical implications of this work are centred on the application of critical realism to a study of discourse and identity, which is a topic often associated with social constructionism. This thesis 
demonstrates that critical realism can act as an ontological backbone for discourse analysis that expands the scope of constructionism. As discussed in Chapter 2, it does so by theorising the existence of the extra-discursive and challenging reductionist views in which social structure and identity are viewed in entirely discursive terms. Acknowledging the relevance of critical realism to my discourse analytic writing, I adopt the term 'genesis' in place of the commonly used metaphor of construction, which I hope will challenge the prevalence of constructionist language within the field.

Critical realism, while as mentioned above is perhaps not explicitly observable in the analyses in Chapters 9 and 10, contributes in a broader sense as a guiding philosophy. It inspires the selection of methods and the analytical foci of Chapters 6 to 8 , and as such the direction this thesis takes. It guides the contributions at other levels and these are outlined further in the following sections.

\subsection{THEORETICAL CONTRIBUTION}

The theoretical contribution of this study lies primarily in the conceptual model of identity presented in Chapter 3. The model seeks to address philosophical weaknesses of well-known constructionist understandings of identity in discourse and anchors it within a critical realist frame. The identity model has implications for the field, as it attempts to curb runaway discourse reductionism by acknowledging its importance yet situating it within a complex conceptual structure. The model builds on the constructionist approach of Bucholtz and Hall (2005) and supplements it with Gee's (2000) four-strand distinction that allows for material and structural aspects of the self. Discourse, while an important part of identity genesis and the locus of identity recognition, negotiation and contestation, is argued to be only one aspect in the ontology of identity. This has implications for much discourse and identity work, especially that which aims to explore extra-discursive constraints on identity genesis. Locating these theories in a cohesive manner under the ambit of critical realism is the attempted contribution of this portion of the thesis. 


\subsection{METHODOLOGICAL CONTRIBUTION}

At the methodological level, this study seeks to demonstrate the productive gains that can be made by using a critical realist exploratory and intensive study design. I present a straightforward method in Chapter 5 that is compatible with its philosophical roots; however, the particular methods employed may seem unremarkable from an IS and discourse analysis perspective. In response I have attempted to show how they can be philosophically rooted, thanks largely to the pioneering work of Sayer (2010). While the methods remain the same as or similar to other mainstream approaches, the philosophical underlabouring I carry out provides the clarity that other methods do not always provide. This means that context is gathered through ethnographic immersion not only to understand discourse better, as is often the case with ethnographic work in discourse analysis, but in order to gain an understanding of the structured relations between discourses and their referents.

\subsection{ANALYTICAL CONTRIBUTION}

The first set of analytical contributions relates to the examination of the extra-discursive referents of discourse, as discussed in Chapter 6. I seek to show how discourse analysis can productively engage with these concerns, supported and guided by critical realism, and I find that the physical and social structures to which discourses refer can have important, albeit more hidden, roles to play in discursive systems. This is an important way forward for discourse analysis in New Zealand where that which resides outside our discursive knowledge is incorporated into discourse analytic practice, an approach that is uncommon, and if carried out, not often philosophically supported. The arguments in Chapter 6 attempt to outline how the physical referents of the small country, inequality and bi/multiculturalism discourses have real existence; whether this is accepted or not is a philosophical question which this thesis has sought to navigate.

I have also tried to contribute at an analytical (and simultaneously theoretical) level through the proposed conceptual structures of egalitarianism and tall poppy, two discourses which have not had systematic examination from a linguistic perspective in New Zealand. 
In Chapter 7, I show how such discourses can be analytically accessed and described. The model of egalitarianism I present has implications for not only linguistic but also sociological investigation of this important discourse, as it provides a conceptual distinction of two primary dimensions of talk on an increasingly salient topic. I find that 'equality' and 'equity' have significant explanatory power and provide the ability to tease out the different ways in which participants index this discourse. Likewise, tall poppy is both talked about and enacted in the data set. I separate it into three strands that relate to its identity, process and discourse. Tall poppy has also been of sporadic and inconsistent focus within New Zealand from a discourse perspective, an issue that this study attempts to emphatically address.

Further analytical gains are achieved through the investigation of the discourses of the relatively unexplored context of Wellington, New Zealand. This study gives insight into how a relatively situated space can influence meaning making on-the-ground. This is covered in detail in Chapter 8, which focuses squarely on these subnational discourses, or more geographically constrained forms of sociocultural discourse. The discourses in this context are identified as characterising Wellington as political, left-wing and a small town, which contrasts with other places in the country. This chapter comprises the first comprehensive study of these Wellington discourses as they appear in talk.

The two case studies in Chapters 9 and 10 also attempt to make important analytical contributions. They both demonstrate that detailed discourse analysis at the micro level can be productively carried out within a critical realist frame, and identify the potential benefits that can be gained from incorporating references to macro factors as covered in the earlier analytical chapters. Chapter 9 demonstrates this in a close examination of interactional discourse which focuses on intersubjectivity, a process of stancetaking considered central to the stance triangle (Du Bois, 2007). The chapter charts the development of Ashley's political allegiance as our stances interact which affects how her affiliation is eventually explicitly confirmed. The chapter shows that consideration of the full context of talk and its links to other parts of the discursive system provides a deeper understanding of what is a complex intersubjective achievement from which the researcher cannot be effaced. It demonstrates that consideration of 
both structure and intersubjective relations is necessary to gain a better view of identity genesis in talk; this is, for example, highlighted by the role of subnational discourses and their physical referents in Ashley's Coromandelite identity.

Chapter 10 presents the second case study, that of Steven, and focuses on the complementary process of stance multiplicity in which he demonstrates two salient identities, that of his religious and political selves, and their associated stance acts. The way in which these intertwine is explored in detail, indicating that often the stances involved in identity genesis cannot be clearly delimited. The complex nature of managing multiplex identities demonstrates the way in which genesis is carried out within a rich structural and discursive system. The focus on multiplicity in Steven's case suggests that a unidimensional approach to identity cannot capture the way in which multifarious identities are generated in relation to one another. This further supports the utility of the realist identity model presented in Chapter 3, as each has institutional, affinitive and discursive aspects.

The two case studies, which make up a substantial proportion of the thesis, provide a greater understanding of the micro-discursive features of intersubjectivity and multiplicity in stancetaking. This underlines the importance of these processes to the study of discourse and identity in general.

\subsection{DIRECTIONS FOR FUTURE RESEARCH}

Any detailed scholarly undertaking sheds light on certain aspects of concern to the potential neglect of others. The exploratory nature of this study within a relatively undocumented context provides a measure of insight, though certain avenues are sidestepped in light of overarching aims. This opens up the possibility of fruitful future research into topics related to that of this thesis. This most generally refers to power and ideology which are important aspects of the study of political discourse (see, for example, Blackledge, 2005; Chilton, 2004; Fairclough \& Fairclough, 2012; Wodak, 1989).

As mentioned in Chapter 1, this study is positioned alongside CDA though does not share its general focus on power and emancipation (Chouliaraki \& Fairclough, 1999, pp. 29-30; Phillips \& Jørgensen, 2002, p. 64; Wodak et al., 2009, p. 7). The adoption of critical realism, how- 
ever, suggests an element of critique in this work. This is primarily carried out at the philosophical level in terms of a critique of constructionist discourse reductionism and the anthropocentrism inherent in the epistemic fallacy. This is driven by the predominance of constructionist discourse approaches in New Zealand and the apparent necessity to provide a philosophically supported way forward. More research is required to engage in critical realist explanatory critique at an analytical level which aims to uncover unjust or hegemonic structures with a view to change (see Collier, 1994).

Closely related to this are questions of power and ideology. My focus in Chapter 2 is on the archaeological works of Foucault given their importance in understanding the concept of discourse. Foucault's later genealogical works, concerned with questions of power (Al-Amoudi, 2007; Smart, 1985, p. 41), are highly influential, which suggests that a general focus on power in the New Zealand political context is an important avenue for research. In a similar vein, the question of ideology deserves further scrutiny. Given its importance, particularly in the political realm, ideological research in New Zealand discourse presents an exciting opportunity for future investigation.

A useful follow-up to this study would be the exploration of another major New Zealand centre, such as Auckland or Christchurch, in order to provide a basis for discursive comparison with a view to further refining and testing the models of sociocultural discourse I have presented and also charting the boundaries of subnational Wellington discourses. With this study I hope to provide a launching pad for such work and set the scene for research that aims to gain further insight into the nature of discourse and identity in New Zealand.

\subsection{FINAL WORD}

Sitting at Lenka's kitchen table, reeling as I was from her strong condemnation of communists, I gathered my thoughts and moved the topic away from politics, having not realised how sensitive it could be for some Czechs who had grown up with it in many ways brutally forced into their collective consciousness. Had I somehow the foresight to understand that the way in which Lenka reacted was inextricably bound to the context in which we interacted, then 
perhaps I would have left her house without the sense of shock that I then felt. Her views on communists, as revealing as they were to me at the time, occurred within a rich context of sociocultural, subnational and interactional discourse, all patterned by the extra-discursive influences of the space and time in which we found ourselves in the Czech Republic. Had I recorded our conversation, teased out our stances and situated them alongside my somewhat more limited ethnographic understanding of the Czech context, then perhaps her view would have been less surprising. What I now know, which I did not appreciate then as a young English teacher, is that we are all political animals relating to one another in contexts which shape the kind of people that we are. 



\section{TRANSCRIPTION CONVENTIONS}

Transcription key adapted from Vine et al. (2002).

\begin{tabular}{|c|c|}
\hline$/ / \backslash$ & $\begin{array}{l}\text { simultaneous or overlapping utterance of 'first' } \\
\text { speaker }\end{array}$ \\
\hline$/ 11$ & $\begin{array}{l}\text { simultaneous or overlapping utterance of 'second' } \\
\text { speaker }\end{array}$ \\
\hline $1 / / \backslash 1$ & speaker is overlapped more than once during a turn \\
\hline [laughs] & paralinguistic tags or redacted information \\
\hline$::$ & $\begin{array}{l}\text { text between colons is modified by the tag } \\
\text { immediately preceding it }\end{array}$ \\
\hline$[\ldots]$ & omitted section \\
\hline un- & cut off word, both self and other interruption \\
\hline ( ) & untranscribable or incomprehensible speech \\
\hline (well) & transcriber's best guess at unclear speech \\
\hline AND & emphatic speech \\
\hline .hhh & intake of breath \\
\hline$=$ & latched utterances \\
\hline ? & question marker in ambiguous cases \\
\hline+ & pause of up to one second \\
\hline++ & one- to two-second pause \\
\hline+++ & two- to three-second pause \\
\hline (4) & pause over three seconds \\
\hline$[\mathrm{voc}]$ & $\begin{array}{l}\text { untranscribable noises not covered by another } \\
\text { convention }\end{array}$ \\
\hline
\end{tabular}

Note: Capital letters are not used in transcripts except in cases of emphatic stress, thus proper nouns most often appear in lower case. Question marks are only used in cases of textual ambiguity, for example, when a question is not apparent through syntax yet may 
have been indicated through intonation. Paralinguistic information such as [relieved] is based on the transcriber's best guess considering all available contextual information. Due to the conventions being developed for use in a number of corpora, the general principle for non-standard speech is that it is transcribed in the standard orthographic form closest to the full morpheme so that it can be picked up in word frequency counts' (Vine et al., 2002, p. 10). This is with the exception of standardised variants such as cos and gonna. 
PARTICIPANT AND DATA SET DETAILS

B. 1 PARTICIPANTS

\begin{tabular}{|c|c|c|c|c|}
\hline NAME & AGE RANGE & GENDER & ETHNICITY & OCCUPATION \\
\hline Ali Ahmadi & $68-72$ & $M$ & Iranian & Retired \\
\hline Peter Baxter & $63-67$ & $M$ & NZ European/Pākehā & Retired \\
\hline Elizabeth Blake & $23-27$ & $\mathrm{~F}$ & NZ Māori/Pākehā & Student \\
\hline Ashley Braithwaite & $18-22$ & $\mathrm{~F}$ & NZ European/Pākehā & Civil Servant \\
\hline Joe Branstad & $78-82$ & M & NZ European/Pākehā & Retired \\
\hline $\begin{array}{l}\text { Chelsea } \\
\text { Brentwood-White }\end{array}$ & $18-22$ & $\mathrm{~F}$ & NZ European/Pākehā & Student \\
\hline Kieran Connor & $28-32$ & M & NZ European/Pākehā & Civil Servant \\
\hline Jacqui Cooper & $18-22$ & $\mathrm{~F}$ & NZ European/Pākehā & Student \\
\hline Michelle Dempsey & $18-22$ & $\mathrm{~F}$ & NZ European/Pākehā & Student \\
\hline Linda Foley & $78-82$ & $\mathrm{~F}$ & $\begin{array}{l}\text { Irish/NZ } \\
\text { European/Pākehā }\end{array}$ & Retired \\
\hline Maryam Hassani & $68-72$ & $\mathrm{~F}$ & Iranian & Retired \\
\hline Cate Mclver & $18-22$ & $\mathrm{~F}$ & NZ European/Pākehā & Student \\
\hline Desmond Morain & $73-77$ & M & NZ European/Pākehā & Retired \\
\hline Briar Murphy & $48-52$ & $\mathrm{~F}$ & NZ European/Pākehā & Business Owner \\
\hline Willy Oswick & $23-27$ & $M$ & NZ European/Pākehā & Reporter \\
\hline Christen Page-Brown & $18-22$ & $\mathrm{~F}$ & American/Pākehā & Student \\
\hline May Porter & $18-22$ & $\mathrm{~F}$ & NZ European/Pākehā & Student \\
\hline Isaac Quinn & $23-27$ & M & NZ European/Pākehā & Administrator \\
\hline Edith Strauss & $38-42$ & $\mathrm{~F}$ & NZ European/Pākehā & Coordinator \\
\hline Daniel Taylor & $18-22$ & M & NZ European/Pākehā & Student \\
\hline Michael Teoh & $18-22$ & M & NZ Asian & Student \\
\hline Sushanti Vikram & $18-22$ & $\mathrm{~F}$ & Indian & Student \\
\hline Phoebe Westerman & $18-22$ & $\mathrm{~F}$ & NZ European/Pākehā & Administrator \\
\hline Steven Wheeler & $43-47$ & M & NZ European/Pākehā & Priest \\
\hline Fergus Williams & $23-27$ & M & NZ European/Pākehā & Musician \\
\hline Brent Woods & $18-22$ & M & NZ European/Pākehā & Student \\
\hline
\end{tabular}




\begin{tabular}{llc}
\hline \multicolumn{1}{c}{ FILE NAME } & \multicolumn{1}{c}{ LocAtion } & DURATION \\
\hline S1AC200313.MP3 & Café & $00: 20: 54$ \\
S1BM050413.MP3 & Business & $01: 10: 23$ \\
S1BW130213.MP3 & Café & $01: 03: 12$ \\
S1CB160513.MP3 & Café & $01: 33: 34$ \\
S1CM220313.MP3 & Café & $01: 18: 04$ \\
S1CP140313.MP3 & Café (outside) & $00: 55: 57$ \\
S1DM060213.MP3 & Home & $01: 13: 53$ \\
S1DT170513.MP3 & University & $00: 43: 28$ \\
S1ES120313.MP3 & Home & $00: 51: 51$ \\
S1IQ050213.MP3 & Café & $00: 52: 16$ \\
S1JB261112.MP3 & Home & $01: 03: 25$ \\
S1JC080313.MP3 & Café & $01: 00: 30$ \\
S1LF190213.MP3 & Home & $02: 01: 46$ \\
S1MD060513.MP3 & Café & $00: 55: 57$ \\
S1MHAA280213.MP3 & Home & $01: 25: 23$ \\
S1MP150213.MP3 & Home & $01: 48: 11$ \\
S1MT141212.MP3 & Café & $00: 58: 27$ \\
S1PB120313.MP3 & Home & $01: 16: 45$ \\
S1SV080513.MP3 & Café & $00: 50: 42$ \\
S1SW200313.MP3 & Café & $00: 50: 31$ \\
\hline
\end{tabular}


B.2.1 Pilot

\begin{tabular}{llc}
\hline \multicolumn{1}{c}{ FILE NAME } & \multicolumn{1}{c}{ LocAtion } & DURATION \\
\hline PTS1EB311012.MP3 & University & $00: 33: 49$ \\
PTS1KC291012.MP3 & Home & $00: 30: 17$ \\
PTS1WO311012.MP3 & Café & $00: 27: 10$ \\
PTS2011112.MPG & Library [video] & $01: 44: 58$ \\
PTS3EB021112.MP3 & University & $00: 15: 16$ \\
PTS3FW021112.MP3 & Telephone & $00: 16: 37$ \\
PTS3KC011112.MP3 & Home & $00: 16: 13$ \\
PTS3PW021112.MP3 & Office & $00: 16: 39$ \\
& TotAL: & $02: 36: 01$ \\
\hline
\end{tabular}



INFORMATION SHEET AND CONSENT FORM

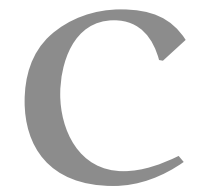

Please turn over 


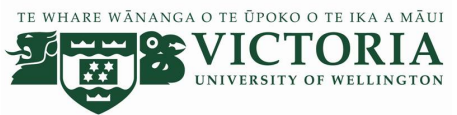

\section{THE LANGUAGE OF POLITICAL IDENTITY}

\section{Project overview}

\section{RESEARCH INFORMATION SHEET}

The aim is to study the language we use when discussing political and social matters. Recordings of the interactions of a number of participants regarding these issues will be gathered and analysed for their linguistic features with the goal of seeing how political identity is represented in talk. This project is approved by VUW's Human Ethics Committee.

\section{The outcomes of the project}

Understanding exactly how we represent our political selves through language gives us insight into the effects of political messages, helps us identify what aspects of these messages are spread and provides a greater understanding of the linguistic features of individuals' political identities. The results of this research may also help us to critically evaluate the political messages we receive and allow us to become conscious of the effect politics has on aspects of our identities.

\section{How will the research be carried out?}

If you agree to take part, you will first be asked to fill out a brief demographic survey and consent form. You will then be asked to participate in an informal discussion with the researcher (approx. an hour). At a later stage the researcher may be in contact regarding participation in a larger group discussion (there is no obligation to attend; groups will comprise of 4-8 members and run for approx. 1.5 hours), followed by a quick debrief (approx. 30 minutes). Depending on the participant quota, your contribution may only be required for the initial discussion. All interactions will be audio recorded, in addition to video recording of the group sessions, then transcribed in detail and analysed for linguistic features.

\section{What will the data be used for?}

The data collected and transcripts produced during the project will be used for the following two purposes: 1) PhD research and 2) journal publications and conference presentations based on this research.

\section{How will my identity be protected?}

The researcher and supervisors treat personally identifiable information with strict confidentiality and will not disclose participants' identities to any other party. All personally identifiable material will be removed from transcripts and published materials and replaced with pseudonyms. The nature of group discussion means that identities will become known to other members of the session in which you participate. Participants that take part in a group discussion are asked to respect the privacy of others by keeping the identities of those present at the session confidential.

\section{Who will have access to the data and how will it be stored?}

Access to the data is restricted to the researcher and the two project supervisors. Written material will be retained for 5 years after the conclusion of the study then digitised and hard copies destroyed. After the completion of the project, audio-visual data, analytical results, digitised written material and all other associated electronic data will be encrypted and securely archived as part of the VUW Language in the Workplace Project (LWP) for the purposes of future study, with access restricted to only those authorised by the LWP Project Director. During the project all data will be secured in locked filing cabinets and on password protected computers.

\section{How can I withdraw from the project?}

You can withdraw from this project at any time within six months after the date on the consent form. You do not need to provide a reason for withdrawal. If you withdraw, all data you have provided will be destroyed immediately, though any contribution you may have made in a group discussion will remain a part of the dataset but omitted from analysis.

\section{What will happen after the project's completion?}

After the research is complete, a summary will be mailed to those involved outlining the major findings of the study. A publically available thesis will then be deposited in VUW's central library.

\author{
School of Linguistics and \\ Applied Language Studies \\ PO Box 600 \\ Wellington 6140
}

\author{
Researcher \\ Jay Woodhams \\ jay.woodhams@vuw.ac.nz \\ (04) $4635233 \times 7531$
}

Supervisors

Dr Meredith Marra

meredith marr@i

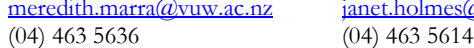




\section{TE WHARE WÃNANGA O TE ŨPOKO O TE IKA A MĀUI}

\section{SICTORIA}

THE LANGUAGE OF POLITICAL IDENTITY

PARTICIPANT QUESTIONNAIRE

Title: Full name:

Preferred first name:

1) Were you born in New Zealand? Yes No

If yes, specify town or region:

If no, a) where were you born?

b) at what age did you come to New Zealand?

2) In which NZ town or region have you spent the majority of your time?

3) What language did you speak at home before going to school?

4) Gender: $\quad$ Male $\square \quad$ Female $\square$

5) Age: (please circle) $\quad 18-22 \quad 23-27 \quad 28-32 \quad 33-37 \quad 38-42 \quad 43-47 \quad 48-52 \quad 53-57$

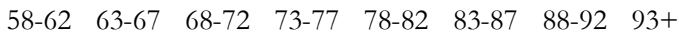

6) Which ethnic group do you identify with?

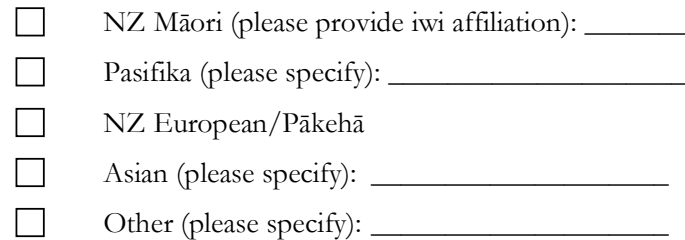

7) What is your highest level of education attained? (please circle)

Postgraduate Bachelors Diploma/Certificate Secondary school qual. No formal qualifications

8) What is your current occupation?

9) Are you eligible to vote in NZ? (a NZ citizen/permanent resident, 18 years or older and have lived in NZ for one year or more without leaving the country) Yes No

$$
\begin{aligned}
& \text { If yes, a) are you enrolled to vote? Yes } \square \quad \text { No } \square \text { General Roll } \square \quad \text { Māori Roll } \square \\
& \text { If yes to } a \text {, are you enrolled on the: } \quad \text { G }
\end{aligned}
$$
b) did you vote in the 2011 general election? Yes

If no to $b$, what year was the last election in which you voted?

For contact purposes, please provide the following details:

I prefer to be contacted by: e-mail

Email address:

Mobile phone:

Home phone: 


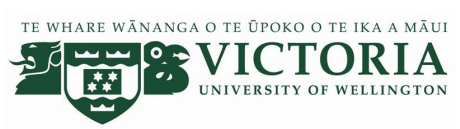

THE LANGUAGE OF POLITICAL IDENTITY

\section{CONSENT TO PARTICIPATE IN RESEARCH}

Researcher: Jay Woodhams

School of Linguistics and Applied Language Studies

Victoria University of Wellington

PO Box 600

Wellington 6140

- I have read and understood the research information sheet.

- I give permission for the video and audio recording of my interactions to be used for the purposes outlined on the information sheet.

- I understand that the researcher and project supervisors will not disclose my identity to any outside party and that all transcripts and published material will have my personally identifiable information removed.

- If I participate in a group discussion, I agree not to disclose the identities of other members of the group to any party not present at the session.

- I understand that within a period of six months from today I am able to withdraw my participation from the project without providing a reason.

- In cases of withdrawal, I understand that the data I have provided at any stage of research will not be used for analysis or publication.

- I understand that interview recordings will be deleted and written material destroyed after withdrawal. However, due to the nature of group discussions, any contribution I have made in a group setting will be retained unless all members of that group withdraw.

- I have had the opportunity to ask questions about the project and have had them answered satisfactorily.

- I give permission for the secure archiving of the data with the Language in the Workplace Project in the School of Linguistics and Applied Language Studies, Victoria University of Wellington.

- I agree to take part in the research project.

\section{Print full name:}

Signature:

Date:

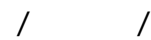

Please tick bere $\square$ ifyou wish to receive a summary of the research results at the conclusion of the project.

Postal address: 
HUMAN ETHICS MEMORANDA

TE WHARE WĀNANGA O TE ŪPOKO O TE IKA A MĀUI

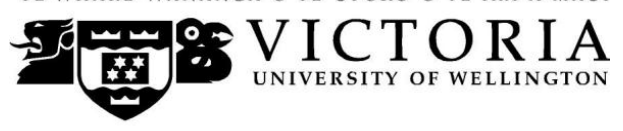
MEMORANDUM
Fax $\quad 0-4-4635209$
Email_Allison.kirkman@vuw.ac.nz

Phone $\quad 0-4-4635676$

\begin{tabular}{l|l}
\hline TO & Jay Woodhams \\
\hline COPY TO & $\begin{array}{l}\text { Meredith Marra } \\
\text { Janet Holmes }\end{array}$ \\
\hline FROM & Dr Allison Kirkman, Convener, Human Ethics Committee \\
\hline
\end{tabular}

\begin{tabular}{l|l}
\hline DATE & 16 October 2012 \\
\hline PAGES & 1 \\
\hline
\end{tabular}

SUBJECT

Ethics Approval: 19489

The Discursive Construction of Political Identity

Thank you for your application for ethical approval, which has now been considered by the Standing Committee of the Human Ethics Committee.

Your application has been approved from the above date and this approval continues until 31 May 2015. If your data collection is not completed by this date you should apply to the Human Ethics Committee for an extension to this approval.

Best wishes with the research.

Allison Kirkman

Human Ethics Committee 


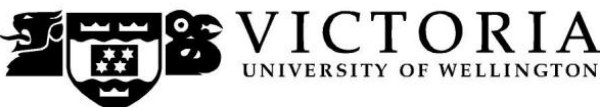

MEMORANDUM
Phone 0-4-4635676

Fax 0-4-4635209

Email_Allison.kirkman@vuw.ac.nz

\begin{tabular}{l|l}
\hline TO & Jay Woodhams \\
\hline COPY TO & Meredith Marra \\
\hline FROM & Dr Allison Kirkman, Convener, Human Ethics Committee \\
\hline
\end{tabular}

\begin{tabular}{l|l}
\hline DATE & 13 February 2013 \\
\hline PAGES & 1 \\
\hline
\end{tabular}

SUBJECT $\quad$ Ethics Approval: 19489

The discursive construction of political identity

Thank you for your request to amend your ethics approval. This has now been considered and the request granted.

Your application has approval until 31 May 2015. If your data collection is not completed by this date you should apply to the Human Ethics Committee for an extension to this approval.

Best wishes with your research.

Allison Kirkman

Human Ethics Committee 

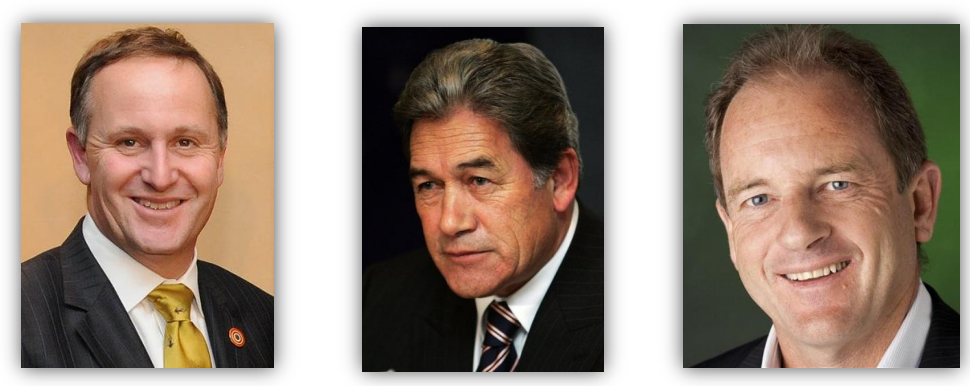

\section{Politics in New Zealand Love it or hate it...}

\section{I want to speak to you}

My project explores the way we talk about politics and political issues in NZ. This is a chance to be part of a new and exciting research direction in linguistics. If you're eligible to vote in $\mathrm{NZ}$ and keen to talk politics, whether positively or negatively, please contact me for more details:

\section{jay.woodhams@vuw.ac.nz}




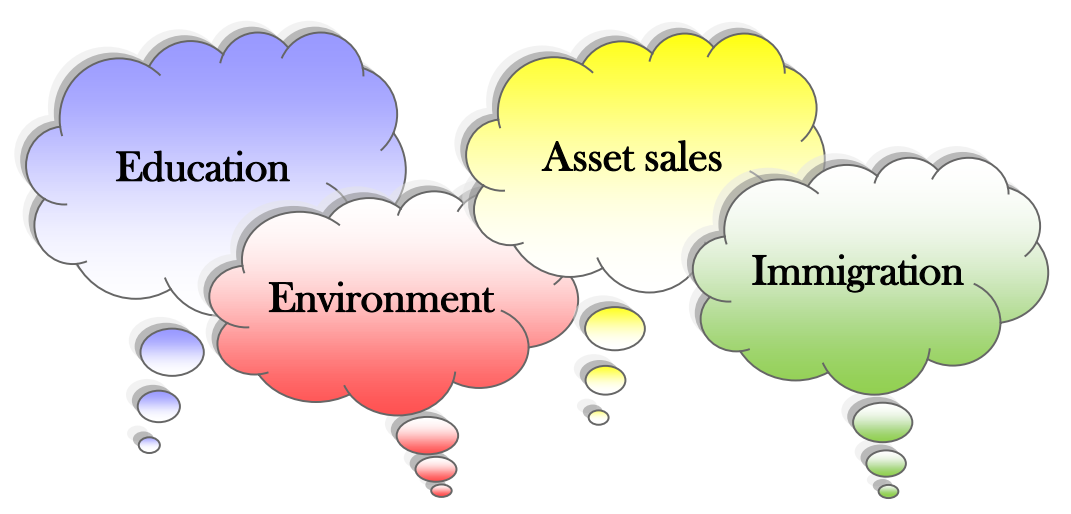

\section{Interested in social and political issues in NZ?}

My project explores the way we talk about the issues that affect us.

This is a chance to be part of a new and exciting research direction in linguistics. If you're eligible to vote in NZ and keen to have an informal chat, please contact me for more details:

\section{jay.woodhams@vuw.ac.nz}

Jay Woodhams

PhD researcher

School of Linguistics and Applied Language Studies

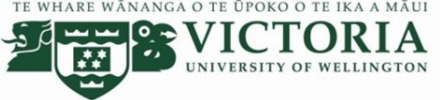


FOLLOW-UP REPORT

Please turn over 


\section{TE Whare WĀNANGa O TE ŪPOKO O TE IKA A MĀUI

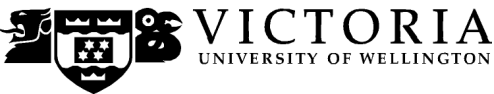

\section{POLITICAL IDENTITY IN NEW ZEALAND}

\section{A Preliminary Report for Research Participants}

January 2014

\section{SUMMARY}

This report has been prepared by Jay Woodhams, $\mathrm{PhD}$ researcher at Victoria University of Wellington, for those who took part in the research project titled 'The language of political identity' between November 2012 and May 2013. Its purpose is to present some preliminary findings and to outline future plans.

\section{PROGRESS REPORT}

Data set

A total of 22 hours and 15 minutes of conversation with 21 individuals was collected during the research period, in addition to 2.5 hours of pilot interviews and a 1.5 hour small group discussion with 5 pilot participants.

\section{Analysis}

Each conversation has been described, listing the content in detail to aid close analysis and transcription at a later stage. The preliminary findings of the description process are discussed in the following section.

\section{Presentation}

On 3 December 2013 a small portion of the dataset was presented at the 4th New Zealand Discourse Conference held at AUT University, New Zealand. The twenty-minute presentation was titled 'The dynamics of political identity construction in informal conversation' and demonstrated how political allegiance was portrayed over the course of a short conversation with one participant. $^{1}$

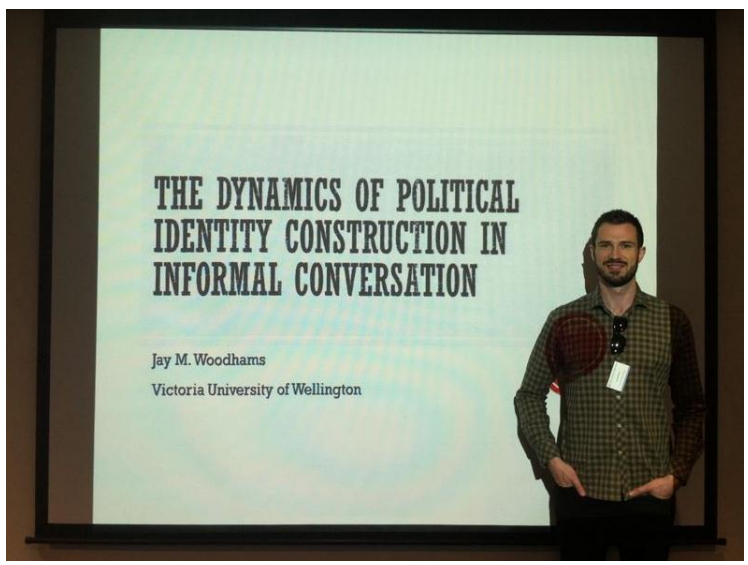

${ }^{1}$ In all work relating to this project, including in this report, names (and initials) of research participants are replaced with pseudonyms and all personally identifiable material removed in line with the policies of Victoria University of Wellington's Research Ethics Committee. 


\section{PRELIMINARY FINDINGS}

\section{Defining 'politics'}

An important issue regarding the definition of politics arose during both the recruitment phase and in the conversations themselves. Some people who expressed initial interest in taking part in the project had reservations about their level of political knowledge, feeling that they were not informed enough about the day-to-day running of parliament or the posturing of various political parties and figures. Despite this, everyone had valuable contributions to make on the 'politics' of their everyday lives, in terms of talking about the issues that affected them in some way, such as asset sales, marriage equality, local council rates or earthquakes.

Some commentators refer to this difference in meaning as being between that of big ' $\mathrm{P}$ ' politics, related to national politics and governance, versus small ' $\mathrm{p}$ ' politics, concerned with the personal political decisions we make every day. This clear division in conversations about politics highlights the difficulty in using one term to cover both meanings.

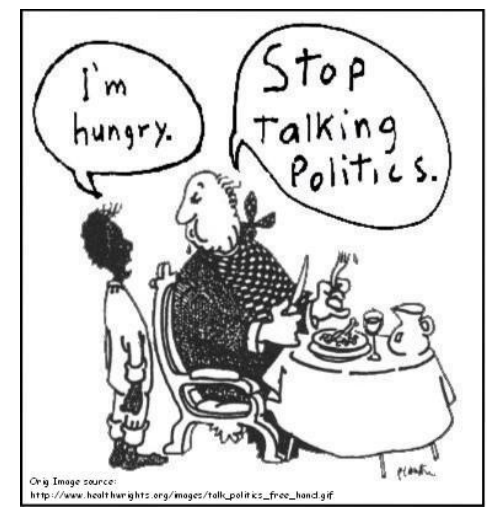

\section{Conversational topics}

The topics covered gave insight into what was important to each person, including both local and global issues ranging from very specific to more far-reaching. The topics were incredibly varied, though certain issues stood out as particularly important to many participants, often because of the current affairs of the time. Examples of conversational topics included:

- Asset sales

- Marriage equality

- Climate change

- Sustainability

- Water rights and ownership

- Government debt

- Immigration

- Education reforms

- Early childhood education

- Kim Dotcom

- Sex industry and prostitution reform

- US political influence

- Social welfare

- Christianity

- Feminism

- Māori culture
- Māori language education

- Financial crisis

- Racism

- Local governance

- Party politics and political figures

- Past occurrences (e.g. Springbok tour, Rogernomics)

- Voting behaviour and turnout

- The role and influence of media

- Activism and protest

- Multiculturalism

- Globalisation

- Gang culture

- Christchurch earthquake

- Social inequality

- Child poverty 


\section{Linguistic features of political talk}

Conversations were varied both in terms of content and language features. However, certain features were especially prominent when discussing politics and political issues. Examples of these are presented below.

\section{Narrative}

Narrative, or storytelling, often arose in response to questions related to the past, such as how people became politically aware or active, or when asking about family or political background. Telling stories is a natural way of conveying this information in an engaging and personal way.

The following excerpt highlights a short narrative: ${ }^{2}$

[...] I mean I remember when I was being interviewed for the [job] the question because I had a very high profile political role in [town] at the time and the [boss] asked me said you know do you think you could keep politics out of the [workplace] and I said no!

Pronouns

One way of looking at political affiliation is through examining pronouns. The use of the words 'us' and 'them', 'we' and 'they' or 'ours' and 'theirs' can give insight into how the person views themselves in relation to a certain group. This is particularly interesting in talk about politics, as pronouns can indicate allegiance to a particular political party or group and create distance from another.

The following excerpt shows pronouns being used to mark a distinction between the voting public ('we') and politicians ('they'):

I started to be aware of what are we doing here you know we are electing these do we know enough about these people? Their background their education qualifications and we want them we want to put that guy or that woman up and we're giving them a purse of money. What? And they're probably going to rob it and of course it's happened! So many times

In the next excerpt the participant uses pronouns to include themselves within a larger group of New Zealanders:

I think we're quite reticent in some ways I think it's that thing I want to be affable I want to be amiable that we're really not as vocal maybe as some other countries

${ }^{2}$ Transcripts have been edited slightly for ease of reading. Words have been replaced to protect identities. 


\section{Metaphor}

Figurative language is not limited to poems and creative works. It permeates our everyday language and is an important focus of study in linguistics. Metaphor is a frequent feature of political talk; for example, it is used when characterising politics as war.

The following excerpt demonstrates this metaphor in action:

So yeah I have to say that there was sometimes hard quite ugly fighting in the trenches running up to 2008 election and I lost all respect for those who chose not to fight [...] conscientious bloody objectors [laughs]

\section{Wider influences}

While each conversation was unique in terms of its contribution to the study, a striking feature of the conversations held was that many participants oriented to similar sociocultural factors, or 'discourses', which are prevalent in New Zealand. For example:

New Zealand and New Zealanders

- Geographically isolated

- Constrained by a small population

- Inventive and self-reliant

- Casual and relaxed
Wellington and Wellingtonians

- Alternative

- Anti-Auckland

- Existing in a 'bubble'

\section{CONCLUSION}

The conversations have proven to be a rich source of insight into the nature of political talk even at this early stage. Future analysis will look further into the use of narrative, pronouns and metaphor, and will remain open to identifying other language features.

I would like to express my sincere gratitude to everyone who volunteered to take part in this project. Your contribution was invaluable as without it this research could not have taken place. In addition to learning much about the language of politics in conversations with New Zealand voters, I also thoroughly enjoyed talking politics with you. This project is the first of its kind in New Zealand, so thank you once again for being an integral part of it.

The final thesis will be deposited for public access at Victoria University's central library in mid-2015.

Sincerely,

Jay Woodhams

Victoria University of Wellington

jay.woodhams@vuw.ac.nz 



\section{GLOSSARY}

Aotearoa The Māori name for New Zealand, popularly translated as 'the land of the long white cloud.'

Jandals Rubber flip-flop style footwear.

Koha A gift, present, offering, donation or contribution.

Kōhanga reo Māori language preschool.

Māori The indigenous people of Aotearoa New Zealand.

Marae A place which surrounds the wharenui [meeting house] where formal greetings and discussions take place, often used in reference to the entire complex.

Pākehā Non-Māori inhabitants of Aotearoa New Zealand, typically referring to those of European descent.

Pōwhiri Welcome, invitation, rituals of encounter or a welcome ceremony on a marae.

Stubbies Short shorts typically worn by labourers and farmers, an item of clothing also popular in Australia.

Tangata whenua Local people, hosts or indigenous people. Literally 'people of the land.'

Te reo Māori The Māori language. 
The Beehive
The name of the executive wing of Parliament, named as such due to its beehive-like shape.

The customary system of values and practices that have developed over time and are deeply embedded in the social context; culture.

Definitions provided by Deverson and Kennedy (2005) and Moorfield (2011). 


\section{REFERENCES}

Abbe, A. \& Brandon, S. E. (2014). Building and maintaining rapport in investigative interviews. Police Practice and Research, 15(3), 207-220. doi:10.1080/15614263.2013.827835

Ahdar, R. J. (1998). A christian state? Journal of Law and Religion, 13(2), 453-482. doi:10.2307/1051480. JSTOR: 1051480

Ahdar, R. J. (2006). Reflections on the path of religion-state relations in New Zealand. Brigham Young University Law Review, 20o6(3), 619.

Ahlness, E. A. (2014). Janteloven and social conformity in Thorbørn Egner's literature. NCUR 2014. Retrieved February 12, 2015, from http://ncurproceedings.org/ojs/index.php/NCUR2014/ article/view/738

Ahmed, H., Balzarova, M. \& Cohen, D. A. (2014). To sell or not to sell; that is the question? Stakeholders' supremacy in the New Zealand electricity industry. Journal of Management \& Organization, 2o(03), 410-414. doi:10.1017/jmo.2014.27

Aijmer, K. (1997). I think-an English modal particle. In T. Swan \& O. J. Westvik (Eds.), Modality in Germanic languages: historical and comparative perspectives (pp. 1-48). Berlin: Mouton de Gruyter.

Al Nashmi, E., Cleary, J., Molleda, J.-C. \& McAdams, M. (2010). Internet political discussions in the Arab world: a look at online forums from Kuwait, Saudi Arabia, Egypt and Jordan. International Communication Gazette, 72(8), 719-738. doi:10 . 1177/1748048510380810

Allen, A. (2000). The anti-subjective hypothesis: Michel Foucault and the death of the subject. The Philosophical Forum, 31(2), 113-130. doi:10.1111/0031-806X.00031

Althusser, L. (1972). Lenin and philosophy, and other essays (B. Brewster, Trans.). New York, NY: Monthly Review Press.

Alvarez-Cáccamo, C. \& Prego-Vázquez, G. (2003). Political crossdiscourse: conversationalization, imaginary networks, and social fields in Galiza. Pragmatics, 13(1), 145-162. 
Álvarez-Rivera, M. (2014). Election resources on the internet: parliamentary elections in the Czech Republic-elections to the Chamber of Deputies. Retrieved March 16, 2015, from http:// www.electionresources.org/cz/

Alvesson, M. \& Sköldberg, K. (2009). (Post-) positivism, social constructionism, critical realism: three reference points in the philosophy of science. In Reflexive methodology: new vistas for qualitative research (2nd ed., pp. 15-52). London: SAGE.

Al-Amoudi, I. (2007). Redrawing Foucault's social ontology. Organization, 14(4), 543-563. doi:10.1177/1350508407078052

Al-Amoudi, I. \& Willmott, H. (2011). Where constructionism and critical realism converge: interrogating the domain of epistemological relativism. Organization Studies, 32(1), 27-46. doi:10. 1177/0170840610394293

Anderson, A. (1991). The chronology of colonization in New Zealand. Antiquity, 65(249), 767-795.

Anderson, B. (2006). Imagined communities: reflections on the origin and spread of nationalism. London: Verso.

Anderson, F. (2000). The big road: the \$227 million highway from Albany to Puhoi. New Zealand Engineering, 54(9), 8-12.

Angouri, J. \& Marra, M. (Eds.). (2011). Constructing identities at work. Basingstoke: Palgrave Macmillan.

Antaki, C., Billig, M., Edwards, D. \& Potter, J. (2003). Discourse analysis means doing analysis: a critique of six analytic shortcomings. Discourse Analysis Online, 1(1). Retrieved from http: //hdl.handle.net/2134/633

APNZ. (2013, May 7). Key backtracks on claim Wellington 'dying city'. Otago Daily Times. Retrieved April 1, 2015, from http:// www.odt.co.nz/news/politics/255820/key-backtracks- claimwellington-dying-city

Archer, M. (1995). Realist social theory: the morphogenetic approach. Cambridge: Cambridge University Press.

Archer, M. (1998). Introduction: realism in the social sciences. In M. Archer, R. Bhaskar, A. Collier, T. Lawson \& A. Norrie (Eds.), Critical realism: essential readings (pp. 189-205). Abingdon, UK: Routledge. 
Archer, M., Bhaskar, R., Collier, A., Lawson, T. \& Norrie, A. (Eds.). (1998). Critical realism: essential readings. Abingdon, UK: Routledge.

Argaman, O. (2009). Linguistic markers and emotional intensity. fournal of Psycholinguistic Research, 39(2), 89-99. doi:10.1007/s10936oo9-9127-1

Arksey, H. \& Knight, P. (1999). Interviewing for social scientists: an introductory resource with examples. London: SAGE.

Ashforth, B. (2001). Role transitions in organizational life: an identitybased perspective. Mahwah, NJ: Lawrence Erlbaum Associates.

Atkinson, P. \& Hammersley, M. (2007). Ethnography: principles in practice (3rd ed.). Abingdon, UK: Routledge.

Audacity Team. (2013). Audacity ${ }^{\circledR}$ : free audio editor and recorder (Version 2.0.5). Retrieved from http://audacity.sourceforge.net/

Austin, P. (1990). Politeness revisited-the dark side. In A. Bell \& J. Holmes (Eds.), New Zealand ways of speaking english (pp. 277293). Clevedon, UK: Multilingual Matters.

Baiocchi, G. (2003). Emergent public spheres: talking politics in participatory governance. American Sociological Review, 68(1), 52-74. doi:10.2307/3088902. JSTOR: 3088902

Baker, L. \& Crellin, B. (2004). Way of the FAFA: a guide to surviving Auckland and Aucklanders. Auckland: Hachette.

Bamberg, M. (2006). Stories: big or small: why do we care? Narrative Inquiry, 16(1), 139-147.

Bamberg, M., de Fina, A. \& Schiffrin, D. (2007a). Introduction to the volume. In M. Bamberg, A. de Fina \& D. Schiffrin (Eds.), Selves and identities in narrative and discourse (pp. 1-8). Amsterdam: John Benjamins.

Bamberg, M., de Fina, A. \& Schiffrin, D. (Eds.). (2007b). Selves and identities in narrative and discourse. Amsterdam: John Benjamins.

Bamberg, M., de Fina, A. \& Schiffrin, D. (2011). Discourse and identity construction. In S. J. Schwartz, K. Luyckx \& V. L. Vignoles (Eds.), Handbook of identity theory and research (pp. 177-199). New York, NY: Springer.

Bamberg, M. \& Georgakopoulou, A. (2008). Small stories as a new perspective in narrative and identity analysis. Text \& Talk, 28(3), 377-396. doi:10.1515/TEXT.2008.018 
Baxter, J. \& Wallace, K. (2009). Outside in-group and out-group identities? Constructing male solidarity and female exclusion in UK builders' talk. Discourse \& Society, 2o(4), 411-429. doi:10. 1177/0957926509104021

Baynham, M. (1996). Direct speech: what's it doing in non-narrative discourse? Fournal of Pragmatics, 25(1), 61-81. doi:10.1016/03782166(94)00074-3

Bekker, S. B. \& Leildé, A. (Eds.). (2006). Reflections on identity in four African cities. South Africa: African Minds.

Bell, A. (1997). The phonetics of fish and chips in New Zealand: marking national and ethnic identities. English World-Wide, 18(2), 243-270. doi:10.1075/eww.18.2.05bel

Bell, A. (1999). Styling the other to define the self: a study in New Zealand identity making. Journal of Sociolinguistics, 3(4), 523541.

Bell, A. (2001). Back in style: reworking audience design. In P. Eckert \& J. Rickford (Eds.), Style and sociolinguistic variation (pp. 139169). Cambridge: Cambridge University Press.

Bell, A. (2014, November 24). Everybody needs good neighbours: the indexical cycle and the differentiation of New Zealand and Australian Englishes. 14th Language \& Society conference. University of Waikato, Hamilton, New Zealand.

Bell, C. (2002). The big 'OE': young New Zealand travellers as secular pilgrims. Tourist Studies, 2(2), 143-158.

Benwell, B. \& Stokoe, E. (2006). Discourse and identity. Edinburgh: Edinburgh University Press.

Berger, A. A. (1976). Anatomy of the joke. Fournal of Communication, 26(3), 113-115. doi:10.1111/j.1460-2466.1976.tbo1913.x

Berger, P. L. \& Luckmann, T. (1966). The social construction of reality: a treatise in the sociology of knowledge. Garden City, NY: Doubleday.

Bhaskar, R. (1975). A realist theory of science. UK: Leeds Books.

Bhaskar, R. (1979). The possibility of naturalism: a philosophical critique of the contemporary human sciences. Brighton, East Sussex: Harvester.

Bhaskar, R. (2009). Scientific realism and human emancipation. Original work published 1986 by Verso. Abingdon, UK: Routledge. 
Bhatia, A. (2006). Critical discourse analysis of political press conferences. Discourse \& Society, 17(2), 173-203. doi:10 . 1177/ 0957926506058057

Bhavnani, K.-K. (1991). Talking politics: a psychological framing of views from youth in Britain. Cambridge: Cambridge University Press.

Biernacki, P. \& Waldorf, D. (1981). Snowball sampling: problems and techniques of chain referral sampling. Sociological Methods \& Research, 10(2), 141-163. doi:10.1177/004912418101000205

Billig, M. (1999). Conversation analysis and the claims of naivety. Discourse \& Society, 1o(4), 572-576. doi:10.1177/0957926599010004007

Blackledge, A. (2005). Discourse and power in a multilingual world. Amsterdam: John Benjamins.

Blair, C. (1987). The statement: foundation of Foucault's historical criticism. Western Journal of Speech Communication: WFSC, $51(4), 364-383$.

Blais, A. (2000). To vote or not to vote? The merits and limits of rational choice theory. Pittsburgh: University of Pittsburgh Press.

Blommaert, J. (2007). Sociolinguistic scales. Intercultural Pragmatics, 4(1), 1-19. doi:10.1515/IP.2007.001

Blommaert, J. \& Bulcaen, C. (2000). Critical discourse analysis. Annual Review of Anthropology, 29, 447-466. doi:10.2307/223428. JSTOR: 223428

Blommaert, J., Collins, J. \& Slembrouck, S. (2005). Spaces of multilingualism. Language \& Communication, 25(3), 197-216. doi:10. 1016/j.langcom.2005.05.002

Blommaert, J. \& Dong, J. (2010). Language and movement in space. In N. Coupland (Ed.), The handbook of language and globalization (pp. 366-385). Malden, MA: Wiley-Blackwell.

Blum-Kulka, S. (1983). The dynamics of political interviews. TextInterdisciplinary fournal for the Study of Discourse, 3(2), 131-153. doi:10.1515/text.1.1983.3.2.131

Bolden, G. B. (2006). Little words that matter: discourse markers 'so' and 'oh' and the doing of other-attentiveness in social interaction. Fournal of Communication, 56(4), 661-688. doi:10. $1111 / \mathrm{j} .1460-2466.2006 .00314 . \mathrm{x}$ 
Bönisch-Brednich, B. (2008). Watching the Kiwis: New Zealanders' rules of social interaction-an introduction. Fournal of New Zealand Studies, (6/7), 3.

Booth, T. \& Booth, W. (1994). The use of depth interviewing with vulnerable subjects: lessons from a research study of parents with learning difficulties. Social Science \& Medicine, 39(3), 415-424. doi:10.1016/0277-9536(94)90139-2

Boston, J. (2014). Child poverty in New Zealand: why it matters and how it can be reduced. Educational Philosophy and Theory, 46(9), 962-988. doi:10.1080/00131857.2014.931002

Boston, J. \& Chapple, S. (2014). Child poverty in New Zealand. Wellington: Bridget Williams Books.

Bowen, G. A. (2008). Naturalistic inquiry and the saturation concept: a research note. Qualitative Research, 8(1), 137-152. doi:10.1177/ 1468794107085301

Bremer, K. \& Roberts, C. (Eds.). (1996). Achieving understanding: discourse in intercultural encounters. Abingdon, UK: Taylor \& Francis.

Briggs, C. L. (1986). Learning how to ask: a sociolinguistic appraisal of the role of the interview in social science research. Cambridge: Cambridge University Press.

Bromgard, G., Trafimow, D. \& Linn, C. (2014). Janteloven and the expression of pride in Norway and the United States. The Journal of Social Psychology, 154(5), 375-378. doi:10 . 1080/ 00224545.2014 .914884

Brown, P. \& Levinson, S. C. (1987). Politeness: some universals in language usage. Cambridge: Cambridge University Press.

Brubaker, R. \& Cooper, F. (2000). Beyond 'identity'. Theory and Society, 29(1), 1-47. doi:10.2307/3108478. JSTOR: 3108478

Bucholtz, M. (2000). The politics of transcription. Journal of Pragmatics, 32(10), 1439-1465. doi:10.1016/So378-2166(99)ooo94-6

Bucholtz, M. (2009). From stance to style: gender, interaction, and indexicality in Mexican immigrant youth slang. In A. Jaffe (Ed.), Stance: sociolinguistic perspectives (pp. 146-170). Oxford: Oxford University Press.

Bucholtz, M. \& Hall, K. (2005). Identity and interaction: a sociocultural linguistic approach. Discourse Studies, 7(4-5), 585-614. doi:10. 1177/1461445605054407 
Bucholtz, M. \& Hall, K. (2007). Language and identity. In A. Duranti (Ed.), A companion to linguistic anthropology (pp. 369-394). Malden, MA: Blackwell.

Buchstaller, I. \& Khattab, G. (2013). Population samples. In R. J. Podesva \& D. Sharma (Eds.), Research methods in linguistics (pp. 74-98). Cambridge: Cambridge University Press.

Buonfino, A. (2004). Between unity and plurality: the politicization and securitization of the discourse of immigration in Europe. New Political Science, 26(1), 23-49. doi:10.1080/0739314042000185111

Burke, P. J. \& Reitzes, D. C. (1981). The link between identity and role performance. Social Psychology Quarterly, 44(2), 83-92. doi:10. 2307/3033704. JSTOR: 3033704

Burr, V. (2003). Social constructionism (2nd ed.). London: Routledge.

Burridge, K. \& Florey, M. (2002). 'Yeah-no he's a good kid': a discourse analysis of Yeah-no in Australian English. Australian fournal of Linguistics, 22(2), 149-171. doi:10.1080/0726860022000013166

Butler, J. (1999). Gender trouble: feminism and the subversion of identity. Abingdon, UK: Routledge.

Callero, P. L. (1985). Role-identity salience. Social Psychology Quarterly, 48(3), 203-215. doi:10.2307/3033681. JSTOR: 3033681

Chafe, W. (1987). Cognitive constraints on information flow. In R. S. Tomlin (Ed.), Coherence and grounding in discourse (pp. 21-52). Amsterdam: John Benjamins.

Charmaz, K. (2006). Constructing grounded theory: a practical guide through qualitative analysis. London: SAGE.

Chilton, P. A. (2004). Analysing political discourse: theory and practice. London: Routledge.

Chilton, P. A. \& Schäffner, C. (2002). Politics as text and talk: analytic approaches to political discourse. Amsterdam: John Benjamins Publishing.

Chouliaraki, L. \& Fairclough, N. (1999). Discourse in late modernity: rethinking critical discourse analysis. Edinburgh: Edinburgh University Press.

Clark, H. (2002, February 21). Prime Minister's address. London School of Economics. Retrieved April 1, 2015, from http : / / www . beehive.govt.nz/node/13082 
Coates, J. (1987). Epistemic modality and spoken discourse. Transactions of the Philological Society, 85(1), 110-131. doi:10.1111/j. 1467-968X.1987.tboo714.x

Coates, J. (2013). Women, men and language: a sociolinguistic account of gender differences in language (3rd ed.). Abingdon, UK: Routledge.

Collier, A. (1994). Critical realism: an introduction to Roy Bhaskar's philosophy. London: Verso.

Corbin, J. \& Morse, J. M. (2003). The unstructured interactive interview: issues of reciprocity and risks when dealing with sensitive topics. Qualitative Inquiry, 9(3), 335-354. doi:10.1177/ 1077800403009003001

Corley, M. \& Stewart, O. W. (2008). Hesitation disfluencies in spontaneous speech: the meaning of um. Language and Linguistics Compass, 2(4), 589-602. doi:10.1111/j.1749-818X.2008.00068.x

Coulmas, F. (1986). Direct and indirect speech. Berlin: Mouton de Gruyter.

Coupland, J. (Ed.). (200o). Small talk. Abingdon, UK: Taylor \& Francis.

Coupland, J. (2003). Small talk: social functions. Research on Language \& Social Interaction, 36(1), 1-6. doi:10.1207/S15327973RLSI3601_ 1

Coupland, N. (2007). Style: language variation and identity. Cambridge: Cambridge University Press.

Coupland, N. \& Jaworski, A. (2009). Social worlds through language. In N. Coupland \& A. Jaworski (Eds.), The new sociolinguistics reader (pp. 1-21). Basingstoke, UK: Palgrave Macmillan.

Coyne, I. T. (1997). Sampling in qualitative research: purposeful and theoretical sampling, merging or clear boundaries? fournal of Advanced Nursing, 26(3), 623-630. doi:10.1046/j.1365-2648.1997. to1-25-00999.x

Crawford, S. A. G. M. (1985). The game of 'glory and hard knocks': a study of the interpenetration of rugby and New Zealand society. The Fournal of Popular Culture, 19(2), 77-92. doi:10.1111/j.00223840.1985.00077.x

Damari, R. R. (2010). Intertextual stancetaking and the local negotiation of cultural identities by a binational couple. Journal of Sociolinguistics, 14(5), 609-629. doi:10.1111/j.1467-9841.2010. 00456.x 
Danermark, B., Ekström, M., Jakobsen, L. \& Karlsson, J. C. (2002). Explaining society: an introduction to critical realism in the social sciences. London: Routledge.

Davies, C. A. (2008). Reflexive ethnography: a guide to researching selves and others (2nd ed.). Abingdon, UK: Routledge.

de Cillia, R., Reisigl, M. \& Wodak, R. (1999). The discursive construction of national identities. Discourse \& Society, 10(2), 149-173. doi:10.1177/0957926599010002002

de Fina, A. (2011). Discourse and identity. In T. A. van Dijk (Ed.), Discourse studies: a multidisciplinary introduction (pp. 263-282). London: SAGE.

de Fina, A. (2012). Discourse and identity. In C. A. Chapelle (Ed.), The encyclopedia of applied linguistics. Chichester, UK: John Wiley $\&$ Sons.

de Fina, A., Schiffrin, D. \& Bamberg, M. (Eds.). (2006). Discourse and identity. Cambridge: Cambridge University Press.

Department of Internal Affairs. (n.d.). Environment Canterbury reviewdiscussion document. Retrieved April 21, 2015, from http:// www . dia . govt.nz / Resource - material - Our - Policy - Advice Areas-Environment-Canterbury

Department of Internal Affairs. (2011). Local government in New Zealand. Retrieved April 1, 2015, from http://www.localcouncils. govt.nz

Department of Internal Affairs. (2015). Local authority election statistics 2013. Retrieved March 31, 2015, from http://www.dia.govt. nz/diawebsite.nsf/wpg_URL/Services-Local-Elections-LocalAuthority-Election-Statistics-2013

Deverson, T. \& Kennedy, G. (Eds.). (2005). The New Zealand Oxford dictionary. Oxford: Oxford University Press.

DiCicco-Bloom, B. \& Crabtree, B. F. (2006). The qualitative research interview. Medical Education, 4o(4), 314-321. doi:10.1111/j.13652929.2006.02418.x

Dickson-Swift, V., James, E. L., Kippen, S. \& Liamputtong, P. (2007). Doing sensitive research: what challenges do qualitative researchers face? Qualitative Research, 7(3), 327-353. doi:10.1177/ 1468794107078515 
Dixon, J. \& Durrheim, K. (2000). Displacing place-identity: a discursive approach to locating self and other. British fournal of Social Psychology, 39(1), 27-44. doi:10.1348/014466600164318

Du Bois, J. W. (1991). Transcription design principles for spoken discourse research. Pragmatics, 1(1), 71-106. doi:10.1075/prag.1. 1.04 boi

Du Bois, J. W. (2007). The stance triangle. In R. Englebretson (Ed.), Stancetaking in discourse: subjectivity, evaluation, interaction (pp. 139-182). Amsterdam: John Benjamins.

Du Bois, J. W. \& Kärkkäinen, E. (2012). Taking a stance on emotion: affect, sequence, and intersubjectivity in dialogic interaction. Text \& Talk, 32(4), 433-451. doi:10.1515/text-2012-0021

Duncombe, J. \& Jessop, J. (2012). 'Doing rapport' and the ethics of 'faking friendship'. In T. Miller, M. Birch, M. Mauthner \& J. Jessop (Eds.), Ethics in qualitative research (2nd ed., pp. 108-121). London: SAGE.

Dynel, M. (2009). Beyond a joke: types of conversational humour. Language and Linguistics Compass, 3(5), 1284-1299. doi:10.1111/ j.1749-818X.2009.00152.X

Eckert, P. (2008). Variation and the indexical field. fournal of Sociolinguistics, 12(4), 453-476. doi:10.1111/j.1467-9841.2008.00374.x

Egan Sjölander, A. \& Gunnarsson Payne, J. (Eds.). (2011). Tracking discourses: politics, identity and social change. Lund, Sweden: Nordic Academic Press.

Electoral Commission. (2013). Voting system. Retrieved March 31, 2015, from http://www.elections.org.nz/voting-system

Electoral Commission. (2014). Who can and can't enrol? Retrieved March 30, 2015, from http://www.elections.org.nz/voters/enrolcheck-or-update-now/who-can-and-cant-enrol

Electoral Commission. (2015). New Zealand election results. Retrieved March 30, 2015, from http://www.electionresults.govt.nz/

Elwood, S. A. \& Martin, D. G. (2000). 'Placing' interviews: location and scales of power in qualitative research. The Professional Geographer, 52(4), 649-657. doi:10.1111/0033-0124.00253

Englebretson, R. (Ed.). (2007). Stancetaking in discourse: subjectivity, evaluation, interaction. Amsterdam: John Benjamins.

Fairclough, I. \& Fairclough, N. (2011). Practical reasoning in political discourse: the UK government's response to the economic crisis 
in the 2008 pre-budget report. Discourse \& Society, 22(3), 243268. doi:10.1177/0957926510395439

Fairclough, N. (1992). Discourse and social change. Cambridge, UK: Polity Press.

Fairclough, N. (2001). The dialectics of discourse. Textus, 14(2), 231242.

Fairclough, N. (2005). Peripheral vision discourse analysis in organization studies: the case for critical realism. Organization Studies, 26(6), 915-939. doi:10.1177/0170840605054610

Fairclough, N. (2010). Critical discourse analysis: the critical study of language (2nd ed.). Abingdon, UK: Taylor \& Francis.

Fairclough, N. \& Fairclough, I. (2012). Political discourse analysis: a method for advanced students. Abingdon, UK: Routledge.

Fairclough, N., Jessop, B. \& Sayer, A. (2002). Critical realism and semiosis. Journal of Critical Realism, 5(1), 2-10. Retrieved June 27, 2012, from http://eprints.lancs.ac.uk/176/

Feather, N. T. (1989). Attitudes towards the high achiever: the fall of the tall poppy. Australian fournal of Psychology, 41(3), 239-267. doi:10.1080/00049538908260088

Feather, N. T. \& McKee, I. R. (1993). Global self-esteem and attitudes toward the high achiever for Australian and Japanese students. Social Psychology Quarterly, 56(1), 65-76. doi:10.2307/2786646. JSTOR: 2786646

Feather, N. T., Volkmer, R. E. \& McKee, I. R. (1991). Attitudes towards high achievers in public life: attributions, deservingness, personality, and affect. Australian Journal of Psychology, 43(2), 85-91. doi:10.1080/00049539108259105

Felton, D. (1998). Advice to tyrants: the motif of 'enigmatic counsel' in Greek and Roman texts. Phoenix, 52(1/2), 42-54. doi:10.2307/ 1088244. JSTOR: 1088244

Fetzer, A. (2010). Hedges in context: form and function of sort of and kind of. In G. Kaltenböck, W. Mihatsch \& S. Schneider (Eds.), New approaches to hedging (pp. 49-71). Bingley, UK: Emerald Group.

Fetzer, A. (2013a). The multilayered and multifaceted nature of political discourse. In A. Fetzer (Ed.), The pragmatics of political discourse: explorations across cultures (pp. 1-18). Amsterdam: John Benjamins. 
Fetzer, A. (Ed.). (2013b). The pragmatics of political discourse: explorations across cultures. Amsterdam: John Benjamins.

Fischer, D. H. (2012). Fairness and freedom: a history of two open societies: New Zealand and the United States. Oxford: Oxford University Press.

Fleras, A. (2011). 'Cooling out troublesome constituents': the politics of managing 'isms' in the Antipodes. In R. Hasmath (Ed.), Managing ethnic diversity: meanings and practices from an international perspective (pp. 119-140). Farnham, UK: Ashgate.

Flood, A. (2015, January 30). Eleanor Catton blasts critics' 'jingoistic national tantrum' [The Guardian]. Retrieved April 2, 2015, from http : / / www. theguardian .com/books / 2015/ jan/30/ eleanor catton-blasts-critics-jingoistic-national-tantrum

Foster, J. E. (1998). Absolute versus relative poverty. The American Economic Review, 88(2), 335-341. JSTOR: 116944

Foucault, M. (2002a). The archaeology of knowledge (A. M. Sheridan Smith, Trans.). Original work published 1969 by Editions Gallimard. Abingdon, UK: Routledge.

Foucault, M. (2002b). The order of things: an archaeology of the human sciences. Original work published 1966 by Editions Gallimard. London: Routledge.

Frauley, J. \& Pearce, F. (2007). Critical realism and the social sciences: methodological and epistemological preliminaries. In F. Pearce \& J. Frauley (Eds.), Critical realism and the social sciences: heterodox elaborations (pp. 3-29). Toronto: University of Toronto Press.

Galinsky, A. D., Wang, C. S., Whitson, J. A., Anicich, E. M., Hugenberg, K. \& Bodenhausen, G. V. (2013). The reappropriation of stigmatizing labels: the reciprocal relationship between power and selflabeling. Psychological Science, 24(10), 2020-2029. doi:10.1177/ 0956797613482943

Gardner, R. (1997). The conversation object $m m$ : a weak and variable acknowledging token. Research on Language \& Social Interaction, 3o(2), 131-156. doi:10.1207/s15327973rlsi3002_2

Gardner, R. (1998). Between speaking and listening: the vocalisation of understandings. Applied Linguistics, 19(2), 204-224. doi:10.1093/ applin/19.2.204 
Gee, J. P. (2000). Identity as an analytic lens for research in education. Review of Research in Education, 25, 99-125. doi:10.2307/1167322. JSTOR: 1167322

Gee, J. P. (2014). An introduction to discourse analysis: theory and method (4th ed.). Abingdon, UK: Routledge.

Geertz, C. (1973). Thick description: toward an interpretive theory of culture. In The interpretation of cultures: selected essays (pp. 330). New York, NY: Basic Books.

Georgakopoulou, A. (2006). Thinking big with small stories in narrative and identity analysis. Narrative Inquiry, 16(1), 122-130. doi:10.1075/ni.16.1.16geo

Giddens, A. (1979). Central problems in social theory: action, structure, and contradiction in social analysis. Oakland, CA: University of California Press.

Glaser, B. \& Strauss, A. (1999). The discovery of grounded theory: strategies for qualitative research. Original work published 1967. Chicago: Aldine Transaction.

Glenn, P. (2003). Laughter in interaction. Cambridge: Cambridge University Press.

Goffman, E. (1955). On face-work: an analysis of ritual elements in social interaction. Psychiatry: Fournal for the Study of Interpersonal Processes, 18(3), 213-231.

Goffman, E. (1967). Interaction ritual: essays in face-to-face behavior. Chicago: Aldine.

Goffman, E. (1974). Frame analysis: an essay on the organization of experience. New York: Harper \& Row.

Goffman, E. (1981). Footing. In E. Goffman (Ed.), Forms of talk (pp. 124159). Oxford: Basil Blackwell.

Gold, H. (Ed.). (1992). New Zealand politics in perspective. Auckland: Longman Paul.

González-Bailón, S., Banchs, R. E. \& Kaltenbrunner, A. (2012). Emotions, public opinion, and u.s. presidential approval rates: a 5year analysis of online political discussions. Human Communication Research, 38(2), 121-143. doi:10.1111/j.1468-2958.2011. 01423. $\mathrm{x}$

Gordon, C. (2004). 'Al Gore's our guy': linguistically constructing a family political identity. Discourse \& Society, 15(5), 607-631. doi:10.1177/0957926504045034 
Grant, L. E. (2012). Culturally motivated lexis in New Zealand English. World Englishes, 31(2), 162-176. doi:10.1111/j.1467-971X.2012. 01738.x

Green, J., Franquiz, M. \& Dixon, C. (1997). The myth of the objective transcript: transcribing as a situated act. TESOL Quarterly, 31(1), 172-176. doi: $10.2307 / 3587984$

Groff, R. (2004). Critical realism, post-positivism, and the possibility of knowledge. London: Routledge.

Groff, R. (2010). Critical realism. In R. Jackson \& M. Hogg (Eds.), Encyclopedia of identity (pp. 153-156). Thousand Oaks, CA: SAGE.

Guest, G., Bunce, A. \& Johnson, L. (2006). How many interviews are enough? An experiment with data saturation and variability. Field Methods, 18(1), 59-82. doi:10.1177/1525822X05279903

Gumperz, J. J. (1982a). Discourse strategies. Cambridge: Cambridge University Press.

Gumperz, J. J. (Ed.). (1982b). Language and social identity. Cambridge: Cambridge University Press.

Gumperz, J. J. (1999). On interactional sociolinguistic method. In S. Sarangi \& C. Roberts (Eds.), Talk, work and institutional order: discourse in medical, mediation and management settings (pp. 453-472). Berlin: Walter de Gruyter.

Gumperz, J. J. (2001). Interactional sociolinguistics: a personal perspective. In D. Schiffrin, D. Tannen \& H. E. Hamilton (Eds.), The handbook of discourse analysis (pp. 215-228). Malden, MA: Blackwell.

Gumperz, J. J. (2009). Contextualization conventions. In N. Coupland \& A. Jaworski (Eds.), The new sociolinguistics reader (pp. 598606). Basingstoke, UK: Palgrave MacMillan.

Gumperz, J. J. \& Roberts, C. (1991). Understanding in intercultural encounters. In J. Blommaert \& J. Verschueren (Eds.), The pragmatics of international and intercultural communication (pp. 51-90). Amsterdam: John Benjamins.

Gunnarsson, B.-L., Linell, P. \& Nordberg, B. (1997). The construction of professional discourse. Abingdon, UK: Taylor \& Francis.

Hacking, I. (1999). The social construction of what? Cambridge, MA: Harvard University Press. 
Haggerty, J. H. (2007). 'I'm not a greenie but... ': environmentality, ecopopulism and governance in New Zealand: experiences from the Southland whitebait fishery. Fournal of Rural Studies, 23(2), 222-237. doi:10.1016/j.jrurstud.2006.11.002

Hamer, D. A. (1988). The New Zealand liberals: the years of power, 18911912. Auckland: Auckland University Press.

Hamilton, M. B. (1987). The elements of the concept of ideology. Political Studies, 35, 18-38. doi:10 . 1111/j . 1467-9248 . 1987 . tboo186.x

Hammersley, M. (1990). What's wrong with ethnography? The myth of theoretical description. Sociology, 24(4), 597-615. doi:10.1177/ 0038038590024004003

Harré, R., Moghaddam, F. M., Cairnie, T. P., Rothbart, D. \& Sabat, S. R. (2009). Recent advances in positioning theory. Theory \& Psychology, 19(1), 5-31. doi:10.1177/0959354308101417

Harrington, L. \& Liu, J. H. (2002). Self-enhancement and attitudes toward high achievers a bicultural view of the independent and interdependent self. Journal of Cross-Cultural Psychology, 33(1), 37-55. doi:10.1177/0022022102033001003

Hawke, G. R. (1979). Acquisitiveness and equality in New Zealand's economic development. The Economic History Review, 32(3), 376-390. doi:10.1111/j.1468-0289.1979.tbo1698.x

Hawke, G. R. (1985). The making of New Zealand: an economic history. Cambridge: Cambridge University Press.

Hay, J. (2000). Functions of humor in the conversations of men and women. Journal of Pragmatics, 32(6), 709-742. doi:10.1016/ So378-2166(99)0oo69-7

Hernández, B., Hidalgo, M. C., Salazar-Laplace, M. E. \& Hess, S. (2007). Place attachment and place identity in natives and non-natives. fournal of Environmental Psychology, 27(4), 310-319. doi:10 . 1016/j.jenvp.2007.06.003

Herzog, H. (2005). On home turf: interview location and its social meaning. Qualitative Sociology, 28(1), 25-47. doi:10.1007/ S11133-005-2629-8

Hill, R. S. (2010). Fitting multiculturalism into biculturalism: MāoriPasifika relations in New Zealand from the 1960s. Ethnohistory, 57(2), 291-319. doi:10.1215/00141801-2009-064 
Holmes, J. (1985). Sex differences and miscommunication: some data from New Zealand. In J. B. Pride (Ed.), Cross-cultural encounters: communication and miscommunication (pp. 24-43). Melbourne: River Seine.

Holmes, J. (1995). Women, men and politeness. London: Longman.

Holmes, J. (1999). Managing in style: flexible discourse at work. In Communication voyages: proceedings of the tenth annual conference of the NZ communication association (pp. 1-15). Auckland: Auckland Institute of Technology. Retrieved February 16, 2015, from http://eric.ed.gov/?id=ED 427545

Holmes, J. (2000a). Doing collegiality and keeping control at work: small talk in government departments. In J. Coupland (Ed.), Small talk (pp. 32-61). Abingdon: Taylor \& Francis.

Holmes, J. (200ob). Politeness, power and provocation: how humour functions in the workplace. Discourse Studies, 2(2), 159-185. doi: $10.1177 / 1461445600002002002$

Holmes, J. (2003). Small talk at work: potential problems for workers with an intellectual disability. Research on Language and Social Interaction, 36(1), 65-84. doi:10.1207/S15327973RLSI3601_4

Holmes, J. (2006a). Gendered talk at work: constructing gender identity through workplace discourse. Malden, MA: Blackwell.

Holmes, J. (2006b). Sharing a laugh: pragmatic aspects of humor and gender in the workplace. Fournal of Pragmatics, 38(1), 26-50. doi:10.1016/j.pragma.2005.06.007

Holmes, J. (2007a). Humour and the construction of Māori leadership at work. Leadership, 3(1), 5-27. doi:10.1177/1742715007073061

Holmes, J. (2007b). Making humour work: creativity on the job. Applied Linguistics, 28(4), 518-537. doi:10.1093/applin/ammo48

Holmes, J. \& Marra, M. (2004). Relational practice in the workplace: women's talk or gendered discourse? Language in Society, 33(3), 377-398. doi:10.1017/Soo47404504043039. JSTOR: 4169353

Holmes, J., Marra, M. \& Schnurr, S. (2008). Impoliteness and ethnicity: Māori and Pākehā discourse in New Zealand workplaces. Journal of Politeness Research, 4(2), 193-219. doi:10.1515/JPLR. 2008.010

Holmes, J., Marra, M. \& Vine, B. (2011). Leadership, discourse and ethnicity. Oxford: Oxford University Press. 
Holmes, J., Marsden, S. \& Marra, M. (2013). Doing listenership: one aspect of sociopragmatic competence at work. Pragmatics and Society, 4(1), 26-53. doi:10.1075/ps.4.1.02hol

Holmes, J. \& Stubbe, M. (2003). Power and politeness in the workplace: a sociolinguistic analysis of talk at work. Harlow, UK: Pearson Education.

Holmes, J., Stubbe, M. \& Vine, B. (1999). Constructing professional identity: 'doing power' in policy units. In S. Srikant \& C. Roberts (Eds.), Talk, work and institutional order: discourse in medical, mediation and management settings (pp. 351-385). Berlin: Mouton de Gruyter.

Holmes, J. \& Woodhams, J. M. (2013). Building interaction: the role of talk in joining a community of practice. Discourse \& Communication, 7(3), 275-298. doi:10.1177/1750481313494500

Houston, S. (2001). Beyond social constructionism: critical realism and social work. British fournal of Social Work, 31(6), 845-861. doi:10. 1093/bjsw/31.6.845

Howarth, D., Norval, A. J. \& Stavrakakis, Y. (Eds.). (2000). Discourse theory and political analysis: identities, hegemonies, and social change. Manchester, UK: Manchester University Press.

Howe, K. R. (2008). The quest for origins (2nd ed.). Rosedale, New Zealand: Penguin Books.

Huckfeldt, R. \& Sprague, J. (1987). Networks in context: the social flow of political information. The American Political Science Review, 81(4), 1197-1216. doi:10.2307/1962585. JSTOR: 1962585

Huddy, L. (2001). From social to political identity: a critical examination of social identity theory. Political Psychology, 22(1), 127-156. doi:10.1111/0162-895X.00230

Hunston, S. (2011). Corpus approaches to evaluation: phraseology and evaluative language. New York, NY: Routledge.

Hunston, S. \& Thompson, G. (Eds.). (200o). Evaluation in text: authorial stance and the construction of discourse. Oxford: Oxford University Press.

Hutchby, I. (2011). Non-neutrality and argument in the hybrid political interview. Discourse Studies, 13(3), 349-365. doi:10.1177/ 1461445611400665

Hutchinson, S. A., Wilson, M. E. \& Wilson, H. S. (1994). Benefits of participating in research interviews. The fournal of Nursing 
Scholarship, 26(2), 161-166. doi:10.1111/j .1547-5069. 1994 . tboo937.x

Hymes, D. (1964). Introduction: toward ethnographies of communication. American Anthropologist, 66(6), 1-34. doi:10.1525/aa.1964. 66.suppl_3.02a0oo10

Iles, J. (2008). In remembrance: the Flanders poppy. Mortality, 13(3), 201-221. doi:10.1080/13576270802181640

Íñigo-Mora, I. (2004). On the use of the personal pronoun we in communities. Journal of Language \& Politics, 3(1), 27-52. doi:10. 1075/jlp.3.1.05ini

Jackson, B. (2008). Portraying leadership in New Zealand: from modest recognition to contemplative action. In E. Griffey (Ed.), The power of portraiture: portraying leadership in New Zealand from 1840 to the present (pp. 10-17). Auckland: David Ling.

Jacobs-Huey, L. (2002). The natives are gazing and talking back: reviewing the problematics of positionality, voice, and accountability among 'native' anthropologists. American Anthropologist, 104(3), 791-804. doi:10.1525/aa.2002.104.3.791

Jacoby, S. \& Ochs, E. (1995). Co-construction: an introduction. Research on Language and Social Interaction, 28(3), 171-183. doi:10. 1207/s15327973rlsi2803_1

Jaffe, A. (2000). Comic performance and the articulation of hybrid identity. Pragmatics, 10(1), 39-59. doi:10.1075/prag.10.1.o2jaf

Jaffe, A. (2009a). Introduction: the sociolinguistics of stance. In A. Jaffe (Ed.), Stance: sociolinguistic perspectives (pp. 3-28). Oxford: Oxford University Press.

Jaffe, A. (Ed.). (2009b). Stance: sociolinguistic perspectives. Oxford: Oxford University Press.

Jefferson, G. (1984). Notes on a systematic deployment of the acknowledgement tokens 'yeah' and 'mm hm'. Paper in Linguistics, 17(2), 197-216. doi:10.1080/08351818409389201

Johansson, M. (2006). Constructing objects of discourse in the broadcast political interview. Journal of Pragmatics, 38(2), 216-229. doi:10.1016/j.pragma.2005.06.016

Johnson, B. \& Clarke, J. M. (2003). Collecting sensitive data: the impact on researchers. Qualitative Health Research, 13(3), 421-434. doi:10.1177/1049732302250340 
Johnstone, B. (2010). Locating language in identity. In C. Llamas \& D. Watt (Eds.), Language and identities (pp. 29-36). Edinburgh, UK: Edinburgh University Press.

Johnstone, B. \& Kiesling, S. F. (2008). Indexicality and experience: exploring the meanings of /aw/-monophthongization in Pittsburgh. fournal of Sociolinguistics, 12(1), 5-33. doi:10.1111/j.14679841.2008.00351.X

Joseph, J. E. (2010). Identity. In C. Llamas \& D. Watt (Eds.), Language and identities (pp. 9-17). Edinburgh, UK: Edinburgh University Press.

Jucker, A. H. (1993). The discourse marker well: a relevance-theoretical account. Journal of Pragmatics, 19(5), 435-452. doi:10.1016/03782166(93)90004-9

Kärkkäinen, E. (2003). Epistemic stance in English conversation: a description of its interactional functions, with a focus on I Think. Amsterdam: John Benjamins.

Kärkkäinen, E. (2006). Stance taking in conversation: from subjectivity to intersubjectivity. Text \& Talk-An Interdisciplinary fournal of Language, Discourse Communication Studies, 26(6), 699-731. doi:10.1515/TEXT.2006.029

Kavanaugh, K. \& Ayres, L. (1998). 'Not as bad as it could have been': assessing and mitigating harm during research interviews on sensitive topics. Research in Nursing \& Health, 21(1), 91-97. doi:10.1002/(SICI) 1098-240X(199802) $21: 1<91::$ AID-NUR10 > 3.0.CO;2-C

Kecskes, I. (2014). Intercultural pragmatics. New York, NY: Oxford University Press.

Kecskes, I. \& Zhang, F. (2009). Activating, seeking, and creating common ground: a socio-cognitive approach. Pragmatics \& Cognition, 17(2), 331-355. doi:10.1075/pc.17.2.06kec

Kennedy, J. C. (2008). Leadership and culture in New Zealand. In J. S. Chhokar, F. C. Brodbeck \& R. J. House (Eds.), Culture and leadership across the world: the GLOBE book of in-depth studies of 25 societies (pp. 397-432). New York, NY: Lawrence Erlbaum Associates.

Kidner, K. (2015). Beyond greenwash: environmental discourses of appropriation and resistance (Unpublished doctoral thesis, Victoria University of Wellington). 
Kirkwood, J. (2007). Tall poppy syndrome: implications for entrepreneurship in New Zealand. fournal of Management and Organization, 13(4), 366-382. doi:10.5172/jmo.2007.13.4.366

Klofstad, C. A. (2007). Talk leads to recruitment: how discussions about politics and current events increase civic participation. Political Research Quarterly, 6o(2), 180-191.

Kotthoff, H. \& Spencer-Oatey, H. (2007). Handbook of intercultural communication. Berlin: Walter de Gruyter.

Kövecses, Z. (1986). Metaphors of anger, pride and love: a lexical approach to the structure of concepts. Amsterdam: John Benjamins.

Kövecses, Z. (2010). Metaphor: a practical introduction (2nd ed.). Oxford: Oxford University Press.

Labov, W. (1966). The social stratification of English in New York City. Washington D.C.: Center for Applied Linguistics.

Labov, W. (1972a). Sociolinguistic patterns. Philadelphia, PA: University of Pennsylvania Press.

Labov, W. (1972b). Some principles of linguistic methodology. Language in Society, 1(01), 97-120. doi:10.1017/Soo47404500006576

Labov, W. (1984). Field methods of the project on linguistic change and variation. In J. Baugh \& J. Sherzer (Eds.), Language in use: readings in sociolinguistics (pp. 28-53). Englewood Cliffs, NJ: Prentice Hall.

Labov, W. (1997). Some further steps in narrative analysis. fournal of Narrative \& Life History, 7(1-4), 395-415. doi:10.1075/jnlh.7. 49som

Labov, W. \& Waletzky, J. (1967). Narrative analysis: oral versions of personal experience. In J. Helm (Ed.), Essays on the verbal and visual arts: proceedings of the 1966 annual spring meeting of the American ethnological society (pp. 12-44). Seattle: University of Washington Press.

Laclau, E. \& Bhaskar, R. (1998). Discourse theory vs. critical realism. Alethia, 1(2), 9-14. doi:10.1558/aleth.v1i2.9

Laclau, E. \& Mouffe, C. (2001). Hegemony and socialist strategy: towards a radical democratic politics (2nd ed.). London: Verso.

Lakoff, G. (2004). Don't think of an elephant! Know your values and frame the debate. White River Junction, VT: Chelsea Green Publishing. 
Lakoff, G. \& Johnson, M. (1980). Metaphors we live by. Chicago: University of Chicago Press.

Lakoff, R. (1975). Language and woman's place. New York: Harper \& Row.

Lambertz, K. (2011). Back-channelling: the use of yeah and $\mathrm{mm}$ to portray engaged listenership. Griffith Working Papers in Pragmatics and Intercultural Communication, 4(1/2), 11-18.

Lampert, M. D. \& Ervin-Tripp, S. M. (2006). Risky laughter: teasing and self-directed joking among male and female friends. fournal of Pragmatics, 38(1), 51-72. doi:10.1016/j.pragma.2005.06.004

Larner, W. (1997). 'A means to an end': neoliberalism and state processes in New Zealand. Studies in Political Economy, 52. Retrieved February 17, 2015, from http://spe.library.utoronto. ca/index.php/spe/article/view/6868

Lauerbach, G. (2006). Discourse representation in political interviews: the construction of identities and relations through voicing and ventriloquizing. Fournal of Pragmatics, 38(2), 196-215. doi:10. 1016/j.pragma.2005.06.015

Lave, J. \& Wenger, E. (1991). Situated learning: legitimate peripheral participation. Cambridge: Cambridge University Press.

Lawson, T. (1998). Economic science without experimentation. In M. Archer, R. Bhaskar, A. Collier, T. Lawson \& A. Norrie (Eds.), Critical realism: essential readings (pp. 144-169). Abingdon, UK: Routledge.

Leudar, I., Marsland, V. \& Nekvapil, J. (2004). On membership categorization: 'us', 'them' and 'doing violence' in political discourse. Discourse \& Society, 15(2-3), 243-266. doi:10 . 1177 / 0957926504041019

Licuanan, P. B. (1994). A moral recovery program: building a peoplebuilding a nation. In M. B. Dy (Ed.), Values in Philippine culture and education (Vol. 1, pp. 35-54). Philippine Philosophical Studies. Washington D.C.: The Council for Research in Values and Philosophy.

Linell, P. (1998). Approaching dialogue: talk, interaction and contexts in dialogical perspectives. Amsterdam: John Benjamins.

Lipson, L. (2011). The politics of equality: New Zealand's adventures in democracy. Original work published 1948 by Chicago University Press. Wellington: Victoria University Press. 
Litosseliti, L. (2003). Using focus groups in research. London: Continuum.

Litosseliti, L. \& Sunderland, J. (2002). Gender identity and discourse analysis. Amsterdam: John Benjamins.

Liu, J. H., McCreanor, T., McIntosh, T. \& Teaiwa, T. (2005). Introduction: constructing New Zealand identities. In J. H. Liu, T. McCreanor, T. McIntosh \& T. Teaiwa (Eds.), New Zealand identities: departures and destinations (pp. 11-20). Wellington: Victoria University Press.

Lloyd, H. D. (1900). A country without strikes: a visit to the compulsory arbitration court of New Zealand. New York: Doubleday, Page \& Co.

Lloyd, H. D. (1901). Newest England: notes of a democratic traveller in New Zealand, with some Australian comparisons. New York: Doubleday, Page \& Co.

Locher, M. A. \& Watts, R. J. (2008). Relational work and impoliteness: negotiating norms of linguistic behaviour. In D. Bousfield \& M. A. Locher (Eds.), Impoliteness in language: studies on its interplay with power in theory and practice (pp. 77-99). Berlin: Walter de Gruyter.

Lonely Planet. (2010, October 31). Lonely Planet's top 10 cities for 2011. Retrieved April 2, 2015, from http://www.lonelyplanet. com/travel-tips-and-articles/76165

Lu, X. (1999). An ideological/cultural analysis of political slogans in communist China. Discourse \& Society, 10(4), 487-508. doi:10. 1177/0957926599010004003

Lyons, A. C., Stephens, C., Morgan, M., Praat, A. C. \& Tuffin, K. (1996). Constructing New Zealand: common linguistic resources in New Zealand political discourse. Australian fournal of Communication, 23(1), 77-90.

Macdonell, D. (1986). Theories of discourse: an introduction. Oxford, UK: Basil Blackwell.

Maclay, H. \& Osgood, C. E. (1959). Hesitation phenomena in spontaneous English speech. Word-fournal of the International Linguistic Association, 15(1), 19-44.

MacLean, M. (1999). Of warriors and blokes: the problem of Māori rugby for Pākehā masculinity in New Zealand. In T. J. Chandler 
\& J. Nauright (Eds.), Making the rugby world: race, gender, commerce (pp. 1-26).

Manicas, P. (1998). A realist social science. In M. Archer, R. Bhaskar, A. Collier, T. Lawson \& A. Norrie (Eds.), Critical realism: essential readings (pp. 313-338). Abingdon, UK: Routledge.

Manusov, V. \& Trees, A. R. (2002). 'Are you kidding me?' The role of nonverbal cues in the verbal accounting process. Fournal of Communication, 52(3), 640-656. doi:10.1111/j.1460-2466.2002. tbo2566.x

Marsden, R. (1999). The nature of capital: Marx after Foucault. London: Routledge.

Martin, J. R. \& White, P. R. R. (2005). The language of evaluation: appraisal in English. Basingstoke, UK: Palgrave Macmillan.

Martin, J. E. (2004). The House: New Zealand's House of Representatives 1854-2004. Palmerston North, New Zealand: Dunmore Press.

Mason, P. (2002). The Big OE: New Zealanders' overseas experience in Britain. In C. M. Hall \& A. M. Williams (Eds.), Tourism and migration: new relationships between production and consumption (65, pp. 87-101). The GeoJournal Library. Netherlands: Springer.

Matheson, P. (2006). The myth of a secular New Zealand. Pacifica: Australasian Theological Studies, 19(2), 177-192. doi:10.1177/ 1030570X0601900204

May, S. (2002). Accommodating multiculturalism and biculturalism in Aotearoa New Zealand: implications for language education. Waikato Journal of Education, 8, 5-26.

May, S. (2004). Accommodating multiculturalism and biculturalism: implications for language policy. In P. Spoonley \& D. G. Pearson (Eds.), Tangata tangata: the changing ethnic contours of New Zealand (pp. 247-264). Melbourne, Victoria: Thomson/Dunmore Press.

McClure, M. (1998). A civilised community: a history of social security in New Zealand 1898-1998. Auckland: Auckland University Press.

McGlone, M. S. \& Wilmshurst, J. M. (1999). Dating initial Maori environmental impact in New Zealand. Quaternary International, 59(1), 5-16. doi:10.1016/S1040-6182(98)0oo67-6 
McHoul, A. \& Grace, W. (1998). A Foucault primer: discourse, power and the subject. Dunedin: University of Otago Press.

McIntosh, J. (2009). Stance and distance: social boundaries, self-lamination, and metalinguistic anxiety in white Kenyan narratives about the African occult. In A. Jaffe (Ed.), Stance: sociolinguistic perspectives (pp. 72-91). Oxford: Oxford University Press.

McLeod, A. L. (Ed.). (1968). The pattern of New Zealand culture. Ithaca, NY: Cornell University Press.

Mehan, H. (1997). The discourse of the illegal immigration debate: a case study in the politics of representation. Discourse \& Society, 8(2), 249-270. doi:10.1177/0957926597008002006

Meyer, J. C. (2000). Humor as a double-edged sword: four functions of humor in communication. Communication Theory, 10(3), 310331. doi:10.1111/j.1468-2885.2000.tboo194.x

Meyerhoff, M. (1994). Sounds pretty ethnic, eh? A pragmatic particle in New Zealand English. Language in Society, 23(03), 367-388. doi:10.1017/Soo47404500018029

Miller, R. (Ed.). (2006). New Zealand government \& politics. Melbourne, Australia: Oxford University Press.

Milroy, J. \& Milroy, L. (1985). Linguistic change, social network and speaker innovation. Journal of Linguistics, 21(02), 339-384. doi:10.1017/Soo22226700010306

Milroy, L. (1987a). Language and social networks (2nd ed.). Oxford: Basil Blackwell.

Milroy, L. (1987b). Social network and language maintenance. In B. Mayor \& A. K. Pugh (Eds.), Language, communication and education (pp. 70-81). Beckenham, UK: Croom Helm.

Milroy, L. \& Gordon, M. (2003). Sociolinguistics: method and interpretation. Malden, MA: Blackwell.

Milroy, L. \& Milroy, J. (1992). Social network and social class: toward an integrated sociolinguistic model. Language in Society, 21(1), 1-26. doi:10.1017/Soo47404500015013

Ministry for Culture and Heritage. (2014, August 5). Wellington cafe culture. Retrieved April 14, 2014, from http://www.nzhistory. net.nz/culture/the-daily-grind-wellington-cafe-culture-19202000 
Mint. (2015, January 25). JLF 2015 | Eleanor Catton: in the last year, I've struggled with my identity as a New Zealand writer [Video file]. Retrieved from https://youtu.be/3E9y3SSFGjA

Mishler, E. G. (2000). Storylines: craftartists' narratives of identity. Cambridge, MA: Harvard University Press.

Modan, G. G. (2007). Turf wars: discourse, diversity, and the politics of place. Malden, MA: Blackwell.

Moita-Lopes, L. P. (2006). On being white, heterosexual and male in a Brazilian school: multiple positionings in oral narratives. In A. de Fina, D. Schiffrin \& M. Bamberg (Eds.), Discourse and identity (23, pp. 288-313). Cambridge: Cambridge University Press.

Molgaard, C. \& Byerly, E. (1981). Applied ethnoscience in rural America: new age health and healing. In D. A. Messerschmidt (Ed.), Anthropologists at home in North America: methods and issues in the study of one's own society (pp. 153-166). Cambridge: Cambridge University Press.

Moorfield, J. C. (2011). Te aka: Māori-English, English-Māori dictionary (3rd ed.). New Zealand: Pearson.

Morgan, D. (2008). The Sacred Heart of Jesus: the visual evolution of a devotion. Amsterdam: Amsterdam University Press.

Morreall, J. (1983). Taking laughter seriously. Albany: SUNY Press.

Morreall, J. (2009). Comic relief: a comprehensive philosophy of humor. Malden, MA: John Wiley \& Sons.

Mouly, V. S. \& Sankaran, J. (2000). The tall poppy syndrome in New Zealand: an exploratory investigation. In M. Sheehan, S. Ramsay \& J. Patrick (Eds.), Transcending boundaries: integrating people, processes and systems (pp. 285-289). Second annual conference of the International Association of Insight and Action. Griffith University, Brisbane, Australia: School of Management.

Mulgan, R. (1989). Maori, Pakeha and democracy. Auckland: Oxford University Press.

Mulgan, R. (2004). Politics in New Zealand (3rd ed.). Auckland: Auckland University Press.

Mullany, L. (2006). 'Girls on tour': politeness, small talk, and gender in managerial business meetings. Fournal of Politeness Research, 2(1), 55-77. doi:10.1515/PR.2006.004 
Myers-Scotton, C. \& Ury, W. (1977). Bilingual strategies: the social functions of code-switching. International fournal of the Sociology of Language, 1977(13), 5-20. doi:10.1515/ijsl.1977.13.5

Nairn, K., Higgins, J. \& Sligo, J. (2012). Children of Rogernomics: a neoliberal generation leaves school. Dunedin: Otago University Press.

Negrón, R. (2012). Audio recording everyday talk. Field Methods, 24(3), 292-309. doi:10.1177/1525822X11432082

Nielsen, D. \& Hay, J. (2005). Perceptions of regional dialects in New Zealand. Te Reo: Journal of the Linguistic Society of New Zealand, 48, 95-110.

Nightingale, D. J. \& Cromby, J. (2002). Social constructionism as ontology: exposition and example. Theory \& Psychology, 12(5), 701-713. doi:10.1177/0959354302012005901

Nolan, M. (2000). Breadwinning: New Zealand women and the state. Christchurch: Canterbury University Press.

Nolan, M. (2007). The reality and myth of New Zealand egalitarianism: explaining the pattern of a labour historiography at the edge of empires. Labour History Review, 72(2), 113-134. doi:10.1179/ $174581807 \mathrm{X} 224560$

Norris, S. (2004). Analyzing multimodal interaction: a methodological framework. New York, NY: Routledge.

Norris, S. (2011). Identity in (inter)action: introducing multimodal (inter)action analysis. Berlin: Walter de Gruyter.

Notten, G. \& de Neubourg, C. (2011). Monitoring absolute and relative poverty: 'not enough' is not the same as 'much less'. Review of Income and Wealth, 57(2), 247-269. doi:10.1111/j.1475-4991. $2011.00443 \cdot \mathrm{x}$

Ochs, E. (1979). Transcription as theory. In E. Ochs \& B. B. Schieffelin (Eds.), Developmental pragmatics (pp. 43-72). New York, NY: Academic Press.

Ochs, E. (1992). Indexing gender. In A. Duranti \& C. Goodwin (Eds.), Rethinking context: language as an interactive phenomenon (pp. 335358). Cambridge, UK: Cambridge University Press.

Ochs, E. (1993). Constructing social identity: a language socialization perspective. Research on Language \& Social Interaction, 26(3), 287-306. doi:10.1207/s15327973rlsi2603\\3 
Ochs, E. (1996). Linguistic resources for socializing humanity. In J. J. Gumperz \& S. C. Levinson (Eds.), Rethinking linguistic relativity (pp. 407-437). New York, NY: Cambridge University Press.

Office of the Clerk. (2013, May 1). Our system of government. Retrieved March 31, 2015, from http://www.parliament.nz/en$\mathrm{nz}$ / about - parliament / how - parliament - works / our - system / ooCLOOCHowPWorks111/our-system-of-government

Oliver, C. (2012). Critical realist grounded theory: a new approach for social work research. British fournal of Social Work, 42(2), 371387. doi:10.1093/bjsw/bcro64

Olssen, E., Griffen, C. \& Jones, F. (2011). An accidental utopia? Social mobility and the foundations of an egalitarian society, 1880-1940. Dunedin: University of Otago Press.

Omoniyi, T. \& White, G. (Eds.). (2006). The sociolinguistics of identity. London: Continuum.

Orb, A., Eisenhauer, L. \& Wynaden, D. (2001). Ethics in qualitative research. Journal of Nursing Scholarship, 33(1), 93-96. doi:10 . 1111/j.1547-5069.2001.00093.x

Orsman, H. W. (1999). A dictionary of modern New Zealand slang. Auckland: Oxford University Press.

Oxley, H. G. (1974). Mateship in local organization: a study of egalitarianism, stratification, leadership, and amenities projects in a semi-industrial community of inland New South Wales. St. Lucia, Queensland: University of Queensland Press.

Parker, I. (1992). Discourse dynamics: critical analysis for social and individual psychology. London: Routledge.

Parliamentary Library. (n.d.). Journals of the House. Retrieved April 1, 2015, from http://www.parliament.nz/en-nz/PB/Debates/ Journals

Partnership Wellington Trust. (2015). The coolest little capital in the world [Wellington Absolutely Positively]. Retrieved April 2, 2015, from http : / / www . wellingtonnz . com / media / media backgrounders/the-coolest-little-capital-in-the-world/

Pearce, F. \& Woodiwiss, T. (2001). Reading Foucault as a realist. In J. Lopéz \& G. Potter (Eds.), After postmodernism: an introduction to critical realism (pp. 51-62). London: Continuum.

Pearson, D. G. (1980). Johnsonville: continuity and change in a New Zealand township. Sydney: Allen \& Unwin. 
Pearson, D. G. (2000). The ties that unwind: civic and ethnic imaginings in New Zealand. Nations and Nationalism, 6(1), 91-110. doi:10.1111/j.1354-5078.2000.00091.x

Peeters, B. (2004a). Tall poppies and egalitarianism in Australian discourse: from key word to cultural value. English World-Wide, 25(1), 1-25. doi:10.1075/eww.25.1.02pee

Peeters, B. (2004b). Thou shalt not be a tall poppy: describing an Australian communicative (and behavioral) norm. Intercultural Pragmatics, 1(1). doi:10.1515/iprg.2004.008

Peirce, C. S. (1998). Of reasoning in general. In The Peirce Edition Project (Ed.), The essential Peirce: selected philosophical writings (Vol. 2, pp. 11-26). Original work published 1895. Bloomington, IN: Indiana University Press.

Pennycook, A. (1994). The politics of pronouns. ELT fournal, 48(2), 173-178. doi:10.1093/elt/48.2.173

Phillips, J. (1996). The hard man: rugby and the formation of male identity in New Zealand. In J. Nauright \& T. J. L. Chandler (Eds.), Making men: rugby and masculine identity (pp. 70-90). London: Frank Cass.

Phillips, J. (2014, October 15). 'Social laboratory of the world', 18901920 [Te Ara-the encyclopedia of New Zealand]. Retrieved April 2, 2015, from http://www.teara.govt.nz/en/visitors opinions-about-new-zealand/page-3

Phillips, L. J. \& Jørgensen, M. W. (2002). Discourse analysis as theory and method. London: SAGE.

Piachaud, D. (1987). Problems in the definition and measurement of poverty. Journal of Social Policy, 16(02), 147-164. doi:10.1017/ Soo47279400020353

Podder, N. \& Chatterjee, S. (2002). Sharing the national cake in post reform New Zealand: income inequality trends in terms of income sources. Fournal of Public Economics, 86(1), 1-27. doi:10. 1016/Soo47-2727(01)oo117-7

Pool, I. (1991). Te iwi Maori: a New Zealand population past, present \& projected. Auckland: Auckland University Press.

Porter, S. (1993). Critical realist ethnography: the case of racism and professionalism in a medical setting. Sociology, 27(4), 591-609. doi:10.1177/0038038593027004003 
Porter, S. (2002). Critical realist ethnography. In T. May (Ed.), Qualitative research in action (pp. 54-72). London, UK: SAGE.

Price, V., Nir, L. \& Cappella, J. N. (2006). Normative and informational influences in online political discussions. Communication Theory, 16(1), 47-74. doi:10.1111/j.1468-2885.2006.00005.x

Proshansky, H. M. (1978). The city and self-identity. Environment and Behavior, 10(2), 147-169. doi:10.1177/0013916578102002

Proshansky, H. M., Fabian, A. K. \& Kaminoff, R. (1983). Place-identity: physical world socialization of the self. Journal of Environmental Psychology, 3(1), 57-83. doi:10 . 1016/ So272-4944(83) 80021-8

Psathas, G. (1995). Conversation analysis: the study of talk-in-interaction. Thousand Oaks, CA: SAGE.

Pullin, P. (2010). Small talk, rapport, and international communicative competence: lessons to learn from BELF. Fournal of Business Communication, 47(4), 455-476. doi:10.1177/0021943610377307

Purvis, T. \& Hunt, A. (1993). Discourse, ideology, discourse, ideology, discourse, ideology... The British fournal of Sociology, 44(3), 473-499. doi:10.2307/591813. JSTOR: 591813

QSR International Pty Ltd. (2012). NVivo qualitative data analysis software (Version 10). QSR International Pty Ltd. Retrieved from https://www.qsrinternational.com/

Quirk, R., Greenbaum, S., Leech, G. \& Svartvik, J. (1985). A comprehensive grammar of the English language (2nd ed.). London: Longman.

Rampton, B. (2006). Language in late modernity: interaction in an urban school. Cambridge: Cambridge University Press.

Rampton, B. (2007a, April 14). Linguistic ethnography, interactional sociolinguistics and the study of identities. In New ways of knowing: bending the paradigm in identity research. Working Papers in Urban Language \& Literacies. Annual conference of the British Sociological Association.

Rampton, B. (2007b). Neo-Hymesian linguistic ethnography in the United Kingdom. Fournal of Sociolinguistics, 11(5), 584-607. doi:10. 1111/j.1467-9841.2007.00341.X

Rapley, M. (1998). 'Just an ordinary Australian': self-categorization and the discursive construction of facticity in 'new racist' polit- 
ical rhetoric. British fournal of Social Psychology, 37(3), 325-344. doi:10.1111/j.2044-8309.1998.tbo1175.x

Rashbrooke, M. (Ed.). (2013). Inequality: a New Zealand crisis. Wellington: Bridget Williams Books.

Reeves, W. P. (1903a). State experiments in Australia \& New Zealand [Volume 1]. New York, NY: E. P. Dutton \& Co.

Reeves, W. P. (1903b). State experiments in Australia \& New Zealand [Volume 2]. New York, NY: E. P. Dutton \& Co.

Registrar General's Office. (1897, April 26). Results of a census of the colony of New Zealand taken for the night of 12th April 1896. Retrieved April 1, 2015, from http://www3 . stats .govt.nz / historic_publications/1896-census/1896-results-census/1896results-census.html

Reyes, A. (2011). Strategies of legitimization in political discourse: from words to actions. Discourse \& Society, 22(6), 781-807. doi:10.1177/0957926511419927

Ribeiro, B. T. (2006). Footing, positioning, voice: are we talking about the same things? In A. de Fina, D. Schiffrin \& M. Bamberg (Eds.), Discourse and identity (pp. 48-82). Cambridge: Cambridge University Press.

Riggins, S. H. (Ed.). (1997). The language and politics of exclusion: others in discourse. Thousand Oaks, CA: SAGE.

Roberts, C. (1998). Awareness in intercultural communication. Language Awareness, 7(2-3), 109-127. doi:10.1080/09658419808667104

Robles, J. S. (2011). Doing disagreement in the House of Lords: 'talking around the issue' as a context-appropriate argumentative strategy. Discourse \& Communication, 5(2), 147-168. doi:10 . 1177/1750481310395452

Sandelowski, M. (1995). Sample size in qualitative research. Research in Nursing \& Health, 18(2), 179-183. doi:10.1002/nur.4770180211

Sarangi, S. \& Roberts, C. (1999). Talk, work and institutional order: discourse in medical, mediation and management settings. Berlin: Walter de Gruyter.

Sayer, A. (1997a). Critical realism and the limits to critical social science. Fournal for the Theory of Social Behaviour, 27(4), 473-488. doi:10.1111/1468-5914.00052 
Sayer, A. (1997b). Essentialism, social constructionism, and beyond. The Sociological Review, 45(3), 453-487. doi:10.1111/1467-954X. 00073

Sayer, A. (2000). Realism and social science. London: SAGE.

Sayer, A. (2004). Why critical realism? In S. Fleetwood \& S. Ackroyd (Eds.), Critical realist applications in organisation and management studies (pp. 6-20). London: Routledge.

Sayer, A. (2010). Method in social science: a realist approach (2nd ed.). Abingdon: Routledge.

Schiffrin, D. (1987). Discourse markers. Cambridge: Cambridge University Press.

Scollon, R., Scollon, S. W. \& Jones, R. H. (2012). Intercultural communication: a discourse approach (3rd ed.). Malden, MA: John Wiley \& Sons.

Scott, D. (2010). Education, epistemology and critical realism. Abingdon, UK: Routledge.

Sealey, A. (2007). Linguistic ethnography in realist perspective. Fournal of Sociolinguistics, 11(5), 641-66o. doi:10.1111/j.1467-9841.2007. 00344.x

Searle, J. R. (1995). The construction of social reality. New York, NY: Simon and Schuster.

Seidman, I. (2013). Interviewing as qualitative research: a guide for researchers in education and the social sciences (4th ed.). New York, NY: Teachers College Press.

Semino, E. \& Masci, M. (1996). Politics is football: metaphor in the discourse of Silvio Berlusconi in Italy. Discourse \& Society, 7(2), 243-269. doi:10.1177/0957926596007002005

Sharifian, F. (2009). Figurative language in international political discourse: the case of Iran. Fournal of Language and Politics, 8(3), 416-432. doi:10.1075/jlp.8.3.04sha

Siegfried, A. (1914). Democracy in New Zealand (E. V. Burns, Trans.). London: G. Bell and Sons.

Silverstein, M. (2003). Indexical order and the dialectics of sociolinguistic life. Language \& Communication, 23(3-4), 193-229. doi:10.1016/So271-5309(03)00013-2

Sims-Schouten, W., Riley, S. C. E. \& Willig, C. (2007). Critical realism in discourse analysis: a presentation of a systematic method of analysis using women's talk of motherhood, childcare and 
female employment as an example. Theory \& Psychology, 17(1), 101-124. doi:10.1177/0959354307073153

Sin, C. H. (2003). Interviewing in 'place': the socio-spatial construction of interview data. Area, 35(3), 305-312. doi:10.1111/14754762.00179

Smart, B. (1985). Michel Foucault. Chichester, UK: Ellis Horwood.

Smith, I. (2008). Maori, Pakeha and Kiwi: peoples, cultures and sequence in New Zealand archaeology. In G. Clark, F. Leach \& S. O'Connor (Eds.), Islands of inquiry (Vol. 29, pp. 367-380). Terra Australis. Canberra, Australia: ANU Press.

Smith, L. T. (1999). Decolonizing methodologies: research and indigenous peoples. Dunedin: University of Otago Press.

Smits, K. (2011). Justifying multiculturalism: social justice, diversity and national identity in Australia and New Zealand. Australian Journal of Political Science, 46(1), 87-103. doi:10.1080/10361146. 2011.546051

Smits, K. (2014). The neoliberal state and the uses of indigenous culture. Nationalism and Ethnic Politics, 2o(1), 43-62. doi:10 . 1080/13537113.2014.879764

Sotillo, S. M. \& Wang-Gempp, J. (2004). Using corpus linguistics to investigate class, ideology, and discursive practices in online political discussions. Language and Computers, 52(1), 91-122.

Speer, S. A. (2007). On recruiting conversation analysis for critical realist purposes. Theory \& Psychology, 17(1), 125-135. doi:10 . 1177/0959354307073155

Spencer-Oatey, H. (Ed.). (200o). Culturally speaking: managing rapport through talk across cultures. London: Continuum.

Spoonley, P. \& Pearson, D. G. (Eds.). (2004). Tangata tangata: the changing ethnic contours of New Zealand. Melbourne, Victoria: Thomson/Dunmore Press.

Statistics New Zealand. (n.d.). Geographic definitions. Retrieved April 14, 2015, from http://www.stats.govt.nz/Census/2013-census/ info-about-2013-census-data/2013-census-definitions-forms/ definitions/geographic.aspx

Statistics New Zealand. (2015a). 2013 census. Retrieved April 14, 2015, from http://www.stats.govt.nz/Census/2013-census.aspx 
Statistics New Zealand. (2015b). Population clock. Retrieved April 14, 2015, from http://www.stats.govt.nz/tools_and_services / population_clock.aspx

Stenhouse, J. (1998). Churches, state and the New Zealand wars: 18601872. Journal of Law and Religion, 13(2), 483-507. doi:10.2307/ 1051481. JSTOR: 1051481

Stenhouse, J. \& Wood, G. A. (2005). Christianity, modernity and culture: new perspectives on New Zealand history. Hindmarsh, Australia: ATF Press.

Stets, J. E. \& Burke, P. J. (200o). Identity theory and social identity theory. Social Psychology Quarterly, 63(3), 224. doi:10.2307/ 2695870

Strauss, A. \& Corbin, J. (1994). Grounded theory methodology: an overview. In N. K. Denzin \& Y. S. Lincoln (Eds.), Handbook of qualitative research (pp. 273-285). Thousand Oaks, CA: SAGE Publications.

Swartz, D. (1997). Culture and power: the sociology of Pierre Bourdieu. Chicago: University of Chicago Press.

Tagliamonte, S. A. (2006). Analysing sociolinguistic variation. Cambridge: Cambridge University Press.

Tagliamonte, S. \& Roberts, C. (2005). So weird; so cool; so innovative: the use of intensifiers in the television series Friends. American Speech, 8o(3), 280-300. doi:10.1215/00031283-80-3-280

Tajfel, H. (1974). Social identity and intergroup behaviour. Social Science Information, 13(2), 65-93. doi:10.1177/053901847401300204

Talmy, S. (2011). The interview as collaborative achievement: interaction, identity, and ideology in a speech event. Applied Linguistics, 32(1), 25-42. doi:10.1093/applin/amq027

Tannen, D. (1986). Introducing constructed dialogue in Greek and American conversational and literary narrative. In F. Coulmas (Ed.), Direct and indirect speech (pp. 311-332). Berlin: Mouton de Gruyter.

Tannen, D. (Ed.). (1993). Framing in discourse. New York, NY: Oxford University Press.

Tannen, D. (2005). Interactional sociolinguistics as a resource for intercultural pragmatics. Intercultural Pragmatics, 2(2), 205-208. doi:10.1515/iprg.2005.2.2.205 
Tannen, D. (2007). Talking voices: repetition, dialogue, and imagery in conversational discourse (2nd ed.). Cambridge: Cambridge University Press.

The World Bank. (2015). World Bank open data. Retrieved April 1, 2015, from http://data.worldbank.org

Thompson, G. \& Alba-Juez, L. (2014). Evaluation in context. Amsterdam: John Benjamins.

Transparency International. (2014). Corruption Perceptions Index 2014. Berlin, Germany. Retrieved from http://www.transparency.org

Tsakona, V. \& Popa, D. E. (Eds.). (2011). Studies in political humour. Amsterdam: John Benjamins.

Tsang, W. K. \& Wong, M. (2004). Constructing a shared 'Hong Kong identity' in comic discourses. Discourse \& Society, 15(6), 767-785. doi:10.1177/0957926504046504

Twigger-Ross, C. L. \& Uzzell, D. L. (1996). Place and identity processes. Journal of Environmental Psychology, 16(3), 205-220. doi:10 . 1006/jevp.1996.0017

UMR Research. (2014). Inequality in New Zealand 2013. Wellington \& Auckland. Retrieved April 1, 2015, from http://umr.co.nz/sites/ umr/files/final_inequality_mar-14_1.pdf

United Nations Development Programme. (1997). Human development report 1997. New York, NY: Oxford University Press.

van der Valk, I. (2003). Right-wing parliamentary discourse on immigration in France. Discourse \& Society, 14(3), 309-348. doi:10.1177/ 09579265030143004

van Dijk, T. A. (1993). Denying racism: elite discourse and racism. In J. Solomos \& J. Wrench (Eds.), Racism and migration in Western Europe (Vol. 3, pp. 179-193). Oxford, UK: Berg.

van Dijk, T. A. (1996). Discourse, power and access. In C. R. CaldasCoulthard \& M. Coulthard (Eds.), Texts and practices: readings in critical discourse analysis (pp. 84-104). London: Routledge.

van Dijk, T. A. (1997). What is political discourse analysis? In J. Blommaert \& C. Bulcaen (Eds.), Political linguistics (pp. 11-52). Amsterdam: John Benjamins.

van Dijk, T. A. (1998). Opinions and ideologies in the press. In A. Bell \& P. Garrett (Eds.), Approaches to media discourse (pp. 21-63). Oxford, UK: Blackwell. 
van Dijk, T. A. (2000). Ideologies, racism, discourse: debates on immigration and ethnic issues. In J. ter Wal \& M. Verkuyten (Eds.), Comparative perspective on racism (pp. 91-116). Aldershot, UK: Ashgate.

van Dijk, T. A. (2006a). Discourse and manipulation. Discourse \& Society, 17(3), 359-383. doi:10.1177/0957926506060250

van Dijk, T. A. (2006b). Ideology and discourse analysis. Journal of Political Ideologies, 11(2), 115-140. doi:10.1080/13569310600687908

van Langenhove, L. \& Harré, R. (1999). Introducing positioning theory. In R. Harré \& L. van Langenhove (Eds.), Positioning theory: moral contexts of intentional action (pp. 14-31). Oxford, UK: Blackwell.

van Teijlingen, E. \& Hundley, V. (2002). The importance of pilot studies. Nursing Standard, 16(40), 33-36. doi:10.7748/ns2002. 06.16.40.33.c3214

van Zoonen, L., Muller, F., Alinejad, D., Dekker, M., Duits, L., van Romondt Vis, P. \& Wittenberg, W. (2007). Dr. Phil meets the candidates: how family life and personal experience produce political discussions. Critical Studies in Media Communication, 24(4), 322-338. doi:10.1080/07393180701560849

Vesnic-Alujevic, L. (2011). Communicating with voters by blogs? Campaigning for the 2009 European Parliament elections. Discourse \& Communication, 5(4), 413-428. doi:10.1177/1750481311418098

Victoria University of Wellington. (2007, July 13). Human ethics policy. Wellington: Research Policy Group. Retrieved March 31, 2015, from http: / / www. victoria . ac. nz / documents / policy / research-policy/human-ethics-policy.pdf

Vine, B., Johnson, G., O’Brien, J. \& Robertson, S. (2002). Wellington archive of New Zealand English transcriber's manual. Language in the Workplace Occasional Papers, 5. Retrieved from http:// victoria.ac.nz/lals/lwp/docs/ops/op5.htm

Vine, B., Kell, S., Marra, M. \& Holmes, J. (2009). Boundary-marking humour: institutional, gender and ethnic demarcation in the workplace. In N. R. Norrick \& D. Chiaro (Eds.), Humor in interaction (pp. 125-139). Amsterdam: John Benjamins.

Volckmann, R. (2013, August 6). Roy Bhaskar interview [Video file]. Retrieved March 26, 2015, from https://youtu.be/8YGHZPg-19k 
Wald, K. D. \& Calhoun-Brown, A. (2014). Religion and politics in the United States (7th ed.). Lanham, MD: Rowman \& Littlefield.

Wales, K. (1996). Personal pronouns in present-day English. Cambridge, UK: Cambridge University Press.

Walker, S. (1989). Rogernomics: reshaping New Zealand's economy. Wellington: GP Books.

Walrond, C. (2012, July 13). Small country syndrome [Te Ara-the encyclopedia of New Zealand]. Retrieved April 1, 2015, from http://www.teara.govt.nz/en/kiwis-overseas/page-2

Walrond, C. (2013, August 20). Natural environment-geography and geology [Te Ara-the encyclopedia of New Zealand]. Retrieved March 31, 2015, from http://www.teara.govt.nz/en/map/2377/ new-zealands-isolated-position

Walsh, K. C. (2004). Talking about politics: informal groups and social identity in American life. Chicago: University of Chicago Press.

Walter, R. \& Jacomb, C. (2008). Oceania: New Zealand. In D. M. Pearsall (Ed.), Encyclopedia of archaeology (pp. 1738-1747). New York, NY: Academic Press.

Wanhalla, A. (2008). Women 'living across the line': intermarriage on the Canadian prairies and in southern New Zealand, 1870-1900. Ethnohistory, 55(1), 29-49. doi:10.1215/00141801-2007-045

Wanhalla, A. (2013). Matters of the heart: a history of interracial marriage in New Zealand. Auckland: Auckland University Press.

Webb, B. \& Webb, S. (1959). Visit to New Zealand in 1898; Beatrice Webb's diary with entries by Sidney Webb. Wellington: Price, Milburn and Company by permission of the Passfield Trust.

Weizman, E. (2006). Roles and identities in news interviews: the Israeli context. Fournal of Pragmatics, 38(2), 154-179. doi:10.1016/j . pragma.2005.06.018

Wellington City Council. (n.d.). What to do in Wellington. Retrieved April 2, 2015, from http://wellington.govt.nz/about-wellington/ what-to-do

Wetherell, M. (2007). A step too far: discursive psychology, linguistic ethnography and questions of identity. Journal of Sociolinguistics, $11(5), 661-681$. doi:10.1111/j.1467-9841.2007.00345.x

Whitehouse, H. (2014). 'Not greenies' at school: investigating the discourses of environmental activism in regional Australia. Aus- 
tralian fournal of Environmental Education, 3o(1), 106-111. doi:10. 1017/aee.2014.33

Whitehouse, H. \& Evans, N. (2010). 'I am not a greenie, but': negotiating a cultural discourse. Australian fournal of Environmental Education, 26.

Wilcox, C. \& Robinson, C. (2010). Onward Christian soldiers? The religious right in American politics (4th ed.). Boulder, CO: Westview Press.

Wilkinson, R. \& Pickett, K. (2010). The spirit level: why equality is better for everyone. London: Penguin UK.

Willig, C. (1999). Beyond appearances: a critical realist approach to social constructionist work. In D. J. Nightingale \& J. Cromby (Eds.), Social constructionist psychology: a critical analysis of theory and practice (pp. 37-52). Buckingham, UK: Open University Press.

Wilson, J. (1991). The linguistic pragmatics of terrorist acts. Discourse \& Society, 2(1), 29-45. doi:10.1177/0957926591002001002

Wilson, J. \& Stapleton, K. (2012). Discourse in the shadows: discursive construction and the Northern Ireland Assembly. Discourse \& Society, 23(1), 69-92. doi:10.1177/0957926511419930

Wodak, R. (Ed.). (1989). Language, power and ideology: studies in political discourse. Amsterdam: John Benjamins.

Wodak, R. (2011). Critical discourse analysis. In K. Hyland \& B. Paltridge (Eds.), The Continuum companion to discourse analysis (pp. 38-53). London: Continuum.

Wodak, R. (2014, November 1). The 'language of walls'-resemiotizing identity and border politic. 5th Critical Approaches to Discourse Analysis Across Disciplines (CADAAD) conference. Eötvös Loránd University, Budapest, Hungary.

Wodak, R., de Cillia, R., Reisigl, M. \& Liebhart, K. (Eds.). (2009). The discursive construction of national identity. Edinburgh: Edinburgh University Press.

Wodak, R. \& Meyer, M. (2009). Methods of critical discourse analysis (2nd ed.). London: SAGE.

Wolfram, W. (1970). Sociolinguistic implications for educational sequencing. In R. W. Fasold \& R. W. Shuy (Eds.), Teaching standard English in the inner city (pp. 105-119). Washington D.C.: Center for Applied Linguistics. 
Woodhams, J. M. (2011). Trimming the safety net: metaphorical representations of social welfare in New Zealand political discourse (Unpublished master's research dissertation, Victoria University of Wellington).

Woodhams, J. M. (2012). A journey towards employment: metaphorical representations of social welfare in New Zealand. Metaphor and the Social World, 2(1), 41-6o. doi:10.1075/msw.2.1.03woo

Yates, M. \& Youniss, J. (1998). Community service and political identity development in adolescence. Fournal of Social Issues, 54(3), 495-512. doi:10.1111/j.1540-4560.1998.tbo1232.x

Zhang, M. \& Mihelj, S. (2012). Hong Kong identity and the presspolitics dynamics: a corpus-assisted discourse study. Asian fournal of Communication, 22(5), 506-527. doi:10.1080/01292986.2012. 701315 